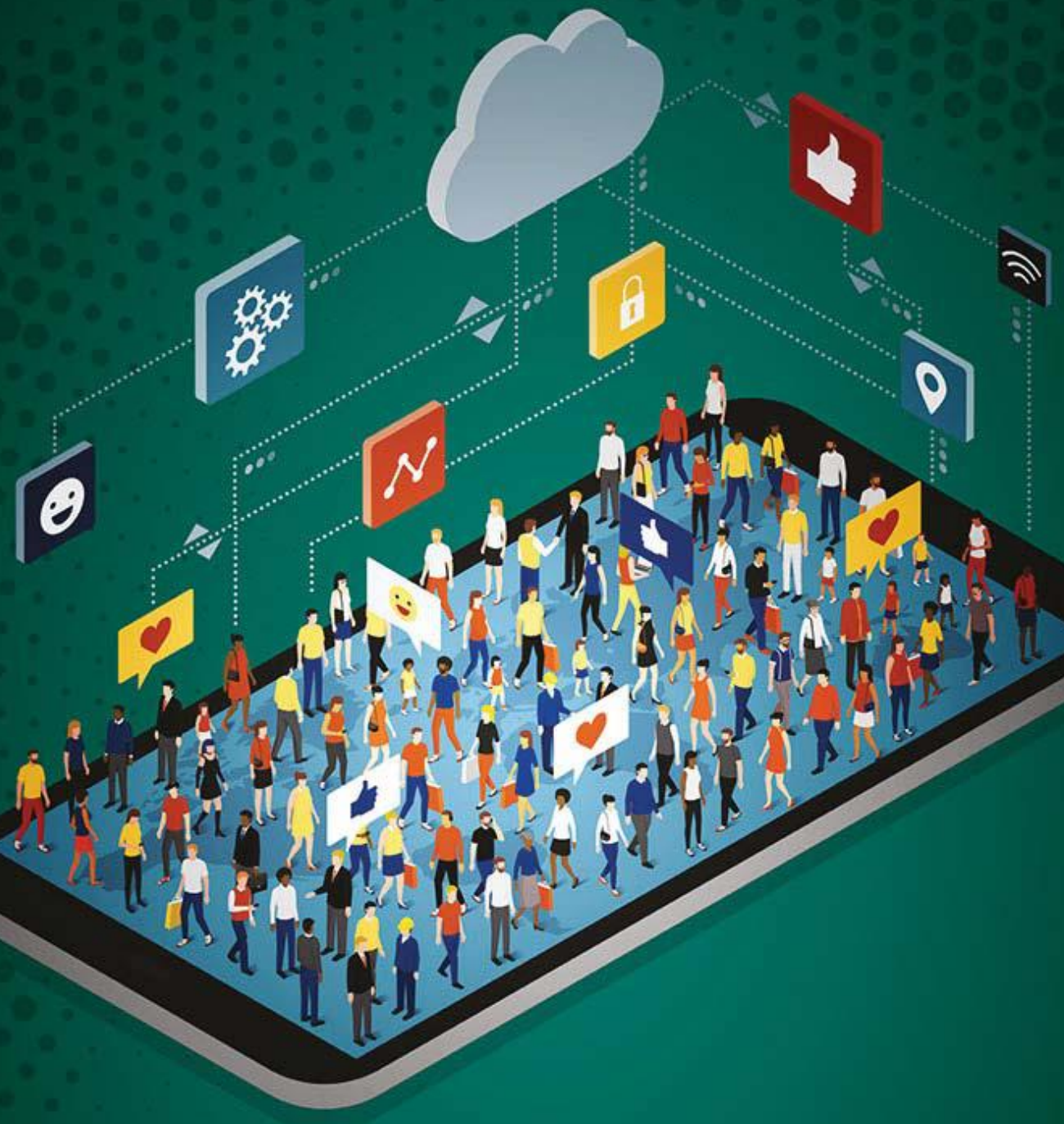

\title{
PRÁCTICAS COMUNICATIVAS EN ENTORNOS DIGITALES
}

- DELIA CROVI DRUETTA (coordinadora)

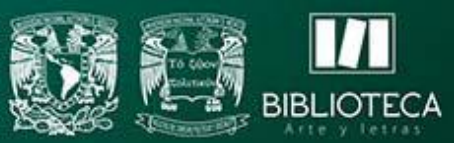




\section{DIRECTORIO}

Universidad Nacional Autónoma de México

Enrique Luis Graue Wiechers

Rector

Leonardo Lomelí Vanegas

Secretario General

Leopoldo Silva Gutiérrez

Secretario Administrativo

Mónica González Contró

Abogada General

Joaquín Díez-Canedo Flores

Director General de Publicaciones y Fomento Editorial

Facultad de Ciencias Políticas y Sociales

Angélica Cuéllar Vázquez

Directora

Arturo Chávez López

Secretario General

Juan Manuel López Ramírez

Secretario Administrativo

Ilan Edwin Garnett Ruíz

Jefe del Departamento de Publicaciones

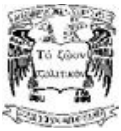




\title{
PRÁCTICAS COMUNICATIVAS EN ENTORNOS DIGITALES
}

\author{
Delia Crovi Druetta \\ (coordinadora)
}

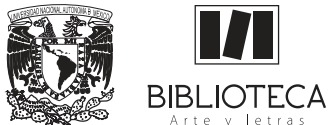


Esta investigación, arbitrada a "doble ciego" por especialistas en la materia, se privilegia con el aval de la Facultad de Ciencias Políticas y Sociales de la unAM.

Libro electrónico del Proyecto SEP-CONACYT, CB2012/178329

Jóvenes y cultura digital. Nuevos escenarios de interacción social

Prácticas comunicativas en entornos digitales

Delia Crovi Druetta

(coordinadora)

Primera edición: 19 de jujnio de 2018.

D.R. (C) Universidad Nacional Autónoma de México

Ciudad Universitaria, Delegación Coyoacán, C.P. 04510, CDMX, Facultad de Ciencias Políticas y Sociales, Circuito Mario de la Cueva s/n, Ciudad Universitaria, Delegación Coyoacán, C.P. 04510, México, CDMX.

D.R. (C) Ediciones La Biblioteca, S.A. de C.V.

Azcapotzalco la Villa No. 1151

Colonia San Bartolo Atepehuacán

C.P. 07730, México, CDMX.

Tel. 55-6235-0157 y 55-3233-6910

Email: contacto@labiblioteca.com.mx

\section{ISBN UNAM: 978-607-30-0737-5}

ISBN EDITORIAL: 978-607-8364-64-0

Diseño: Fernando Bouzas Suárez

Cuidado de la edición: Ma. Eugenia Campos Cázares

Queda prohibida la reproducción parcial o total, directa o indirecta, del contenido de la presente obra, sin contar previamente con la autorización expresa y por escrito de los editores, en términos de lo así previsto por la Ley Federal de Derechos de Autor y, en su caso, por los tratados internacionales aplicables.

Impreso y encuadernado en México

Printed and bound in México 


\section{Índice}

Presentación. . . . . . . . . . . . . . .

De jóvenes, redes digitales y utopías no resueltas

Delia Crovi Druetta . . . . . . . . . . . . . . . . . . . . . . 15

Elementos para comprender la interacción juvenil en las redes sociales digitales

María Consuelo Lemus Pool

Miriam González Montalvo . . . . . . . . . . . . . . . . . . . . 33

Uso de redes sociales digitales entre estudiantes universitarios: trazos para la reflexión desde una perspectiva de género

Gladys Ortiz Henderson

Rocio López González

Karla Edurne Romero Ramos . . . . . . . . . . . . . . . . . . . . . 55

El nivel socioeconómico y el dominio del idioma inglés, elementos de acceso y ampliación de la brecha en la cultura digital

Ma. Guadalupe González Lizárraga

Esther Hugues Santa Cruz

María Teresa Becerra Traver . . . . . . . . . . . . . . . . . . . . . 77

Universitarios, desarrollo de habilidades digitales comunicativas.

Del ámbito escolar y la vida cotidiana

Blanca Flores Ramirez

Luz María Garay Cruz . . . . . . . . . . . . . . . . . . . . . . . . 97

Ocho de cada diez gatos prefieren El Komander:

Una aproximación a expresiones de discriminación cultural en memes en redes sociodigitales

Gabriel Pérez Salazar

Esaú Salvador Bravo Luis

Montserrat Del Bosque Carrillo . . . . . . . . . . . . . . . . . . . 113

Movimientos conectivos y redes sociales: análisis de la Red Anonymous en Twitter

Rodrigo Perera Ramos. 
El imaginario tecnocomunicacional del tuitero.

Usuarios activos de Twitter en la ciudad de Querétaro, México

Enrique Iturralde Chaparro . . . . . . . . . . . . . . . . . . 157

Un abordaje a las redes sociales digitales, los videojuegos,

y los medios sociales

David Cuenca Orozco . . . . . . . . . . . . . . . . . . . . . . . . . .175

Interactividad desde la tecnología Web:

de la conceptualización a la operacionalización

Rafael Leonardo Ochoa Urrego . . . . . . . . . . . . . . . . . . . .193

Anexo 1. Cuestionario del Proyecto

SEP-CONACYT CB2012/178329 . . . . . . . . . . . . . 217

Anexo 2. Cuestionario diagnóstico de

habilidades comunicativas digitales . . . . . . . . . . . 223 


\section{Presentación}

Los trabajos que se incluyen en la primera parte del libro "Prácticas comunicativas en entornos digitales", se derivan de la investigación "Jóvenes y cultura digital. Nuevos escenarios de interacción social" de la que fui responsable técnica. Este estudio se desarrolló entre inicios del año 2013 y enero de 2017, y fue financiado por el programa Ciencia Básica SEP-CONACYT que había aprobado su desarrollo en noviembre de $2012(\mathrm{CB} 2012 / 178329)^{1}$. La segunda parte de esta obra integra contribuciones originales, afines al tema, que son producto de estudios específicos que sus autores están llevando a cabo acerca de las prácticas comunicativas digitales que despliegan los jóvenes.

Cuando iniciamos esta nueva investigación, habíamos concluido y publicado el estudio "Jóvenes y apropiación tecnológica. La vida como hipertexto" (Crovi, 2013) ${ }^{2}$ en el que exploramos un universo diferente: jóvenes estudiantes y jóvenes trabajadores de la ciudad de México. Entonces la perspectiva fue observar esos procesos desde tres conceptos básicos: acceso, uso y apropiación de las tecnologías digitales, buscando identificar algunas de las muchas condiciones que determinan las brechas digitales. Este antecedente alimentó con sus resultados al que desarrollamos posteriormente, referido a jóvenes y cultura digital. En el nuevo trabajo no sólo cambiamos el enfoque teórico, sino que construimos una metodología diferente, consideramos un universo ampliado a varias universidades públicas del país y se enriqueció el equipo de investigadores con la incorporación de nuevos miembros.

Creemos que las prácticas que conforman la cultura digital están apenas construyendo su propia historia, y que los estudios sobre ellas deben ser variados en sus perspectivas teórico-metodológicas porque constituyen

1 Agradecemos al Programa Ciencia Básica SEP-CONACYT, convocatoria 2012, el financiamiento del proyecto "Jóvenes y cultura digital. Nuevos escenarios de interacción social” (CB2012/178329), así como la presentación de sus hallazgos en la obra: Crovi, D. 2016. "Redes sociales digitales. Lugar de encuentro, expresión y organización para los jóvenes". México: UNAM-La Biblioteca. Reconocemos asimismo, que el financiamiento de este libro: "Prácticas comunicativas en entornos digitales", también es producto de esa misma investigación y sus fuentes de financiamiento.

2 Además de esa obra de 2013, referimos otros libros que abordan aspectos particulares del mismo tema: Crovi, D. (2009) "Acceso, uso y apropiación de las TIC en comunidades académicas"; Crovi, D.; López, M.A. y López, R. (2009) "Redes sociales. Análisis y aplicaciones"; Garay, L.M. (2009). "Tecnologias de información y comunicación. Horizontes interdisciplinarios y temas de investigación”. México: UPN. 
un registro de su evolución. En este sentido, abordar un mismo tema en universos y espacios geográficos diferentes, así como desde otras categorías de análisis, enriquecen esos registros y su conocimiento científico.

A partir de estas premisas, la investigación SEP-CONACYT Ciencia Básica permitió experimentar un nuevo ejercicio investigativo, multidisciplinario e interinstitucional, ya que participaron comunicólogos, psicólogos, pedagogos y antropólogos, cuyo nexo y punto de encuentro es el interés por dos temas que se tocan: las juventudes y el uso de las tecnologías digitales. El protagonismo alcanzado por las redes sociales digitales y debido a que las consideráramos un nuevo escenario de interacción entre la juventud y otros grupos sociales, nos llevó a profundizar su análisis mediante un amplio trabajo empírico que permitió identificar hallazgos tan sorprendentes como estimulantes para seguir indagando en las nuevas y singulares vertientes que ofrece el tema. Identificamos también el creciente interés de otros investigadores por estudiar aspectos específicos de tales interacciones, análisis que merecen ser integrados a este libro con el fin de alimentar el registro y evolución de las prácticas digitales juveniles.

Esta obra está integrada por diez trabajos, los que fueron agrupados en dos partes interrelacionadas. Las primeras contribuciones refieren cruces y matices acerca del vínculo estudiantes-digitalización derivados directamente de los hallazgos obtenidos en los casos de estudio de la investigación SEP-CONACYT. Algunos de aspectos no fueron desarrollados en el libro que reporta los hallazgos globales de la investigación, debido a razones de espacio y estructura.

El segundo grupo de capítulos, analiza de manera puntual sujetos y prácticas de interacción emergentes en redes sociodigitales. En estos trabajos, sus autores presentan reflexiones en torno prácticas comunicativas novedosas, propias de los procesos digitales.

Como sabemos, las redes digitales abren un amplio abanico de abordajes y temas, por lo este libro podría incluir el estudio de un número mayor de sujetos y prácticas comunicativas que tienen lugar en ese ámbito. Sin embargo, los autores que participan en esta obra estuvieron vinculados de distintas maneras al estudio original, por lo que sus análisis abordan actividades comunicativas emergentes propias de la redes sociodigitales. Los estudiantes, el género, el idioma inglés, los contextos sociales, los memes, los movimientos sociales digitales, Twitter, los videojuegos y así como reflexiones generales sobre la interacción desde la mirada de la ingeniería, amalgaman en este libro una narrativa singular sobre nuevos sujetos y nuevas experiencias digitales. 
Los hilos conductores de estas contribuciones son dos: los jóvenes como usuarios preponderantes (aunque no únicos) de las redes sociales digitales, y las propias redes, que constituyen ese nuevo espacio social (Echeverría, 1999) donde despliegan actividades comunicativas con contenido e intencionalidad diversa. Como lugar de encuentro, las redes llegan a las sociedades modernas con la capacidad de ofrecer inmediatez en el tiempo y supresión de distancias, recursos que suelen ser escasos y por tanto valiosos, en los ámbitos urbanos.

Los capítulos I al V derivan directamente de la investigación original y fueron escritos por investigadores participantes en el estudio, por lo que es posible afirmar que sus cruces y matices se articulan en torno a estudiantes y digitalización. Estos trabajos corresponden a hallazgos colaterales, no suficientemente profundizados en la ya mencionada obra general y su presentación de resultados.

En el primero, “Jóvenes, redes digitales y utopías no resueltas”, de mi autoría, analizo el modelo político-económico en el cual surge la digitalización, indicando algunos de los factores que orientan su destino. Refiero asimismo la emergencia de actores y objetos culturales de nuevo cuño que, por consiguiente, dan lugar a nuevas prácticas sociales desarrolladas en una dimensión espacio-temporal distinta. Para cerrar el análisis, identifico algunas de las utopías de la digitalización, concebidas desde el optimismo que la considera omnipotente, capaz de solucionar algunos de los rezagos sociales y culturales existentes. Contrasto estas utopías con ciertos elementos de realidad que señalan su corte quimérico, y que indican lo mucho que aún resta por hacer en materia de políticas públicas al respecto.

La segunda contribución: "Elementos para comprender la interacción juvenil en las redes sociales digitales", corresponde a una propuesta de María Consuelo Lemus Pool y Miriam González Montalvo. Las autoras, a partir de aportaciones teóricas novedosas, revisan desde nuevas perspectivas los procesos de interacción en redes digitales entre jóvenes, buscando profundizar en sus dinámicas. Lemus y González relacionan desde una mirada sociocultural la interacción de tres aspectos específicos: la edad de los sujetos que interactúan; la incidencia de los capitales económico, social y cultural en esos procesos; y las habilidades digitales de los usuarios. Este trabajo muestra la necesidad de seguir enriqueciendo un tema, todavía en construcción, a partir de nuevos enfoques teórico y cruces con interpretaciones ya clásicas.

Gladys Ortiz Henderson, Rocío López González y Karla Edurné Romero Ramos, trabajan conjuntamente en el tercer trabajo: "Uso de redes 
sociales digitales entre estudiantes universitarios: trazos para la reflexión desde una perspectiva de género". Parten de los resultados de la investigación original, con el propósito de comparar el género, un punto de vista que no se analizó en el informe general de la misma. Retoman dos casos de dicha investigación: el de Universidad Autónoma Metropolitana, unidad Lerma (UAM-Lerma) y el de Universidad Veracruzana (UV). Se trata de dos universidades públicas cuyos entornos presentan importantes diferencias en lo social, cultural y geográfico. Sin embargo, los hallazgos primarios indicaron que hay coincidencias y divergencias en cuanto a la cultura digital de esos jóvenes universitarios. Además de describir ambos contextos, las autoras reflexionan desde una perspectiva de género acerca de aspectos específicos que identifican en las prácticas juveniles de acceso y uso de las redes digitales: el comportamiento de los estudiantes al navegar en Internet; las percepciones acerca de la cultura digital; la participación y la interacción. El contraste pone en evidencia las ya mencionadas consonancias y disonancias, propias de una generación juvenil definida y diferenciada por su contexto.

El cuarto apartado, titulado "El nivel socioeconómico y el dominio del idioma inglés, como elementos de acceso y ampliación de la brecha en la cultura digital", fue desarrollado por María Guadalupe González Lizárraga, Esther Hugues Santa Cruz y María Teresa Becerra Traver. En estas reflexiones toman como referencia los resultados obtenidos en el estudio de caso de la Universidad de Sonora (UNISON), que formó parte de la investigación Ciencia Básica SEP-CONACYT. No obstante, ya que en el reporte general no se profundizar sobre la incidencia de la frontera como lugar geográfico desde donde se llevan a cabo las interacciones en redes sociales digitales, el capítulo IV aborda ese matiz sustantivo. En los hallazgos de este caso se identificaron dos aspectos contextuales destacados: el nivel socioeconómico (de medio a alto) y el dominio del idioma inglés. Ambos aspectos cobran especial interés por tratarse de una universidad ubicada en un estado fronterizo. Las autoras profundizan estas dimensiones como elementos que influyen tanto en el acceso a tecnologías de generaciones recientes, como por la facilidad que otorga a los usuarios el dominio del inglés, lengua hegemónica para el manejo del software y también para la navegación debido a que buena parte de los contenidos están en ese idioma. Con esta contribución se pone de manifiesto una vez más, que aunque el contexto no determina, si condiciona (Lévy, 2007).

El quinto trabajo se titula "Universitarios, desarrollo de habilidades digitales comunicativas. Del ámbito escolar y la vida cotidiana" y fue escrito por Blanca Flores Ramírez y Luz María Garay Cruz de la Univer- 
sidad Pedagógica Nacional. Estas reflexiones parten de una investigación distinta a la ya referida SEP-CONACYT Ciencia Básica, y está enfocada a la relación entre redes sociales digitales y educación superior. Sus resultados les permiten corroborar algunos de los hallazgos del estudio SEP-CONACYT original, por lo que constituye una contribución ulterior al mismo. Es importante considerar que la Dra. Garay Cruz fue parte activa de la investigación original y como tal ha recuperado algunos de sus resultados, formulando nuevos planteamientos y retos sobre el tema evidenciados en la tesis de maestría de Blanca Flores Ramírez. Aunque como se dijo, se trata de una investigación distinta e independiente, arriva a resultados coincidentes con el primer estudio SEP-CONACYT, lo que permite percibir entre ambos un mutuo reforzamiento. Como su título lo indica, el trabajo analiza de manera detallada el despliegue de habilidades digitales en redes sociales por parte de universitarios, los que reconocen la existencia de un escenario integrado, sin rupturas, por el ámbito escolar y por otras prácticas cotidianas.

En lo que considero una segunda parte de esta obra, los cinco capítulos siguientes permiten a los autores presentar sus reflexiones sobre temas específicos de prácticas comunicativas en las redes sociales digitales, producto de estudios que vienen realizando. Su incorporación refleja la necesidad de reflexionar acerca de sujetos y prácticas de interacción específicas o emergentes en las redes sociodigitales. Sin agotar la enorme variedad de esas prácticas, estos capítulos recogen las perspectivas de autores que analizan algún uso expresivo particular y sus características.

Bajo el sugerente título "Ocho de cada diez gatos prefieren El Komander: una apropiación y expresión de discriminación cultural en redes sociodigitales", tres autores analizan el fenómeno de los memes. Gabriel Pérez Salazar, un experto en el tema, une sus reflexiones a las de Esaú Salvador Bravo Luis y Monserrat Del Bosque Carrillo, para entregarnos un trabajo que parte de un deslinde necesario: identidad y discriminación en los memes. Este binomio, que en ocasiones puede representar las dos caras de una misma moneda cultural, permite a los autores identificar expresiones de discriminación cultural en el rico ámbito de los memes. Estas expresiones, tan atractivas como ingeniosas, son también vehículos para manifestaciones de exclusión sobre ciertos grupos sociales, por ejemplo indígenas, o ante consumos culturales como la banda y el reggaetón. Aunque conducto para la expresión de ideas y perspectivas divergentes, los memes no dejan de ofrecer aristas diversas en las que se yuxtaponen recursos inagotables de creatividad, burla, sarcasmo y exclusión. 
Rodrigo Perera Ramos es autor del trabajo "Movimientos conectivos y redes sociales: análisis de la Red Anonymous en Tritter". Inicia su texto delimitando, caracterizando y definiendo los movimientos conectivos, que desde su perspectiva son llamados así por ser quienes se han apropiado de recursos digitales para organizarse y expresarse en comunidades virtuales. Las redes sociodigitales son para ellos un elemento clave, que el autor devela en su estudio de caso: Anonymous, refiriendo el tipo de redes empleadas y presentando una tipificación de las mismas. La aportación de Rodrigo Perera es de especial interés para la comunicación, porque enfatiza su importancia dentro de las acciones colectivas y conectivas.

El siguiente trabajo que forma parte de esta obra, aborda otros de los temas centrales en el uso de las redes: Twitter. Enrique Iturralde Chaparro presenta los resultados obtenidos en un trabajo de campo desarrollado en la ciudad de Querétaro, cuyos hallazgos le permiten trazar algunas líneas de reflexión sobre estos twitteros y su propio imaginario tecno-informacional. Como lo advierte su autor, las reflexiones y hallazgos no son generalizables por cuanto reportan datos de un universo concreto. No obstante, se despliegan líneas de reflexión que pueden ser retomadas en investigaciones futuras, esto sin dejar de mencionar que todo trabajo empírico sobre apropiación de redes sociales contribuye a fortalecer el tejido de experiencias e ideas que aún se están construyendo, para un mejor conocimiento de las diversas prácticas que se llevan a cabo en dichas redes.

David Cuenca Orozco ha venido trabajando en los últimos años un tema de gran interés, cuya aceptación y crecimiento entre los jóvenes resultan reveladores: los videojuegos. En su trabajo "Un abordaje a las redes sociales digitales, los videojuegos, y los medios sociales”, el autor escoge para sus reflexiones una forma específica de juego: el que se lleva a cabo en redes sociales digitales. Su aporte enfatiza la mirada de la comunicación, perspectiva que resulta destacada debido a que suele ser poco referenciada, y menos aún interrelacionada con otras perspectivas disciplinares.

El libro cierra con una aportación desde la ingeniería industrial y de organizaciones: "Interactividad web: de la conceptualización a la operacionalización" de Rafael Leonardo Ochoa Urrego. El autor delimita y define primero la interactividad como un proceso esencial tanto para la interacción como para la comunicación, a la que también considera un componente natural de las tecnologías digitales. Desde su campo de conocimiento, se da a la tarea de construir puentes con las ciencias sociales, presentando primero un amplio recorrido acerca del concepto interacción, para luego esbozar una propuesta de operacionalización y medición. Se trata sin duda de un ofrecimiento de gran interés para quienes estudian 
estos temas en el ámbito de las ciencias sociales, aunque como el propio autor lo señala, con retos y contradicciones por superar. La inclusión de este trabajo, con una perspectiva diferente a la de las ciencias sociales, constituye una provocación que busca despertar el interés por la interdisciplinariedad. Al mismo tiempo, devela la preocupación que existe en otros campos de conocimiento por las redes sociciodigitales y las interacciones que en ellas se producen, aunque observadas a partir de otros marcos conceptuales. Cruzar las fronteras disciplinares es un reto que debemos plantearnos para comprender mejor un fenómeno expresivo y relacional tan complejo como el que tiene lugar en las redes sociales digitales.

En toda obra que se integra con visiones y perspectivas diferentes sobre un tema amplio como el de las redes sociales digitales, los matices son diversos y contribuyen a transformar a ese tema en un prisma, que puede ser percibido desde diferentes ángulos, obteniendo imágenes distintas. La transformación tecnológica, pero sobre todo social y cultural emanada de la organización, la expresión y las relaciones que se establecen en las redes sociales digitales, ofrece la oportunidad de contribuciones diversas debido a que no sólo son tópicos nuevos para la investigación, sino que también se expanden en múltiples objetos y sujetos que transforman las prácticas cotidianas.

La intención de este libro no es encontrar hallazgos comunes o establecer las mismas líneas de resultados: su propósito es mostrar la diversidad. Como ya se dijo, buscamos contribuir al registro de la evolución de las prácticas digitales, sus características y consecuencias.

Como podrá verse a lo largo de su lectura, el libro "Prácticas comunicativas en entornos digitales" ofrece reflexiones acerca de algunas de las interacciones que se despliegan en escenarios digitales diversos, dinámicos y cambiantes. Si acaso logramos identificar algunas coincidencias en este tejido complejo, serán sin duda aquellas que indican que las redes sociales digitales, comunes a un gran número de personas a nivel mundial, se desdoblan en prácticas diversas con las que los usuarios se expresan, se organizan $\mathrm{y}$ sobre todo se encuentran determinados por condiciones personales $\mathrm{y}$ sociales situadas.

Las interacciones pueden llegar a acentuar más el aspecto relacional que su contenido: es saber que el otro, el igual o no, está allí presente en un like, en un reenvío o en alguna otra expresión que puede ir de la plena aceptación al más franco rechazo, exclusión o agresión. Este tipo de intercambios parecen ser el motor de una sociedad aún poco organizada para llevar a cabo actividades colectivas haciendo uso de esos recursos digitales. 
Las redes constituyen un canal expresivo privilegiado y aunque no nos gusten muchos de los contenidos que transmiten, están allí como nuevo espacio social para propiciar el encuentro, romper el aislamiento, reforzar la identidad y también pasar de lo virtual al ámbito del espacio físico cuando las circunstancias así lo permiten y los usuarios así lo deciden.

Junto con los análisis sobre aspectos específicos de la comunicación en redes sociodigitales, esta obra procura abrir un camino de investigación y búsqueda en torno a otros temas y sujetos que de manera vertiginosa están cambiando la cultura con prácticas singulares fundadas en la digitalización. 


\section{De jóvenes, redes digitales y utopías no resueltas}

\section{Delia Crovi Druetta}

El propósito de este trabajo es reflexionar sobre las condiciones que acompañan y determinan las interacciones que los jóvenes llevan a cabo en las redes sociales digitales, a partir de los resultados generales obtenidos por la investigación del programa Ciencia básica SEP-CONACYT (20122017) "Jóvenes y cultura digital. Nuevos escenarios de interacción social" del cual fui responsable técnica. El estudio arrojó importantes datos empíricos sobre estos procesos los que fueron reportados en un libro anterior ${ }^{1}, \mathrm{y}$ como toda investigación, más allá de sus hallazgos globales sugiere temas y aspectos emergentes a profundizar mediante nuevos análisis. En este capítulo recupero algunos aspectos que no fueron tratados en los hallazgos globales, pero que a mi juicio menerecen ser analizados en una obra como la presente.

Dividiré esta exposición en cuatro escenarios que considero sustantivos para referir las condiciones en que grupos juveniles de estudiantes urbanos, se apropian de los recursos de la digitalización, alimentando a partir de ellos la construcción de una cultura digital. Estos ámbitos son:

1. El contexto: modelo político-económico en el que surge la digitalización.

2. La emergencia de novedosos actores y objetos culturales, así como prácticas sociales que se concretan en una nueva dimensión espacio-temporal.

3. El ciclo de interacciones propuesto como cierre de la investigación referida, tratándolo ahora como turbina que permite repensar su dinámica.

4. Algunas utopías no resueltas.

En cada uno de estos escenarios, esbozaré aspectos que deberían tomarse en cuenta en el diseño de políticas públicas sobre juventud y cultural digital, por lo general poco explícitas en relación a estas prácticas.

1 Los hallazgos de la investigación Ciencia Básica SEP-CONACYT referida, se presentan en la obra: Crovi D. et al. (2016). "Redes sociales digitales. Lugar de encuentro, expresión y organización para los jóvenes”. México. UNAM-La Biblioteca. Por su parte, las reflexiones presentadas en este capítulo se desprenden de esa investigación, sin embargo, no son temas tratados ni forman parte del mencionado libro. 


\section{El contexto: modelo político-económico que sustenta la digitalización}

Cuando en 1973 Daniel Bell menciona por primera vez la idea de una sociedad de la información abre una discusión que, retomada con fuerza a finales de los 90, busca dar un nombre a este tipo de sociedad ${ }^{2}$. Producto de esas reflexiones primero le llamarían de la información, para pasar posteriormente a denominarse sociedad del conocimiento o también, abarcando ambas ideas, sociedad de la información y el conocimiento. Para entonces la digitalización apenas iniciaba un voraz camino ascendente hacia su masificación, y una sociedad así denominada enunciaba un cambio social de buen signo, así como con muchos beneficios para los ciudadanos.

El proceso de digitalización consiste en el cambio del lenguaje analógico al digital, es decir, el paso generalizado hacia un formato binario y numérico. Se considera esencial en el desarrollo y puesta en marcha del proyecto sociedad de la información y el conocimiento, debido a que la digitalización está vinculada a la construcción de redes de contenido e intercambio; la disponibilidad de un amplísimo volumen de información; la oferta de una nueva dimensión espacio-temporal y la innovación constante de tecnologías. Tales transformaciones permiten señalar que ese proceso no sólo debe verse desde lo tecnológico, sino que debe comprenderse como el motor de cambios sociales diversos (educativos, laborales, industriales, de entretenimiento y ocio, entre otros), que han llevado al ejercicio de nuevas prácticas sociales y culturales.

Desde la mirada del campo de la comunicación, son notables cuatro antecedentes: la búsqueda de un Nuevo Orden Informativo Internacional iniciado en la década de los 70 con el fin de reorganizar los flujos noticiosos globales; la Conferencia Intergubernamental sobre políticas de comunicación en América Latina y el Caribe, San José, Costa Rica (1976); el diagnóstico "La informatización de la sociedad" (1978) de Alain Minc y Simon Nora que analizan en Francia la combinación telecomunicaciones con procesamiento informático de datos, reflexiones a partir de las cuales se acuña el término telemática; y el informe MacBride "Un solo mundo, voces múltiples. Comunicación e información en nuestro tiempo" (1980).

2 El término resurge en la década de los 90 , siendo adoptado por diversos países y organismos internacionales. A partir de 1998, fue escogido primero en la Unión Internacional de Telecomunicaciones y ratificado luego por la Organización de las Naciones Unidas, ONU, para darle nombre a la Cumbre Mundial de Sociedad de la Información, realizada en 2003 en Ginebra, Suiza. Este nombre se repite en la segunda Cumbre llevada a cabo en Túnez en 2005. 
Aunque hubo otros hechos destacados, para la comunicación son hitos que fijan su atención en un tema común: encontrar caminos para un flujo informativo más equitativo; así como analizar nuevos objetos y prácticas culturales que indican el surgimiento de un proceso complejo y multifactorial, de amplio alcance y repercusiones, que conocemos ahora como sociedad de la información y el conocimiento, modelo en el cual la digitalización cumple un papel fundamental. Mientras se abordaban estas preocupaciones específicas del campo, el mundo recibió en la década de los 90 al neoliberalismo, propuesta político-económica que ya venía gestándose, fundada en el desgaste del modelo anterior. El nuevo modelo, complementado con la globalización, conformaría el concepto globalización neoliberal, que lleva casi tres décadas de aplicación y del cual la digitalización es uno de sus ejes.

¿Por qué es importante ligar la digitalización con la emergencia del modelo neoliberal? Porque desde mi perspectiva los objetos tecnológico-culturales y las prácticas que los acompañan, canalizan y refuerzan algunas de las premisas de la globalización neoliberal ${ }^{3}$. Entre ellas destacan: privatización; liberalización-desregulación; desplazamiento del enfoque en las clases sociales hacia un interés por el individuo y la familia; una suerte de presente continuo en las prácticas sociales y sus consecuencias; así como el reemplazo de las tradicionales instancias de mediación social por otras de nuevo cuño ${ }^{4}$.

Respecto a la privatización, es factible afirmar que el sector telecomunicaciones, (salvo regulaciones puntuales y servicios públicos anteriores), ha quedado en manos del sector privado. Como sabemos, los servicios más empleados: telefonía móvil, redes sociales digitales, circulación y transferencia de datos, nuevas formas de distribución de productos audiovisuales, entre otros, están manejados por corporaciones empresariales con fuerte presencia en el sector telecomunicaciones.

En general los usuarios de Internet y redes sociales pocas veces tienen presente que sus interacciones se concretan mediante servicios ofrecidos casi exclusivamente por empresas con fines de lucro que determinan sus prácticas culturales. Facebook, YouTube y Twitter, así como Instagram, resultaron en nuestro estudio ser las redes sociales más usadas, sin embargo,

3 Al pasar a formar parte importante del modelo neoliberal, los medios tradicionales han hecho algo parecido: mediante acciones informativas y propagandísticas lo promueven, informan sobre sus ventajas y beneficios, sin explicar riesgos y desventajas. 4 Debido al enfoque de estas reflexiones, excluyo otros aspectos económicos precisos del neoliberalismo, como son pago puntual de la deuda externa, control de la inflación y control de los salarios. 
pocos conocen sus estructuras empresariales e intereses. La misma invisibilidad técnica y económica que experimentaron las audiencias respecto de la radio, la televisión, el cine y en menor grado de la prensa, es palpable ahora frente a los recursos digitales.

Este desconocimiento es similar o mayor respecto a la legislación que regula este sector. La desregulación favorece al sector empresarial que maneja los nuevos medios, permitiendo una creciente concentración de estos servicios en pocos actores económicos. Destaca asimismo, la tendencia a liberalizar las normas laborales (algunas de las cuales se establecieron en la sociedad industrial), promoviendo tareas por obra determinada o free lance, que en general conducen a una irreversible pauperización del ámbito laboral.

Un elemento central que contribuye a la liberalización de las contrataciones laborales, se origina en la nueva dimensión espacio-temporal que ofrecen objetos y procesos digitales. El rompimiento de fronteras físicas y de la linealidad temporal, abren la posibilidad de trabajar, estudiar, relacionarse, entretenerse a distancia, lo que da una sensación de libertad, aunque posea también desventajas. El orden y organización del tiempo fomentado por la sociedad industrial, separaba en compartimentos diferentes las principales actividades sociales. Esta estructuración desaparece ante la posibilidad de conexión permanente que, aunque ofrece sensación de libertad, también genera dependencia a una práctica permanente de consulta informativa para mantener las relaciones sociales, laborales, escolares y otras de carácter afectivo o temático, concretadas mediante el uso de pantallas eslabonadas.

Estas pantallas múltiples se han convertido en un rasgo común entre usuarios jóvenes de objetos técnicos digitales, debido a que son parte de una generación que posee habilidades para hilvanar discursos provenientes de tabletas, computadoras, teléfonos inteligentes y un sinfín de novedosos productos, distinguiendo en su uso el más apto para cada actividad. La capacidad de integrar información dispersa, formando mosaicos informativos sobre su propia realidad, es sin duda una de las características que distingue a los grupos juveniles.

Si valoramos su magnitud social, Internet constituye hasta ahora un ámbito escasamente regulado, y a pesar de algunos intentos por legislarlo, su complejidad y reclamos sociales lo han ido postergando. Esto, sin embargo, no fue impedimento para que sus emisores padecieran algunas reacciones y persecuciones de sectores gubernamentales o privados. $\mathrm{La}$ telefonía móvil, otro de los pilares de la digitalización, cuenta por su parte 
con un marco legal más sólido, producto de la competencia entre los operadores de ese sector, así como los reiterados reclamos de los usuarios que alzan sus voces para defender algunos derechos. En ambos casos se trata de medios nuevos con novedosos modelos de negocio en los cuales el más desprotegido es el usuario, de allí que no ha sido fácil que éste se defienda pero tampoco que el avasallamiento empresarial sea definitivo.

La complejidad técnica y el escaso interés por transparentarla, contribuye a que la liberalización del sector empresarial y la desregulación laboral deje su huella en las prácticas sociales. Es posible advertir esta impronta en la escasa perspectiva crítica que expresan los usuarios ante los nuevos medios, lo que puede conducir a la aceptación de las condiciones impuestas por sectores privados y gubernamentales como si fueran irreversibles.

Cabe agregar dos aspectos más que, desde mi perspectiva, surgen del modelo neoliberal en el que se asienta la digitalización: el fomento al individualismo y el impulso a una suerte de presente continuo. Mientras las sociedades anteriores tenían en las clases sociales uno de sus ejes para explicarse y reflexionar sobre sí mismas como colectividad, el neoliberalismo valora los mecanismos de competencia, desarticulando con ello la noción de trabajo común; asimismo, pondera el individualismo, desplazando ese centro de atención hacia los sujetos y la familia. Tal vez es por ello que en el estudio realizado, los jóvenes usuarios prefieren el uso individual de aparatos y recursos digitales, en los que despliegan preferentemente interacciones personales con sus pares acerca de temas y preferencias compartidas, pero no se insertan en grupos organizados. Respecto al presente continuo, la incertidumbre que conlleva un modelo flexible, desregulador y liberalizador de ciertas normas sociales, conduce a vivir pensando sólo en el instante vital. El futuro planificado donde antes se situaban metas esperables, ahora se traslada a un descontextualizado día a día, donde parece no registrarse antecedente y ni consecuente. Entre la contingencia diaria y un futuro incierto, los sujetos optan por vivir el momento, lo que les resta capacidad para analizar y hacer planes que vayan más allá de retribuciones inmediatas, si las hay. En suma, individualismo y presente continuo tejen una narrativa fragmentada de la vida misma y las relaciones sociales, relato social en el cual los recursos digitales son pieza clave.

Una reflexión especial merecen las redes sociales e Internet considerados como recursos para canalizar, y en ocasiones reemplazar, instancias de mediación social cuya fuerza en otros tiempos fue innegable: sindicatos, partidos políticos, organizaciones de la sociedad civil, algunos medios de comunicación, religiones y educación. Sin embargo, estas mediaciones 
digitales carecen de elementos fundamentales para que tal reemplazo sea efectivo: organización, duración en el tiempo, fuerza legal y reconocimiento de sus interlocutores sociales o políticos. Es verdad que las expresiones en red dan lugar a agendas temáticas que pueden o no trasminarse a otros medios y otras instancias, pero también es cierto que como dicen los propios estudiantes que fueron consultados en el estudio realizado, pocas veces sus movilizaciones en red llegan a concretarse en acciones de corte legal o en cambios específicos planteados en alguna demanda. De sus propias respuestas se deduce también que son pocos quienes planifican sus interacciones para que se desarrollen tanto en el ciberespacio como en el espacio físico. A pesar de su pericia para moverse sin rompimientos entre ambos entornos, en general se decantan por la comodidad de la expresión virtual.

En este contexto, para devenir en nuevas instancias de mediación social, las redes sociales e Internet deben aún recorrer un largo camino si quieren compartir con otros actores esferas tan destacadas de articulación social. Esta trayectoria deberá considerar organización, permanencia en el tiempo, dominio de los temas que se expresan y reclaman, una dialéctica efectiva entre espacio virtual y físico, así como el desarrollo de habilidades digitales que permitan sacar el mayor provecho de los recursos disponibles y los que constantemente aparecen como producto de las innovaciones tecnológicas. Ello no implica negar a las redes digitales la capacidad de articular otro tipo de acciones, como es la creación de agendas, la interlocución entre sujetos y grupos, el apoyo a movimientos sociales, así como la organización de encuentros y eventos diversos. Pero sus virtudes de fácil acceso, disponibilidad relativamente abierta y volumen informativo descomunal, están acompañadas por la fragmentación de contenidos y su fatal volatilidad.

\section{Novedosos objetos y prácticas culturales emergentes en un nuevo espacio social}

Las prácticas sociales que emergen de la digitalización han estado regidas por políticas públicas que buscan el acceso para lograr el ansiado modelo de una sociedad de la información y el conocimiento. No obstante, se han descuidado otros dos pasos del proceso de incorporación tecnológica: el uso y la apropiación.

Una de las premisas de los organismos internacionales ha sido lograr el acceso universal, meta aún inconclusa pero que ha merecido el interés de diferentes gobiernos nacionales, lo que les ha llevado a desarrollar desta- 
cados programas para dotar de tecnologías a todos por igual. Esta postura tecnodeterminista ve en la provisión de recursos técnicos la solución a muchos problemas y el camino hacia una sociedad de la información y el conocimiento. Aunque en las primeras propuestas sólo se hablaba de brechas digitales, no pasó demasiado tiempo antes que la UNESCO advirtiera que existen también brechas cognitivas, resultado de condiciones educativo-culturales inequitativas. Superar las brechas cognitivas existentes es un desafío mayor por cuanto atañe a las políticas públicas nacionales de cultura y educación, no obstante, constituye el único recurso para ir más allá del manejo de lo técnico, formando usuarios capaces de moverse en el nivel de las significaciones. A pesar de la identificación de esta dimensión, es poco lo que se ha hecho para conocer mejor las rutinas de uso de las nuevas tecnologías, análisis y acciones que podrían dotar de insumos a las políticas públicas que buscan detonar procesos de digitalización para el cambio social.

Junto con las políticas públicas, como ya lo señalé, las prácticas cotidianas de los usuarios de los nuevos medios digitales, permiten visualizar y ejercer una dimensión espacio-temporal de doble sentido. Por un lado, la interlocución con lugares remotos y el uso de tiempos sincrónicos o asincrónicos para interactuar, concretan las metas de la globalización neoliberal; y por otro, conducen a los usuarios a una ruptura importante con sus prácticas anteriores, lo cual les exige un nuevo orden y jerarquización del espacio y el tiempo. La sensación de libertad ofrecida por estos medios, materializada en pantallas eslabonadas, socava otras prácticas reguladas por horarios y lugares: la escuela, el trabajo, la organización de actividades personales cotidianas, los encuentros sociales, entre otras. Aunque esta situación abre la posibilidad de convivencia entre la vieja y la nueva propuesta, debido a que no todos los sistemas sociales han dejado atrás lugares y horarios, son muchos los usuarios que están experimentando una vida activa libre de las ataduras que suponen las antiguas normas de espacio y tiempo.

Esta nueva dimensión permite explorar otras realidades, confrontarlas con las propias, estar informado sobre recursos o decisiones de otras latitudes y tiempos. Como resultado, se crea una apetencia por lo lejano que se superpone con lo cercano: estar con amigos y familia, pero conectados con interlocutores ausentes en lo real, presentes en lo virtual. Entre los adultos este es tal vez el reclamo más recurrente: la preferencia juvenil por lo virtual y el desinterés por lo presencial, un tema a profundizar.

A los nuevos medios y prácticas sociales se suman, entre otros, dos elementos dignos de ser señalados: la búsqueda de conocimientos paralelos 
para lograr ser funcional en el mundo de la digitalización, generalmente de manera extracurricular; y la posibilidad de convertirse en emisores emergentes a partir de sus ventajas.

Tanto en el estudio que realizamos sobre jóvenes y cultura digital, como en trabajos anteriores del mismo equipo de investigadores ${ }^{5}$, surgen resultados que indican que el desarrollo de habilidades digitales rara vez se lleva a cabo en la escuela. Allí se fomentan los primeros contactos con ciertos aparatos y ejercicios de uso, pero son los pares (amigos, parientes, conocidos, colegas) los que les comparten el conocimiento digital y luego mediante la experimentación, desarrollan habilidades en el manejo de los diferentes objetos técnicos que aparecen. Algunos, los menos, asisten a cursos. Este es un vacío a llenar: los sistemas educativos deben tomar en sus manos el desarrollo de habilidades digitales si queremos, al final del camino, construir una sociedad de la información y el conocimiento basada en recursos digitales que propician el trabajo colaborativo en red, así como señalar posibles caminos para la selección y jerarquización de la información disponible.

En cuanto a los emisores emergentes, cabe señalar que Internet primero y más tarde las redes sociales digitales, permiten que en potencia quienes tienen conexión, puedan emitir contenidos. Esta búsqueda de décadas, en el ámbito de los medios tradicionales tomó el atajo de pequeños espacios de réplica o respuestas, pero nunca alcanzó el ideal del Emi-Rec (Cloutier, 1975), o sea de roles intercambiables que permiten una comunicación dialógica. En distintos niveles, la educación incorporó la posibilidad de contar con sus Emi-Rec con el fin de captar opiniones, realizar tareas participativas, consolidar algunas líneas de pensamiento o acción entre profesores y estudiantes. Por su parte, las organizaciones sociales, educativas y privadas, ensayaron desde los inicios de la www ocupar espacios de emisión para presentar sus logros y objetivos con el fin de alimentar procesos de comunicación dialógicos. Asimismo, los propios sujetos presentan contenidos diversos en los que canalizan sus perspectivas personales, haciendo uso de recursos digitales y de la apertura que ofrecen las redes para contar con espacios personales de expresión.

En sus propuestas de retorno, los medios de comunicación tradicionales ofrecieron diferentes modalidades, pero en ellas la capacidad de dialogar casi siempre ha estado circunscrita a ciertos parámetros establecidos

5 Pueden consultarse los trabajos de Crovi, D. (2013), Jóvenes y apropiación tecnológica. La vida como hipertexto. México: UNAM-Sitesa Ediciones; y Garay, L.M. (2009). Tecnologias de información y comunicación. Horizontes interdisciplinarios y temas de investigación. México: UPN. 
por los propios medios. La posibilidad que ofrecen los recursos digitales de abrir espacios para que todos, hipotéticamente, puedan ser emisores emergentes, se consolidan en nuevas formas de expresión como periodismo ciudadano ${ }^{6}$ o el confuso término de posverdad ${ }^{7}$.

El periodismo ciudadano se concibe como un ejercicio informativo mediante el cual se crea conciencia ciudadana, se proponen temas o problemas que construyen agenda y se abre la posibilidad de diálogo con los medios de comunicación, el poder y las audiencias. Es posible afirmar que este tipo de ejercicio ciudadano no sólo es alternativo a los discursos hegemónicos, sino que amplía la mirada sobre los hechos sociales, al tiempo en que se construye a sí mismo como interlocutor.

En cuanto a la posverdad, la aceptación del término no es unánime y las conceptualizaciones son muchas. En general se le interpreta con un ejercicio para modelar la opinión pública, en el cual los hechos objetivos tienen menor valor que las creencias personales o las apelaciones emotivas. Aunque ambos conceptos, periodismo ciudadano y posverdad, parecen sugerir una ampliación de puntos de vista diferentes a los de las agendas hegemónicas, en realidad mientras el primero retoma al sujeto y lo empodera para informar sobre su contexto; en la posverdad se empodera a los sentimientos, las apreciaciones e interpretaciones personales, convirtiendo a la información en un recurso aún más maleable de lo que ha sido hasta ahora.

Los hallazgos del estudio al que estoy haciendo referencia, muestran una fuerte tendencia a la socialización en redes sociales, además indican la aplicación recurrente de un modelo difusionista que amplía la cobertura de la información. Esto permite pensar que tal vez la característica preponderante de estas redes es ser un medio para socializar, al que le estamos pidiendo más de lo que le es posible dar. No obstante, también es aceptable inferir que pueden canalizar habilidades de interacción de los usuarios hacia otros temas de interés personal o social, que cohabitan con lo que

6 Concibo al periodismo ciudadano como un ejercicio informativo mediante el cual se crea conciencia ciudadana, al tiempo que se proponen temas o problemas que construyen agenda y abren la posibilidad de diálogo con los medios de comunicación, el poder y las audiencias.

7 Hay muchas conceptualizaciones de posverdad, algunas de las cuales son contradictorias debido a que es un tema aún en discusión. La Real Academia Española (RAE) lo incorporó a su diccionario a finales de 2017, en tanto que el de Oxford la define como: "relativo a las circunstancias en las que los hechos objetivos influyen menos a la hora de modelar la opinión pública que los llamamientos a la emoción y a la creencia personal" (2017). 
preferentemente hacen los jóvenes ahora: desarrollar conversaciones amigables en línea, repetir y dar like a contenidos de otros.

Este conjunto de emisiones es casi inabarcable y adquiere características diferentes: no todos buscan establecer una comunicación dialógica, no todos son Emi-Rec, en realidad son muchos los que reproducen el modelo de difusión en sus contenidos sin esperar establecer el diálogo que posibilita la digitalización. Los resultados del estudio del cual parten estas reflexiones, muestran que los jóvenes consultados son sobre todo repetidores, les gusta conversar en red, replicar mensajes de los otros y convertirse en sus difusores. Aun cuando podamos aceptar que la misión central de las redes sociales digitales es ser una suerte de megáfonos modernizados, digitalizados y recargados para otras funciones, repetir mensajes de otros también puede indicar un vacío de contenidos o dificultad para expresarse.

¿Es esto acaso el resultado de políticas de silencio, aislamiento y censura aplicadas a los ciudadanos? ¿Es producto de una educación deficiente que no enseña a decir, reclamar, expresar, compartir? ¿O será acaso que estamos ante la necesidad palpable de desarrollar habilidades que vayan más allá de manejar objetos técnicos, instalándose en el saber decir, en la expresión y la opinión?

Muchas veces vemos con inquietud que desde el anonimato que dan los seudónimos o nombres creados para las redes, se expresan agresiones, ataques devaluatorios o amenazantes. Si como afirma Javier Echeverría (2000) las redes son un nuevo espacio social, podemos esperar en ellas actitudes y expresiones que van del amor al odio, de la adhesión al rechazo, del gusto al disgusto, mismas que se dan también en el mundo real. Por ello, será difícil sino imposible, erradicar expresiones negativas en las redes, porque como todo espacio social incluye a una variedad enorme de sujetos que siendo diferentes, buscan armonizar pero también discrepar o agredir.

No obstante, la oportunidad única que ofrecen los medios digitales de una comunicación dialógica, libre de fronteras geográficas y temporales, es aún un tema para conocer mejor y capacitar para hacer uso de estos beneficios. La interacción vista como una ruptura del aislamiento es, a mi juicio, una práctica a trabajar que permitirá, aunque sea lentamente, abonar un camino de mayor respeto hacia los demás y sus opiniones. También es asignatura pendiente dosificar presencia y virtualidad, para no perturbar diálogos presenciales que exigen compromiso y atención, con mensajes virtuales que tal vez puedan esperar por sus propias condiciones de sincronía y asincronía. 
Cuando Leontiev (1978) y Vigostky (1976) trabajan sobre la teoría de la acción, lo hacen viendo el surgimiento de nuevos e importantes objetos técnicos. Estas propuestas, miradas desde el campo de la comunicación, refieren un entorno en el que los medios que hoy día llamamos tradicionales, iniciaban su despegue. Lejos estaban estos autores de prever lo que sucedería varias décadas después con los productos de la digitalización que se renuevan permanentemente y amplían de manera constante los servicios que brindan a los usuarios, siempre orientados por un modelo inequitativo cuyo fin es la obtención de ganancias.

Lo importante del punto de vista de estos autores, es que no sólo miran el desarrollo técnico, sino que enfatizan las prácticas sociales que acompañan a esos objetos y su significado. Si entendemos por tecnología a un producto científico destinado a resolver un problema o desafío para lo cual emplea instrumentos, métodos y técnicas, encontramos sentido a las afirmaciones de Leontiev y Vigostky. No se trata sólo de desarrollar objetos con un fin predeterminado, sino del ejercicio de procedimientos complejos que involucran sentidos y significados. Esta mirada de un cambio cultural originado en los objetos técnicos, sus prácticas y significaciones, nada tiene que ver con la postura tecnodeterminista que propone y desarrolla proyectos o políticas donde la sola innovación tecnológica es capaz de resolver problemas y rezagos. Las actividades de los sujetos están, hoy más que nunca, permeadas por innumerables productos técnicos y pantallas múltiples encadenadas. No obstante, el cambio cultural que propician no se agota en esos recursos: apenas inicia en ellos como vehículos para desarrollar, crear, modificar contenidos y prácticas sociales.

\section{Ejes para repensar el ciclo de interacciones}

Los hallazgos de la investigación "Jóvenes y cultura digital. Nuevos escenarios de interacción social”, nos llevaron a proponer una figura, el Ciclo de interacción, que reúne elementos centrales de tales interacciones digitales detectados en el trabajo empírico (ver Figura 1). En este Ciclo de interacción se tipifican los intercambios predominantes entre los jóvenes consultados: inicia en quienes sólo visualizan contenidos (Discreto), pasando luego a quienes visualizan un mensaje y lo trasladan (Selectivo), después a quienes modifican aunque sea escuetamente un contenido y lo trasladan (Enlace), finalmente en una escala que valoramos como superior, están quienes crean (Comunicativo). Si bien su representación gráfica nos dice esto, en realidad el ciclo fue concebido como una turbina en la que ingresan elementos activos que dan fuerza, poder y movimiento a 
las interacciones. Así, por impulso del resto de los actores y del entorno, quienes desempeñan un rol pueden pasar a otro, o simplemente optar por papeles diferenciados según tema, ocasión, personajes y hechos en los que interactúan.

\section{Figura 1. Ciclo de interacción}

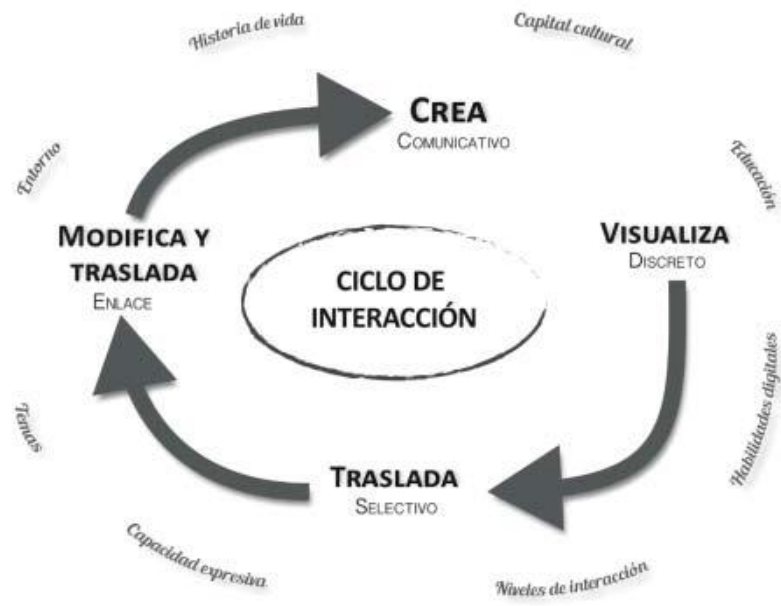

Fuente: Crovi, D. (2016).

Debido a que toda interacción, presencial o virtual, es grupal y por ello se lleva a cabo entre sujetos, implica poner en juego la identidad personal que también es relacional. Por ello, tal como ocurre cuando nos vinculamos con los demás en actividades presenciales ante circunstancias diversas, en las redes digitales los jóvenes interactúan condicionados por las circunstancias y desplegando diferentes matices identitarios.

Encontramos que las interacciones que los jóvenes desarrollan en sus redes sociales pueden tener mayor o menor vigor según el tema tratado y sus intereses personales. Esto no representa ninguna novedad, ya que históricamente los receptores escogen a sus medios según esos mismos parámetros, elementos que les permiten construir su identidad personal y fortalecer su ideología, entendida como visión del mundo.

Gilberto Giménez (2010) considera que las identidades individuales surgen de un proceso subjetivo y auto-reflexivo, mediante el cual los sujetos en un entorno social situado, definen sus diferencias y les auto asignan atributos culturales, los cuales son relativamente estables en el tiempo y revisten valor para ese contexto. Giménez agrega que es indispensable que 
el sujeto añada a esos elementos, su auto identificación. Desde esta perspectiva, la identidad constituye un proceso relacional del sujeto con su entorno social y significativo, en medio del cual adopta una postura personal que lo distingue y autodefine.

A partir del escenario descrito, cabe destacar que los procesos educativos pueden tener la capacidad de promover movilidad entre las interacciones en red, haciendo a algunas más intensas con el fin de que aumenten su impacto social. O dicho de otro modo, no debemos conformarnos con una interactividad que se quede, preferentemente, en el diálogo entre amigos (virtuales y reales); que explore únicamente relaciones sociales o que sólo esté destinada a copiar sin decir nada nuevo. Quien sólo visualiza contenidos en red, mediante acciones educativas adecuadas puede ser potenciado hasta convertirse en un creador de mensajes sobre determinados temas que sean de su interés.

En el círculo exterior de la figura se indican algunos elementos del entorno que inciden en el sujeto que es discreto, selectivo, enlace o comunicativo. Frente a algunas actividades o temas de la vida cotidiana, ellos pueden permanecer sólo expectantes, pero ante otros mediante procesos educativos planificados, se les puede dotar de mayor capacidad expresiva y de interlocución. No se trata, sin embargo, de crear habilidades instrumentales que induzcan a lograr efectos predeterminados, sino de dar herramientas de expresión, capacidad de diálogo, argumentación, así como habilidades digitales.

El desarrollo de habilidades expresivas y argumentativas, debe ser tarea de distintos niveles educativos, desde los iniciales a los profesionales. Entre los profesionales, tanto las carreras de comunicación como la formación en otras disciplinas afines o no, tienen ante sí el reto de fortalecer esas capacidades creativas y dialógicas que permitirán a los usuarios beneficiarse de las potencialidades de las redes digitales.

Aunque los contenidos sigan estando condicionados por las preferencias de los usuarios, dotar de capacidades expresivas es fundamental para impedir que se limite, como ha sucedido hasta ahora, el verdadero desarrollo de una sociedad de la información y el conocimiento basada en el trabajo colaborativo en red y en el gran volumen de información disponible. Sabemos que este tipo de sociedad ha demostrado hasta el momento ser inequitativa y reproductora de las condiciones materiales de exclusión existentes, pero si pensamos en este modelo social con la intervención de sujetos formados para interpretar, jerarquizar y reflexionar en torno a los insumos informativos, podría evitarse que muchos líderes de las redes sean 
sólo reproductores de contenidos comerciales o colonizadores de un nuevo escenario de esparcimiento.

La evolución de las redes digitales y su importancia social están dando lugar a algunos movimientos que buscan certificar que las fuentes informativas sean sólidas, confiables, y con ello detener la difusión de mensajes socialmente perjudiciales. Las propias empresas dueñas de esas redes intentan, de manera incipiente, acciones para separar verdad de ficción o falsedad; fuentes solventes de otras que no lo son; certificar contenidos y quitar otros. Estas acciones pendulares pueden ser un camino hacia la censura, pero también hacia la creación de normas de convivencia en este nuevo espacio social, que sin duda son necesarias para seguir gozando de sus beneficios y acotando sus excesos.

La educación parece ser siempre el camino más largo, pero también en ocasiones aparece como el único capaz de desarrollar condiciones para esa convivencia social. Por ello considero que debe tomar en sus manos el desarrollo de recursos educativos capaces de hacer que los jóvenes sean más activos, abandonen el aislamiento e interactúen en beneficio de causas propias y sociales necesarias. La meta es que se muevan desde la comodidad de la repetición hacia un escenario más pleno de organización, expresión y encuentro.

\section{A manera de cierre: utopías no resueltas}

Eduardo Galeano define a la utopía como un horizonte: en la medida en que nos acercamos, se aleja. El mundo digital, concebido como nuevo espacio social, está plagado de utopías, de horizontes hacia los cuales avanzamos pero que son esquivos y se hacen cada vez más complejos. Cierro estas reflexiones mencionando sólo algunas de esas utopías sobre las cuales es necesario seguir indagando a fin de conjurar su olvido: el equívoco del tecnodeterminismo; las características efectivas de la cultura digital juvenil; la calidad de la participación social digital; y la tarea indispensable de seguir enlazando voces.

Reitero la necesidad de descartar la visión tecnodeterminista, utopía fundamental que considera que la sola provisión de aparatos/acceso, sustituye la complejidad de un proceso en el que el uso y la apropiación de las tecnologías digitales son parte de un plan personal y social para lograr un cambio cultural. Este complejo proceso va más allá del acceso, ya que comprende las preferencias de los sujetos, sus acciones, pero también su marco de significaciones, así como prácticas determinadas por factores diversos que no excluyen sus propias condiciones materiales de vida. Mientras las 
políticas públicas sigan sin considerar los procesos de uso y apropiación de las innovaciones tecnológicas, y partan de la idea falaz que sostiene que es suficiente dotar de muchas tecnologías para lograr un cambio cultural y promover el progreso, estaremos alejándonos de un horizonte de transformaciones sociales y culturales posibles.

Buena parte de los programas públicos con empleo de tecnologías digitales que no alcanzaron sus metas, quedaron truncos o se suspendieron, tuvieron una inconfesable mirada tecnodeterminista. No obstante, para quienes trabajan con estos recursos digitales de manera directa, está claro que esos procesos son multifactoriales y un mismo programa puede arrojar resultados diferentes según su entorno. Estas experiencias revelan que en todo proceso de acceso, uso y apropiación tecnológica, existe un sujeto situado, con un contexto que lo condiciona mas no lo determina (Lèvy, 1999).

La calidad de la participación es otra de las utopías no alcanzadas. Las redes dan la posibilidad de participar, de abandonar el aislamiento para abrirse hacia los demás con la meta de dialogar, expresarse u organizarse. Sin embargo, entre los jóvenes consultados en el estudio sobre cultura digital existen aún muchas dudas acerca de si ellos mismos (que no se reconocen como nativos digitales), son parte de una cultura digital. Es posible que perciban carencias en materia de habilidades digitales, pero también de un capital social y cultural adecuado para argumentar sus mensajes o defenderlos desde una racionalidad fuerte y responsable, sin dudas e incertidumbres. Por eso usan menos Twitter y se entregan más al diálogo entre pares en Facebook: escogen proximidad afectiva frente a responsabilidad argumentativa. No se perciben preparados para dialogar, replicar u objetar en situaciones en las que deben respaldar sus posiciones frente a otras. $¿$ ¿n problema de las redes sociales? En principio no, las redes son sólo el espacio en que se manifiestan estas carencias: todo apunta a los rezagos educativos que atraviesan muchas capas de la sociedad, entre ellas la calidad de la participación, de la organización y expresión en redes digitales.

Mientras las políticas públicas sobre juventudes estén equivocando su punto de partida, según el cual los jóvenes no sólo son conectivos sino activos permanentes en la producción de contenidos en red, capaces de intrigar desde esos ámbitos ante el orden establecido, se están alejando de su propio horizonte utópico. Esos jóvenes, en realidad, participan más repitiendo que creando y lo hacen sin sentirse seguros de formar parte de una cultura digital. En esta generación, como en todas las precedentes, la juventud sólo lucha contra sus raíces parentales y el orden social establecido, sin el fin de abolir lo existente, sino con el propósito de posicionarse como una nueva generación que alienta cambios y busca crear un entorno favorable 
a sus prácticas. Es mediante estos procesos que los jóvenes construyen su identidad personal y buscan pequeñas transformaciones sociales. No son las grandes revoluciones, son apenas cambios coyunturales que los hacen sentir más cómodos con su tiempo, usando su propio marco de significaciones.

Pero también hay que alertar sobre una suerte de placebo de participación: aquella que anida sólo en las redes, dejando fuera 'el afuera', el espacio social real. Dar like o repetir implica compromiso limitado con la actividad o tema en el ámbito físico, también les lleva a quedarse entre gente que piensa igual, sin dar un paso al frente para lograr un cambio o al menos expresar una idea. Si bien muchos likes y retuits pueden crear tendencias y posicionar temas en la agenda pública, son interacciones que aluden a un compromiso social exiguo y una actitud vaga en el proceso de abrir el encierro. Por ello no están a la altura de ser considerados un emisor emergente, ellos mismos piensan que no dan la talla para ese ejercicio, lo cual conduce a una especie de renuncia, de claudicación en la defensa de ideas personales y de las posibilidades propias de las redes.

Finalmente, ¿enlazar voces es una tarea menor? La mayoría de los jóvenes que participaron en nuestro estudio son reproductores de contenido ajeno, se adscriben al modelo difusionista, pero cabe preguntarnos por qué sucede esto. ¿Será acaso que las redes con su liviandad y brechas que crean exclusiones tienen como misión fundamental repetir y con ello crear corrientes de información que se acercan como olas a las agendas públicas pero rápidamente se retraen ante nuevas olas y nuevos sucesos?

Este mecanismo hilvana con la idea ya expuesta sobre un presente continuo, sin antecedente ni consecuente, que lleva a saturarnos de hechos, algunos de los cuales se quedan en las agendas públicas y su discusión, en tanto que otros, como las olas, se repliegan volviendo a un inconmensurable mar de informaciones. Mientras los medios de comunicación tradicionales, por condiciones de producción y costo, tienden cada vez más a hacer pasar ese mar de informaciones por el embudo de la reiteración y la redundancia, en las redes puede ocurrir lo contrario: fragmentación y caos que no permiten eslabonar sucesos, argumentos y actores.

Los jóvenes participan, pero lo hacen en un círculo acotado de amigos like o reales, y reducen sus temas a preferencias también acotadas a sus gustos personales y de los interlocutores. Esta circunstancia permite pensar que tal vez estemos lejos aún de contar con un número mayor de jóvenes creadores de contenidos que amplíen las agendas y les den continuidad. Algunos se han convertido en ciberactivistas o en líderes de las redes que comercializan sus potencialidades, pero aún es reducido el grupo. 
La vida sin duda está hecha de temas banales que se interceptan con grandes metas y relatos. Hasta el momento las redes sociales digitales parecen albergar a todos. Como nuevo espacio social tienen las condiciones para replicar en el ámbito digital, abrirse a voces nuevas, presentar discursos repetitivos y otros originales, están también los mensajes que deberían callarse o los que habría que mostrar mejor, todos abordando pequeños y grandes temas que según cada historia personal pueden ser sustantivos o no.

Tal vez la utopía mayor, la más abarcadora, es pedirle a las redes sociales digitales y los sujetos que interactúan en ellas, condiciones que no hemos podido alcanzar durante muchos siglos en el espacio físico. En realidad esta es una utopía del hombre buscando un mejor entorno, una sociedad más equitativa, condiciones de vida más humanas y por ello es un horizonte que, con redes digitales o sin ellas, siempre se nos escapa.

\section{Bibliografía}

Conferencia Intergubernamental sobre políticas de comunicación en América Latina y el Caribe, San José, Costa Rica (1976). Declaración de San José. Nueva Sociedad No. 25, julio-agosto 1976, pp. 116-139. Recuperado de http://nuso.org/media/articles /downloads/251_1.pdf

Cloutier, Jean (1975). L’Ere d’Emerec. Montreal: Presse de 1’Université de Montréal.

Echeverría, J. (2000). Un mundo virtual. Barcelona: De Bolsillo.

Giménez, G. (2010). Cultura, identidad y procesos de individualización. México: IIS-UNAM. Disponible en: http://conceptos.sociales.unam. $\mathrm{mx} /$ conceptos_final/ 625trabajo.pdf

Informe MacBride (1980). Un Solo Mundo. Voces Múltiples. Comunicación e Información en nuestro tiempo. Organización de las Naciones Unidas para la Educación, la Ciencia y la Cultura, UNESCO, México, Fondo de Cultura Económica.

Leontiev, A. (1978). Actividad, conciencia y personalidad. Buenos Aires, Argentina: Ediciones Ciencias del Hombre.

LÈvy, P. (1999). Cibercultura. La cultura de la sociedad digital. Barcelona: Anthropos.

Nora, S. y A. Minc (1980). La informatización de la sociedad. México. Fondo de Cultura Económica.

Vigost ky, L. (1976). El desarrollo de los procesos psicológicos superiores. Barcelona, España: Editorial Crítica S.L. 



\title{
Elementos para comprender la interacción juvenil en las redes sociales digitales
}

\author{
María Consuelo Lemus Pool ${ }^{1}$ \\ Miriam González Montalvo ${ }^{2}$
}

En este capítulo nos proponemos recuperar enfoques teóricos que analizan a la interacción como una actividad sociocultural, con la finalidad de comprender los diversos elementos que están involucrados en este proceso al usar redes sociales digitales. Tomamos como elemento central de esta reflexión al sujeto y las etapas de vida que son parte de su desarrollo.

Estas reflexiones parten de los resultados de la investigación "Jóvenes y cultura digital. Nuevos escenarios de interacción social” (Crovi, 2016) los cuales evidenciaron que existen diferentes niveles de interacción en las redes sociales digitales de acuerdo con ciertos rasgos de los diversos grupos juveniles. Ello puede deberse, entre otras cosas, a la adquisición de mayor capital cultural, experiencias de vida en general, temáticas con las que se identifican y en las que se van centrando sus intereses y por lo tanto van consolidando su identidad. Lo anterior coincide con el progreso de los jóvenes en su formación académica (la transición de la educación media superior a la superior), ya que estos ámbitos de socialización tienen una estrecha interconexión con el uso de las tecnologías digitales.

Para desarrollar este planteamiento el documento se divide en tres apartados generales. El primero desarrolla la interacción desde la perspectiva sociocultural, con el propósito de comprender cómo se relaciona con rasgos tales como la edad, el capital económico, social y cultural, las habilidades digitales e incluso las experiencias de vida. En el segundo se vincula la interacción en redes digitales con el concepto de juventudes, a fin de analizar cómo se interrelacionan en el contexto de esta generación que nació inmersa en las tecnologías digitales. Por último, profundizaremos en algunos resultados empíricos que describen la interacción que desarrollan jóvenes estudiantes de la Ciudad de México, retomando para ello los hallazgos de la fase cuantitativa del proyecto de Ciencia Básica

1 Comunicóloga. Doctora en Ciencias Políticas y Sociales por la Universidad Nacional Autónoma de México. consuelo.lemuspool@gmail.com

2 Comunicóloga. Estudiante de Licenciatura en Ciencias de la Comunicación de la Universidad Nacional Autónoma de México.miriam.montalvo@politicas.unam.mx. Ambas autoras participamos en el proyecto SEP-CONACYT "Jóvenes y cultura digital. Nuevos escenarios de interacción social", del cual se desprenden estas reflexiones. 
SEP-CONACYT "Jóvenes y cultura digital. Nuevos escenarios de interacción social", en la que se aplicaron 1,548 cuestionarios a estudiantes de educación media superior y superior, de escuelas públicas y privadas de la capital del país (Crovi, 2016). Con última aproximación a las opiniones y autopercepciones de las actividades que realizan en redes sociales digitales, es posible conocer más acerca de las prácticas de navegación en el ciberespacio que desarrollan los jóvenes que participaron en el estudio.

\section{La interacción desde la perspectiva sociocultural}

La referencia más sistematizada y consistente respecto a la interacción social se remonta al campo de la psicología, en la década de 1930. De acuerdo con Delia Crovi (2009) fueron Alexei Leontiev y Lev Vygotski quienes establecieron que el desarrollo intelectual no se configura únicamente al interior de la mente del sujeto, sino que requiere de la interacción con los otros y con el entorno sociocultural para desarrollar la actividad cognitiva. Fue a partir del estudio de las funciones psíquicas inferiores y superiores, que se desprendió el análisis de los planos de interacción (intra-psicológico e inter-psicológico) mediados por herramientas y enmarcados por un conocimiento históricamente situado (Vygotski, 1976). La interacción fue considerada como un proceso de articulación entre el individuo y la sociedad, del cual se generaba la dupla más importante de esta relación: la acción y el actuar (Leontiev, 1978).

Vygotski (1976) destaca que el lenguaje es el principal instrumento que organiza la interacción social, y es a partir de éste que se construye la transmisión dinámica del conocimiento cultural, social e histórico. Por lo tanto, la interacción tiene como uno de sus elementos sustanciales el intercambio de sentido simbólico, ya que genera un proceso integrador, creador de pautas de comportamiento, con la capacidad de construir relaciones de pertenencia, filiación e identidad. En este punto, conviene precisar que la comunicación es la que hace posible la mutua comprensión y el entendimiento. Por ello resulta más significativo el entramado generado por el encuentro, el contacto, la organización y la acción, que la trasmisión de información (Santoyo, 1985). Sin embargo, en tanto es un mecanismo generador de realidades sociales intersubjetivas, también es un concepto complejo al momento de aterrizarlo en un análisis formal de sus procesos debido a que tiene múltiples dimensiones y planos de desarrollo. Eso provoca que no se tenga una estructura con límites claros entre el campo psicológico individual y social, ni que se haya esclarecido su influencia. 
Lo que es social no se convierte directamente en individual, sino que pasa por una herramienta psicológica, una mediación, y este mediador es el signo, que es un medio de actividad interna que se orienta al dominio de uno mismo, es decir, que está orientado internamente (Vygotski, 1976, p. 123).

Esta actividad mediadora, sostenida en el empleo de signos y herramientas, se relaciona estrechamente con lo que Rafael Santoyo (1985) denominó determinación recíproca o inter-juego: "el grupo es el lugar donde el individuo transforma en cierta medida su individualidad, al darse cuenta de que su yo se resuelve, se complica y se transforma en el nosotros" (p. 58). Desde esta perspectiva, es posible analizar la interacción a partir del carácter social del aprendizaje, el cual involucra aspectos como la coordinación, organización, cooperación y establecimiento de relaciones de influencia recíproca entre los sujetos involucrados.

Santoyo (1985) también propone otra vía para aclarar el concepto de interacción y aterrizar su análisis: una definición inversa o antítesis. Para este autor lo opuesto a la interacción es la serialidad. Una serie correspondería a conjuntos de personas que comparten un tiempo, un espacio e incluso una actividad similar, pero que no generan una reciprocidad en sus acciones, por ejemplo, personas que viajan juntas en un autobús, que están en una sala de conciertos o que se encuentran en un salón de clase. De acuerdo con este autor:

Lo que hace cada sujeto incluido en la serie no tiene direccionalidad hacia los otros integrantes de la situación. Los otros, aun cuando son percibidos no aparecen como significativos. Esta falta de significatividad resultaría del hecho de que el otro no aparece comprometido en relación a las necesidades o expectativas de cada sujeto. La finalidad buscada puede ser la misma, pero no aparece compartida. El logro del objetivo no remite los unos a los otros, no los relaciona activamente (Santoyo, 1985, p. 62)

Como puede observarse, la interacción se genera cuando la presencia y las respuestas del otro son tomadas en cuenta, incluidas o anticipadas en la actitud del sujeto. Esto es lo que genera el inter-juego de determinación recíproca y de orientación mutua, desencadenando la acción, ya que la finalidad compartida los relaciona activamente.

Para estudiar la interacción, por lo tanto, no es posible únicamente centrarse en la acción fragmentada de alguno de los actores intervinientes, en la incidencia del feedback o respuesta dentro del sistema, así como tampoco en la cantidad de símbolos intercambiados. Todos estos plantea- 
mientos, aunque han resultado significativos, minimizan de manera considerable el proceso de interacción al no tener una perspectiva de conjunto.

En este contexto surgen algunos cuestionamientos: ¿cuáles son los componentes que inciden en las diversas formas que toma la comunicación para llegar a ser un proceso de determinación recíproca y de orientación mutua?, ¿ ¿a qué se debe que en algunos contextos la interacción se quede en sus expresiones mínimas (como el contacto) y en otros sea el detonante de la acción colectiva?

Para responderlos proponemos el estudio de la interacción desde una perspectiva que engloba al sujeto y su interrelación con los elementos de su entorno, las etapas de vida que son parte de su desarrollo, así como de los capitales que dispone para dar sentido a estas prácticas de interacción en los entornos digitales.

\section{Entorno de las prácticas sociales}

Al hablar de la interacción, es imposible explicar de manera única la diversidad de prácticas que se dan en torno a esa actividad. Mucho menos tener una sola justificación de lo que acontece con ella en los entornos digitales. Por lo anterior, es necesario encontrar cuáles son algunos de los factores que se asocian a esta práctica. Las propuestas de Pierre Bourdieu (1988) para comprender cómo acontecen estas experiencias en un campo social $^{3}$ determinado, resultan adecuadas para el planteamiento que estamos desarrollando.

De acuerdo con Bourdieu (1988) las prácticas pueden comprenderse en relación con los diversos capitales que se interrelacionan en un campo, lo cual hace que varíen según el contexto y que cada capital tenga un peso diferente en cada escenario donde se está interactuando.

Para comprender el hecho de que el mismo sistema de propiedades (que determina la posición ocupada en el campo de las luchas de clase y que es determinado por ella) tenga siempre la mayor eficacia explicativa, sea cual sea el campo considerado, y que el peso relativo de los factores varíe de un campo a otro según los casos, basta con darse cuenta que, al ser el capital una relación social, es decir, una energía social que ni existe ni produce sus efectos si no es en el campo en la que se produce y se reproduce, cada una de las propiedades agregadas

3 El campo social para Bourdieu es: "una construcción analítica mediante la que se designa un conjunto específico y sistemáticos de relaciones sociales; es decir, se trata de una especie de sistema, definible sólo históricamente, que permite trasladar al análisis social la dinámica de relaciones que se desarrollan en la práctica" (Bourdieu, 2001, p. 15). 
a la clase recibe su valor y su eficacia de las leyes específicas de cada campo: en la práctica, esto es, en un campo particular, todas las propiedades incorporadas (disposiciones) u objetivadas (bienes económicos o culturales) vinculadas a los agentes, tienen valor, son pertinentes y eficaces en cada campo, ya que en relación con ese campo, funcionan como capital específico y, en consecuencia, como factor explicativo de las prácticas (Bourdieu, 1988, p. 112).

Desde la perspectiva de este autor, el concepto capital puede entenderse como "un trabajo acumulado, bien en forma de materia, en forma interiorizada o incorporada" (Bourdieu, 2001, p. 131) y se puede derivar del lugar del cual se obtenga así como de alguna transformación. El capital se presenta en al menos tres maneras: económico, social y cultural. Con el fin de comprender su relación con el proceso de interacción en redes sociales digitales, definiremos cada uno brevemente.

El capital económico se conforma de los recursos monetarios y bienes materiales que los individuos pueden institucionalizar en derechos de propiedad. Puede convertirse en otros capitales, como el social y cultural, sin embargo, no es un proceso lineal.

El capital social es un elemento que le permite al individuo afrontar las necesidades cotidianas y de reproducción social. Pierre Bourdieu (2001) lo define de la siguiente manera:

El capital social está constituido por la totalidad de recursos potenciales o actuales asociados a la posesión de una red duradera de relaciones más o menos institucionalizadas de conocimiento y reconocimiento mutuos. Expresado en otra forma, se trata aquí de la totalidad de recursos basados en la pertenencia a un grupo. El capital total que poseen los miembros individuales del grupo les sirve a todos, conjuntamente, como respaldo, amén de hacerlos -en el sentido más amplio del término- merecedores de crédito. (Bourdieu, 2001, p. 148-149. Cursivas del autor).

Como se observa, el desarrollo del capital social se representa a través de una red de relaciones. Identifica la pertenencia a un grupo social que puede derivar en ciertos beneficios, los cuales según el mismo autor, podrían ser materiales y simbólicos. Además, fomenta el aumento de compromiso en un grupo para realizar una acción colectiva.

El cultural es el tercer tipo de capital, respecto al cual Bourdieu (2001) precisa que puede existir en tres estados: el incorporado, el objetivado y el institucionalizado. Los distingue de la siguiente manera:

(...) en el estado interiorizado o incorporado, esto es en forma de disposiciones duraderas del organismo; en el estado objetivado, en forma 
de bienes culturales, cuadros, libros, diccionarios, instrumentos, maquinaria, que son resultado de disputas intelectuales, de teoría y de sus críticas; y finalmente, en el estado institucionalizado, una forma de objetivación que debe considerarse aparte porque confieren propiedades enteramente originales al capital que debe garantizar (Bourdieu, 2001, 136).

Los capitales entran en juego y se explican en relación con el habitus: "sistema de disposiciones duraderas y transferibles (que funcionan) como principios generadores y organizadores de prácticas y representaciones" (Bourdieu, 1991, p. 92). Esto significa que las prácticas se adaptan a un fin para funcionar como "estructuras estructurantes", sin ser producto de obediencia a determinadas reglas. En palabras del propio autor, el habitus actúa como marco que puede explicar las prácticas:

Es el habitus, en cuanto conjunto de esquemas o principios clasificatorios, disposiciones incorporadas, etc., y el interés (la ilusión) que surge de la relación entre ese sistema de disposiciones y las posibilidades y censuras del entorno. La acción obedece a un sentido práctico, a una lógica práctica, que es la de "espontaneidad generadora" del babitus. Y recurre a la regla, al ritual codificado, en las situaciones de incertidumbre y de violencia en las que precisamente dada esa espontaneidad, el interés se decanta hacia la formalización de las prácticas (Bourdieu, 2001, p. 43).

La teoría de la práctica cultural de Pierre Bourdieu es todo un tema en sí mismo, pero en el marco del análisis que nos interesa, los capitales sirven para comprender y explicar los elementos que inciden en las interacciones de los jóvenes en las redes sociales digitales. Ello debido a que son elementos que van determinando el tipo, nivel e intensidad de interacción generada en ciertos contextos, según el campo que se configura a través de tales interacciones. Por ejemplo, el capital económico ayuda a explicar la dimensión del acceso a tecnologías digitales propias, disponibilidad de conexiones de calidad, así como recursos técnicos para estar compartiendo mensajes. Por otra parte, el capital social influye en el conjunto de relaciones que dotan de sentido y profundidad a la interacción, las cuales pueden estar formadas por amigos, familia, compañeros, profesores, por alguna experiencia laboral o por ser miembros de alguna organización (formal o informal) que puede incluso presentarse de manera física o virtual. De la misma forma, el capital cultural permite comprender cómo se logra el conocimiento o dominio de las herramientas tecnológicas, el cual conduce a la apropiación de estos recursos y su aplicación en experiencias originales e innovadoras. 
Todo lo anterior se contextualiza en el habitus circunscrito a un campo. Esto permite entender por qué no resulta lo mismo interactuar en las redes digitales en función de un trabajo escolar, de una conversación con amigos o con la familia, o en defensa de un tema social. Cada campo va prefigurando las prácticas que se relacionan con el tipo de interacción que se espera en las plataformas virtuales y las diferencias para acceder a estas también están enmarcadas por los capitales que posea o no el individuo, de acuerdo con la particularidad de cada historia de vida.

Desde nuestra perspectiva, los autores que empleamos en este marco de referencia realizan una clara aportación conceptual para comprender la dimensión sociocultural de la interacción y las múltiples prácticas culturales que convergen en el ciberespacio. Aunque sus trabajos son previos a las tecnologías digitales, desde la solidez de sus contribuciones teóricas es posible identificar los procesos de interacción de los jóvenes en las redes sociales digitales.

\section{Juventud e interacción}

La juventud es, en primer lugar, un segmento "que alberga grupos con características singulares, derivadas de aspectos socioculturales y psicológicos, así como económicos y contextuales, que los determinan" (Crovi, 2016, p. 28). Esto significa que la juventud es un concepto que se desarrolla bajo una construcción social, histórica y cultural que ha adquirido definiciones y delimitaciones distintas respecto a la época y la posición geográfica.

La interacción social en la etapa de la juventud es significativa para la consolidación de un rasgo que posibilita todo el desarrollo posterior del individuo: la identidad, que está condicionada por el entorno sociocultural de los individuos a partir de múltiples elementos. Desde nuestra perspectiva, los jóvenes desarrollan una interacción particular en las redes sociales digitales debido a su entorno, oportunidades de acceso al capital económico, social y cultural, así como la acumulación de experiencias de vida, que se dan en forma diferenciada al interior de cada grupo. Asimismo, al ser la juventud una construcción social, cada individuo vive esta etapa y sus fases de transición de diferente manera.

El desarrollo biológico reflejado en la edad, tiene una incidencia en lo que respecta a cambios del cuerpo, salud, energía y capacidad reproductiva de los sujetos, pero el planteamiento de este análisis la edad incide, no desde la biología sino desde la construcción histórico-social, es decir, en términos de los rasgos que comparten los jóvenes que integran una 
generación, la cual "hace referencia a la socialización de los individuos que nacieron en una época determinada, quienes internalizan los códigos y patrones culturales de su tiempo" (Margulis, 2001, p. 46).

La edad también es una referencia que se asocia de manera indirecta al nivel de escolaridad, ocupación preponderante para muchos jóvenes. El contexto educativo es un importante ámbito de socialización y provee de características particulares a la interacción de acuerdo con el tipo de escuela, el grupo de amigos, los intereses académicos, entre otros aspectos.

En el estudio general que enmarca estas reflexiones (Crovi, 2016), los rangos de edad considerados se asociaron al concepto de juventud alargada, con el fin de aplicar no sólo el cuestionario al que estamos haciendo referencia, sino otros instrumentos como fueron: grupos focales, grupos de discusión y entrevistas en profundidad ${ }^{4}$. En el caso de los cuestionarios, debido a que se aplicaron entre estudiantes de educación media superior y superior, fueron excepcionales los jóvenes mayores a los 25 años.

Las características de la muestra favorecieron la comparación entre los dos niveles de educación consultados y su contraste en dos tipos de instituciones educativas: públicas y privadas. Como elementos de contexto, estos ámbitos de referencia escolar son relevantes en tanto representan diferentes oportunidades para aprender, adquirir experiencias, relacionarse con el entorno, suscribir modelos de valores, conductas y procesos de pertenencia, así como participar en una comunidad de referencia. Cada etapa escolar tiene la potencialidad de ir moldeando las formas de pensar, conocer y comunicarse en sus relaciones cara a cara y en las que se propician en las redes sociales digitales.

A partir de lo anterior, esbozamos las características esenciales de los jóvenes según la etapa de vida que implica el ámbito escolar de los niveles medio superior y superior. En este contexto, tomaremos la edad sólo como un referente temporal relacionado con la construcción histórico-social de la cual son parte los jóvenes de una generación.

En primer lugar ubicamos la etapa de la educación media superior. Este nivel de escolaridad suele estar entre los 15 y los 18 años. Lo anterior tiene incidencia en la conformación de la identidad individual, colectiva y social, lo cual le posibilitará al joven la comprensión de sí mismo, la adquisición de habilidades sociales y la aceptación o negación de las normas de su entorno social (Dávila, 2004). En este ámbito relacional, la

4 Una referencia más detallada sobre esta categoría puede encontrarse en Crovi, D. (2016). Redes sociales digitales. Lugar de encuentro, expresión e interacción para los jóvenes. México: UNAM / La Biblioteca. 
necesidad de independencia resulta en confrontaciones frente a los padres, propiciando un vacío emocional, y para compensarlo le destinan suma importancia a la amistad y a las opiniones que de ella emergen.

De acuerdo con los planteamientos de Vygotski (1976), puede decirse que es a través de estas situaciones de tensión entre la aceptación y rechazo al interior de los grupos de amigos, la familia y quienes integran su comunidad de referencia, que se consolida el desarrollo de la personalidad, ya que se adquieren las habilidades de actuar y asumir la responsabilidad de sus hechos, al generar conductas deliberadas, mediadas e interiorizadas. Esta situación también tiene significativa incidencia en cuanto al uso que le dan a las redes sociales digitales, las cuales suelen funcionar más para comunicarse y socializar que para producir contenidos o analizar información (Crovi, 2016).

Por otra parte, el rol central de los jóvenes en esta etapa, es ser estudiantes. Constituye una etapa de preparación para la vida laboral, pero aún con un bajo compromiso y una percepción lejana del futuro (Crovi, 2009).

En términos de construcción de la identidad, esta etapa temprana de la juventud, cuando apenas se ha superado la adolescencia, está caracterizada por un aprendizaje observacional en el cual el comportamiento de los pares, grupos externos y modelos de liderazgo, tienen relevancia en términos de proyección de una imagen, desarrollar confianza en sí mismo y en los demás. También es experimental porque a los jóvenes les gusta explorar (prácticas, comportamientos, sentimientos, pensamientos), aventurarse, correr riesgos y en las equivocaciones dan paso a la reflexión, aprenden de sus experiencias, se conocen a sí mismos, proceso que los orilla a crecer y madurar, según una noción adultocéntrica.

Las escuelas de nivel medio superior cumplen una función de preparación para las exigencias de disciplinas universitarias y profesionales cuando el joven sigue su formación. El trato a los estudiantes de este nivel, en términos de control y vigilancia, son diferentes en los bachilleratos de acuerdo a la institución a la que pertenezcan (pública o privada), y a su vez existen diferencias, debido a que algunos proporcionan a los jóvenes mayor o menor autonomía. No obstante, es un espacio para experimentar, pero también para comenzar a adquirir responsabilidades (Weiss, 2012).

Ahora bien, al pasar al nivel superior (el ingreso suele darse desde los 18 años en adelante y el egreso a partir de los 21), se genera otra dinámica que implica una etapa diferente en múltiples aspectos. En lo que respecta al desarrollo cognitivo, la capacidad de razonamiento analítico y reflexivo aumenta notablemente, por lo tanto, empiezan a evaluar riesgos y a tomar 
decisiones conscientes entendiendo las consecuencias de sus actos. Paulatinamente, van consolidando sus valores morales, religiosos y sexuales así como comportamientos próximos a los del adulto. Esta situación se ve reflejada en expectativas más realistas, racionales y con un más alto sentido de compromiso hacia algún tema.

Otro aspecto de cambio que es notable en esta transición, corresponde a la función que ejercen las dinámicas relacionales. Las opiniones e influencia de los amigos tienden a disminuir gracias a que consolidan sus gustos, adquieren mayor confianza, el proceso de construcción de su identidad se va fortaleciendo y defienden puntos de vista propios. Algunos especialistas refieren que a partir de los 19 años existe un regreso de los jóvenes hacia su familia, lo cual incrementa sus relaciones de pertenencia e identidad, sin embargo, este proceso "no se manifiesta de la misma manera o de forma homogénea, al contrario, la diversidad es su principal característica” (Dávila, 2004, p.94).

$\mathrm{E}$ l ámbito universitario refuerza un sentido de autonomía para la toma de decisiones, ya que se trata de un periodo decisivo para el futuro de la vida de cada individuo. Por ejemplo, en esta etapa se decide si continúa con su formación académica; elige un campo o área de especialización; alcanza la mayoría de edad que le permite participar en la toma de decisiones como ciudadano; se integra al ámbito laboral o forma una familia, elecciones que dependen del proyecto de vida y de las circunstancias contextuales a las que se enfrente.

La universidad favorece un ambiente de aprendizaje que puede formar una capacidad crítica al confrontar múltiples puntos de vista. Este entorno también propicia un tiempo proclive a la exploración en libertad, el aprendizaje y disfrute, pero también la preparación sistemática y racional. La dimensión analítica, orientada al futuro profesional entre los jóvenes, se presenta como una condición que les genera diversas exigencias desde su contexto, por ejemplo, la competitividad desplegada por las políticas neoliberales establecidas en la mayoría de los países de América Latina, con diferentes aproximaciones según la clase social y el entorno del joven (Suárez y Pérez, 2008).

Como puede verse, en cada etapa la interacción social puede tomar una función diferente, según el contexto de cada joven. Desde las primeras fases de formación de la identidad individual y colectiva este proceso integrador es el que propicia las pautas para el rol que el sujeto habrá de representar en un sistema social más amplio, a través de la exploración de prácticas, comportamientos, esquemas de pensamiento, la formación 
de vínculos de pertenencia, filiación y confianza que permiten la toma de decisiones, Estas dinámicas van configurando una condición compartida que constituye el primer elemento para comprender la interacción: ¿qué significa esta práctica para el sujeto en relación con la etapa vital que está afrontando y las condiciones de su entorno?

\section{Evolución de la interacción de los jóvenes en las redes sociales digitales}

En este último apartado, como ya se dijo, reflexionamos en torno a los resultados empíricos de la fase cuantitativa del proyecto "Jóvenes y cultura digital. Nuevos escenarios de interacción social” (Crovi, 2016). El objetivo es profundizar en los hallazgos relativos a la interacción e interpretar desde la perspectiva sociocultural los cruces por edad, nivel educativo y género que se desprendieron de este trabajo.

Retomamos la información de dos preguntas del cuestionario ${ }^{5}$ para desarrollar los cruces de datos y su interpretación correspondiente: el comportamiento al navegar en las redes sociales digitales y el nivel de interacción. Esto debido a que consideramos que son nodales para pensar la interacción en redes sociales digitales.

Para ello, en los dos siguientes apartados abordamos los resultados de las dos preguntas examinadas. En términos generales, el planteamiento que se está desarrollando pretende identificar los detonantes del proceso de interacción en las redes sociales digitales desde una perspectiva integral. De este modo buscamos incluir tanto los elementos que inciden en la etapa vital que transita el joven, como aquellos que determinan las prácticas según los capitales que disponen y recursos con los que llevan a cabo esta interacción.

\subsection{Comportamiento al navegar en las redes sociales digitales}

La primera pregunta analizada fue: "Pensando en tu comportamiento" cuando navegas por Internet y estás en las redes sociales ¿con cuál descripción te identificas más?”, las opciones de respuesta reflejaron una serie de auto-percepciones entre las que podían identificarse los participantes. Estos perfiles fueron:

5 En el Anexo 1 se encuentra el cuestionario aplicado.

6 En esta pregunta el comportamiento puede ser entendido como la conducta o manera de actuar. 
1. Discreto, que hace referencia a alguien que forma parte de la red pero no tiene interacción con otros.

2. Selectivo, un usuario que interactúa con pocas personas, no le gusta comunicarse o no tiene muchas razones para hacerlo.

3. Enlace, quien tiene interacción con algunas personas, le agrada comunicarse pero lo hace sólo cuando hay razones importantes para ello.

4. Comunicativo, caracterizado por tener interacción con muchas y diversas personas, le agrada comunicarse y está en contacto con todos frecuentemente y que lo motiva a crear contenidos y a compartirlos (Crovi, 2016).

Desde la perspectiva sociocultural de la interacción, identificarse con un perfil para estar en contacto y comunicarse con otras personas en las redes sociales digitales, pone de manifiesto una conducta que no sólo se circunscribe a cómo y con qué frecuencia usan la plataforma virtual estos jóvenes, también refleja la importancia del contacto social según la etapa que están transitando, su personalidad, así como las habilidades de comunicación y socialización con las que cuentan.

En los resultados generales de esta pregunta, la tendencia destacada del comportamiento al navegar en las redes sociales digitales fue la de Enlace (49\%). Esto significa que los usuarios adoptan la función de vínculo de información, reproducen y replican los mensajes o contenidos de otros, pero se comunican en los entornos digitales sólo cuando existen razones importantes para entrar en relación (Figura 1). Aunque este perfil resultó ser el más significativo entre todos los grupos, existen variaciones en los cruces de información que dan luz a algunas diferenciaciones en la navegación en las redes digitales.

Figura 1. Comportamiento al navegar en las redes sociales digitales

\begin{tabular}{|c|c|c|}
\hline $1.6 \%$ & $13.1 \%$ & \\
\hline $\begin{array}{c}\text { Discreto } \\
\text { (visualiza) }\end{array}$ & $\begin{array}{c}\text { Selectivo } \\
\text { (traslada) }\end{array}$ & (modificay traslada) \\
\hline
\end{tabular}

* $3.1 \%$ respondió que no se identifica con ninguno de los perfiles Fuente: elaboración propia. 
Según el nivel educativo, los resultados muestran que en el nivel medio superior, los perfiles más relevantes para estos jóvenes son los de Discreto y Selectivo, es decir, usuarios que interactúan con pocas personas que ellos mismos eligen o que adoptan una actitud de observador al navegar. Al pasar al nivel superior el perfil de navegación con el que más se identifican es el Comunicativo. Esto significa que esos usuarios establecen lazos diversos, les agrada comunicarse y están constantemente en contacto con muchas personas mientras navegan.

Estos mismos datos se corroboran analizando los rangos de edad. Conforme crecen van pasando de una navegación del tipo Enlace y Selectiva a una Comunicativa. Para los jóvenes de entre 16 y 17 años (educación media superior) el perfil más relevante fue el Discreto, edad en la que se ubican aún en escuelas de nivel medio superior. Entre los 18 y 19 años el perfil Selectivo fue más recurrente. Para los de entre 20 y 22 años destacó mayormente el Enlace. $Y$ de los 23 años en adelante, fue entre quienes se disparó el número de aquellos que se identificaron con el perfil Comunicativo.

En términos de la interacción social que se genera en cada una de las etapas anteriores, es posible observar que la transición hacia el ámbito universitario, en el que existe un cambio en el círculo de amigos y en el tipo de dinámicas de colaboración con fines escolares, así como el incremento de las habilidades sociales, con el fin de consolidar pertenencia e identidad, se va adoptando un perfil más abierto, reflexivo y expuesto en el ámbito digital. Es probable que los jóvenes de nivel medio superior requieran cuidar más su imagen virtual y real, por lo que también navegan de manera discreta y selectiva, comparten información y se comunican, pero de una manera más focalizada y sólo con propósitos específicos.

Entre las escuelas públicas y privadas también existen diferencias significativas. Por lo general las escuelas privadas cuentan con un número más pequeño de alumnos y los que tienen una posición socioeconómica más alta que aquellos que cursan sus estudios en instituciones públicas. Planteamos que de acuerdo con el tipo de escuela también se propicia una socialización diferente, según el perfil del joven en las redes sociales digitales, lo cual puede estar relacionado con los capitales (económico, social y cultural) que entran en juego en cada contexto. Es decir, un tipo de comportamiento que se relaciona con una construcción de identidad asociada a un habitus específico, sin dejar de lado el acceso temprano a las tecnologías digitales cuyas prácticas se interceptan con el estatus y el manejo lúdico de estas tecnologías. 
En cuanto a las diferencias por género, se identificó una mayor inclinación por parte de las mujeres a sentirse identificadas con el perfil Enlace y Comunicativo. Entre los hombres, existe una mayor tendencia a navegar como Selectivos e incluso a no identificarse con ninguno de los perfiles propuestos. Estos resultados se pueden relacionar con los roles culturales que históricamente les han sido asignados a hombres y mujeres, ya que a estas últimas se les ha atribuido una socialización más continua y abierta, el mundo de los afectos, así como el tener una relación más profunda con los otros. Estas diferencias refuerzan la idea de que la interacción es una construcción social y culturalmente situada.

En términos generales, puede verse que a mayor edad existe la percepción de que navegar en redes es más dinámico, ya que cuentan con mayores repertorios para interactuar y contactos frecuentes, que pueden matizarse con tres elementos clave: ocupación, especialización profesional y contexto socioeconómico. Primero, las ocupaciones de estos jóvenes, debido a que tienen más tiempo disponible para estar presentes en las redes digitales, que se reduce conforme avanzan en su formación académica. Segundo, está el tránsito del nivel medio superior al superior, el cual les permite la especialización dentro de un área académica, además de las experiencias de vida: nuevas redes de contactos, ideas más claras, temas de interés más concretas, grupos diversos para afiliarse, entre otras. Tercero, también inciden los roles de género, su propia identidad de clase o su contexto.

\subsection{Nivel de interacción en las redes sociales digitales}

La segunda pregunta que retomamos valoró el nivel de interacción que los usuarios desarrollan en las redes sociales digitales. Para ello se propusieron nueve actividades: tres del nivel bajo, tres del medio y otra cantidad similar del alto, en las que se midió la frecuencia, habilidades digitales y temáticas a las que se asocian tales acciones (Anexo 1. Cuestionario). En la investigación general (Crovi, 2016), se propuso una tipología de interacción en las redes sociales digitales representada por un ciclo en el que inciden el capital cultural, el nivel de educación, las habilidades digitales, la capacidad expresiva, las temáticas de interés, el entorno del joven y su historia de vida. Tal valoración buscó contar con parámetros para identificar las actividades más frecuentes que realizan los jóvenes al navegar y sus autopercepciones acerca de qué niveles de habilidades digitales poseen, así como su articulación con la acción colectiva.

Entre los resultados generales de la investigación encontramos que seis de cada diez participantes se identificaron con el nivel de interacción 
bajo, relacionado con actividades como copiar y reenviar mensajes sin modificarlos; dar like o poner marcas a los mensajes que les agradan y conversar. Sólo dos de cada diez jóvenes se ubicaron en un nivel medio, que refiriere actividades de mayor complejidad relacional y cognitiva: compartir mensajes haciendo un pequeño cambio al original, adherirse a causas o peticiones de apoyo, y generar mensajes propios para el círculo de amigos o conocidos. En un nivel alto, en el cual también se ubicaron sólo dos de cada diez, destacaron acciones como planear eventos, fiestas y movilizaciones empleando alguna estrategia; difundir información en alguna página o grupo; así como ser parte de una wiki, foro o espacio colaborativo.

\section{Figura 2. Nivel de interacción en las redes sociales digitales}

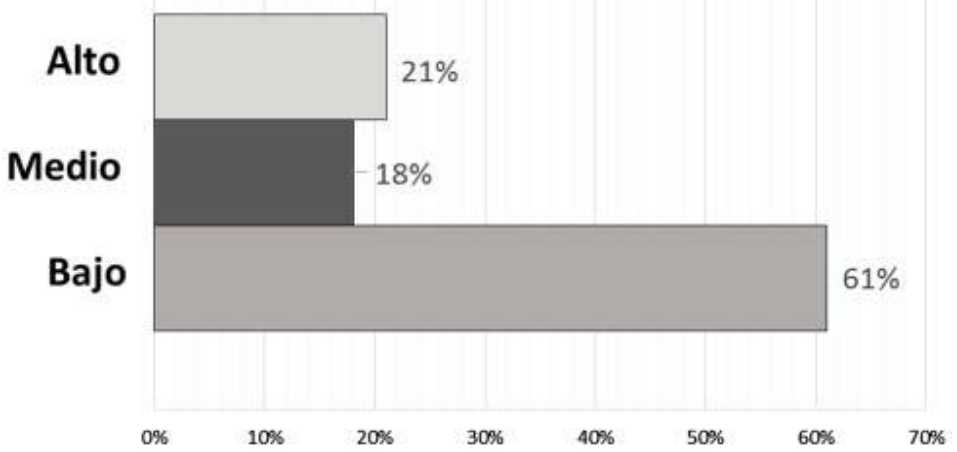

Fuente: elaboración propia.

En las redes sociales digitales la interacción toma forma en las actividades que desarrollan los usuarios y la naturaleza que éstas adquieren para el encuentro, el contacto y la experiencia recíproca. Sin embargo, para que se articule esta unidad de intercambio e inter-juego que da lugar al vínculo social, es necesario no sólo el acceso a la tecnología, sino las habilidades sociales que permitan interpretar la conducta propia frente al otro y hacer lecturas simultáneas de la inter-subjetividad que se está generando (Santoyo, 1985). Estos procesos están dados por el tipo de actividad realizada en la plataforma, la frecuencia y fruición que genera en el usuario (Crovi, 2016).

Realizar actividades con un mayor nivel de interacción también se relaciona con el potencial de acción social que ésta genera y el grado de compromiso que los participantes adquieran en esta actividad. Por ejem- 
plo, para los jóvenes de educación media superior son más relevantes las actividades como producir mensajes para interactuar con su círculo de conocidos o amigos; reenviar contenidos imprimiendo en ellos un comentario propio y adscribirse a grupos con los cuales concuerdan o firmar a favor de aquellas causas que les llaman la atención. Por el contrario, para los que estudian el nivel universitario, existe una marcada inclinación hacia actividades como conversar en línea y chatear. Lo anterior puede relacionarse con el capital social que poseen estos jóvenes y la necesidad de afirmar en redes los contactos que los vinculan a un grupo.

Al evaluar estas diversas actividades a partir de los rangos de edad, los resultados revelan que los jóvenes de entre los 18 y 19 años prefieren reenviar mensajes haciéndoles un cambio para destacar por qué les agrada o no tal contenido. Sin embargo, entre todos los grupos de edad restantes, resultó más relevante el dialogar en las redes digitales, sea de manera sincrónica o asincrónica. La centralidad del diálogo en las redes sociales digitales permite ver su estrecha relación con la apropiación de las herramientas socioculturales que son más significativas en este contexto.

De estos resultados también pudiera concluirse, aparentemente, que a mayor edad y formación académica se desarrolla un mayor nivel de interacción, sin embargo, este proceso no es lineal. Los resultados del cuestionario muestran que, en efecto, a mayor edad existe la capacidad de desarrollar mayores niveles de interacción, pero también existen casos puntuales de jóvenes que realizan preponderantemente las actividades del nivel alto, los cuales estuvieron ubicados en los 16, 19 y de 25 años en adelante $^{7}$. Cabe señalar, sin embargo, que estos son casos excepcionales de jóvenes que cuentan con el potencial de expresión, liderazgo o conocimiento para participar de manera colaborativa en temas de su interés; ser administradores de una página web, blog o grupo; así como movilizar recursos para llevar a cabo eventos de diversa índole.

En este sentido, el mayor o menor capital cultural es el primer planteamiento para comprender las interacciones realizadas por estos jóvenes. $\mathrm{Al}$ contar en mayor o menor medida con los estados descritos por Bourdieu (2001), es decir, al ser sujetos que están estudiando y que de acuerdo con el nivel educativo suman nuevos conocimientos cada vez más especializados (estado incorporado) y buscan contar con bienes culturales como el acceso a herramientas tecnológicas (estado objetivado).

$7 \quad$ En el nivel alto de las actividades de interacción se ubicaron 321 jóvenes, que corresponden al $20.7 \%$ de los 1,548 jóvenes que participaron en el estudio cuantitativo. 
Los resultados generales de la investigación muestran que para interactuar en un nivel alto en las redes sociales digitales, con fines de acción colectiva, los jóvenes que usan estos espacios requieren una motivación intrínseca para desarrollar una participación activa, tener las capacidades de comunicación (escrita, oral o incluso gráfica), así como ser parte de una comunidad mayor que circunscriba tal participación. Las temáticas que propician esta interacción son tan variadas como los jóvenes mismos. Van desde el ocio generalizado, diversión y entretenimiento, hasta los temas de incidencia social y participación ciudadana. Por ello la interacción debe comprenderse a la luz de estos múltiples escenarios (Crovi, 2016).

En el cruce de datos sobre el que estamos reflexionando, es interesante observar que de acuerdo con el tipo de escuela existen diferencias significativas en estas actividades de interacción. En el nivel medio superior es donde se observan con mayor claridad estas disparidades, ya que la diferencia entre quienes estudian en una escuela privada y realizan actividades de interacción en un nivel alto fue 13 puntos más arriba que aquellos adscritos a una escuela pública. Esta situación se repite en el ámbito universitario, aunque la diferencia es de sólo nueve puntos.

Una primera deducción que surge de estas diferencias, es que entre ambos niveles educativos existe una incorporación diferente en el acceso y uso de las tecnologías digitales al ámbito didáctico. Ello se origina en razones muy diversas, que van desde promover su empleo hasta contar con diseños pedagógicos para su incorporación efectiva en los procesos educativos. Pero también, cada sistema (público o privado) constituye un campo diferente, que concibe el desarrollo de las habilidades digitales como prioridad de manera distinta. Al respecto, la investigación general corroboró que a las instituciones privadas asisten jóvenes de nivel socioeconómico alto y medio, y a las públicas los de nivel medio y medio-bajo, como resultado de estos contrastes "el nivel socioeconómico influye en el acceso a las tecnologías digitales, ya que los jóvenes de nivel más alto tienen mayores recursos para adquirir equipos más modernos, de más ancho de banda y con más capacidad" (Crovi, 2016, p. 43).

Desde nuestra perspectiva, cada sistema educativo socializa la adquisición de aparatos y las habilidades digitales en estrecha relación con la clase social y sus roles en las actividades productivas propias del estrato económico al cual pertenecen. Aunque la escuela es un ámbito donde se puede alcanzar cierta homogeneidad en el acceso y uso, estas diferencias entre niveles y sistemas obedecen también a la dinámica sociocultural que se genera dentro de cada una. 
Ahora bien, en cuanto al género y el nivel de interacción, las mujeres perciben tener un nivel más elevado que el de los hombres, sobre todo en actividades como compartir mensajes haciendo un pequeño cambio; desarrollar contenidos para su círculo de contactos y adherirse a causas o peticiones. Los hombres desarrollan más actividades de nivel bajo, como compartir mensajes sin modificarlos, dar like y conversar. Esto último podría leerse como parte de los marcos culturales que también inciden en la interacción: existen habilidades de socialización en el contexto de las jóvenes, quienes podrían ser más afines al compartir, intercambiar información, estar en contacto, así como solidarizarse con otros y brindar apoyo, debido a los roles asignados al género femenino.

También existen similitudes y diferencias respecto a las temáticas que son de interés al navegar en las redes sociales digitales. Los aspectos de coincidencia muestran que existen gustos y preferencias que mueven la interacción de los jóvenes por igual. Por ejemplo, navegar con fines de ocio, diversión y entretenimiento es una de las principales coincidencias que existen entre ambos géneros, entre todos los grupos de edad, nivel y tipo de escuela.

Respecto a estos últimos resultados, podemos observar que la lógica generadora de la interacción en estos espacios digitales está orientada por una búsqueda constante del ocio y el entretenimiento, lo cual confiere el sentido práctico del uso de estas herramientas (Bourdieu, 1988). En primer lugar, el origen de estas plataformas, eminentemente comerciales, fue con fines de esparcimiento, por lo tanto esta actividad constituye el principal marco explicativo de las prácticas que ahí se generan. En segundo término, la cultura del ocio en este contexto digital se ha vuelto más compleja a través de las redes sociales digitales, ya que una misma plataforma digital no tiene un sentido único en su uso: la apropiación de estas herramientas propicia que la industria del entretenimiento esté presente de manera continua.

La interacción en estos espacios digitales es un proceso variable y multiforme, que puede desarrollarse en una complejidad de niveles de acuerdo con la finalidad del actor al desplegar tal acción. Desde la perspectiva sociocultural, estas actividades son relevantes no sólo en términos de la cantidad de información que se intercambia y el proceso comunicativo que se desarrolla, ya que esta es sólo la dimensión observable de cómo se va construyendo el complejo entramado del diálogo. El contexto sociocultural es el que ayuda a comprender cómo se estructura la interacción, a través de qué mecanismos se convierte en una dimensión recíproca, con fines compartidos y acción común. Como refleja esta aproximación empírica, 
para su comprensión es necesario profundizar también a las etapas de vida, el género, la clase social y una multitud de elementos que contextualizan a esta actividad, así como de manera destacada sobre los temas que los atrapan y disparan los procesos de interacción.

\section{Reflexiones finales}

Tal como lo indicamos, la interacción se comporta como una unidad de convivencia social y permite la construcción de los referentes de sentido a través de la comunicación. Debido a que se trata de un proceso complejo, ha sido necesario perfilar dimensiones de análisis para comprenderla con mayor profundidad. En este trabajo, en el cual nos decantamos por la perspectiva sociocultural, hemos propuesto una primera aproximación para abordar esta escurridiza noción con los mayores elementos de contextualización, sin embargo, no excluye otras miradas.

En cuanto a la interacción que se desarrolla en las redes sociales digitales, concluimos que esta área de investigación, vista desde el campo de la comunicación, aún tiene el reto de profundizar en aquellos elementos que generan interacción, así como entender la estructura de la unidad de acción que promueve la construcción de los vínculos sociales, en niveles y formas diferentes.

Cada etapa de vida y cada construcción sociocultural asigna un peso diferente a interactuar, ya que es a través de estos procesos que se consolida el desarrollo de la identidad, el sentido de pertenencia, confianza y las habilidades sociales básicas que se externarán en el comportamiento del joven. En este contexto, para comprender la relevancia de la interacción digital es necesario integrar una mirada que vincule el sistema de interacciones offline y on line del joven, a fin de profundizar acerca del sentido de tales las prácticas.

Por otro lado, es necesario destacar los determinantes intrínsecos que generan procesos diferenciados de interacción al interior de las redes sociales digitales. De manera sucinta planteamos algunos factores de incidencia directa, como son el nivel de educación, oportunidades de acceso al capital económico, cultural y social, así como el entorno sociocultural. Pero sin duda, desde el plano de la psicología individual y social también requerimos estudiar más a fondo cómo inciden las habilidades digitales, la personalidad, la capacidad expresiva y, en general las historias de vida, que dan como resultado jóvenes con un alto nivel de interacción en los entornos digitales, en tanto que en otros ese nivel es bajo. 
Lo que estos resultados recalcan es que los jóvenes no interactúan en las redes sociales digitales de manera única, ni lineal ni delimitada a un único tema. Estas reflexiones refuerzan la idea de que no basta el acceso para generar una interacción en los escenarios virtuales. En esos espacios las interacciones también están orientadas por la especificidad de su campo de acción, el contexto de los usuarios, así como la vinculación a ciertos capitales que dotan de más o menos recursos a los jóvenes para que interactúen o dejen de hacerlo.

En suma, nuestras reflexiones colocan al joven y su contexto vital como centro del análisis, lo que permite dimensionar con mayor claridad el lugar que verdaderamente ocupan las tecnologías digitales en los procesos de investigación en redes sociales digitales. Ello nos conduce a sostener que la interacción es multifactorial, constituye un concepto complejo, de diversos niveles, cuyos elementos de análisis deben ser exploradas mediante nuevos estudios empíricos.

\section{Bibliografía}

Bourdieu, P. (1988). La distinción. Madrid: Taurus.

Bourdieu, P. (2001). Las formas del capital. Capital económico, capital cultural y capital social. En P. Bourdieu (Ed.), Poder, Derecho y Clases Sociales (2da ed., pp. 131-164). Bilbao: Desclée de Brouwer.

Casal, J., Masjuan, J. M., \& Planas, J. (1991). La inserción social y profesional de los jóvenes. Madrid, España: Ministerio de Educación y Ciencia.

Crovi, D. (2009). Acceso, uso y apropiación de las TIC en comunidades académicas. Diagnóstico en la UNAM. México: UNAM/ Plaza y Valdés Editores.

Crovi, D. (2016). Redes sociales digitales. Lugar de encuentro, expresión e interacción para los jóvenes. México: UNAM / La Biblioteca.

DÁvila, O. (2004). Adolescencia y juventud: de las nociones a los abordajes. Última década, 12(21), pp. 83-104. Recuperado a partir de http:// www.scielo.cl/scielo.php?pid=S0718-22362004000200004\&script=sci_arttext

Leontiev, A. (1978). Actividad, conciencia y personalidad. Buenos Aires, Argentina: Ediciones Ciencias del Hombre.

Marc, E., \& Picard, D. (1992). La interacción social. Cultura, instituciones y comunicación. Barcelona, España: Paidós. 
Margulis, M. (2001). Juventud: una aproximación conceptual. En S. Donas (Ed.), Adolescencia y Juventud en América Latina (pp. 41-56). Costa Rica: Libro Universitario Regional (EULAC-GTZ).

McGivern, R. (2002). Cognitive efficiency on a match to sample task decreases at the onset of puberty in children. Brain and Cognition, 50(1), pp. 73-89. Recuperado a partir de http://www.sciencedirect.com/ science/article/ pii/S027826260200012X

Santoyo, R. (1985). En torno al concepto de Interacción. Perfiles Educativos, (27), 56-71.

SuÁrez, M.H., y Pérez, J.A. (Coords). (2008). Jóvenes universitarios en latinoamérica hoy. México: SES-UNAM; SIJ-UNAM; CIIJ; M.A. Porrúa.

Vygotski, L. (1976). El desarrollo de los procesos psicológicos superiores. Barcelona, España: Editorial Crítica S. L.

Weiss, E. (2012). Jóvenes y bachillerato. En E. Weiss (coord.) Jóvenes y bachillerato, pp. 7-32, México, D.F.: ANUIES. 



\title{
Uso de redes sociales digitales entre estudiantes universitarios: trazos para la reflexión desde una perspectiva de género
}

\author{
Gladys Ortiz Henderson ${ }^{1}$ \\ Rocío López González ${ }^{2}$ \\ Karla Edurne Romero Ramos ${ }^{3}$
}

En este capítulo comparamos resultados de dos universidades públicas que participaron en el proyecto SEP-CONACYT "Jóvenes y cultura digital. Nuevos escenarios de interacción social" ${ }^{4}$, instituciones que pertenecen a contextos diferenciados: la Universidad Veracruzana, ubicada en el suroeste de México y la Universidad Autónoma Metropolitana-Lerma, del centro del país. La comparación tiene como objetivo central analizar las similitudes y diferencias que existen entre las mujeres y los hombres universitarios en su comportamiento, prácticas sociales, participación e interacción en el uso de las redes sociales digitales para abonar elementos para la reflexión desde una perspectiva de género.

Se analizan exclusivamente los datos recabados en el cuestionario aplicado en cada una de estas universidades (ver Anexo 1), estructurado en seis secciones: 1) Datos personales (sexo, edad, trabajo y actitud al navegar en Internet); 2) Cultura Digital (percepciones en los cambios de usos de dispositivos, navegación en Internet y habilidades digitales); 3) Participación en las redes (en el que se plantearon diversas temáticas

1 Doctora en Ciencias Antropológicas por la Universidad Autónoma Metropolitana, unidad Iztapalapa; Maestra en Ciencias de la Comunicación por la Universidad de Sussex, Reino Unido. Profesora e investigadora de tiempo completo, titular B, Departamento de Estudios Culturales, Universidad Autónoma Metropolitana, unidad Lerma. Miembro del Sistema Nacional de Investigadores.

2 Doctora en Pedagogía por la Universidad Nacional Autónoma de México. Maestra en Innovación Educativa por la Universidad de Sonora. Investigadora del Programa de Investigación e Innovación en Educación Superior de la Universidad Veracruzana. Miembro del Sistema Nacional de Investigadores, nivel 1.

3 Doctorante en Educación por la Universidad de La Laguna, España. Licenciada y Maestra en Ciencias de la Comunicación por la Universidad Nacional Autónoma de México. Especialista en Tecnología Educativa y Estudios de Género.

4 Los datos y resultados amplios acerca de los hallazgos en cada universidad fueron reportados en el libro Redes Sociales Digitales. Lugar de encuentro, expresión y organización para los jóvenes (Crovi, 2016), producto de la investigación "Jóvenes y cultura digital. Nuevos escenarios de interacción social". 
como medio ambiente, educación, trabajo, arte, entretenimiento, sociedad, derechos humanos, política y religión); 4) Niveles de interacción (frecuencia, habilidades y plataformas, así como temáticas detonadoras) y 5) Nivel socioeconómico (Crovi, 2016).

Cabe mencionar que en la revisión de la literatura sobre jóvenes universitarios y su relación tanto con las tecnologías digitales como con las redes sociales digitales, realizada por las autoras de este capítulo (Ortiz 2012; Ortiz y López, 2013; Domínguez y López, 2015) se encontró que son escasos los trabajos en México que abordan la problemática del acceso, uso y apropiación de las tecnologías digitales y, más aún, de las redes sociales digitales entre las y los jóvenes desde una perspectiva de género. Asimismo, se detectó una centralización de la investigación, ya que existe mayor producción de conocimiento en universidades ubicadas en la Ciudad de México y zona metropolitana, en comparación con las universidades ubicadas en el interior del país.

En general, cuando se aborda la problemática del acceso, uso y apropiación de las tecnologías digitales desde una perspectiva de género, se hace mención de la brecha digital, es decir, la brecha que existe entre quienes tienen acceso a Internet y las diversas tecnologías digitales y quienes no lo tienen, siendo las mujeres las que presentan desventajas en este sentido. Castaño (2009), por ejemplo, plantea que la brecha digital es una problemática aún presente en Europa a la cual se le agrega la segunda brecha digital que no se limita al acceso a dispositivos tecnológicos o al empleo de Internet por parte de las mujeres, sino que tiene que ver con el desarrollo de habilidades digitales.

Según la autora, la llamada brecha digital tiene en sí misma diferentes brechas: infraestructura, contenidos y género, ya que las niñas y mujeres tienen mayores dificultades de acceso, debido a que sólo algunos grupos privilegiados lo logran. Indica también que el estudio de la brecha digital no puede limitarse al análisis del acceso a Internet (primera brecha digital), sino debe dar un paso más e involucrarse en la determinación de los usos y la intensidad de empleo de Internet. La segunda brecha digital tiene que ver con las oportunidades que crean estas innovaciones tecnológicas a partir del uso que hacen las personas en función de sus necesidades e intereses específicos.

Para Espinar y González (2009) es relevante analizar no sólo el acceso, sino sus características: los temas que se abordan tanto en Internet como en las redes sociales digitales, así como los usos particulares que hacen hombres y mujeres. En este sentido, la perspectiva de género y la episte- 
mología feminista proponen diversas alternativas para explorar las desigualdades a partir de lo que es propio de las mujeres y lo que es propio de los hombres y cómo el contexto imprime ciertas significaciones a las actividades cotidianas. De allí que sea importante analizar el contexto social, histórico, político y cultural en el que se utilizan tanto las tecnologías digitales como las redes sociales digitales, tal como señala Blazquez (2010).

Al respecto Crovi (2004) señala que el problema de la brecha digital se ha enfocado en propuestas relacionadas con la infraestructura tecnológica, por lo que hace hincapié en la necesidad de reflexionar en cinco dimensiones, mismas que están interrelacionadas y se insertan en la urgencia de contar con políticas públicas claras: a) Tecnológica, referente a la infraestructura material disponible y a la actualización; b) Conocimiento, relativo las habilidades y saberes de los sujetos para apropiarse de las tecnologías digitales; c) Información, en donde es sustancial distinguir dos grupos sociales, el sobreinformado con acceso a diversos recursos tecnológicos, y el desinformado con acceso limitado a tecnologías, actualizaciones y contenidos; d) Económica, concerniente a la falta de recursos para acceder a las tecnologías, misma que se manifiesta a nivel personal, como entre los sectores gubernamentales y privados; e) Participación, relacionada con el uso de los recursos tecnológicos que permiten a los sujetos expresarse e intervenir en decisiones y en un contexto democrático.

A partir de estas ideas y referencias surgió el interés de las autoras por realizar un análisis exploratorio-descriptivo sobre los usos de las redes sociales digitales por parte de las y los estudiantes universitarios, en este caso en la UV y en la UAM-Lerma, con el propósito de aportar elementos de análisis que permitan identificar diferencias y similitudes entre mujeres y hombres en su comportamiento, prácticas sociales, participación e interacción en el uso de las redes sociales digitales. Cabe señalar que se trata dos instituciones públicas de educación superior que comparten ciertos elementos que caracterizan a la población estudiantil universitaria en México: en su mayoría son jóvenes de clase alta y media-alta que se dedican a estudiar (sólo una minoría trabaja) y que provienen de zonas urbanas, semi-rurales y rurales. Asimismo, en ambas universidades, la matrícula de mujeres es más alta que la de los hombres.

\section{Contexto de las universidades: UV y UAM-L}

La Universidad Veracruzana inició su existencia formal el 11 de septiembre de 1944. Es la institución de educación superior pública autónoma de mayor impacto en el oriente de la República Mexicana y actualmente 
considerada la más prestigiosa en el estado de Veracruz, con presencia en cinco regiones: Coatzacoalcos-Minatitlán, Orizaba-Córdoba, Veracruz, Xalapa, Poza Rica-Tuxpan y en 28 municipios. El campus central está localizado en la ciudad de Xalapa (capital del estado de Veracruz), la cual cuenta con un amplio movimiento cultural y académico. Cabe destacar que desde sus orígenes, la UV tuvo una vocación artística y cultural muy marcada, ya que gran parte de la oferta cultural del estado está a cargo de dicha institución. Por medio de la docencia, investigación, difusión de la cultura y extensión de servicios busca conservar, crear y transmitir la cultura para el beneficio de la sociedad.

De acuerdo con las cifras de la Dirección de Planeación Institucional, el campus Xalapa cuenta con 32 facultades, 19 institutos y 14 centros. Actualmente la población de estudiantes matriculados de licenciatura (modalidad escolarizada, abierta, Universidad Veracruzana Intercultural, virtual y educación a distancia) y Técnico Superior Universitario es de 24,997 (11,892 hombres y 13,105 mujeres), distribuida en las seis áreas académicas que ofrece la Universidad: Técnica, Humanidades, Económico-Administrativa, Ciencias de la Salud, Biológico Agropecuaria y Artes $(\mathrm{UV}, 2016)^{5}$.

Por otra parte, la Universidad Autónoma Metropolitana (UAM) se creó en 1973 como un organismo con el objetivo de adquirir mayor cobertura educativa a nivel superior en México, ya que tanto la Universidad Nacional Autónoma de México, como el Instituto Politécnico Nacional, enfrentaron agudos problemas en cuanto a su capacidad para incorporar a los estudiantes que solicitaban su ingreso a los estudios de nivel Licenciatura. La UAM inició con tres unidades académicas, construidas durante la década de los setenta: Azcapotzalco, Iztapalapa y Xochimilco, para posteriormente incorporar los planteles de Cuajimalpa y Lerma, de construcción más reciente. En este momento en la UAM se imparten 75 licenciaturas, 62 programas de posgrado, además de dar apoyo a la investigación de alto nivel, así como al desarrollo y difusión de actividades culturales.

La unidad Lerma fue aprobada el 13 de mayo de 2009 por el Colegio Académico que ratificó su creación y su objetivo fue proporcionar mayor cobertura a las necesidades de educación superior en el Estado de México, el cual tiene un importante rezago educativo, a pesar de que cuenta con la Universidad Autónoma del Estado de México, el Colegio Mexiquense, la Universidad Mexiquense del Bicentenario y otras instituciones de carácter

5 Para conocer sobre la génesis de las TIC en la UV, véase Casillas y Ramírez (2015). 
privado. En 2011 iniciaron las clases con tres licenciaturas: Políticas Públicas, Biología Ambiental e Ingeniería en Recursos Hídricos, posteriormente, en el 2013, se abrió una nueva Licenciatura: Arte y Comunicación Digitales. Según datos proporcionados por la Coordinación de Sistemas Escolares de la UAM-Lerma, en la actualidad hay alrededor de 400 estudiantes en esta unidad.

\section{Composición sociodemográfica}

En el caso de la UV, se trabajó con una muestra integrada por $55 \%$ de mujeres y $45 \%$ de hombres, de entre 18 y 34 años. Las y los estudiantes procedían en su mayoría del estado de Veracruz, pero también se registraron originarios de otras entidades cercanas como Puebla, Tabasco, Tamaulipas y Oaxaca. La diversidad de los rasgos de origen de las y los jóvenes estudiantes habla de un fenómeno de multiculturalidad. En el caso de la matrícula de la UV, esta situación es algo que se refleja más en la ciudad de Xalapa, sede del campus universitario y de este estudio, donde la migración y establecimiento de individuos de otros municipios, estados e incluso países, construye una ciudad con diversas actividades artísticas, sociales y culturales que suelen estar ligadas a la institución universitaria.

Otro dato relevante, respecto al perfil de los participantes, fue que un $16 \%$ son estudiantes que trabajan. Según sus respuestas sobre el nivel socioeconómico ${ }^{6}$, siete de cada diez pertenecen al nivel socioeconómico alto y medio alto; dos de cada diez están en el nivel medio y en el bajo sólo se ubicó uno de cada diez.

En el caso de la UAM-Lerma, la muestra estuvo integrada por un $58 \%$ de mujeres y $42 \%$ de hombres, cuyas edades van de los 17 a los 32 años. Las y los estudiantes proceden de la Ciudad de México y de distintas zonas y comunidades del Estado de México cercanas al municipio de Lerma de Villada, como Toluca, Ocoyoacac, San Pedro Totoltepec, Atarasquillo, entre otros.

6 El procedimiento completo para el cálculo del nivel socioeconómico se desarrolló en el libro coordinado por Crovi (2016). Se utilizó la regla 10 x 6 de la Asociación Mexicana de Agencias de Inteligencia de Mercado y Opinión (AMAI), tomando en cuenta características de la vivienda, infraestructura básica, sanitaria, tecnología y de entretenimiento; así como el acceso a capital humano a través de la escolaridad máxima del jefe de familia. El nivel $\mathrm{AB}$, el más alto, dispone de todos los servicios, acceso a educación, así como posibilidad de distribución del gasto; el estrato E corresponde a la clase socioeconómica más baja, es aquella que tiene las mínimas posibilidades de acceso al conjunto de bienes, servicios y estilo de vida, relacionado a sus capacidades de consumo (López-Romo, 2009). 
En cuanto al nivel socioeconómico el 59\% es de clase alta y media-alta; $40 \%$ es de clase media y media-baja y sólo un $1 \%$ es de clase baja. Se destaca que un $23 \%$ trabaja y que quienes lo hacen tienen entre 23 y 25 años. La composición sociodemográfica refleja la diversidad de juventudes que acuden a las aulas de esta universidad, pues se pueden encontrar jóvenes que provienen de zonas urbanas, semi-rurales y rurales, así como jóvenes que viven en los alrededores y otros que pueden tardar hasta dos horas en llegar a la sede universitaria.

\section{Comportamiento al navegar en Internet ${ }^{7}$}

En cuanto a la navegación en las redes sociales digitales, para la investigación referida fue significativo comprender cómo se auto-perciben estos jóvenes al formar parte de alguna de estas redes. Con el fin de identificar estas opiniones se propusieron cuatro perfiles que pretenden reflejar esta actitud o comportamiento de los usuarios, tal y como se indica en el libro referido de Crovi (2016):

Consideramos en el perfil Discreto a aquellos usuarios que sólo observan y aunque usan o forman parte de una red, no interactúan con otras personas o lo hacen muy poco. El Selectivo interactúa con pocas personas que él mismo escoge, tiene dificultades o pocas razones para comunicarse con un grupo mayor o simplemente no le gusta hacerlo. Enlace es el perfil que alude a un joven que interactúa con algunas personas, le agrada hacerlo pero sólo se comunica cuando considera que hay razones importantes para ello, cumpliendo así una función de puente o vínculo entre destinatarios con los cuales suele compartir contenidos. Finalmente, los Comunicativos son quienes tienen una actitud abierta, son sociables, interactúan con muchas personas, les agrada comunicarse, estar en contacto constantemente y establecer lazos diversos, condiciones que los mueven a crear contenidos y compartirlos (p. 70).

$\mathrm{Al}$ indagar sobre el comportamiento que tienen las y los jóvenes universitarios de la UV cuando navegan en las redes sociales digitales, se observó que la actitud predominante fue la de Enlace. En cuanto a las diferencias entre hombres y mujeres, como se puede ver en la Figura 1, se identificó

7 En el apartado del cuestionario se tenían las siguientes opciones de respuesta: a) Discreto: "Formo parte de una red pero no tengo interacción con ninguna persona"; b) Selectivo: "Tengo interacción con pocas personas, no tengo muchas razones para comunicarme o no me gusta hacerlo"; c) Enlace: "Tengo interacción con algunas personas, me agrada hacerlo pero me comunico sólo cuando hay razones importantes"; d) Comunicativo: "Tengo interacción con muchas y diversas personas, me gusta comunicarme y estar en contacto con todos constantemente"; e) Ninguno: "Ninguna opción me describe". 
que son más las mujeres (72\%) quienes consideraron tener esta actitud, en comparación con los hombres (61\%).

Figura 1. Comportamiento de las y los jóvenes de la Universidad Veracruzana cuando navegan en las redes sociales digitales

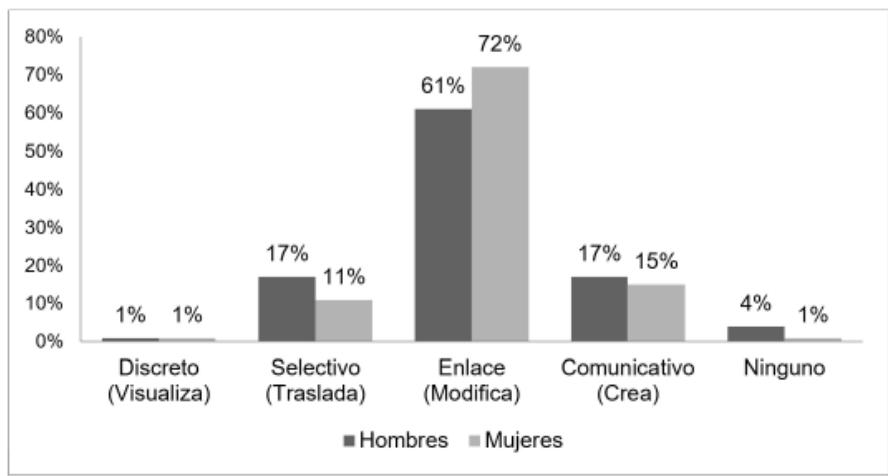

Fuente: Elaboración propia

En la UAM-Lerma el comportamiento de los estudiantes hombres y mujeres al navegar en Internet es similar; en realidad no hay diferencias estadísticamente representativas en este rubro. Ambos sexos tienen una actitud de Enlace y la diferencia que se presenta es mínima, pues oscila en casi dos por ciento entre hombres y mujeres (Figura 2).

Figura 2. Comportamiento de las y los jóvenes de la UAM-Lerma al navegar en las redes sociales digitales

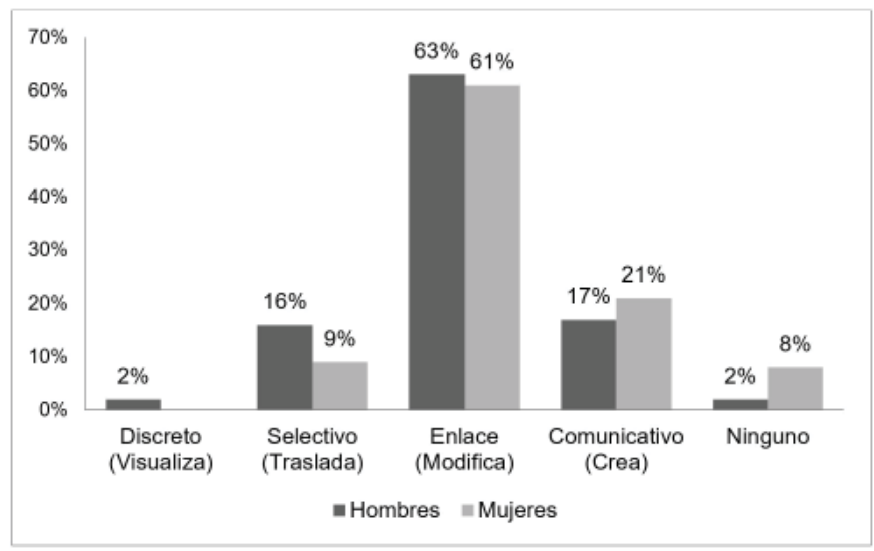

Fuente: Elaboración propia 
Como puede observarse, en ambas universidades el comportamiento al navegar en Internet, tanto de hombres como mujeres, se identifica con una navegación tipo Enlace, lo cual indica que las y los jóvenes universitarios se mantienen en una postura media: no son tan sociables como pudiera uno suponer desde una perspectiva más adultocéntrica y utilizan las redes sociales digitales para interactuar con cierta moderación, es decir, sólo le hablan a ciertas personas y cuando la ocasión lo amerita. Un porcentaje mucho menor corresponde a quienes son Comunicativos, es decir, los que pasan el día interactuando y comunicándose con muchas personas.

\section{Cultura digital}

La cultura digital constituye un concepto complejo, no obstante, muy empleado en tiempos recientes. Para abordarlo, en la investigación general se definió como:

Podemos hablar de una cultura digital en la medida en que se produce la incorporación de la digitalización a las prácticas sociales de los individuos, transformándolas. Aunque el proceso es el mismo, los recursos a apropiarse han cambiado sustantivamente, creando un ciberespacio, rompiendo fronteras de espacio y tiempo, permitiendo nuevas formas de expresión, organización e interacción (Crovi, 2016, p. 37).

A partir de esta conceptualización, se abordaron las autopercepciones de los participantes en relación a habilidades digitales, dependencia tecnológica, uso simultáneo de múltiples plataformas y dispositivos, así como la apropiación de estos espacios para diversos fines.

En el caso de la UV, los datos permitieron observar que los hombres son más activos desde corta edad en Internet (56\%) en comparación con las mujeres (49\%). Sin embargo, la mayoría de ellos (90\%) y ellas (88\%) indicaron tener acceso a Internet desde diferentes aparatos, además de ser capaces de hacer varias cosas al mismo tiempo en sus dispositivos (71\%, hombres y $74 \%$, mujeres).

En cuanto a la afirmación relativa a la habilidad para navegar en Internet y resolver cualquier problema técnico de conexión cabe decir que $56 \%$ de los hombres señalaron estar "de acuerdo" o "completamente de acuerdo", frente a un 38\% de las mujeres que contestaron afirmativamente al respecto.

Es interesante observar que tanto ellas como ellos señalaron por igual el no tener sentimientos de ansiedad y soledad si olvidan o pierden el celular. Asimismo, contestaron por igual el no estar de acuerdo con la afirmación 
"no puedo imaginar mi vida sin redes sociales". Sin embargo, la indecisión sobre esta última idea está presente en ambos sexos.

\section{Tabla 1. Afirmaciones sobre el uso de los recursos digitales entre las y los jóvenes de la Universidad Veracruzana}

\begin{tabular}{|c|c|c|c|c|c|c|c|c|c|c|}
\hline \multirow[t]{2}{*}{ Afirmaciones } & \multicolumn{2}{|c|}{$\begin{array}{c}\text { Completa- } \\
\text { mente en } \\
\text { desacuerdo }\end{array}$} & \multicolumn{2}{|c|}{$\begin{array}{c}\text { En } \\
\text { desacuerdo }\end{array}$} & \multicolumn{2}{|c|}{$\begin{array}{l}\text { Ni de acuer- } \\
\text { do ni en } \\
\text { desacuerdo }\end{array}$} & \multicolumn{2}{|c|}{ De acuerdo } & \multicolumn{2}{|c|}{$\begin{array}{l}\text { Completa- } \\
\text { mente de } \\
\text { acuerdo }\end{array}$} \\
\hline & $\mathrm{H}$ & $M$ & $\mathrm{H}$ & M & $\mathrm{H}$ & M & $\mathrm{H}$ & M & $\mathrm{H}$ & M \\
\hline $\begin{array}{c}\text { Soy un usuario activo } \\
\text { de Internet desde } \\
\text { corta edad }\end{array}$ & $5 \%$ & $7 \%$ & $19 \%$ & $20 \%$ & $20 \%$ & $24 \%$ & $38 \%$ & $39 \%$ & $18 \%$ & $10 \%$ \\
\hline $\begin{array}{l}\text { No puedo imaginar mi } \\
\text { vida sin redes sociales }\end{array}$ & $19 \%$ & $17 \%$ & $34 \%$ & $35 \%$ & $29 \%$ & $31 \%$ & $11 \%$ & $12 \%$ & $7 \%$ & $5 \%$ \\
\hline $\begin{array}{l}\text { Soy capaz de hacer } \\
\text { muchas cosas al mismo } \\
\text { tiempo mientras utilizo } \\
\text { alguna tecnología }\end{array}$ & $2 \%$ & $1 \%$ & $11 \%$ & $9 \%$ & $16 \%$ & $16 \%$ & $49 \%$ & $49 \%$ & $22 \%$ & $25 \%$ \\
\hline $\begin{array}{c}\text { Tengo acceso a Internet } \\
\text { desde diferentes } \\
\text { dispositivos }\end{array}$ & $1 \%$ & $1 \%$ & $3 \%$ & $5 \%$ & $6 \%$ & $6 \%$ & $42 \%$ & $48 \%$ & $48 \%$ & $40 \%$ \\
\hline $\begin{array}{c}\text { Navego en Internet } \\
\text { individualmente y } \\
\text { desde mi dispositivo } \\
\text { personal }\end{array}$ & $1 \%$ & $1 \%$ & $2 \%$ & $2 \%$ & $3 \%$ & $6 \%$ & $39 \%$ & $44 \%$ & $55 \%$ & $47 \%$ \\
\hline $\begin{array}{c}\text { Si olvido o pierdo el ce- } \\
\text { lular me siento aislado } \\
\text { y ansioso }\end{array}$ & $16 \%$ & $16 \%$ & $31 \%$ & $28 \%$ & $30 \%$ & $32 \%$ & $16 \%$ & $17 \%$ & $7 \%$ & $7 \%$ \\
\hline $\begin{array}{c}\text { Tengo habilidad para } \\
\text { navegar en Internet } \\
\text { y resolver cualquier } \\
\text { problema técnico de } \\
\text { conexión }\end{array}$ & $3 \%$ & $5 \%$ & $10 \%$ & $22 \%$ & $31 \%$ & $35 \%$ & $39 \%$ & $30 \%$ & $17 \%$ & $8 \%$ \\
\hline $\begin{array}{c}\text { Creo que Internet es } \\
\text { un nuevo espacio para } \\
\text { defender alguna causa } \\
\text { o luchar en contra de } \\
\text { las injusticias }\end{array}$ & $4 \%$ & $3 \%$ & $10 \%$ & $9 \%$ & $40 \%$ & $51 \%$ & $31 \%$ & $31 \%$ & $15 \%$ & $6 \%$ \\
\hline
\end{tabular}

Fuente: Elaboración propia

En el caso de la UAM-Lerma también los hombres son más activos en Internet que las mujeres desde corta edad, con un 32\% y un 23\% respectivamente. En otros rubros el uso de recursos digitales es similar entre hombres y mujeres, así como su percepción sobre los mismos. La mayoría de ellos (66\%) y ellas (63\%) estuvieron en desacuerdo con la idea de no poder imaginar su vida sin Internet. Ambos concordaron en que son capaces de hacer varias cosas al mismo tiempo en sus dispositivos (46\% hombres y $47 \%$ mujeres). 
Tal como sucedió en la Universidad Veracruzana, en la UAM-Lerma ambos sexos tienen igual acceso a Internet desde diferentes aparatos y navegan desde su dispositivo personal, tampoco hay diferencias significativas respecto de los sentimientos de ansiedad y soledad que pueden experimentarse si olvidan el celular, ya que tanto ellas como ellos no están de acuerdo con esa afirmación.

\section{Tabla 2. Afirmaciones sobre el uso de los recursos digitales entre las y los jóvenes de la UAM-Lerma}

\begin{tabular}{|c|c|c|c|c|c|c|c|c|c|c|}
\hline Afirmaciones & $\begin{array}{c}\text { Comple- } \\
\text { ta-mente en } \\
\text { desacuerdo }\end{array}$ & \multicolumn{2}{|c|}{$\begin{array}{c}\text { En des- } \\
\text { acuerdo }\end{array}$} & \multicolumn{2}{|c|}{$\begin{array}{c}\text { Ni de acuer- } \\
\text { do ni en } \\
\text { desacuerdo }\end{array}$} & \multicolumn{2}{|c|}{ De acuerdo } & \multicolumn{2}{c|}{$\begin{array}{c}\text { Completa- } \\
\text { mente de } \\
\text { acuerdo }\end{array}$} \\
\cline { 2 - 12 } & $\mathrm{H}$ & $\mathrm{M}$ & $\mathrm{H}$ & $\mathrm{M}$ & $\mathrm{H}$ & $\mathrm{M}$ & $\mathrm{H}$ & $\mathrm{M}$ & $\mathrm{H}$ & $\mathrm{M}$ \\
\hline $\begin{array}{c}\text { Soy un usuario activo } \\
\text { de Internet desde corta } \\
\text { edad }\end{array}$ & $17 \%$ & $26 \%$ & $19 \%$ & $21 \%$ & $32 \%$ & $30 \%$ & $21 \%$ & $13 \%$ & $11 \%$ & $10 \%$ \\
\hline $\begin{array}{c}\text { No puedo imaginar mi } \\
\text { vida sin redes sociales }\end{array}$ & $44 \%$ & $41 \%$ & $22 \%$ & $22 \%$ & $17 \%$ & $25 \%$ & $11 \%$ & $5 \%$ & $4 \%$ & $5 \%$ \\
\hline $\begin{array}{c}\text { Soy capaz de hacer } \\
\text { muchas cosas al mismo } \\
\text { tiempo mientras utilizo } \\
\text { alguna tecnología }\end{array}$ & $3 \%$ & $3 \%$ & $11 \%$ & $19 \%$ & $37 \%$ & $28 \%$ & $24 \%$ & $22 \%$ & $22 \%$ & $25 \%$ \\
\hline $\begin{array}{c}\text { Tengo acceso a Inter- } \\
\text { net desde diferentes } \\
\text { dispositivos }\end{array}$ & $4 \%$ & $3 \%$ & $14 \%$ & $18 \%$ & $16 \%$ & $23 \%$ & $26 \%$ & $13 \%$ & $39 \%$ & $41 \%$ \\
\hline $\begin{array}{c}\text { Navego en Internet } \\
\text { individualmente y } \\
\text { desde mi dispositivo } \\
\text { personal }\end{array}$ & $3 \%$ & $3 \%$ & $8 \%$ & $5 \%$ & $10 \%$ & $13 \%$ & $21 \%$ & $14 \%$ & $58 \%$ & $62 \%$ \\
\hline $\begin{array}{c}\text { Si olvido o pierdo el ce- } \\
\text { lular me siento aislado } \\
\text { y ansioso }\end{array}$ & $43 \%$ & $34 \%$ & $23 \%$ & $24 \%$ & $18 \%$ & $25 \%$ & $9 \%$ & $8 \%$ & $6 \%$ & $7 \%$ \\
\hline $\begin{array}{c}\text { Tengo habilidad para } \\
\text { navegar en Internet } \\
\text { y resolver cualquier } \\
\text { problema técnico de } \\
\text { conexión }\end{array}$ & $5 \%$ & $5 \%$ & $20 \%$ & $27 \%$ & $34 \%$ & $39 \%$ & $20 \%$ & $19 \%$ & $20 \%$ & $8 \%$ \\
\hline $\begin{array}{c}\text { Creo que Internet es } \\
\text { un nuevo espacio para } \\
\text { defender alguna causa } \\
\text { o luchar en contra de } \\
\text { las injusticias }\end{array}$ & $0 \%$ & $9 \%$ & $16 \%$ & $15 \%$ & $30 \%$ & $27 \%$ & $29 \%$ & $29 \%$ & $16 \%$ & $18 \%$ \\
\hline
\end{tabular}

Fuente: Elaboración propia

Dentro del tema habilidades digitales, uno de los rubros en los que se puede observar una diferencia importante, es el referido las destrezas para resolver cualquier problema técnico de conexión. Sus autopercepciones indican que sólo 8\% de las mujeres contestó estar "completamente de 
acuerdo" en contar con tales habilidades, mientras que entre los hombres esta percepción sube a 20\% (véase Tabla 2).

Un dato a destacar en esta sección es que en ambas universidades los hombres son más activos que las mujeres en Internet desde corta edad, lo cual se vincula con lo que socialmente se concibe y refuerza como lo propio de los niños y lo propio de las niñas. En este sentido se apoya la hipótesis de la socialización diferencial según el género, la cual indica que en el seno escolar y familiar a los hombres se les suele empujar más hacia lo tecnológico, mientras que a las mujeres se les aleja del contacto con la tecnología con distintos mecanismos tales como estereotipos y expectativas asociadas a su género (González-Palencia y Jiménez, 2016).

Los datos recabados constatan que los hombres acceden de manera más temprana a la tecnología que las mujeres, cuestión que, sin duda, repercute en los usos y apropiaciones posteriores, así como en el dominio de las herramientas digitales, dotándolos a ellos de una cercanía que les puede ofrecer mayor seguridad y destreza a lo largo de su vida.

Asimismo, los resultados demuestran que los hombres se sienten más cómodos que las mujeres a la hora de navegar en Internet y en la tarea de resolver problemas técnicos. Los porcentajes son reveladores en este rubro: $56 \%$ de los hombres frente a un 38\% de mujeres en la UV y $40 \%$ de los hombres frente a un $27 \%$ de las mujeres en la UAM-L. Cabe señalar que se evidencia en este estudio la cuestión de género en cuanto a que, culturalmente, se considera a los hombres más aptos para arreglar descomposturas y cuestiones técnicas que las mujeres. Aparece de nuevo no sólo la segunda brecha digital que menciona Castaño (2008), sino los roles de género asociados a lo que es propio de las mujeres y lo que es propio de los hombres.

\section{Participación}

Las tecnologías digitales son herramientas que están generando nuevos canales de participación para que individuos, grupos o comunidades se expresen e interactúen. La participación, en este sentido, puede definirse como:

(...) todos aquellos actos de presencia individual o grupal en un proceso de toma de decisiones. En la actualidad y en especial debido a la disminución del Estado a partir de las políticas neoliberales impuestas desde la década de los 80 del siglo pasado, el concepto está estrechamente ligado a reivindicaciones ciudadanas, así como a procesos de toma de decisiones públicas con el objeto de incidir en la resolución de problemas colectivos. Entendida de este modo, la participación tiene un fuerte componente de acción, elemento fundamental para los procesos de interacción (Crovi, 2016, p. 34). 
Al indagar sobre los temas acerca de los cuales hay interés por participar entre las y los estudiantes en la Universidad Veracruzana, resaltaron dos: a) educativos y académicos (77\%) y b) ocio, diversión y entretenimiento (76\%). Un porcentaje considerable (67\%) indicó interesarse por temas de medio ambiente y artístico-culturales (62\%), en tanto que los temas menos abordadas fueron los religiosas (39\%) y políticos (27\%).

$\mathrm{Al}$ realizar un análisis comparativo entre hombres y mujeres, surgen algunas diferencias importantes. Por ejemplo, respecto a los temas relacionados con el medio ambiente, $71 \%$ de los hombres los prefiere, frente al 63\% de las mujeres. Otro tema donde difieren hombres y mujeres es trabajo y empleo, ya que mientras que el 55\% de los hombres manifestó interés, sólo 41\% de las mujeres lo hizo. En la cuestión de problemas sociales los hombres predominaron con un $67 \%$ frente a las mujeres con un $54 \%$. Aunque son pocos quienes dijeron interesarse por temas políticos, los hombres nuevamente mostraron mayor interés con un $48 \%$ en contraste con un $42 \%$ de mujeres. Sin embargo, un dato relevante es que las mujeres (30\%) se interesan más que los hombres (24\%) en lo educativo y académico. Finalmente, tanto hombres como mujeres, mostraron desinterés en los temas religiosos y, tanto hombres como mujeres, mostraron un alto interés en cuanto a los temas relacionados con el ocio y la diversión como lo muestra la siguiente tabla.

\section{Tabla 3. Temas de interés de las y los jóvenes de la Universidad Veracruzana (\%)}

\begin{tabular}{|c|c|c|c|c|c|c|c|c|}
\hline \multirow{2}{*}{ Temas } & \multicolumn{2}{|c|}{ Alto } & \multicolumn{2}{c|}{ Medio } & \multicolumn{2}{c|}{ Bajo } & \multicolumn{2}{c|}{ Nada } \\
\cline { 2 - 8 } & $\mathrm{H}$ & $\mathrm{M}$ & $\mathrm{H}$ & $\mathrm{M}$ & $\mathrm{H}$ & $\mathrm{M}$ & $\mathrm{H}$ & $\mathrm{M}$ \\
\hline $\begin{array}{c}\text { Medio ambiente, ecología y protección } \\
\text { de animales }\end{array}$ & $22 \%$ & $21 \%$ & $42 \%$ & $49 \%$ & $25 \%$ & $20 \%$ & $11 \%$ & $10 \%$ \\
\hline $\begin{array}{c}\text { Educativos/académicos } \\
\text { De trabajo y empleo }\end{array}$ & $24 \%$ & $30 \%$ & $51 \%$ & $48 \%$ & $17 \%$ & $15 \%$ & $8 \%$ & $7 \%$ \\
\hline Artísticos/culturales & $20 \%$ & $8 \%$ & $35 \%$ & $33 \%$ & $27 \%$ & $30 \%$ & $18 \%$ & $29 \%$ \\
\hline De ocio, diversión y entretenimiento & $34 \%$ & $26 \%$ & $45 \%$ & $46 \%$ & $15 \%$ & $20 \%$ & $6 \%$ & $8 \%$ \\
\hline Problemas sociales y ciudadanos & $22 \%$ & $15 \%$ & $45 \%$ & $39 \%$ & $21 \%$ & $28 \%$ & $12 \%$ & $18 \%$ \\
\hline Defensa de derechos humanos & $22 \%$ & $17 \%$ & $33 \%$ & $36 \%$ & $27 \%$ & $29 \%$ & $18 \%$ & $18 \%$ \\
\hline Políticos & $16 \%$ & $10 \%$ & $32 \%$ & $21 \%$ & $24 \%$ & $29 \%$ & $28 \%$ & $40 \%$ \\
\hline Religiosos & $8 \%$ & $7 \%$ & $20 \%$ & $18 \%$ & $31 \%$ & $35 \%$ & $41 \%$ & $40 \%$ \\
\hline
\end{tabular}

Fuente: Elaboración propia 
En la UAM-L las y los jóvenes se interesan, en general, por los siguientes temas: educativos y académicos (95\%); medio ambiente, ecología y protección de animales (92\%). Los temas menos relevantes son los políticos (74\%) y los religiosos (48\%), y aunque los políticos presentan un porcentaje relativamente alto, se ubicaron en penúltimo lugar de entre los demás temas propuestos en el cuestionario.

Al realizar un análisis comparativo entre hombres y mujeres, surgen algunas diferencias que hay que señalar. Un 17\% de los hombres muestra un alto interés en el empleo y trabajo, frente a un $12 \%$ de las mujeres. Los problemas políticos son de mayor interés para ellos con un $31 \%$ frente a un $20 \%$ de las mujeres, también los temas sociales les interesan más a ellos con un $25 \%$, en comparación con un $20 \%$ de las mujeres. Sin embargo, ellas tienen un alto interés en la defensa de los derechos humanos con un $23 \%$, frente a sólo un $13 \%$ correspondiente a los hombres.

Tal como ocurrió en la UV tanto hombres como mujeres mostraron desinterés por los temas religiosos; en tanto que hombres y mujeres expresaron un alto interés en el ocio y la diversión. A diferencia de la UV, en la UAM-L los temas del medio ambiente y ecología, así como los educativos y académicos despertaron interés por igual entre hombres y mujeres.

\section{Tabla 4. Temas de interés de las y los jóvenes de la UAM-Lerma (\%)}

\begin{tabular}{|c|c|c|c|c|c|c|c|c|}
\hline \multirow{2}{*}{ Temas } & \multicolumn{2}{|c|}{ Alto } & \multicolumn{2}{c|}{ Medio } & \multicolumn{2}{c|}{ Bajo } & \multicolumn{2}{c|}{ Nada } \\
\cline { 2 - 9 } & $\mathrm{H}$ & $\mathrm{M}$ & $\mathrm{H}$ & $\mathrm{M}$ & $\mathrm{H}$ & $\mathrm{M}$ & $\mathrm{H}$ & $\mathrm{M}$ \\
\hline $\begin{array}{c}\text { Medio ambiente, ecología y protec- } \\
\text { ción de animales }\end{array}$ & $32 \%$ & $32 \%$ & $46 \%$ & $48 \%$ & $15 \%$ & $14 \%$ & $6 \%$ & $6 \%$ \\
\hline Educativos/académicos & $29 \%$ & $25 \%$ & $49 \%$ & $52 \%$ & $19 \%$ & $17 \%$ & $2 \%$ & $6 \%$ \\
\hline De trabajo y empleo & $17 \%$ & $12 \%$ & $36 \%$ & $32 \%$ & $30 \%$ & $32 \%$ & $17 \%$ & $23 \%$ \\
\hline Artísticos/culturales & $26 \%$ & $24 \%$ & $37 \%$ & $43 \%$ & $28 \%$ & $21 \%$ & $9 \%$ & $11 \%$ \\
\hline De ocio, diversión y entretenimiento & $19 \%$ & $20 \%$ & $48 \%$ & $34 \%$ & $24 \%$ & $34 \%$ & $9 \%$ & $12 \%$ \\
\hline Problemas sociales y ciudadanos & $25 \%$ & $20 \%$ & $29 \%$ & $43 \%$ & $34 \%$ & $28 \%$ & $11 \%$ & $8 \%$ \\
\hline Defensa de derechos humanos & $13 \%$ & $23 \%$ & $31 \%$ & $34 \%$ & $35 \%$ & $28 \%$ & $21 \%$ & $15 \%$ \\
\hline Políticos & $31 \%$ & $20 \%$ & $25 \%$ & $21 \%$ & $22 \%$ & $34 \%$ & $22 \%$ & $25 \%$ \\
\hline Religiosos & $5 \%$ & $3 \%$ & $18 \%$ & $9 \%$ & $30 \%$ & $35 \%$ & $47 \%$ & $53 \%$ \\
\hline
\end{tabular}

Fuente: Elaboración propia 
Tanto en la UV como en la UAM-Lerma el tema de mayor interés para hombres y para mujeres fue el relacionado con lo educativo y lo académico, esto debido a su papel preponderante como estudiantes universitarios. En segundo lugar, para la UV está el ocio y la diversión, en tanto que en este rubro para la UAM-Lerma está el tema del medio ambiente. Tales intereses reflejan el contexto de la región en donde se ubica cada universidad y las licenciaturas que estudian estos jóvenes: la UV caracterizada por sus múltiples actividades culturales y la UAM-Lerma, que cuenta con una Licenciatura en Biología Ambiental, se hace notar por su constante preocupación y concientización sobre este tema, mismo que permea en todas sus actividades universitarias. Es importante decir que los temas políticos y religiosos son los que menor interés despiertan entre los estudiantes de ambas universidades, hombres y mujeres, aunque en la UAM-Lerma se presentaron porcentajes más altos que en la UV respecto al interés por la política.

Un dato relevante para ser leído desde una perspectiva de género es que los hombres de ambas universidades se preocupan más por el tema del trabajo y del empleo, además de inclinarse hacia los temas sociales y políticos. Estas respuestas resultan interesantes en una sociedad y una cultura que empuja a los hombres a buscar trabajo para ser los proveedores del hogar y tener aspiraciones laborales, adquiriendo por tanto mayor disposición a competir para contar con un trabajo remunerado. De ello se deriva seguramente la importancia que estos jóvenes atribuyen a este tipo de temas. Asimismo, sobresale la inclinación masculina por la política y la sociedad, rubros que han sido asociados con el espacio público, históricamente reservado a los hombres.

\section{Interacción}

La interacción es uno de los conceptos centrales para comprender el cambio que está sucediendo en campo de las tecnologías digitales. Se trata también de una categoría multidimensional que en la investigación general se la define como una conducta grupal que es parte constitutiva de todo proceso comunicativo.

La interacción, tal como lo sostiene Leontiev y Vygostky, es una experiencia que implica aprendizaje debido a que el individuo que se enfrenta a ella no siempre cuenta con una conducta previa organizada, y en determinadas circunstancias (como la digitalización), requiere además habilidades para manejar ciertos instrumentos que le permitan romper el aislamiento. Frente a este desafío, tiene que elaborar un marco conductual 
nuevo y comprobar su pertinencia mediante las respuestas que reciba, las que lo conducirán a ratificar o rectificar su conducta. Este aprendizaje lo confronta con sus propios marcos conductuales y afectivos previos, los que debe reelaborar para dar lugar a la apropiación de los nuevos objetos culturales que llegan acompañados de prácticas y rutinas de comportamiento. Cada individuo hace suyo al conjunto de objetos, prácticas, rutinas, transformando sus relaciones y actividades cotidianas (Crovi, 2016, p. 35).

$\mathrm{Al}$ indagar sobre la interacción que llevan a cabo comúnmente en las redes sociales digitales, se encontró que las dos actividades principales que realizan las y los estudiantes de la Universidad Veracruzana, varias veces al día o a la semana, son "conversar en línea o chatear" (84\%) y "dar like o marcar como favorito algún mensaje" (66\%).

\section{Tabla 5. Nivel de habilidad con la que realizan diversas acciones las y los jóvenes de la Universidad Veracruzana}

\begin{tabular}{|c|c|c|c|c|c|c|}
\hline \multirow{2}{*}{ Acciones } & \multicolumn{2}{|c|}{ Alto } & \multicolumn{2}{|c|}{ Medio } & \multicolumn{2}{|c|}{ Bajo } \\
\hline & $\mathrm{H}$ & M & $\mathrm{H}$ & M & H & M \\
\hline $\begin{array}{l}\text { Copiar, compartir o reenviar mensajes } \\
\text { que encuentran en la red sin modificar }\end{array}$ & $23 \%$ & $23 \%$ & $66 \%$ & $62 \%$ & $12 \%$ & $15 \%$ \\
\hline Dar like o marcar como favorito algún mensaje & $34 \%$ & $42 \%$ & $51 \%$ & $47 \%$ & $15 \%$ & $11 \%$ \\
\hline Conversar en línea o chatear & $50 \%$ & $58 \%$ & $43 \%$ & $37 \%$ & $7 \%$ & $5 \%$ \\
\hline $\begin{array}{l}\text { Copiar-pegar, compartir o reenviar mensajes } \\
\text { haciéndoles algún cambio }\end{array}$ & $28 \%$ & $24 \%$ & $61 \%$ & $60 \%$ & $11 \%$ & $16 \%$ \\
\hline $\begin{array}{l}\text { Firmar o suscribirse a páginas o mensajes } \\
\text { de otras personas }\end{array}$ & $20 \%$ & $19 \%$ & $56 \%$ & $58 \%$ & $24 \%$ & $23 \%$ \\
\hline $\begin{array}{l}\text { Generar mensajes para mis amigos } \\
\text { o círculos de conocidos }\end{array}$ & $36 \%$ & $35 \%$ & $50 \%$ & $54 \%$ & $14 \%$ & $11 \%$ \\
\hline $\begin{array}{l}\text { Planear y/o convocar eventos, fiestas } \\
\text { o movilizaciones diseñando una estrategia }\end{array}$ & $31 \%$ & $22 \%$ & $54 \%$ & $55 \%$ & $15 \%$ & $23 \%$ \\
\hline $\begin{array}{l}\text { Administrar, postear o difundir información, } \\
\text { mensajes o multimedia en alguna página o grupo }\end{array}$ & $26 \%$ & $22 \%$ & $55 \%$ & $58 \%$ & $19 \%$ & $20 \%$ \\
\hline $\begin{array}{l}\text { Participar en alguna wiki, foro } \\
\text { o espacio colaborativo }\end{array}$ & $13 \%$ & $4 \%$ & $54 \%$ & $60 \%$ & $33 \%$ & $36 \%$ \\
\hline
\end{tabular}

Fuente: Elaboración propia

El análisis de la interacción de acuerdo con el género (véase Tabla 5), permite observar que las diferencias en el nivel de habilidades entre hombres y mujeres, son reducidas, ya que ambos concentran los porcentajes en el punto medio de la escala. Por otra parte, en dos acciones son las mujeres quienes sobresalen en el nivel alto: dar like (42\% mujeres y hombres 34\%) y conversar o chatear en línea ( $58 \%$ mujeres y $50 \%$ hombres). Por su parte, 
son más los hombres que se consideran expertos en copiar, compartir o enviar mensajes con modificaciones 28\%, frente al 24\% de las mujeres; planear y convocar eventos (hombres 31\%, mujeres $22 \%$ ), así como administrar o postear información ( $26 \%$ hombres y $22 \%$ mujeres).

También en el caso de las y los jóvenes de la UAM-Lerma la actividad más popular, o sea la que realizan varias veces al día todas y todos, es el "conversar en línea y/o chatear" (48\%), seguida de "dar like o marcar como favoritos mensajes de texto" (32\%).

$\mathrm{Al}$ analizar por separado a mujeres y hombres (ver Tabla 6) se observa que las mujeres sobresalen en cuanto a las habilidades relativas a la comunicación y el compartir en línea: ellas, más que ellos, difunden información, dan likes, conversan en línea o chatean, reenvían mensajes o contenidos, firman o se suscriben a páginas, administran, postean y circulan información. La única actividad en la que los hombres destacan es en el planear o convocar a eventos, fiestas y movilizaciones a través de una estrategia. Es importante subrayar que las mujeres se ubican en el nivel alto, debido a que tienen porcentajes elevados en el dar like o marcar como favorito algún mensaje (43\%), así como conversar en línea o chatear (51\%).

\section{Tabla 6. Nivel de habilidad con la que realizan diversas acciones las y los jóvenes de la UAM-Lerma (\%)}

\begin{tabular}{|c|c|c|c|c|c|c|}
\hline \multirow{2}{*}{ Acciones } & \multicolumn{2}{|c|}{ Alto } & \multicolumn{2}{|c|}{ Medio } & \multicolumn{2}{|c|}{ Bajo } \\
\hline & $\mathrm{H}$ & M & $\mathrm{H}$ & M & $\mathrm{H}$ & M \\
\hline $\begin{array}{l}\text { Copiar, compartir o reenviar mensajes } \\
\text { que encuentran en la red sin modificar }\end{array}$ & $13 \%$ & $17 \%$ & $70 \%$ & $67 \%$ & $16 \%$ & $15 \%$ \\
\hline Dar like o marcar como favorito algún mensaje & $26 \%$ & $43 \%$ & $56 \%$ & $46 \%$ & $18 \%$ & $10 \%$ \\
\hline Conversar en línea o chatear & $30 \%$ & $51 \%$ & $65 \%$ & $45 \%$ & $5 \%$ & $4 \%$ \\
\hline $\begin{array}{l}\text { Copiar-pegar, compartir o reenviar mensajes } \\
\text { haciéndoles algún cambio }\end{array}$ & $16 \%$ & $24 \%$ & $72 \%$ & $61 \%$ & $12 \%$ & $15 \%$ \\
\hline $\begin{array}{l}\text { Firmar o suscribirse a páginas o mensajes } \\
\text { de otras personas }\end{array}$ & $11 \%$ & $18 \%$ & $54 \%$ & $53 \%$ & $34 \%$ & $28 \%$ \\
\hline $\begin{array}{l}\text { Generar mensajes para mis amigos } \\
\text { o círculos de conocidos }\end{array}$ & $15 \%$ & $31 \%$ & $68 \%$ & $54 \%$ & $17 \%$ & $15 \%$ \\
\hline $\begin{array}{l}\text { Planear y/o convocar eventos, fiestas } \\
\text { o movilizaciones diseñando una estrategia }\end{array}$ & $19 \%$ & $16 \%$ & $54 \%$ & $45 \%$ & $26 \%$ & $39 \%$ \\
\hline $\begin{array}{l}\text { Administrar, postear o difundir información, } \\
\text { mensajes o multimedia en alguna página o grupo }\end{array}$ & $12 \%$ & $16 \%$ & $69 \%$ & $53 \%$ & $19 \%$ & $31 \%$ \\
\hline $\begin{array}{l}\text { Participar en alguna wiki, foro } \\
\text { o espacio colaborativo }\end{array}$ & $11 \%$ & $4 \%$ & $46 \%$ & $40 \%$ & $43 \%$ & $56 \%$ \\
\hline
\end{tabular}

Fuente: Elaboración propia 
En suma, en cuanto a sus interacciones en línea, las principales actividades de los jóvenes, hombres y mujeres de las dos universidades, son "conversar en línea o chatear" y "dar like o marcar como favorito algún mensaje", aunque cabe decir que en estos rubros ellas se consideran más expertas que ellos en ambos contextos universitarios. Asimismo, en las dos universidades, tanto para los hombres como para las mujeres, los porcentajes más elevados en cuanto a su nivel en habilidades digitales está en un punto medio, lo que indica que, en general, no se consideran tan hábiles en el uso de tecnologías digitales, en su navegación en Internet y en su uso de las redes sociales digitales.

Al observar más de cerca los datos, se identifica que en la UV los hombres se perciben en un nivel más alto que las mujeres en las distintas habilidades digitales, aunque en la UAM-Lerma son ellas las que sobresalen en este sentido, siendo, como ya se dijo, la organización o planeación de eventos, fiestas o movilizaciones el rubro en el que los hombres tienen un porcentaje mayor. En cuanto a este último punto, en las dos universidades son los hombres los que mayormente organizan o planean eventos y movilizaciones a través de las redes sociales digitales. Esto sugiere que, en general, ellos suelen ser quienes ejecutan tareas que tienen que ver con el actuar, planear y organizar mientras que ellas suelen ser quienes realizan tareas relacionadas con la comunicación (expresar sentimientos, ser empáticas) y el compartir información.

\section{A manera de cierre}

En términos generales se puede afirmar que no existe una brecha de acceso a los dispositivos, a Internet y a las redes sociales digitales entre los hombres y las mujeres que participaron en este estudio, lo que les posibilita estar siempre conectados. Es probable que esto se deba a que se trata de estudiantes de nivel superior y de zonas urbanizadas o semi-urbanizadas donde el acceso y la conectividad es más común que en otras zonas, como las rurales o marginales.

Asimismo, una mirada preliminar indica que no existen diferencias radicales entre hombres y mujeres en el comportamiento, prácticas sociales, participación e interacción en el uso de las redes sociales digitales. Sin embargo, al observar con más detalle los datos, hay rubros en los que se puede ver que las diferencias de género derivadas del entorno social y cultural permean en cómo hombres y mujeres se aproximan de manera diferenciada a las tecnologías digitales. Por ejemplo, en ambas universidades los hombres acceden de manera más temprana a la tecnología que las mu- 
jeres, además de que se sienten más cómodos con el uso de la tecnología y con sus habilidades técnicas. Asimismo, ellos están más interesados en los temas políticos, de trabajo y empleo que ellas. Por otro lado, mientras las mujeres suelen dar más likes en Facebook, los hombres se concentran en la planeación y organización de eventos.

Según García, Gros y Escofet (2012), quienes efectúan un ejercicio similar al que realizamos en este texto pero con jóvenes españoles, indican que las estudiantes mujeres priorizan un uso más académico e informativo orientado hacia una pedagogía más participativa y comunicativa, mientras que los estudiantes varones continúan prefiriendo los usos más lúdicos de las tecnologías digitales. Sin embargo, las autoras señalan que ambos sexos muestran tendencias generales similares y que las mayores diferencias parecen estar más asociadas a otras variables, por ejemplo, el semestre que cursan o la licenciatura de origen.

Por su parte, Ponce de León y Castillo (2010), quienes trabajan con jóvenes estudiantes de la región de Biobío, Chile, indican que las jóvenes estudiantes presentan un nivel más alto de uso de tecnología en su labor académica en comparación con los hombres, además de que ellos suelen considerarse como más hábiles que ellas en este aspecto, aunque sus usos están más bien relacionados con el ocio y el entretenimiento y no tan especializados como podría suponerse. Sin embargo, según estas autoras, en las mujeres pesan aún los estereotipos y prejuicios que se han transmitido de generación en generación ya que ellas no consideran que el ámbito tecnológico les sea propio, sino más bien un dominio de los hombres.

Los resultados que presentamos y los que rescatamos previamente de estudios similares, nos permiten sugerir que mientras estas diferencias entre hombres y mujeres, por mínimas que sean, no se resuelvan en el ámbito social, en la familia, en los medios de comunicación, en la casa o en la escuela, difícilmente se resolverán en el ámbito digital y en las interacciones en línea. Una de las reflexiones a la que podemos llegar es que la importancia de identificar diferencias y similitudes entre mujeres y hombres en el acceso, uso y apropiación de las redes sociales digitales, desde una perspectiva de género, permite evidenciar que esta brecha no es del todo visible, debido a que no sólo se trata de contabilizar el acceso y frecuencia de uso, también tiene que ver con el sentido que le atribuyen a tal uso y al dominio significativo de las redes sociales digitales.

En la actualidad, cuando debido a su expansión las Tecnologías de la Información y Comunicación (TIC) son consideradas una de las columnas vertebrales de la sociedad (Castells, 1999), es importante indagar en 
el cómo las mujeres y los hombres se aproximan a ellas, con la finalidad de potenciar a las mujeres en cuanto al manejo teórico y práctico de esas tecnologías digitales y erradicar las desigualdades que aún se presentan, por mínimas que pudieran parecer.

Si bien en las poblaciones universitarias estudiadas se puede vislumbrar que tanto hombres como mujeres se asemejan en su comportamiento, prácticas sociales, participación e interacción en el uso de las redes sociales digitales, el reto siguiente es integrar e interpretar la situación contextual de las y los jóvenes universitarios, indagar en torno a las razones del uso, qué sentido configuran y analizar si las desigualdades en los entornos presenciales y la violencia de género permean en la apropiación de los espacios digitales. Es importante, asimismo, reflexionar sobre la denominada segunda brecha digital que refiere Castaño (2009), la cual hace alusión al uso especializado y a las distintas habilidades que se deben poseer para manejar adecuadamente estas tecnologías digitales en las distintas facetas de la vida (escuela, trabajo, vida cotidiana), ya que éstas van cambiando conforme se transforman los artefactos tecnológicos que se utilizan cotidianamente. En este sentido, sin duda, el tema de la alfabetización digital sigue siendo una tarea nodal en la actualidad, ya que la educación es la intervención política más importante para mejorar las habilidades digitales de niñas y mujeres.

Para finalizar, es menester señalar que este texto constituye un primer acercamiento a los datos recabados a través del cruce cuantitativo que realizamos para comparar a mujeres y hombres universitarios de dos instituciones con contextos diferenciados en su acceso, uso y apropiación de redes sociales digitales, que describe un panorama inicial. Sin embargo, consideramos que es necesario continuar profundizando en el tema, sobre todo desde perspectivas cualitativas, que ayuden a comprender cómo se está dando esta relación entre redes sociales digitales y estudiantes universitarios, para contar con diversos elementos que coadyuven a repensar el diseño de una propuesta de formación integral, desde una perspectiva de género. Ello permitiría ir abonando a la construcción de una educación con perspectiva de género, una cultura ciudadana y un sentido de responsabilidad social en el ámbito de la educación formal, no formal e informal, buscando favorecer la igualdad de derechos y oportunidades entre las y los estudiantes universitarios. 
Uso de redes sociales digitales entre estudiantes universitarios...

\section{Bibliografía}

Blázquez, N. (2010). Epistemología feminista: Temas centrales. En Blázquez, N., Flores, F. y Ríos, M. (eds.). Investigación feminista: epistemología, metodología y representaciones sociales (pp. 21-38). México: UNAM/Centro de Investigaciones Interdisciplinarias en Ciencias y Humanidades/Centro Regional de Investigaciones Multidisciplinarias/Facultad de Psicología.

Casillas, M. A. y Ramírez-Martinell, A. (2015). Génesis de las TIC en la Universidad Veracruzana: Ensayo de periodización. México: Productora de Contenidos Culturales Sagahón Repoll.

Castaño, C (2009). La segunda brecha digital y las mujeres jóvenes, Cuadernos del Mediterráneo, 11, pp. 218-224.

CastelLs, M. (1999). La era de la información. La sociedad red. Vol. 1. México: Siglo XXI.

Crovi, D. (2004). Sociedad de la información y el conocimiento: algunos deslindes imprescindibles. En Delia Crovi (Coord.), Sociedad de la información y el conocimiento: entre lo falaz y lo posible, pp. 17-56, Buenos Aires: La crujía.

Crovi, D. (2016). Redes sociales digitales. Lugar de encuentro, expresión y organización para los jóvenes. México: UNAM - La Biblioteca.

Domínguez F. y López, R. (2015). Jóvenes universitarios y uso de redes sociales en México. Líneas de investigación en la década 2004-2014. Revista de Comunicación, 14, 48-69.

Espinar, E. y González, M. (2009).Jóvenes en las redes sociales virtuales: un análisis exploratorio de las diferencias de género. Feminismo/s, 14, pp. 87-106.

García, I., Gros, B. y Escofet, A. (2012). La influencia del género en la cultura digital del estudiantado universitario. Athenea Digital, 12(3), pp. 95-114.

González-Palencia, R. y Jiménez, C. (2016). La brecha de género en la educación tecnológica. Ensaio: Avaliação e Políticas Públicas em Educação, 24(92), pp. 743-771.

López-Romo, H. (2009). Los niveles socioeconómicos y la distribución del gasto. Recuperado de http://www.amai.org/NSE/NivelSocioeconomicoAMAI.pdf/

Ortiz, G. (2012).L@s jóvenes y su relación con la red internet: de la adicción al consumo cultural, Razón y Palabra. Revista Electrónica en América 
Latina especializada en Comunicación, 78, pp. 1-15. Recuperado de http:// www.razonypalabra.org.mx/varia/N78/2a parte/27_Ortiz_V78.pdf

Ortiz, G. y López, R. (2013). Expresión, interacción y activismo social: hacia una construcción de escenarios digitales entre los jóvenes mexicanos. En L. Valdés y S. Morales (comps.), Industrias culturales, medios y públicos: de la recepción a la apropiación. Argentina: Universidad Nacional de Córdoba. Recuperado de http://www.publicacioncompanam2013. eci.unc. edu.ar/datos-de-publicacion/

Ponce, R. y Castillo, N. (2010). Una mirada de Género al uso de Tic en la Educación Superior. En J. Sánchez (ed.), Congreso Iberoamericano de Informática Educativa, pp. 763-770, Santiago de Chile.

Universidad Veracruzana (2016). Anuario. Dirección de Planeación institucional de la Universidad Veracruzana. Recuperado de https://www. uv.mx/informacion-estadistica/files/2014/01/Facultades_Institutos_ Centros_Laboratorios.pdf 



\title{
El nivel socioeconómico y el dominio del idioma inglés, elementos de acceso y ampliación de la brecha en la cultura digital
}

\author{
Ma. Guadalupe González Lizárraga ${ }^{1}$ \\ Esther Hugues Santa Cruz ${ }^{2}$ \\ María Teresa Becerra Traver ${ }^{3}$
}

La cultura digital en la actualidad se ha convertido en un tema extensamente debatido en todas las esferas sociales. La forma en que está impactando en los jóvenes que integran nuestras comunidades universitarias, es una cuestión que nos compete al formar parte de estas instituciones. Varios son los aspectos que pueden ser analizados en torno a la influencia que tiene esta cultura en los estudiantes, desde el tipo de recursos tecnológicos que poseen, hasta la manera de cómo, cuándo y para qué los usan.

Con el fin de aportar al debate acerca de este tema, el presente trabajo analiza el nivel socioeconómico y el manejo del idioma inglés entre estudiantes de la Universidad de Sonora, dos elementos que marcan la desigualdad o brecha en las poblaciones de jóvenes universitarios, entre aquellos que cuentan con mayores oportunidades y condiciones de vida, en contraste con quienes no las poseen. El conocimiento de estos elementos puede constituirse en un área de oportunidad para que las instituciones de educación superior impulsen acciones al interior de los programas educativos e intenten reducir estas diferencias entre los estudiantes que acuden a sus aulas.

El diseño del trabajo se centra en la medición de tres variables, una dependiente, la Cultura Digital (CD), y dos independientes, el nivel socioeconómico de las familias de los estudiantes, y el conocimiento o manejo del idioma Inglés como Lengua Extranjera.

Para comprender el problema de investigación, es importante ubicar al lector en el contexto de la muestra poblacional objeto de análisis, esto es, los estudiantes que se forman en la Universidad de Sonora (UNISON),

1 Dra. en Filosofía por la Universidad de Montreal, profesora de la Universidad de Sonora en el programa de Maestría en Innovación Educativa.

2 Estudiante de Doctorado en Humanidades en la Universidad de Sonora, y profesora del Departamento de Lenguas Extranjeras.

3 Dra. en Educación y profesora en el Departamento de Educación de la Universidad de Extremadura. 
la institución de educación superior de mayor importancia y antigüedad en el estado de Sonora, que concentra el mayor porcentaje de la matrícula universitaria en la región (ANUIES, 2013-2014). Se distingue, además, por su amplia y variada oferta educativa a nivel de licenciatura y posgrado. En el Plan de Desarrollo Institucional (PDI, 2013-2017) se reporta 40,955 estudiantes inscritos, de los cuales 29,311 se ubican en 77 programas de pregrado, 832 en 49 programas de posgrado, 717 en talleres de arte y 10,095 en cursos de idiomas. Esta institución ha invertido durante la última década, una buena parte de sus recursos para ofrecer a sus estudiantes instalaciones equipadas con tecnologías digitales en laboratorios de cómputo (Universidad de Sonora 2013).

El Estado de Sonora se sitúa al norte de la República Mexicana, y cuenta con una extensa región fronteriza con los Estados Unidos ${ }^{4}$. Históricamente ha sido reconocido a nivel nacional como uno de los de mayor aportación al Producto Interno Bruto (PIB) debido a la importante actividad económica que genera. De acuerdo con un estudio reportado por el Gobierno de la República Mexicana y el Consejo Nacional de Ciencia y Tecnología (CONACYT, 2013), la entidad se ubica en la sexta posición de los 32 estados respecto al avance en Ciencia, Tecnología e Innovación. Asimismo, de acuerdo con datos del Sistema Electrónico de las Regiones Socioeconómicas de México del Instituto Nacional de Estadística, Geografía e Informática (INEGI, 2015) se puede observar que Sonora está clasificada dentro de las regiones de mayor nivel de bienestar en el país en donde los ingresos per cápita juegan un papel fundamental.

A partir de este contexto geográfico regional, sostenemos la hipótesis de que estos jóvenes se encuentran bajo tres condiciones que los colocan en una posición de relativa ventaja respecto al acceso a la cultura digital. Estas condiciones son la posibilidad de adquirir dispositivos tecnológicos de manera rápida y de bajo costo, conforme van apareciendo y circulan al otro lado de la frontera por su cercanía con la misma. Al mismo tiempo, cuentan con un nivel socio-económico mayor al promedio reportado para el resto de la República Mexicana (INEGI, 2015), elemento que facilita la inversión de mayores recursos para contar con estos bienes. De igual forma, esta cercanía geográfica les permite una mayor disposición al manejo del idioma inglés.

$4 \quad$ Algunos de estos datos ya fueron descritos en el capítulo "Una aproximación a diversos elementos de la cultura digital en estudiantes: caso Universidad de Sonora" del libro Redes sociales digitales. Lugar de encuentro, expresión y organización para los jóvenes (Crovi, 2016). México: UNAM-La Biblioteca. Sin embargo, consideramos oportuno repetirlos para una mejor comprensión del contexto. 
Como un primer acercamiento a esta población universitaria, y con la finalidad de argumentar la hipótesis planteada, se presenta un estudio previo en relación con el acceso que los estudiantes tienen a las tecnologías digitales (también conocidas como TIC). Moreno (2011) realizó un estudio con una muestra de estudiantes de entre tercero y quinto semestre, para el campus Hermosillo. Entre los principales resultados reportados se encuentran los siguientes: el 90\% de los estudiantes declaró poseer computadora personal; de estos equipos, el 60\% es de tipo Laptop; el 70\% tienen acceso a Internet desde su casa. Por otra parte, otro dato relevante es que el $22 \%$ se conecta en la escuela (UNISON); el $4.5 \%$ emplea una conexión a Internet desde su trabajo; y el 3.5\% se conecta desde un café-Internet. En el mismo estudio se destaca, con relación al uso de las TIC como promotoras del aprendizaje, que el $80 \%$ de los estudiantes considera que el uso de éstas los motiva, y que tanto la computadora como el Internet son importantes en sus estudios, apreciando que estas herramientas fortalecen su capacidad de investigación y permiten desarrollar trabajo colaborativo. A nivel de manejo de las TIC en las tareas escolares, el 4.5\% de los encuestados declaró dominar un conocimiento estratégico de ellas, el 39\% se ubicó en dominio moderado y el 56\% restante respondió no tener conocimiento sobre combinar dos o más tecnologías para resolver algún problema académico en específico.

En el mismo sentido, de manera reciente (2014-2016) se desarrolló un estudio como parte del proyecto "Jóvenes y cultura digital. Nuevos escenarios de interacción social” (Crovi, 2016), que abordó la cercanía de esta población universitaria con la cultura digital. Los resultados obtenidos indican que los jóvenes de la UNISON se identifican con ella, ya que incorporan el uso de los recursos tecnológicos a su vida académica y de entretenimiento porque es práctico, inmediato y agradable interactuar con el mundo a través de estas herramientas. A partir de la versatilidad que conjugan, en un primer momento el color, el sonido, el movimiento y paulatinamente el acceso a la recreación, información y formación por medio de la interacción con los medios, completando el proceso de socialización con los otros, bajo el uso de estas herramientas (González-Lizárraga, en Crovi 2016).

Los jóvenes realizan constantemente prácticas que los acercan a la cultura digital, como son compartir elementos de socialización y comunicarse con otros. Estas actividades se reflejan en los principales resultados y se entienden principalmente porque tienen acceso a Internet desde diferentes dispositivos, cuando navegan lo hacen desde sus propios recursos electrónicos, realizan varias actividades al navegar (escolares, consultar temas 
de interés y de entretenimiento), tienen habilidades para resolver problemas técnicos o de conexión y consideran que Internet es un espacio para expresarse. Sin embargo, los jóvenes en este estudio interactúan con pocas personas, y aunque les agrada hacerlo, sólo se comunican cuando hay razones importantes, es decir cuando tienen una intención clara (Crovi, 2016).

De manera adicional se observa en la muestra que compone el estudio que referimos, que un porcentaje considerable posee un nivel socioeconómico alto, y un buen manejo del idioma inglés (González-Lizárraga, en Crovi, 2016). Al respecto, Pearce y Rice (2014) afirman que la competencia en el inglés es una influencia fuerte en la adopción y uso de tecnología, y esto a su vez resalta una gran brecha entre las comunidades de élite y las que no lo son.

Al tomar como base estos elementos, se plantea que los estudiantes de la UNISON presentaron una mayor identificación con la cultura digital. Los datos obtenidos en esta población indicaron que el nivel socioeconómico y el dominio del inglés podían constituir variables diferenciadoras, y tales elementos son los que generaron las presentes reflexiones.

\section{Cultura digital, una aproximación conceptual}

Los recursos tecnológicos o TIC han sido diversificados y su uso generalizado en las prácticas de la vida cotidiana ha generado una cibercultura o cultura digital. Estudiar esta cultura entre los jóvenes, marca sin lugar a dudas el avance tecnológico y las formas de expresión de la población en general y particularmente en la población que se desenvuelve diariamente en las aulas universitarias.

Para la definición del concepto se consideraron tres autores que han estudiado de distinta manera la cultura digital. En primer lugar Lèvy (2007) menciona que la cultura digital es el conjunto de redes o sistemas culturales que han surgido y que han sido configurados por el impacto de los recursos digitales en la sociedad (Facebook, Twitter, wikis, páginas web, blogs, correo electrónico, mensajes de texto, llamadas, etcétera). Sin embargo, el autor señala que a esta cultura la constituyen otros aspectos aparte de los sistemas computacionales o digitales, tales como las prácticas de los usuarios, entornos y medios culturales simbólicos, los cuales están directamente relacionados con la información, la comunicación, el conocimiento o la educación.

Marcelo Urresti (2008) señala que la cibercultura (término que utiliza para referirse a la cultura digital), se dirige directamente a los jóvenes, ya 
que con el constante uso de los recursos matizan las prácticas que realizan en la vida cotidiana, y señala que esta circunstancia ha sucedido de manera muy rápida si se piensa en la historia de la humanidad. El autor sostiene que "en términos de evolución histórica, las generaciones jóvenes son las primeras que adoptan las innovaciones tecnológicas vinculadas con la informática y las nuevas comunicaciones, funcionando simultáneamente como pioneros y difusores" (p. 15). Además, considera que en esta nueva condición existen cinco elementos que definen un nuevo sistema cultural juvenil: el de los objetos, los géneros confusos de la comunicación, el paradigma del prosumidor (fusión de productor y consumidor), las transformaciones de la intimidad y por último las nuevas formas de comunidad.

Una tercera aportación es la de Bringué y Sádaba (2009), quienes explican que son los niños y los jóvenes los que mejor se han adaptado a las nuevas formas de comunicación a través de los recursos digitales en la vida cotidiana y que poseen rasgos de uso constante de contenidos y servicios, caracterizados por la comunicación social, la experiencia lúdica, y el multiacceso y la multitarea. Sostienen también que es importante ampliar el concepto, para lo cual se tendrían que considerar algunos elementos recurrentes en los jóvenes con altos índices en el uso de recursos digitales que les proporcionan habilidades variadas. Debido a su experiencia desde corta edad, poseen habilidades para integrar estos recursos a la vida cotidiana, son multitarea (cuentan con la capacidad de realizar varias actividades mientras navegan en Internet), también se caracterizan por el acceso a múltiples pantallas (computadora, teléfono celular, tabletas, etc.), desarrollan prácticas desde un dispositivo personal y navegan de forma individual.

\section{Una relación entre el nivel socioeconómico y la cultura digital}

Como se ha mencionado, el factor económico es un elemento que condiciona el acceso a la cultura digital entre los jóvenes. En países como México, en el que acceso está limitado a un sector reducido de la población, se reproduce desigualdad.

Diversos autores (Reguillo, 2000; Crovi, 2002; Pérez, 2006; Galván, 2014), señalan que el nivel socioeconómico guarda una relación directa con el acceso y el uso de los recursos digitales. Según la Asociación Mexicana de Internet (AMIPCI, 2015), un porcentaje importante de los usuarios de Internet corresponde a los niveles socioeconómicos altos, ya que el conjunto de esos estratos sociales representan el 93\% de usuarios de Internet y como podría esperarse, un menor porcentaje de usuarios corresponde al nivel bajo (7\%). 
Autores como Crovi (2009); Carvalho, Bessa, Oliviera, Guedes, Peres y Magalhães (2012), así como Galván (2014), han señalado que esta diferenciación en la población acerca del acceso y uso de recursos digitales se ubica entre las razones que originan la brecha digital. A pesar de que el uso de estos recursos se ha incrementado y se utiliza para distintas prácticas cotidianas, en México la población presenta importantes diferencias en lo económico, y su actuación en la llamada sociedad de la información es desigual. Por lo anterior, el uso de los recursos digitales no se ha generalizado a todos los ámbitos sociales y presenta inequidades.

Urresti (2008) señala que el acceso actualmente es generalizado aunque lento en los sectores de ingresos reducidos, por ejemplo, en comunidades alejadas a las ciudades o lugares menos poblados quedan excluidos. Sin embargo, el autor menciona que jóvenes de distintas clases sociales acceden a la tecnología, aunque existen diferencias en el tipo de acceso, los recursos tecnológicos y cognitivos que poseen, además de las formas de comunicación y navegación que desarrollan. Definitivamente el manejo y uso que hacen de las TIC es lo que hace la diferencia, ya que dependen de las condiciones económicas y características de la vida diaria, propias de cada segmento socioeconómico al que pertenecen los jóvenes, por lo que también el desarrollo de habilidades es diferenciado.

Crovi (2010) sostiene que la razón para que los individuos permanezcan en línea no siempre es la posibilidad económica para hacerlo: algunos que cuentan con esas posibilidades optan por estar al margen del uso de las tecnologías, tomando una decisión personal y a pesar de la presión del medio social. También es posible afirmar que debido a que no cuentan con los recursos ni la infraestructura para estar conectados, algunos jóvenes no utilizan esos, recursos quedando excluidos de las modas y demandas sociales de su propia generación. Esta autora afirma asimismo, que algunos de los que tienen acceso a los dispositivos, desarrollan habilidades en el uso pero carecen de las habilidades cognitivas necesarias para jerarquizar o discriminar la información que reciben o para interpretarla, por lo que se les dificulta aplicarla a las actividades de sus vidas cotidianas.

Romo y Tarango (2015) llevaron a cabo un estudio en cuatro instituciones de educación superior (tres públicas y una privada, todas ubicadas en la ciudad de Chihuahua, México), en 18 programas educativos de nivel licenciatura. La muestra de este estudio fue sobre 524 estudiantes (empleando un nivel de confianza de $95 \%$ y un margen de error de $5 \%)$. Los autores concluyeron que resolver el acceso y uso de las TIC en las comunidades universitarias es el punto de partida para reducir de raíz las brechas digitales, e incluso orientar la cibercultura hacia la apropiación y 
estadios superiores. Estos autores advierten que en cuanto a los factores sociodemográficos, el género del estudiante no muestra relación con su nivel cibercultural; la edad presenta una ligera relación con este nivel y se identificaron menores niveles de cibercultura conforme aumenta la edad. En cuanto al estado civil, el casado se asocia al más bajo nivel; la condición laboral no influye, mientras que tanto los estudiantes que trabajan como los que sólo estudian tienen el mismo nivel de cibercultura. Estos autores afirman que existen mayores niveles de apropiación en las casas de los estudiantes cuando hay un número más alto de computadoras y cuando el estudiante pasa más horas conectado a Internet.

\section{Una relación entre el idioma inglés y la cultura digital}

El inglés también puede ser indicador de una brecha digital y cognitiva, ya que el grado de conocimiento del idioma influye en la integración a las prácticas ligadas con los recursos digitales, así como en la especialización en los recursos y acceso al conocimiento albergado en Internet (Hugues, 2015; Fonseca, 2010).

$\mathrm{E}$ l inglés es el idioma preponderante en la red, y es en esta lengua que se encuentran los lugares más novedosos, más actualizados e interesantes desde un punto de vista científico (Cabero, 2004). Aunque investigaciones más recientes pueden indicar otras tendencias, un estudio de 2001 de la empresa Global Reach indica que el $45 \%$ del contenido que se encuentra en Internet está en inglés, un $9.8 \%$ en japonés y un $8.4 \%$ en chino, en tanto que el contenido en español es de un 5.4\% (citado en Serrano y Martínez, 2003). Esto conlleva la necesidad de trabajar desde las instituciones (colegios, universidades) para que el idioma no sea una barrera de acceso a la información y a su vez a la cultura. Por el contrario, se espera que el idioma sirva como una herramienta en la educación integral y como enlace al conocimiento y comunicación global.

En ese contexto, por ser el inglés el idioma que destaca en las redes, se ha convertido en elemento constitutivo de la brecha digital y cognitiva. El papel que juega el inglés tiene una influencia directa en el uso de ciertas plataformas, ya que el tipo de información y habilidades que el sujeto desarrolla son diferentes a las de los individuos que no manejan ese idioma. De alguna forma, contar con cierto conocimiento o habilidad en el idioma, permite acceder a mayor cantidad de información, debido a que gran parte del contenido en los sitios web está en esa lengua (W3TECHS, 2014). 
Aunque en la actualidad se puede ver un esfuerzo en los administradores de las páginas web para proporcionar opciones de traducción en sus contenidos, existen pocos estudios que analizan esta influencia, lo cual podría determinar que los jóvenes mantengan prácticas diferenciadas dependiendo del manejo del inglés.

Existen distintas posturas con relación a la relevancia del inglés en la cultura digital, las cuales debaten acerca de su influencia en el acceso a los recursos, a la información y habilidades que podrían proporcionar. Crovi (2002) señala que la competencia en el idioma inglés no es suficiente para interactuar adecuadamente con las máquinas, y argumenta que se necesitan también otras habilidades que lo complementen. No obstante, esta autora coincide con Albatch, Reisberg y Rumbley (2009) en que un manejo limitado del inglés podría resultar insuficiente para interactuar con la tecnología y el software ya que sus instrucciones están en esa lengua, quitando a los usuarios su capacidad de innovar o crear y convirtiéndolos en simples repetidores de lecciones o enseñanzas previas.

Armendáriz y Ruiz (2005) afirman que es una necesidad incluir programas de alfabetización informática en la educación superior, y que se tendría que impulsar el desarrollo de habilidades en el idioma inglés para hacer uso efectivo del material disponible a través de los recursos digitales. Expresan que se requieren profesionales preparados con conocimientos de otros idiomas y habilidades informáticas, con el fin de potenciar el uso de las redes sociales digitales.

Uzelac y Cvjetičanin (2008) sostienen que las limitaciones en cuanto al acceso a los recursos tecnológicos están relacionadas directamente con la segmentación de la sociedad junto con las brechas de edad, contextos urbano o rural, nivel socioeconómico, entre otras. Además, expresan que el conocimiento necesario para aprovechar el potencial de la tecnología requiere del inglés, si se quiere tomar parte de los potenciales de Internet, específicamente para alcanzar las posibilidades de comunicación global y consultar fuentes en ese idioma.

De acuerdo con Albatch et al (2009), el idioma inglés cumple una función importante como herramienta de acceso a la información, ya que se le considera una consecuencia de la mundialización, la cual es una realidad en este siglo y ha influido en la educación superior. El aprendizaje de este idioma y de habilidades informáticas (o digitales), actualmente es una realidad en la educación superior en México. No obstante, a partir de las transformaciones en la vida cotidiana con el uso de los recursos digitales, 
se considera necesario explorar el idioma como otra variable que influye en la brecha digital.

\section{Nota metodológica: población, materiales y métodos}

Para el estudio llevado a cabo en la UNISON, el manejo del idioma inglés interesó específicamente por las diferencias que se pudieran dar en las habilidades de comunicación y acceso a la información, es decir, como una forma de medir la llamada brecha digital.

La muestra con la que se trabajó fue una población de estudiantes inscritos en los cursos generales de inglés del Departamento de Lenguas Extranjeras y los diversos programas de licenciatura de la UNISON. Se eligió esta área debido a que se encontraría una mayor diversidad en las formaciones profesionales que cursan los estudiantes y los diferentes semestres de inscripción. Para ello se calculó una muestra considerando la matrícula de 4,912 estudiantes registrados en estos cursos generales. Se solicitó autorización a las autoridades del Departamento, que facilitó una sala de cómputo para invitar a los estudiantes a responder el cuestionario. Debido al interés y apoyo recibido por esta comunidad académica la respuesta de los estudiantes fue inmediata, obteniendo 713 cuestionarios seleccionados por conveniencia. Esta muestra cuenta con un nivel de confianza mayor al 95\% debido que superó la muestra calculada inicialmente de 350 estudiantes bajo un error del $5 \%$.

Los estudiantes que respondieron el cuestionario, según el área académica de la cual provienen, se distribuyen de la siguiente manera.

Tabla 1. Porcentaje de estudiantes que respondieron el cuestionario según el área académica de inscripción

\begin{tabular}{|c|c|}
\hline División/Área & Porcentaje de participantes \\
\hline Ingeniería & $30,4 \%$ \\
\hline Ciencias Sociales & $18 \%$ \\
\hline Ciencias Biológicas y de la Salud & $15 \%$ \\
\hline Económico-administrativas & $14,3 \%$ \\
\hline Humanidades y Bellas Artes & $14,3 \%$ \\
\hline Ciencias Exactas & $8 \%$ \\
\hline
\end{tabular}

Fuente: elaboración propia 
Las características sociodemográficas de los jóvenes que participaron en esta muestra de estudio son las siguientes: el rango de edad oscila entre los 17 y los 30 años. La edad promedio se coloca en los 20 años (DT=2.3). Del total de estos estudiantes, $51 \%$ son mujeres y $49 \%$ son hombres, porcentaje similar presente en la población total de la UNISON (SIE, 2017). Dedicarse de forma exclusiva a los estudios indica, de manera directa, la oportunidad de contar con un soporte económico familiar que permita prolongar la entrada al mercado de trabajo. De esta manera, se observa que el 69\% de la muestra tiene esa condición, mientras que el resto (31\%) comparte sus estudios con una actividad laboral.

El cuestionario que se aplicó a esta muestra es el utilizado en el proyecto "Jóvenes y cultura digital. Nuevos escenarios de interacción social" (Crovi, 2016), el cual fue adaptado a una versión electrónica en la que se utilizó la plataforma Survey Monkey y se incorporó una sección relativa al dominio del idioma inglés.

Para las variables estudiadas se presentan estadísticos descriptivos, asimismo se elaboraron índices para la cultura digital, el nivel socioeconómico y el dominio del idioma inglés (Hugues, 2015). Posteriormente, se realizaron comparaciones a través de análisis de varianza de un factor (ANOVA), con el fin de observar diferencias significativas entre las variables independientes y la variable dependiente.

\section{Resultados}

Los resultados que se presentan en este capítulo se han organizado en cuatro segmentos: 1) la identificación de la muestra con la cultura digital; 2) los niveles socioeconómicos de pertenencia de la muestra de estudio; 3) la proximidad a la cultura digital de acuerdo con el nivel socioeconómico y 4) la proximidad a esta cultura según el manejo del idioma inglés. Nos referiremos enseguida a cada uno de estos segmentos.

\section{Identificación con la cultura digital}

Para evaluar el nivel de identificación con la cultura digital, se describieron situaciones y actividades que llevaron a decidir a los estudiantes entre un mayor o menor acuerdo. Para analizar esta sección se consideró el porcentaje acumulado que corresponde a las opciones de respuesta completamente de acuerdo y de acuerdo, con el fin de identificar las prácticas que definen la cultura digital de los participantes. De esta manera se observó que un número importante de jóvenes, el 61.2\%, son usuarios de Internet desde cor- 
ta edad; $78.6 \%$ se consideraron capaces de realizar diversas tareas mientras navegan por Internet; $89.2 \%$ tienen acceso a Internet desde diferentes dispositivos y $92.5 \%$ navegan de forma individual.

Bajo la misma lógica de porcentaje acumulado de respuestas afirmativas (de completamente de acuerdo y de acuerdo), se colocan con porcentajes menores las prácticas relacionadas con las habilidades digitales y técnicas para resolver problemas de conexión (51.9\%); así como la creencia de que Internet es un nuevo espacio de expresión y defensa de temas sociales $(57.2 \%)$.

La dependencia digital es una percepción más orientada a las opciones de respuesta relacionadas con el desacuerdo o el completamente en desacuerdo, $42 \%$ se ubica en estas opciones de respuesta. Lo mismo se observa para el grado de integración de las plataformas digitales y las redes sociales a la vida cotidiana, en las que se coloca el $44.3 \%$.

A partir de las respuestas de esta sección se conformaron tres grupos: en el primero se ubicó a los estudiantes que tienen una mayor identificación con la cultura digital, esto es, que sus respuestas se colocaron en las opciones de acuerdo y completamente de acuerdo, resultando el grupo más numeroso de estudiantes en esta categoría (84\%); en el segundo grupo quedaron quienes están indecisos, lo que significa que eligieron la opción de respuesta ni de acuerdo ni en desacuerdo, (7\%); y en el tercer grupo se colocaron a quienes no se identifican con la cultura digital o eligieron las opciones de respuesta ubicadas en el desacuerdo o el completamente en desacuerdo (9\%). Como se puede observar, el mayor porcentaje de respuestas se concentra de manera determinante con la identificación de la cultura digital. Sin embargo, el segundo lugar le corresponde a quienes no sienten una identificación con este tipo de cultura. El porcentaje de estudiantes indecisos es el más bajo.

\section{Niveles socioeconómicos en la muestra estudiada}

El nivel socioeconómico proporciona una visión general sobre las condiciones familiares e individuales sobre las que descansa la formación universitaria en esta muestra, de tal manera que está representada por los bienes y servicios que poseen las familias de los estudiantes, así como la escolaridad y empleo del jefe de familia. De acuerdo con la clasificación utilizada por López-Romo (2009) para la población mexicana estos niveles se ubican en seis categorías, correspondiendo al nivel más alto a $\mathrm{AB}$, y al más bajo a la $\mathrm{E}$ (clasificación retomada y detallada en el estudio de Crovi, 2016). 


\section{Figura 1. Distribución de los estudiantes de acuerdo con el nivel socioeconómico}

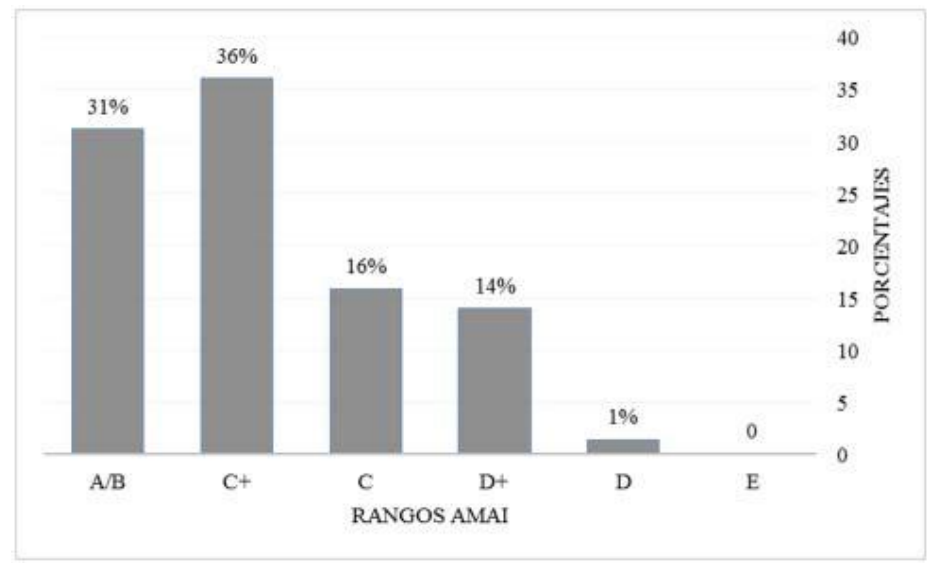

Fuente: elaboración propia

Como se observa en la Figura 1, y de acuerdo a los indicadores utilizados, es posible observar un grupo mayoritario de estudiantes que gozan de muy buenas condiciones familiares, propicias para realizar sus estudios, sin que la alimentación ni el transporte sea una preocupación para ellos, asimismo cuentan con bienes tecnológicos para el entretenimiento y la escuela, por lo que pudiéramos decir que sus familias pertenecen al grupo que tiene los mejores niveles de vida en el estado. Al extremo opuesto de la gráfica, en los segmentos correspondiente a la población más pobre ninguno de los estudiantes se coloca ahí, mientras que en el segmento $\mathrm{D}$, que indica un nivel de pobreza sólo se coloca $1 \%$ de la muestra. Esto nos permite observar que esta población universitaria está integrada por jóvenes de clase media y alta, y que de los niveles económicos más bajos no están ingresando, o ya se salieron de la institución.

\section{Proximidad a la cultura digital de acuerdo con el nivel socioeconómico}

Para identificar el posible efecto diferenciador entre las prácticas relacionadas con la cultura digital en función del nivel socioeconómico de los participantes, se generó una variable sintética que está representada por el cociente de la suma de las preguntas sobre cultura digital entre el total de preguntas.

A través del análisis de varianza de un factor (ANOVA), se observaron diferencias significativas en las prácticas que definen la cultura digital 
en función del nivel socioeconómico ( $\mathrm{F}=12,630 ; \mathrm{gl}=4 ; \mathrm{p}<0,05)$. Como se observa en la Tabla 2, el promedio de la variable que representan las prácticas relacionadas con la cultura digital disminuye gradualmente en la medida que disminuye también el nivel socioeconómico.

\section{Tabla 2. Estadísticos descriptivos de cultura digital por nivel socioeconómico}

\begin{tabular}{|c|c|c|c|}
\cline { 2 - 4 } \multicolumn{1}{c|}{} & $N$ & Media & DT \\
\hline AB = Alto & 215 & 3,75 & 0,461 \\
\hline C+ = Medio alto & 250 & 3,67 & 0,525 \\
\hline C = Medio & 112 & 3,49 & 0,548 \\
\hline D+ = Medio bajo & 99 & 3,40 & 0,514 \\
\hline D = Bajo & 10 & 3,16 & 0,553 \\
\hline Total & 686 & 3,62 & 0,525 \\
\hline
\end{tabular}

Fuente: elaboración propia

Este resultado indica que el nivel socioeconómico de pertenencia no sólo determina el acceso a bienes tecnológicos (Internet y dispositivos), además juega un papel fundamental en la medida que se asocia al aumento o disminución de las prácticas relacionadas a la cultura digital de los estudiantes. Conforme este nivel aumente o disminuya, se constituye en una brecha entre los estudiantes que se colocan en los segmentos socioeconómicos más desprotegidos, en contraste contra quienes cuentan con mayores niveles de ingresos.

\section{Proximidad con la cultura digital según el manejo del idioma inglés}

Con el fin de analizar el efecto del manejo del idioma inglés en la muestra se construyeron tres niveles de dominio de la lengua. El mayor porcentaje se ubica en un nivel de inglés básico, esto es el 38\%; en segundo lugar se coloca en el nivel de inglés intermedio el 34\%; y por último están aquellos ubicados en el nivel avanzado, el 28\%. Estos datos indican que aun cuando la distribución entre estos tres grupos es relativamente homogénea, el manejo del idioma inglés de la muestra se encuentra en mayor porcentaje en las áreas de inglés básico e intermedio, lo que sumado representa $72 \%$.

$\mathrm{Al}$ analizar la influencia de esta variable con la cultura digital, utilizando un análisis de varianza de un factor (ANOVA), se observan diferencias significativas $(\mathrm{F}=8,879 ; \mathrm{gl}=2 ; \mathrm{p}<0,05)$. Es decir, que el manejo del idioma inglés sí influye en la cultura digital. Como se puede observar en la Tabla 3, las medias de los niveles de cultura digital disminuyen a medi- 
da que disminuye el manejo del idioma inglés. Es decir que entre mayor manejo del idioma inglés, mayor será la identificación a la cultura digital.

\section{Tabla 3. Manejo del idioma inglés en la cultura digital}

\begin{tabular}{|c|c|c|c|}
\cline { 2 - 4 } \multicolumn{1}{c|}{} & $\mathrm{N}$ & Media & DT \\
\hline Avanzado (70-100\%) & 198 & 3.73 & .521 \\
\hline Intermedio (40-60\%) & 237 & 3.61 & .503 \\
\hline Básico (0-30\%) & 261 & 3.53 & .542 \\
\hline Valores perdidos & 17 & & \\
\hline Total & 713 & 3.61 & .529 \\
\hline
\end{tabular}

Fuente: elaboración propia

En ese sentido y según los resultados obtenidos en este estudio, el manejo del idioma es un elemento importante, ya que se confirma lo que Pearce y Rice (2014) señalaban acerca de que en la adopción o integración de la utilización de recursos tecnológicos a la vida cotidiana, es posible identificar que el idioma favorece la integración a la cultura digital. De manera que se puede observar que en la muestra del presente estudio, entre más competencia en el idioma, más se identifican con ese tipo de cultura.

\section{Discusión y conclusiones}

Los resultados encontrados permiten hacer algunas afirmaciones específicas acerca de este estudio. En términos generales, se puede decir que los estudiantes participantes se encuentran en un contexto que les provee de ciertos elementos para acceder a facilitadores de la cultura digital. La posición geográfica del estado y el nivel socioeconómico al que pertenecen, son un ejemplo de ventaja aparente, aunado a algunas otras variables que han sido analizadas y apoyan esta afirmación tomando matices diversos.

Nuestras conclusiones corroboran los resultados obtenidos por Torres-Díaz e Infante (2011), quienes afirman que el nivel de ingresos de la familia del estudiante influye en los usos e intensidad de uso de las herramientas de Internet, lo que les hace suponer que el aspecto socioeconómico se vincula de manera directa con el aumento de la brecha digital entre los jóvenes universitarios.

Se puede afirmar también que los estudiantes participantes se han apropiado de la cultura digital toda vez que han accedido desde la infancia a varios dispositivos electrónicos desde su casa. Sin embargo, la dependencia digital (como no sentirse ansiosos si pierden el celular, o negar que 
pueden vivir sin las plataformas o redes sociales) indican que no es un rasgo precisamente acentuado.

Los jóvenes que participaron presentan las características a las cuales Bringué y Sádaba (2009) hacen referencia, ya que se encuentran inmersos en esta cultura: la mayoría está de acuerdo en que realizan varias tareas al tiempo que navegan en Internet (tareas escolares, búsqueda de información, conversar, dar like, etc.), tienen habilidades para resolver problemas técnicos de conexión e incluso consideran que los recursos digitales son un espacio para expresarse. Esta tendencia en las prácticas de los jóvenes, consideradas típicas de las nuevas generaciones, como lo es el mantenimiento de una cercanía con los recursos tecnológicos en su vida cotidiana, es lo que confirma una apropiación cada vez mayor de la cultura digital en estas generaciones (Lèvy, 2007; García-Canclini, 2012; López, 2012; Crovi 2013). Estos hallazgos concuerdan también con los resultados encontrados por Romo y Tarango (2015), quienes afirman que también existen mayores niveles de cibercultura cuando en las casas de los estudiantes hay un número más alto de computadoras y cuando el estudiante pasa más horas conectado a Internet.

La identificación que se presenta respecto a la cultura digital, se puede afirmar que aun cuando es muy alta, existe un porcentaje nada despreciable (16\%) que no se refleja con este tipo de cultura, lo que abre una posibilidad de indagación puntual al respecto. La importancia de profundizar en los motivos que colocan a los estudiantes en la postura de no identificación con la cultura digital podría permitir reflexionar sobre su postura hacia una cultura predominante, no porque busquemos uniformidad en las respuestas de los estudiantes, sino porque es precisamente la diferencia lo que da mayor posibilidad de conocimiento.

Los resultados obtenidos de las variables diferenciadoras a partir de las pruebas realizadas, apoyan la hipótesis de que a mayor nivel socioeconómico y mayor competencia en el idioma inglés, los estudiantes tendrán una mayor identificación con la cultura digital. Por lo que es posible afirmar que, en tanto los jóvenes tengan más acceso a las tecnologías digitales y un nivel mayor de formación en el idioma inglés, más alta será la posibilidad de reducir diferencias entre ellos. En suma, estas variables pueden marcar vías de evaluación y de las diferencias que existen en términos de acceso a la digitalización entre estas poblaciones universitarias. 
El nivel socioeconómico y el dominio del idioma inglés...

\section{Bibliografía}

Altbach P. G., Reisberg L. y Rumbley L. E. (2009). Tras la pista de una revolución académica: Informe sobre las tendencias actuales. Resumen ejecutivo. Paris: UNESCO. Recuperado de https://goo.gl/DLi18L

ANUIES (2013-2014). Anuarios estadísticos de Educación Superior. Recuperado de https://goo.gl/OWTVDH

Armendáriz. A. y Ruiz, C. (2005). El aprendizaje de lenguas extranjeras y las tecnologias de la información: Aprendizaje de próxima generación. Buenos Aires, Argentina: Lugar Editorial.

Asociación Mexicana de Internet - AMIPCI (2015). $11^{\circ}$ Estudio sobre los hábitos de los usuarios de Internet en México 2015. Recuperado de https://goo.gl/AAL2aZ

Bringué, X. y Sádaba, C. (2009). La Generación Interactiva en México. Niños y Adolescentes frente a las pantallas. Revista Razón y Palabra, 14(69), pp. 1-31. Recuperado de https://goo.gl/NN1cfx

CABero, J. (2004). Reflexiones sobre la brecha digital y la educación. En Soto, F. y Rodríguez, J. (Coords), Tecnología, educación y diversidad: retos y realidades de la inclusión digital, pp. 23-42. Murcia: Consejería de Educación y Cultura.

Carvalho, D., Bessa, M., Oliveira, L., Guedes, C., Peres, E. y Magalhães L. (2012). New interaction paradigms to fight the digital divide: A pilot case study regarding multitouch technology. Procedia Computer Science, Vol. 14, pp. 128-137. Recuperado de http://dx.doi.org/10.1016/j. procs.2012.10.015

Crovi, D. (2002). El abismo digital, ¿Condicionante de los acuerdos comerciales? Ponencia presentada en el Coloquio panamericano "Industrias culturales y diálogo entre civilizaciones". Recuperado de https://goo.g1/ hVK5O1

Crovi, D. (2009). Acceso, uso y apropiación de las TIC en comunidades académicas: Diagnóstico en la UNAM. México, D.F: Universidad Nacional Autónoma de México.

CRovi, D. (2010). Jóvenes, migraciones digitales y brecha tecnológica. Revista Mexicana de Ciencias Políticas y Sociales, 209, pp. 119-134.

CRovi, D. D. (2013). Jóvenes y apropiación tecnológica: La vida como hipertexto. México: UNAM.

Crovi, D. (2016) Redes sociales digitales. Lugar de encuentro, expresión y organización para los jóvenes. México: UNAM-La Biblioteca. 
Fonseca, C. (2010) Aprendizaje en la era digital: Brecha digital y brecha cognitiva. http://www.cepal.org/elac2015/noticias/paginas/7/40837/ clotilde-fonseca.pdf

Galván, L. (2014). Conoce de la brecha digital en México. Universo PYME. Recuperado de https://goo.gl/X3c0ve

García Canclini, N. (2012). Jóvenes, culturas urbanas y redes digitales. En García, N., Cruces, F., y Urteaga, M. (Coords.), De la cultura postindustrial a las estrategias de los jóvenes, pp. 3-24. Madrid: Fundación Telefónica. Recuperado de https://goo.gl/mr8qGM

González-LizÁrraga, M. G. (2016). Una aproximación a diversos elementos de la cultura digital en estudiantes: caso Universidad de Sonora. En D. Crovi (coord.) Redes sociales digitales. Lugar de encuentro, expresión y organización para los jóvenes. México: UNAM-La Biblioteca.

Gobierno de la República Mexicana y CONACYT (2013). Agenda de innovación de Sonora: documentos de trabajo. Diagnóstico del sistema de innovación. Recuperado de https://goo.gl/Z4bUpQ

Gómez, E. y Lara, T. (2010). Cultura digital y vida cotidiana en Iberoamérica: Una revisión crítica más allá de la comunicación. Razón y Palabra, Núm. 73. Recuperado de https://goo.gl/rz4pHG

GonzÁlez, M.G. (2016). "Una aproximación a diversos elementos de la cultura digital en estudiantes: caso Universidad de Sonora". En Crovi, D. Redes sociales digitales. Lugar de encuentro, expresión y organización para los jóvenes. México: UNAM-La Biblioteca.

Hugues, E. (2015). Cultura digital e interacción a través del uso de recursos digitales en los jóvenes universitarios. (Tesis de Maestría en Innovación Educativa). Hermosillo: Universidad de Sonora.

Instituto Nacional de Estadística y Geografía -INEGI (2015). Sistema electrónico de las regiones socioeconómicas de México. Recuperado de https://goo.gl/AvEkZu

LÈvy, P. (2007). Cibercultura: Informe al Consejo de Europa. Rubí, Barcelona: Anthropos.

López Romo, H. (2009). Los niveles socioeconómicos y la distribución del gasto. Instituto de Investigaciones Sociales S.C. Recuperado de https:// goo.gl/kGjjdR

López, R. (2012). Jóvenes universitarios: uso de las tecnologías digitales. (Tesis de Doctorado en Pedagogía). México: Universidad Nacional Autónoma de México. 
El nivel socioeconómico y el dominio del idioma inglés...

Moreno, M.O. (2011). Conocimiento y uso de las TIC desde la perspectiva de los estudiantes de la Universidad de Sonora. (Tesis de Maestría en Innovación Educativa). Hermosillo: Universidad de Sonora.

Naciones Unidas (2015). Objetivos de Desarrollo del Milenio. Informe de 2015. Nueva York. Recuperado de http://www.un.org/es/millenniumgoals/pdf/2015/mdg-report-2015_spanish.pdf

Ortega, E. (2012). Aprendices, emprendedores y empresarios. En García, N., Cruces, F., y Urteaga, M. (Coords.), Jóvenes, culturas urbanas y redes digitales, pp. 109-130. Madrid: Fundación Telefónica. Recuperado de https://goo.g1/mkRn9

Pearce, K. E. y Rice, R. E. (2014). The Language Divide-The Persistence of English Proficiency as a Gateway to the Internet: The Cases of Armenia, Azerbaijan, and Georgia. International Journal of Communication, 8, 26. Recuperado de https://goo.gl/04UhWi

Peña-López, I. (2010). Framing the Digital Divide in Higher Education. Revista de Universidad y Sociedad del Conocimiento (RUSC), 7(1), pp. 2-6. Recuperado de https://goo.gl/gUlkCp

Pérez, G. (2006). El determinismo tecnológico: una política de estado. Revista Digital Universitaria, 7(10), pp. 2-7. Recuperado de https:// goo.g1/8uIs67

Raya, E. y Merino, L. (2004). Brecha digital, exclusión social y sociedad del conocimiento [Recurso electrónico]. Recuperado de https://goo.gl/qk$\mathrm{cB} 4 \mathrm{C}$

Reguillo, R. (2000). Pensar los jóvenes. Un debate necesario. En: Estrategias del desencanto. La emergencia de culturas juveniles en Latinoamérica. Buenos Aires: Norma.

Romo J. R., y Tarango, J. (2015). Factores sociodemográficos, educativos y tecnológicos en estadios iniciales de cibercultura en comunidades universitarias. Apertura. Revista de innovación educativa, 7 (2), pp. 1-15.

Serrano, A. y Martínez, E. (2003). La brecha digital. Mitos y realidades. Mexicali, Baja California: Universidad Autónoma de Baja California.

SIE - Sistema de Información Estadística de la UNISON (2017). Sección alumnos, población estudiantil por género, y sección oferta educativa por programas de estudio. Recuperado de https://goo.g1/D0W7mu

Stillo, M. (2012). Los discursos sobre la inclusión digital: Reconsideraciones sobre la Brecha Digital. COMMONS - Revista de Comunicación y Ciudadania Digital, 1(1), pp. 36-57. 
Torres-Díaz, J. \& Infante, A. (2011). Desigualdad digital en la universidad: usos de Internet en Ecuador [Digital Divide in Universities: Internet Use in Ecuadorian Universities]. Revista Comunicar, 37, pp. 81-88. https://doi.org/10.3916/C37-2011-02-08

Universidad de Sonora (2013). Plan de Desarrollo Institucional de la Universidad de Sonora 2013-2017. Universidad de Sonora, México. Disponible en: http://www.uson.mx/institucional/pdi2013-2017.pdf

Urresti, M. (2008). Ciberculturas juveniles: Los jóvenes, sus prácticas y sus representaciones en la era de Internet. Buenos Aires: La Crujía Ediciones.

Uzelac, A. y Cvjetičanin, B. (2008). Digital culture: The changing dynamics. Zagreb: Institute for International Relations.

Wев Technologies Surveys -W3TECHS (2014). Usage of content languages for websites. Recuperado de https://goo.gl/vup35o

Yánez, M. (2015). La participación de jóvenes universitarios a través de distintas plataformas digitales. ¿Una forma de ciberactivismo? (Tesis de Maestría en Innovación Educativa). Hermosillo: Universidad de Sonora. 



\title{
Universitarios, desarrollo de habilidades digitales comunicativas. Del ámbito escolar y la vida cotidiana'
}

\author{
Blanca Flores Ramírez \\ Luz María Garay Cruz
}

Desde hace algunos años, las redes sociales digitales han generado interés entre la comunidad académica que se ha dedicado a estudiar acerca de los usos, contextos, integración y apropiaciones que los sujetos hacen de ellas en diversos ámbitos de su vida cotidiana; este auge es más evidente en la última década, pues los usuarios de Internet aumentan año con año. En nuestro país, particularmente, cada vez con más frecuencia, los mexicanos que cuentan con este servicio, tienen como actividad primordial el acceso a las redes sociales digitales. De acuerdo con el documento Hábitos de los usuarios de internet en México 2016 (AMIPCI, 2016), hoy en día existen de 65 millones de usuarios de Internet en nuestro país, de los cuales, el 56\% se encuentra dentro del conjunto etario de los 13 a los 34 años de edad, es decir, personas jóvenes de acuerdo con la definición de las Naciones Unidas (personas con edades comprendidas entre los 15 y los 24 años de edad) y del IMJUVE, el Instituto Mexicano de la Juventud (personas de los 12 a los 29 años de edad).

Si bien la condición etaria no es la única característica que define al sector juvenil, es un marco de referencia para identificar y analizar las prácticas que realizan, así como su función dentro de la sociedad en tanto actores estratégicos para la renovación de los entornos culturales, sociales, económicos, políticos, entre otros. En nuestro país, nueve de cada 10 internautas acceden a una red social digital, esta actividad se colocó en el número uno, seguida de la actividad en cuentas de correo electrónico y en tercer lugar, la búsqueda de información. De igual forma, AMIPCI (2016) reporta que los usuarios pasan en promedio más de siete horas conectados a la red, siendo el lugar primordial su hogar, seguido de la conexión en dispositivos móviles, el trabajo y, en cuarto lugar, la escuela; asimismo tener un smartphone o teléfono inteligente es muy importante para el 77\% de los encuestados.

1 Este trabajo deriva de la tesis "Jóvenes, Redes sociales digitales y Educación Superior: entre la vida cotidiana y la vida escolar", de la línea de Tecnologías de la Información y la Comunicación en Educación de la Maestría en Desarrollo Educativo (generación 2014-2016) de la Universidad Pedagógica Nacional. 
Ante este panorama, resulta interesante cuestionar cómo es que los usuarios hacen uso e integración de las tecnologías y de las redes sociales digitales en particular, concibiéndolas como espacios emergentes que han modificado la manera de comunicarse, realizar consumos culturales, construir saberes, aprender e interactuar con los otros. Ante ello la escuela y la educación se enfrentan a un reto sobre las formas tradicionales de llevar a cabo los procesos de formación, vinculados con las exigencias de la llamada cultura digital.

La escuela como institución tiene un papel protagónico en este escenario, ya que alberga un número considerable de jóvenes que día a día interactúan tanto dentro como fuera del mundo digital. En este sentido, y de acuerdo con Puiggrós (1988), un sistema educativo puede definirse como las diversas formas y los múltiples procesos educativos que se desarrollan en una formación social; no se trata solamente del sistema escolar ni exclusivamente de aquellos procesos institucionales, no es solamente lo que está legitimado como educativo o de los términos que ocupa el lugar de lo educacional en el discurso pedagógico hegemónico, pues la educación rebasa los muros establecidos para concebirse como un proceso presente en diversas prácticas sociales.

Una de las cuestiones que nos interesó abordar en este texto es la relación entre la vida escolar y la vida cotidiana de los jóvenes, es decir, la relación que existe entre la cultura institucional de la escuela y las otras formas de apropiación de la cultura que las y los jóvenes tienen a su disposición en la actualidad. Al respecto, Morduchowicz (2012) afirma que es necesario acercar la cultura popular a la escuela y la escuela a la cultura popular, lo cual no es un tema menor, ya que acceder a la cultura desde el espacio escolar permite que los alumnos entiendan quiénes son, cómo se los define socialmente, cómo es y cómo funciona la sociedad en la que viven.

Situar lo que ocurre en la cotidianidad del aula y describir las situaciones a las que se enfrentan los estudiantes y cómo resuelven sus necesidades, equipados con nuevas herramientas, propias de su ambiente cultural informal y de los llamados ecosistemas digitales, constituye uno de los intereses por los que se decidió indagar sobre la relación entre vida cotidiana y vida escolar. Fuera del ámbito escolar, los jóvenes poseen ciertas habilidades respecto al manejo de las tecnologías digitales e Internet, como la selección de información, el compartir diversos elementos, la gestión y organización del tiempo, la interacción con los pares, entre otras cosas. Resultó interesante analizar qué usos les dan y qué contextos enmarcan la actividad de los sujetos dentro de las redes sociales digitales, así como 
la manera en que llevan a cabo diversos procesos de comunicación individuales o colectivos en su paso por la escuela, pero también fuera de ella.

Por tal motivo, la investigación que dio lugar a este documento, tuvo como objetivo, identificar y analizar las formas en las que las redes sociales digitales son usadas e integradas por los jóvenes de educación superior, así como la manera en que desarrollan ciertas habilidades comunicativas que les permiten ejercer diversas prácticas, las cuales están enmarcadas por la tecnología digital, la inmediatez, la ruptura espacio-temporal, lo multimedial, lo hipertextual y la relación que establecen con otros espacios de su vida escolar, personal, familiar y social.

Algunas preguntas de las que se partió fueron las siguientes: ¿qué habilidades de uso en las redes sociales digitales permiten incorporarlas a la vida cotidiana y vida escolar de los jóvenes?, ¿qué tanto las redes sociales digitales han modificado la manera de comunicarse e interactuar de los jóvenes universitarios?, ¿cuáles son las prácticas que se han generado a partir de la interacción en las redes sociales digitales, dentro de los procesos formativos de los jóvenes en educación superior?

Consideramos que por sus características y propósitos, este estudio complementa y profundiza algunos de los aspectos abordados en la investigación "Jóvenes y cultura digital. Nuevos escenarios de interacción social”, razón por la cual se integra a esta publicación. Como se verá en las siguientes páginas, consideramos que son los trabajos empíricos los que nos acercan a un mejor conocimiento de la cultura digital juvenil, elemento necesario para la educación y el diseño de políticas públicas de este sector.

\section{Redes sociales digitales}

Hablar de redes sociales digitales refiere como punto de partida el desarrollo de la llamada red de redes: Internet. Actualmente, la producción académica sobre este campo de conocimiento es amplia pues existen numerosos estudios que han demostrado los cambios que las Tecnologías de la Información y la Comunicación (TIC) han ocasionado al insertarse en diversas actividades que los seres humanos realizamos de forma individual y colectiva (Negroponte, 1996, 1999; Castells, 2001, 2006; Piscitelli, 2002; Tapscott 1998). Así mismo, Trejo Delarbre (2002), afirma que la red de redes forma parte de la vida contemporánea, pero su aún insuficiente cobertura es uno de los desafíos principales para los países en donde el desarrollo de Internet ha sido minoritario o desigual. 
En este contexto, la propagación, uso y popularidad de los sitios de redes sociales digitales es un fenómeno social y comunicacional que sigue consolidándose como el centro de atención de un nuevo ecosistema de relaciones e interacciones de la sociedad actual (Campos, 2013). El mismo autor considera que, aunque en apariencia las redes sociales digitales se presentan como sistemas muy abiertos, flexibles, eficientes y participativos, es necesario entender la complejidad de su dimensión social y comunicacional, pues el análisis se presenta en la relación que pueden establecer los individuos, los medios, la tecnología, la cultura y lo social.

Una de las principales características de las redes sociales digitales es que implican otras formas para socializar, por ejemplo, al romper las barreras espacio-temporales y posibilitar altos niveles de interacción entre los usuarios. Al respecto Trejo (2002) afirma que debe haber motivo de preocupación en el análisis superficial que mucha gente hace de éstas, pues los vínculos en las redes sociales digitales enriquecen y crean extensiones para relacionarnos, pero no reemplazan otras formas de relación personal y social. Este autor incluso agrega que algunos análisis han confirmado que mientras más intenso es el uso, mayor es la capacidad del individuo para socializar fuera del ciberespacio (Trejo, 2002).

Lo anterior reforzó el interés por analizar el desarrollo de las habilidades digitales comunicativas, ya que se sabe que los jóvenes adquieren gran cantidad de información fuera de la escuela, toman decisiones rápidamente, están acostumbrados a obtener respuestas casi instantáneas a sus acciones, son altamente multimediáticos y sus niveles de interacción con los otros, a través de las redes y fuera de ellas, son elevados.

En este sentido, ¿cuál es el papel de la escuela para capitalizar las capacidades, aptitudes y actitudes de este grupo de jóvenes? Jóvenes que necesitan desarrollar habilidades para el manejo de la información, para la comunicación, la resolución de problemas, el desarrollo del pensamiento crítico, la creatividad, la innovación, la autonomía, la colaboración y el trabajo en equipo, competencias y habilidades que se presumen necesarias para la sociedad actual.

\section{Habilidades comunicativas digitales}

En documentos que versan sobre la llamada Sociedad de la Información y el Conocimiento (SIC) se hace mención, constantemente, a las habilidades comunicativas digitales que demandan un dominio por parte del sujeto, hay autores que prefieren hablar de competencias digitales, informáticas o tecnológicas para referir a un mismo fenómeno que engloba los 
saberes, habilidades, actitudes y aptitudes necesarias para el uso y apropiación de la tecnología digital.

Una de las posturas que más ha proliferado dentro del campo educativo es la de competencias digitales, la cual se ha propuesto desde la Organización de las Naciones Unidas para la Educación, la Ciencia y la Cultura (UNESCO), argumentando que surge por la necesidad de integrar el reconocimiento del sujeto y sus procesos (saber ser) además de un conjunto de conocimientos (saber), las habilidades y destrezas (saber hacer) que desarrolla un individuo en relación con los otros (saber convivir), con el objetivo de emplearlas para responder a situaciones reales dentro de la SIC (UNESCO, 2004, 2008).

De igual manera, de acuerdo con Navío (2005) las competencias implican habilidades, conocimientos y saberes propios de un campo, pero también involucran aspectos socio-afectivos, actitudes y aptitudes, comportamientos y conductas. Es decir, nos encontramos con un concepto amplio, complejo y difícilmente operativo.

Por lo tanto, desde la postura de este trabajo, el uso conceptual de competencia imposibilitaba su operatividad, dado su nivel de complejidad y amplitud. Por ello, para fines de la presente investigación se retomó el concepto de habilidades digitales que propone Lemus (2013) el cual permite acotar un conjunto de saberes relacionados con el uso y aplicación de las TIC, dejando de lado otros aspectos que dificultaran la operatividad de la categoría.

Una vez aclarado el concepto del cual se parte en este texto, damos paso a describir la habilidad comunicativa, que puede entenderse como la capacidad de comprender y expresar mensajes, así como desarrollar procesos argumentativos, apoyados en la asertividad de las relaciones interpersonales. Lo anterior, se relaciona con el desarrollo de la observación, el habla, la lectura y la escucha, de tal manera que se optimice la comunicación sujeto a sujeto y entre sujetos (Edel, 2011).

Se reitera que, para fines de este trabajo, se optó por trabajar desde las habilidades comunicativas digitales ya que el interés recayó en el conjunto de saberes que se vinculan, particularmente con el uso y aplicación de las TIC. A continuación se especifican las tres habilidades abordadas: gestión de la información, comunicación interpersonal, y creación y organización de grupos, mismas que fueron seleccionadas y construidas a partir de la revisión de la bibliografía especializada, por considerarse básicas dentro de la dinámica comunicativa de los entornos digitales, así como por su permu- 
tabilidad dentro de actividades de la vida cotidiana y escolar de los jóvenes universitarios, sujetos analizados en este estudio.

\section{Gestión de la información}

La gestión de la información es entendida como la forma en que los individuos organizan los contenidos a los que acceden mediante diversas vías, es decir, aquellas habilidades cognitivas, pero también comunicativas, que les permiten desarrollar capacidades para la búsqueda, selección y distribución de la información. Es importante señalar que estas habilidades se aplican por igual al análisis de la información de manera convencional a través de libros, revistas, medios masivos de comunicación y a través de la red de redes, la Internet (Lemus, 2013).

Esta habilidad comunicativa digital tiene gran importancia ya que funciona como precedente de otras, como es la actividad de búsqueda de información, actividad frecuente cuando se accede a Internet.

\section{Comunicación interpersonal}

Al respecto, Gallardo (2002) menciona que este tipo de comunicación es entendida como la interacción en la que un individuo transmite estímulos para modificar la conducta de otros. En este nivel de interacción las formas de comunicación adquieren gran relevancia para la plena comprensión de los participantes, donde existe una relación de reciprocidad estrecha entre los sujetos, lo cual constituye un acto social básico.

Si la habilidad anterior, gestión de la información, se desarrolla en un ámbito de acción individual (debido a que es el propio sujeto quien define las estrategias respecto a lo que hace con la información), la comunicación interpersonal en cambio, obliga al sujeto en su individualidad a reconocer a otros interlocutores, con los que tendrá que establecer procesos de comprensión, reciprocidad e intercambio, entre otros, es decir, obliga al sujeto a reconocerse en colectividad.

\section{Creación y organización de grupos}

Finalmente, la habilidad comunicativa relacionada con la creación y organización de grupos integra a las dos habilidades descritas anteriormente, ya que al analizar esta habilidad podemos afirmar que necesitamos procesos de organización, búsqueda, selección y distribución de información, así como niveles de interacción con nuestros pares, familia o maestros para 
establecer niveles óptimos de intercambio y reciprocidad, de manera grupal.

Otra característica importante de los grupos, que se relaciona fuertemente con la habilidad de creación y organización de los mismos, es definida también por Gallardo (1990, p. 76) al afirmar que la formación de un grupo parte de ciertas necesidades colectivas. El autor afirma que necesita por lo menos tres redes comunicativas básicas: 1) normativa, aquélla que establece roles, reglas y normas de operación de los grupos, 2) comunicativa, la que permite el flujo de información y facilita el funcionamiento del grupo y 3) de mantenimiento y desarrollo grupal, para proveer a los grupos de compatibilidad para poder vincularse a otros.

\section{Estrategia metodológica}

El enfoque metodológico que guió el trabajo de investigación fue cualitiativo, ya que interesaba visibilizar los intercambios que los estudiantes de nivel superior de universidades públicas realizan en las redes sociales digitales y el espacio escolar. Analizar sus relaciones sociales, sus maneras acceder y gestionar la información en los espacios digitales y físicos en los que interactúan y se relacionan.

Se retomó un aspecto clave del enfoque cualitativo que permite "reconstruir la realidad tal como la observan los actores de un sistema social previamente definido, ya que se fundamenta en una perspectiva interpretativa centrada en el entendimiento de las acciones de los seres humanos y las instituciones" (Hernández, Collado y Baptista, 2010, p.8).

En un primer momento se buscó entender la estructura de las redes sociales digitales, para lo cual se llevó a cabo una revisión amplia de las fuentes bibliográficas, hemerográficas, documentales y de páginas electrónicas relacionadas con el tema, mismas que dieran cuenta de la expansión de las redes sociales digitales entre los jóvenes estudiantes de nivel superior, el uso de Internet dentro de este grupo poblacional y los datos estadísticos al respecto.

En un segundo momento, se realizaron diversas inmersiones al trabajo de campo para la recolección de datos e información que recuperaran las narrativas de los jóvenes, rescatando desde su perspectiva y puntos de vista el uso que hacen de las redes sociodigitales, la manera en cómo las han incorporado a su vida cotidiana y en sus prácticas escolares, los momentos en los que han tenido que desarrollar cierto tipo de habilidades, de qué forma o con ayuda de quién lo han hecho, así como los tiempos que 
invierten y las acciones que realizan cuando se conectan a Facebook, entre otras cuestiones.

Una de las herramientas que permitieron el acopio de la información fue el "Cuestionario diagnóstico de habilidades comunicativas digitales" el cual se elaboró a partir de los planteamientos de Zapata Ros (2013), UNESCO $(2004,2008)$ y Lemus $(2013)$ respecto a las competencias y, particularmente, a las habilidades digitales descritas anteriormente (Anexo 1).

El cuestionario se enfocó en las tres habilidades antes mencionadas: 1) gestión de la información, 2) comunicación interpersonal, así como 3) la creación y organización de grupos. Dicho conocimiento responde, como ya se mencionó, a que estas tres habilidades se consideran básicas para un proceso comunicativo efectivo y debido a que tales habilidades son permutables entre la vida cotidiana y la vida escolar.

En cuanto a la aplicación, el cuestionario fue contestado por 94 jóvenes, 21 hombres y 73 mujeres de las licenciaturas en Pedagogía de la Universidad Nacional Autónoma de México (UNAM) y en Psicología Educativa de la Universidad Pedagógica Nacional (UPN). Es necesario aclarar que el cuestionario no es representativo, debido al diseño y al objetivo del presente estudio, siendo la función principal de dicho instrumento servir de diagnóstico para la selección de jóvenes en la conformación de entrevistas grupales y grupos de discusión.

Posterior a la aplicación del cuestionario diagnóstico de habilidades comunicativas digitales, se conformaron tres grupos de discusión, dos de ellos estuvieron constituidos por jóvenes a los que se les había aplicado el cuestionario diagnóstico y un grupo más a los que no se les aplicó el cuestionario. La decisión de conformar este último grupo se tomó porque fue complicado reunir un grupo de discusión en la Universidad Pedagógica Nacional, por ello en dicha institución se llevó a cabo una entrevista grupal. De esta manera, con el grupo adicional, conformado por 7 jóvenes (5 mujeres y 2 hombres) se constituyó un universo de jóvenes más amplio que aportara una mayor cantidad de información para enriquecer el estudio.

El primer grupo se conformó por 8 participantes (2 hombres y $6 \mathrm{mu}-$ jeres); el segundo grupo estuvo constituido por 7 participantes ( 3 hombres y 4 mujeres) y el tercer grupo se conformó por 5 mujeres y 2 hombres. Las sesiones fueron únicas y duraron dos horas cada una.

Cabe señalar que el cuestionario diagnóstico se aplicó a 94 jóvenes, de los cuales 18 participaron en dos de los grupos de discusión y en la en- 
trevista grupal. 7 jóvenes más conformaron otro grupo de discusión, aun cuando no se les aplicó el cuestionario diagnóstico.

A continuación se presentan los principales hallazgos del trabajo en relación con las categorias de análisis presentadas, pero antes se describe la manera en que los jóvenes han aprendido a usar la tecnología y el tipo de equipo con el que cuentan.

\section{Aprender a usar las tecnologías digitales}

Con relación al uso de dispositivos digitales, de los 94 jóvenes que contestaron el cuestionario 76 tienen computadora portátil y 73 cuentan con teléfono celular inteligente; sólo 53 tienen computadora de escritorio y 35 cuenta con tableta digital.

Con relación a la conexión que los jóvenes tienen a Internet, 90 de ellos cuentan con un servicio particular en sus hogares, siendo el lugar principal en el que se conectan, seguido de la universidad donde estudian, según reportan 72 jóvenes. Finalmente, 38 del total, tiene conexión permanente ya que cuenta con un paquete de datos móviles en su teléfono celular.

Una cuestión importante es que 80 de los jóvenes afirman que el aprendizaje de uso de sus dispositivos y en general de Internet fue de manera autónoma; en segundo lugar, 39 reportan que fue gracias a la ayuda de padres, amigos o familiares, mientras que únicamente 13 jóvenes del total mencionaron haber tenido algún tipo de enseñanza relacionada con el uso de las TIC dentro de las instituciones educativas (ya sea desde primaria, secundaria, preparatoria o en la propia universidad).

En este sentido, es interesante identificar cómo los sujetos son conscientes de sus procesos formativos con la tecnología:
(...) considero que hay dos formas de verlo, por ejemplo, yo tuve clases de computación en secundaria, bachillerato y hasta en primaria, era una computación bastante arcaica sobre cómo prender el equipo, cómo apagarlo, cómo usar Word, Excel y todo eso, pero buscar en Internet, las referencias, los estilos y las formas en cómo se utiliza ahorita [...] lo aprendí de manera autodidacta (Alan, 20 años).

En la cita anterior podemos identificar además, que las instituciones educativas conservan una postura tradicional respecto a la enseñanza de contenidos, habilidades y actitudes relacionadas con el uso de las TIC, es decir, de acuerdo con la percepción de los jóvenes en su proceso formativo, la escuela básica (primaria y secundaria) proporciona únicamente contenidos técnicos acerca del uso de la tecnología, tales como el uso de 
programas como procesadores de texto, hojas de cálculo, presentación de contenidos, entre otros.

Sin embargo, existe una deficiencia en la enseñanza de formas novedosas y potenciales de uso; lo anterior nos lleva a reafirmar lo que los jóvenes reportan: el aprendizaje es autónomo porque existe una necesidad de uso, de las demandas que les exige aprender a usar una nueva aplicación o programa y de los beneficios que ello tendrá en su formación académica:

(...) en mi experiencia, yo aprendí conforme los programas se fueron actualizando puesto que creo que conforme se abre una nueva red social nadie te enseña a usarla, o sea, tú tienes que ir aprendiendo, y pienso que es un proceso autodidacta como dice Alan, pues tienes que mostrar cierto compromiso ante los aprendizajes que vas a tener de cómo utilizar la tecnología, de los beneficios (Fernanda, 20 años).

De acuerdo con lo anterior, resulta interesante que la política educativa del gobierno actual haya establecido en el Plan Nacional de Desarrollo 2013-2016, una directriz con respecto a la Educación de calidad y, dentro de ese ámbito, la vinculación de la educación con las necesidades sociales y económicas actuales: “...es necesario innovar el sistema educativo para formular nuevas opciones y modalidades que usen las nuevas tecnologías de información y de la comunicación, con modalidades de educación abierta y a distancia" (PND, 2013, p. 62). Sin embargo, a pesar de ser una directriz, resulta ser todavía un panorama lejano ya que la formación en cuanto al uso de las tecnologías digitales sigue siendo de tipo herramental o técnica, cuando es necesario desarrollar habilidades con respecto al uso innovador, creativo y crítico.

De la misma forma, se siguen dejando de lado los conocimientos que los jóvenes han desarrollado fuera de la institución escolar, mismos que podrían ser tomados en cuenta para identificar las deficiencias y oportunidades que los estudiantes poseen en vías de ofrecer actividades formativas más significativas de acuerdo con sus contextos, intereses y potencialidades.

(...) yo creo que en general no se enseñan habilidades, en la primaria igual y llevaste informática o algo así, creo que la mayoría llevamos, pero en general siempre te enseñan como la educación a la antigüita de prender los aparatos, etc., en la secundaria tienes una computadora o Internet pero no es como tal que te lo enseñen en la escuela, si no que era como tenerlo en casa y así autónomamente lo usas; como tal que te lo enseñen en la escuela creo que no (Aydee, 20 años).

(...) en mi experiencia, yo en toda la primaria tuve computación y yo si considero que me enseñaron bien por ejemplo lo básico de Word, de la paquetería de Office me enseñaron por lo menos lo básico [...], 
en secundaria llevé informática entonces también me enseñaron más cosas de tecnología, ya cuando entré a la preparatoria y a la universidad [cambió], aquí siento que te lo demandan mucho pero no te enseñan cómo, o sea te lo demandan mucho porque tu autónomamente o por tus propios medios tienes que ver cómo le vas a hacer, porque no te enseñan a usar bases de datos o a meter palabras claves para encontrar lo que necesitas" (Ana, 23 años).

Finalmente, respecto al aprendizaje de uso de la tecnología, resulta interesante lo que menciona Ana, ya que la educación sobre tecnología se encuentra presente en niveles de educación básica, anteriores al nivel medio superior o superior, es decir, el primer acercamiento que tienen los niños y jóvenes con las computadoras e Internet es en espacios escolares, lo cual concuerda con investigaciones realizadas anteriormente como la de Garay Cruz (2013) quien afirma también que a pesar de que la escuela ofrece esta inmersión inicial "no existen estrategias para el desarrollo de esas habilidades básicas hasta posicionarlas en el dominio de las TIC” (p. 135).

Por lo anterior, la universidad parece tener deficiencias respecto a ofertar contenidos relacionados con las TIC, sobre todo en áreas de conocimiento como las ciencias sociales y las humanidades, de las que forman parte los sujetos de este estudio, ya que a pesar de que existe un discurso que realza las potencialidades de la tecnología, ésta no se ve aprovechada de forma amplia dentro de esta área de conocimiento.

\section{Gestión de la información, comunicación y organización de grupos}

Es importante señalar que los sujetos de estudio de esta investigación pertenecen a un sector particular de jóvenes: universitarios, estudiantes de instituciones públicas de Educación Superior, urbanos, con un alto consumo digital, que tienen cuentas activas en redes sociales digitales y que pasan en promedio seis horas al día conectados a Internet. Son un tipo particular de jóvenes que en efecto, tienen como característica esencial su relación estrecha con la tecnología y las redes.

A partir de lo anterior, y sumado a la manera en que han aprendido a usar las tecnologías digitales, se puede inferir que estos jóvenes han reestructurado sus prácticas, así como la forma en la que llevan a cabo ciertas actividades académicas, por ejemplo, la manera eficaz e inmediata en la que buscan y encuentran información. Asimismo, la portabilidad y la conectividad permanente les permite albergar dicha información en distintos dispositivos electrónicos. La posibilidad de estar conectados con 
amigos o familiares que no se encuentran en el mismo espacio geográfico les permite un ahorro de tiempo considerable para realizar otras actividades, lo cual consideran una ventaja de la tecnología.

Estos jóvenes concluyen que la comunicación interpersonal es una habilidad que necesitan desarrollar, ya que la comunicación a través de redes sociales digitales lleva a generar malentendidos tanto en sus grupos de amistades, como en los académicos; es decir, al no poseer las habilidades necesarias para poder expresar lo que se piensa a través del texto escrito. Ellos evaden participar en discusiones donde deben formular argumentos que se basen en normas gramaticales mínimas, acompañadas de una buena redacción, sintaxis y ortografía, para evitar que sus mensajes sean interpretados de una manera distinta a como ellos los pensaron.

Lo anterior sin duda abre una problemática sobre las formas de comunicación y los procesos formativos de los jóvenes, ya que la comunicación escrita es parte fundamental de la vida académica, pero también es clave en procesos comunicacionales dentro de su vida cotidiana.

Al respecto, estos jóvenes demandan que sea la institución escolar la que los apoye en el desarrollo de esas habilidades, ya que no solamente necesitan la comunicación interpersonal para chatear de forma eficiente, sino que la comunicación como proceso es imprescindible en su formación académica, en la elaboración de ensayos, investigaciones o tesis, requisitos que acompañan los planes curriculares dentro de las Universidades.

Otro de los puntos clave de este estudio, es que los jóvenes utilizan las redes sociales digitales de manera integrada, esto quiere decir que no separan su mundo dentro de la escuela, o fuera de ella, sino que integran los dos ámbitos y otros más, como el trabajo o actividades artísticas y culturales, ya que en el mundo digital confluyen muchas de sus prácticas sociales. Asimismo, como se apuntó en su momento, la red tiene un carácter relacional, lo que permite que estos jóvenes puedan albergar diversas actividades dentro de una plataforma con la posibilidad de agrupar y clasificar una serie de contactos con los que pueden chatear, crear eventos recreativos, estudiar, compartir información, comunicarse e interactuar.

Cabe señalar que si bien los jóvenes afirman integrar las redes sociales tanto a su vida cotidiana como a su vida escolar, esta integración es básica, ya que puede haber un nivel de uso que habilita a los jóvenes a estar al tanto de las novedades tecnológicas, pero ello no se traduce necesariamente en un dominio de estos instrumentos: los jóvenes continúan siendo consumidores de contenido, ya que aun cuando pueden tener las capacidades 
para crear sus propios productos culturales y circularlos en el ciberespacio, no lo realizan.

Lo anterior, abre otro tipo de cuestionamientos respecto a los niveles en que los jóvenes se están apropiando de la tecnología (Winocur, 2007 y Garay, 2010) y los usos que hacen de ella, ya que si bien los jóvenes se consideran autónomos para desarrollar ciertas habilidades (sobre todo las de gestión de información) existen otras más ligadas al desarrollo de habilidades de tipo superior, como la negociación, la colaboración y la creación, que no se desarrollan ampliamente y ellos lo asumen.

En este sentido, la escuela tiene un papel importante de acción, ya que es dentro de esta institución donde pueden ofrecerse elementos que permitan a los jóvenes desarrollar habilidades, las cuales, aunadas a su conocimiento tecnológico, se conviertan en oportunidades para integrar las TIC con un nivel favorable de dominio, a la par de generar y ofertar un abanico de consumos mediáticos acordes a los intereses de la población, ya que uno de los fines de la educación es el de dotar de herramientas a los actores educativos para que puedan desarrollar esquemas de pensamiento y acción que permitan atender diversas demandas, sobre todo de grupos minoritarios.

Al respecto, tanto las instituciones gubernamentales como los tomadores de decisiones en política educativa, tienen la responsabilidad de cumplir con la cobertura de necesidades de la población. En este sentido llama la atención que algunos gobernantes impulsen el simple despliegue tecnológico al dotar de dispositivos electrónicos, tales como tablets y computadoras a educadores y educandos, sin tomar en cuenta los rezagos que deben cubrirse respecto a su uso e integración.

Sin lugar a dudas, la escuela sigue siendo un espacio clave en el cual se generan, debaten y reestructuran las representaciones del mundo.

Los resultados de esta investigación abonan en gran medida a los hallazgos realizados por el grupo de trabajo del proyecto "Jóvenes y cultura digital. Nuevos escenarios de interacción social", ya que ofrece datos empíricos que coinciden en gran medida en varios aspectos, entre ellos desmitificar la idea de que los jóvenes son hábiles y competentes para el uso de los recursos tecnológicos de manera natural. Ha quedado demostrado que es necesario trabajar con ellos para el desarrollo de habilidades digitales más complejas, que vayan más allá del uso instrumental de los gadgets. También destaca que los usos de vida cotidiana y escolar se dan de manera paralela, lo cual demuestra que para los jóvenes las tecnologías digitales 
Universitarios, desarrollo de habilidades digitales comunicativas...

forman parte de sus prácticas sociales en diversos ámbitos y no hacen una separación entre lo físico y lo digital.

El reto está en seguir indagando y explorando más este universo social para contar con información que nos permita retratar de una manera más sistemática, los cambios en las prácticas comunicativas y educativas de los jóvenes.

\section{Bibliografía}

Asociación Mexicana de Internet -AMIPCI (2016) Hábitos de los usuarios de internet en México. México: AMIPCI-Elogia. Recuperado de https://www.amipci.org.mx/images/Estudio_Habitosdel_Usuario_2016.pdf

Campos, F. (2013). Redes sociales. Antología de artículos publicados en la Revista Latina de Comunicación Social. España: Sociedad Latina de Comunicación Social.

Castells, M. (2001). La Galaxia Internet. España: Areté.

Castells, M. (2006) La sociedad red. España: Alianza Editorial.

Castells, M. (2014). "El poder de las redes" en Vanguardia, n. 50, pp. 8-13.

Crovi, D., López, M. A. y López, R. (2009). Redes Sociales: análisis y aplicaciones. México: UNAM-Plaza y Valdés.

Crovi, D. (coord.) (2013). Jóvenes y apropiación tecnológica. La vida como hipertexto. México: Sitesa/UNAM.

Crovi, D. y Lemus, M. (2014). Interacciones juveniles en redes sociales digitales. Reporte de la fase metodológica de un estudio en proceso. AMIC (Eds.). En Memoria electrónica del XXVI Encuentro Nacional de AMIC. San Luis Potosí, México: AMIC.

Crovi, D. y López, R. (2014). Interacción en Redes Sociales Digitales. Jóvenes Estudiantes y trabajadores describen sus prácticas en red. ALAIC (Eds.). En Memoria electrónica del XII Congreso de la Asociación Latinoamericana de Investigadores de la Comunicación, Lima, Perú: ALAIC.

Edel, R. (2011) Competencias digitales en las Instituciones de Educación Superior. Ponencia en el XI Congreso Nacional de Investigación Educativa, COMIE/UANL/UNAM.

FEIXA, C. (2014).De la Generación @ a la \#Generación: la juventud en la era digital. España: NED. 
Gallardo, A., (1990). Curso de teorías de la Comunicación. México, Cromocolor

Gallardo, A. (2002). Algunos aspectos empíricos de la comunicación y la educación. Documento de Trabajo, México, CECTE

Garay, L. (2010). (coord.) Acceso, uso y apropiación de TIC entre los docentes de UPN. Diagnóstico. México: UPN.

Garay, L. (2013). "¿Qué dicen de las TIC quienes estudian en la Universidad Pedagógica Nacional?”. En D. Crovi (coord.) (2013). Jóvenes y apropiación tecnológica. La vida como hipertexto. México: Sitesa/UNAM

Garay, L. (2014). Prácticas de uso de recursos digitales dentro y fuera del aula. Tres perfiles docentes. Estudio cualitativo. Ponencia en el XXVI Encuentro de AMIC, 22 y 23 de mayo de 2014, San Luis Potosí, México.

Garay, L. (2015) "Jóvenes, dispositivos móviles y consumo de contenidos mediáticos. El ocio en los tiempos digitales" en Ortíz, G. y Garay, L. (coords.) Comunicación, cultura y educación. Nueve aproximaciones al estudio de las tecnologías digitales. México: UAM Lerma y Juan Pablos Editores, pp. 25-43.

Garay, L. (2013). Jóvenes creativos. Estrategias y redes culturales. México: Juan Pablos Editor-UAM Iztapalapa.

García, C. (2006). Diferentes, desiguales y desconectados. España: Gedisa.

Hernández, Collado y Baptista. (2010). Metodología de la investigación. Quinta edición, México: McGraw Hill Interamericana

Lemus, P. (2013) El desarrollo de habilidades digitales en profesores que usan plataformas de aprendizaje en linea: el caso b@bitat puma. Tesis para obtener el grado de Maestra en Comunicación. México: FCPyS-UNAM.

Morduchowicz, R. (2012). Los adolescentes y las redes sociales. Buenos Aires: FCE.

Negroponte, N. (1999). Ser digital. México: Atlántida-Océano.

Piscitelli, A. (2002). Ciberculturas 2.0 en la era de las máquinas inteligentes. Buenos Aires: Paidós.

PND (2013). Plan Nacional de Desarrollo (2013-2018). México: Gobierno de la República.

Puiggrós, A. (1999). (coord.). En los límites de la educación. Niños y jóvenes del fin de siglo. Argentina: Homo Sapiens.

TApscott, D. (1998). Creciendo en un entorno digital: la generación Net. México, McGrawHill. 
Universitarios, desarrollo de habilidades digitales comunicativas...

TApscotт, D. (2009). Grown up digital: how the net generation is changing your world. New York: McGraw-Hill.

TRejo, D. (2002). “Internet, la gran conversación” en Revista Iberoamericana, vol. II, núm. 6, pp.161-178.

UNESCO (2004) Estándares de competencia en TIC para docentes. París: UNESCO.

UNESCO (2008). Las tecnologías de la información y la comunicación en la formación docente. París: UNESCO.

UNESCO (2009) Comunicado de la Conferencia Mundial sobre la Educación superior 2009, La nueva dinámica de la Educación Superior y la investigación para el cambio social y el desarrollo. París: UNESCO.

UNESCO (2011) Educación de calidad en la Era Digital. Documento interno de trabajo en la Reunión Regional Ministerial para América Latina y el Caribe, 12 y 13 de mayo de 2011, Buenos Aires, Argentina.

Winocur, R. (2007) "Nuevas tecnologías y usuarios. La apropiación de las TIC en la vida cotidiana” en Revista Telos, No. 73, octubre-diciembre, pp. 1-6.

Zapata, R. (2013) Gestión del aprendizaje en Educación Superior y web social. [En línea] http://goo.gl/uLDosJ (Fecha de consulta 20/09/15). 


\title{
Ocho de cada diez gatos prefieren El Komander: Una aproximación a expresiones de discriminación cultural en memes en redes sociodigitales'
}

\author{
Gabriel Pérez Salazar ${ }^{2}$ \\ Esaú Salvador Bravo Luis ${ }^{3}$ \\ Montserrat Del Bosque Carrillo ${ }^{4}$
}

\section{Introducción}

El conjunto de herramientas para la administración de redes sociales en línea, también conocidas como redes sociodigitales, ${ }^{5}$ constituyen espacios

1 Este trabajo forma parte del proyecto Identidad e interacción en redes sociales en línea, del Cuerpo Académico Consolidado Comunicación, Cultura y Sociedad, de la Facultad de Ciencias de la Comunicación de la Universidad Autónoma de Coahuila, cuya coordinación estuvo a cargo de Julieta Carabaza González en el periodo 20152016. Los autores reconocemos los comentarios en Facebook del investigador Julián Woodside, de la Universidad del Claustro de Sor Juana, que inspiraron una parte del abordaje de este trabajo; así como el análisis realizado por Iztaccíhuatl Castor López, estudiante de pregrado en la Facultad de Ciencias de la Comunicación de la Universidad Autónoma de Coahuila.

2 Doctor en Ciencias Políticas y Sociales por la Universidad Nacional Autónoma de México. Su línea de investigación está dada por la comunicación y las innovaciones tecnológicas. Actualmente es profesor de tiempo completo en la Facultad de Ciencias de la Comunicación de la Universidad Autónoma de Coahuila.

3 Doctor en Comunicación por la Universidad Nacional de la Plata, Argentina. Posdorcorado en Investigaciones Interdisciplinarias en Ciencias y Humanidades CEIICH-UNAM. Su principal línea de investigación consiste en el estudio de Objetos Anómalos en Internet y su relación con los Usos Sociales de la Tecnología. Actualmente es Profesor de tiempo completo en la Facultad de Ciencias de la Comunicación de la Universidad Autónoma de Coahuila y Co-coordinador de la línea de investigación Internet Visualidades yVida Cotidiana del Doctorado en Ciencias y Humanidades para el Desarrollo Interdisciplinario, UNAM/CEIICH-UAdeC/CEII.

4 Estudiante de pregrado en la Facultad de Ciencias de la Comunicación y colaboradora en el proyecto del que se desprende este trabajo.

5 Se trata de servicios en línea que se caracterizan por permitir la interacción entre sus usuarios, a partir de los perfiles públicos en los que hacen una representación de sí mismos y se relacionan con los demás (Ellison, 2007). En ellos, destacan por su popularidad Facebook, Twitter, Pinterest, Snapchat, entre muchas otras. 
de interacción en los cuales los usuarios llevan a cabo una serie de expresiones, a partir de las que construyen parte de su identidad; al menos en su dimensión como operación de representación ante los demás. En cada tweet, comentario y publicación de estado (donde, en el caso de jóvenes, frecuentemente se emplean memes), quienes utilizan estas plataformas, dan indicios de las estructuras culturales en las que se ubican, y que forman parte de los marcos interpretativos con los que negocian su realidad. Estas estructuras culturales configuran la noción de construcción del otro, como sujeto actante dentro del mismo entorno, que vehicula la construcción de dichos marcos interpretativos. Nos relacionamos y nos construimos por otros y a través de los otros (Del Río, 2006).

Los memes en Internet, es decir, estas unidades culturales que están sujetas a procesos de replicación y reinterpretación con diversos grados de fidelidad, alcance y longevidad (Dawkins, 1976), serán entendidos como recursos sígnicos de expresión, con una muy amplia variedad de usos sociales. Igual como ocurre con cualquier otro signo, pueden ser empleados con intenciones que van desde la exaltación de los actos humanos más nobles, hasta la denostación, el insulto, la calumnia y, como abordaremos en las siguientes páginas, la discriminación. Si bien reconocemos el muy frecuente empleo de memes con un sentido prosocial, ${ }^{6}$ consideramos que es de la mayor relevancia reflexionar en torno a estos otros actos comunicativos que inciden de manera negativa en aspectos como la ciudadanía, la tolerancia y el respeto a la diversidad.

Desde esta perspectiva, plantearemos que nuestra unidad y objeto de análisis es el resultado de procesos bio-socio-culturales, generados por la estrecha relación objetual con artefactos electrónicos, que contienen la capacidad algorítmica para interrelacionar contenidos digitales aparentemente inconexos, pero que están construidos desde códigos programáticos ${ }^{7}$ que facilitan su enlace, como ocurre a partir de computadoras y dispositivos móviles como smartphones o tabletas electrónicas. De este modo, el potencial del código programático junto con el dispositivo que lo aloja, cobra relación con su contexto; el sentido, conexión y significado, ocurre cuando el sujeto lo interrelaciona con su entorno inmediato y lo sitúa en canales específicos de distribución, como aquellos en los que hemos ubicado nuestro trabajo de campo.

6 Como suele ocurrir a partir del meme faith in humanity restored.

7 Entendemos esta categoría como la estructura digital ensamblada a partir del lenguaje de programación que permite la funcionalidad, adherencia y modificación de imagen, video, texto y audio. 
Así, a partir de una breve revisión de las nociones identidad y discriminación, el objetivo central de este capítulo, será hacer una revisión de la manera en que procesos relacionados con tales categorías, se manifiestan en una selección no probabilística y no representativa de memes observados en línea. De manera específica, describiremos la forma en que se expresan diversos actos de discriminación cultural, a partir de la publicación y replicación de memes que hemos encontrado en Facebook y Twitter.

\section{De identidad y discriminación: algunas nociones necesarias}

De manera coloquial, la identidad es frecuentemente entendida como lo que se es. Como revisaremos enseguida, académicamente hablando, el asunto es más complejo, sin embargo, ciertamente haremos referencia a esta esencia del ser, que es la base de toda interacción social. Como argumentaremos, identidad y discriminación son dos asuntos estrechamente relacionados, ya que todo acto discriminatorio ocurre precisamente a partir de lo que se concibe de esa alteridad con la que se establece alguna relación, en este caso, desigual. De esta forma, hablaremos en primer lugar de la identidad como categoría central, tratando luego de establecer vínculos con este otro fenómeno que niega a priori un trato equitativo y justo.

En 1934, George Herbert Mead escribió Mind, self, and society. En esta obra, Mead construyó la noción del self, que permite entender la manera en que tienen lugar las interacciones en el plano social, y cómo el sujeto se ubica a sí mismo a partir de ellas. Dicho ser, dice este autor, es una estructura que parte de la experiencia con los demás, y que media en toda relación que se establece. Socialmente hablando, se es, precisamente a partir de tales interacciones, en los que incontables procesos de comunicación contribuyen a establecer una distinción entre sí mismos y los otros.

Este es uno de los puntos de partida más claros en torno a la teorización de la identidad en las ciencias sociales. La mayor parte de los autores que han abordado este asunto, se adscriben de alguna manera al ya mencionado planteamiento de Mead, y reiteran que se trata, ante todo, de una operación de distinción entre alter y ego. Sin embargo, desde este mismo autor, el asunto no se limita a la mera diferenciación, sino que incide también en diversos procesos socio-cognitivos, como una estructura que regula la manera en que tienen lugar las relaciones con los demás. Así, para autores como Castells (1999), Giménez (2000), Mandoki (2006) y 
Berger y Luckman (2006); ${ }^{8}$ la identidad se erige como una categoría que hace referencia no sólo a dicha distinción, sino también como una matriz interpretativa a través de la cual el sujeto se ubica en relación con el mundo social al que pertenece.

De esta manera, dicha matriz identitaria puede ser entendida como una especie de membrana presente en todo acto social, y como es evidente, en todo acto comunicativo también; tanto en la interpretación como en la enunciación. Lo anterior significa que cada persona entiende al mundo desde lo que es, como el resultado de toda interacción en la que haya participado. Sin embargo, esto se manifiesta también del sujeto hacia el resto de la sociedad, en cada uno de sus actos. Lo que se hace, proyecta lo que se es, idea que Giddens recalca al afirmar que "no somos lo que somos, sino lo que hacemos" (1997, p. 96). Como Austin (1962) y Searle (1994) han sugerido, todo acto comunicativo refleja al menos una parte de la esencia del emisor: somos lo que expresamos. Así, reiteramos, la identidad como membrana opera en ambos sentidos: somos al interpretar la realidad, al ubicarnos en relación con ella; pero también somos al enunciarla (y, por ende, al contribuir a su construcción), a partir de una gran variedad de posibilidades, a las que recientemente se agrega el uso de memes en línea.

Con base en lo anterior, en todo proceso de enunciación que tiene lugar en usuarios de Internet, se refleja siempre una parte de esta estructura identitaria propuesta por Mead. Esto bien puede estar sujeto a controles y manipulaciones intencionales, como ocurre en el caso de las Relaciones Públicas (RRPP), en las que las organizaciones buscan construir una identidad corporativa que favorezca el logro de sus objetivos. Sin embargo, en la mayor parte de las personas, sus interacciones y enunciaciones cotidianas, suelen estar mucho menos planeadas. Sobre todo en contextos institucionalmente poco estructurados, como es el caso de las redes sociodigitales, la interacción ocurre de manera mucho más espontánea; particularmente a partir de los rompimientos espacio-temporales que dicha mediación implica. Como hemos encontrado en trabajos anteriores (Pérez-Salazar y Gervasi, 2015), es mucho más probable que una persona opere en los ambientes virtuales en términos comunicativos más cercanos a su esencia (como ser culturalmente estructurado), y no necesariamente desde intenciones instrumentales como en las relaciones públicas.

8 Incluimos también a autores relevantes de la Psicología Histórico-Cultural como Pablo Del Río (2006), Michael Cole (1996), Rolando García (2006) y Evan Ilyenkov (1977). 
Estas estructuras de las que hemos hablado están inevitablemente cruzadas por toda la gama de construcciones sociales que se encuentran en el repertorio cultural, desde aquellas que apelan a lo más sublime de la naturaleza humana, hasta las que denotan una serie de prejuicios y estereotipos. De esta forma, al analizar cualquier acto comunicativo, en muchos casos es posible inferir la estructura cultural de la que surge, y que puede resultar tanto en elementos de tolerancia y respeto a la diversidad, como todo lo contrario; pero que al cabo, dan cuenta de nuestra identidad. Una sociedad en la que prevalecen enunciaciones solidarias es, en términos de Mead, al menos en parte, una sociedad solidaria. Y una en la que se presentan prácticas discursivas discriminatorias, así sea disfrazadas de broma o juego, a fin de cuentas es también, en parte, una sociedad discriminatoria.

A partir de Bokser (2008), podemos recalcar la ya sugerida relación que existe entre la identidad y la discriminación. El pluralismo implica, según esta autora, "la plena aceptación de la Otredad, de la diversidad, de aquéllos que no son como yo" (p. 72). En el extremo opuesto se encuentra la discriminación, noción que ha sido abordada desde muy diversas perspectivas, y que en resumen puede ser entendida como:

La expresión más contundente, tanto individual como colectiva, de la negación del principio de igualdad de la condición humana. Refleja la incapacidad social, política y cultural para dar cuenta de la alteridad y de las diferencias (Bokser, 2008, p. 72).

Como Giddens (2000) y Beck (2011) proponen, la discriminación es una manifestación que está íntimamente relacionada con otras formas de negación de la diversidad, como los prejuicios, el racismo y la intolerancia. El Consejo Nacional para Prevenir la Discriminación en México (CONAPRED) define este fenómeno como "la situación en la que por prejuicios a una persona o grupo de personas se les da un trato desfavorable, generalmente por pertenecer a una categoría social específica" (en Bokser, 2008 , p. 73). Esta misma institución señala la gravedad de sus efectos, en virtud de que:

Niega el ejercicio igualitario de libertades, derechos y oportunidades a
cualquier persona; la excluye y la pone en desventaja para desarrollar
de forma plena su vida; la coloca, además, en una situación de alta vul-
nerabilidad. Esa desventaja sistemática, injusta e inmerecida, provoca
que quienes la padecen sean cada vez más susceptibles a ver violados
sus derechos en el futuro (CONAPRED, 2010, p. 6).

Como es posible sustentar a partir de estos trabajos, la discriminación se presenta con base en la pertenencia a una categoría social determinada, es 
decir, a un colectivo con el que se comparten una serie de rasgos identificadores. En las definiciones clásicas de racismo, el prejuicio frecuentemente ocurre a partir de "distinciones físicas socialmente representativas" (Giddens, 2000, p. 280), donde aspectos como raza y grupo étnico, suelen ser el detonante del trato desigual. En el caso de México, esto suele estar asociado al tono de piel, como lo reflejan los datos del CONAPRED, donde se dice que "cuatro de cada diez personas opinan que a la gente se le trata de forma distinta según su tono de piel" (2010, p. 42).

Sin embargo, tales categorías también pueden estar dadas a partir de otras dimensiones, en las que los fenotipos no necesariamente son el factor principal de marginación, como lo plantean autores como Balibar y Wallerstein (1988) cuando proponen la noción del racismo cultural, o Kinder y Sears (1981) al hablar del racismo simbólico. Como Wieviorka (2007) sugiere, hay una evolución en este concepto, de forma que lo estrictamente genético se suma a otros factores de desigualdad de naturaleza cultural. Para los fines del presente trabajo, entenderemos la discriminación como todo acto que, desde esta noción ampliada de racismo, se manifiesta en una forma de menosprecio hacia sujetos o colectivos, que llevan a cabo prácticas culturales distintas a las socialmente consideradas como ideales, o al menos, deseables.

Este es un asunto que, desde factores específicos como las minorías religiosas, ha sido abordado por autores como Weller, Feldman, Purdam y Andrews (2001) y Gervasi, De la Peña y Sánchez (2016); y que a partir de dimensiones como el bagaje cultural de grupos indígenas y de jóvenes urbanos, ha sido reportado por O `Neill (2003), Del Cairo (2004) y Sandoval (2003). No obstante, la discriminación que tiene lugar a partir de los consumos culturales que realizan distintos sectores de la población mexicana es, hasta donde hemos alcanzado a revisar un campo prácticamente inexplorado, y del que pretendemos hacer una primera aproximación en este trabajo.

\section{Expresiones de discriminación cultural en memes en Internet}

Al inicio de este capítulo hemos establecido que los memes están dados por toda unidad cultural que puede ser replicada, sin importar su formato. ${ }^{9}$ En Internet suele tratarse de emoticones, hashtags, ${ }^{10}$ imágenes estáticas, gifs animados y videos; que forman parte de un catálogo en constante trans-

9 En trabajos anteriores (Pérez Salazar, 2014), hemos propuesto una taxonomía más detallada de memes en Internet, que incluyen desde cadenas de caracteres, hasta productos audiovisuales.

10 Etiquetas socialmente construidas que consisten en palabras antecedidas por el signo de numeral (\#), que en inglés recibe el nombre de hash. 
formación, del cual los usuarios echan mano en una amplia variedad de situaciones, compartiéndolos con o sin modificaciones. Por la naturaleza física de esta publicación, nos vemos limitados a referirnos principalmente a memes dados por imágenes estáticas, en los ejemplos que presentaremos en las siguientes páginas.

A partir de la observación y registro sistemático de memes publicados y/o compartidos por usuarios mexicanos de Facebook y Twitter desde 2011, ha sido posible encontrar enunciaciones discriminatorias coincidentes con algunos de los indicadores reportados por CONAPRED (2010), en especial lo relativo al tono de piel y rasgos étnicos.

\section{Figura 1. Memes racistas}
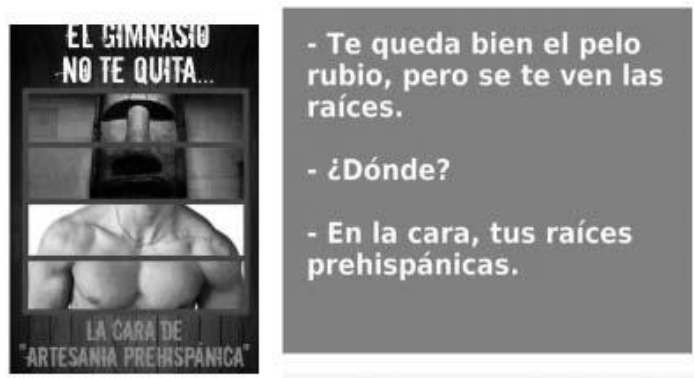

Como la vez que a tu novio se le
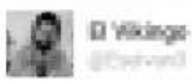

cayó un billete de 100 y se lo regresaron porque pensaron que

A ver criatura prieta, si buscas un hombre alto, guapo y rubio ve a Europa, a esos tipos les encantan las artesanias prehispánicas como tú.

Fuente: Composición hecha a partir de capturas de pantalla en Twitter y Facebook

En estos memes, es posible encontrar expresiones discriminatorias que hacen referencia a lo encontrado por autores como Martínez (2003), Gall (2004), Mijangos-Noh (2009), así como Flores y Telles (2012); en el sentido de que en México prevalece un racismo anti-indígena que durante la mayor parte del siglo XX fue ocultado bajo el discurso oficial del mestizaje y que en muchas ocasiones se ha traducido en una limitación en muchos de sus derechos ciudadanos. 
Sin embargo, como hemos establecido en el objetivo central de este trabajo, enseguida haremos referencia a otras formas de discriminación que están más bien relacionadas con elementos de carácter cultural. Si se parte de una noción amplia de cultura, en los usuarios mexicanos que hemos observado destacan al menos dos grupos de memes que denotan un sentido discriminatorio: el dirigido a grupos indígenas, en los que es notable la referencia que se hace a una parte de su herencia cultural (y no a sus características físicas); y por otro lado, los que tienen que ver con consumos culturales, especialmente en géneros musicales como la banda y el reggaetón.

\subsection{Grupos indigenas}

En México se hablan 92 lenguas indígenas, por alrededor de 6.7 millones de personas. De ellas, el mayor grupo está dado por hablantes de náhuatl, que integra el 23\% del total (INEGI, 2010). A partir de la terminación fonética del nombre de esta lengua, ha surgido un holomeme ${ }^{11}$ cuya enunciación suele estar dada por personas en trajes tradicionales indígenas, a quienes se les atribuyen una serie de frases que forman parte de la cultura popular, adaptadas con la terminación $t$ l.

\section{Figura 2. Racismo hacia elementos culturales indígenas}
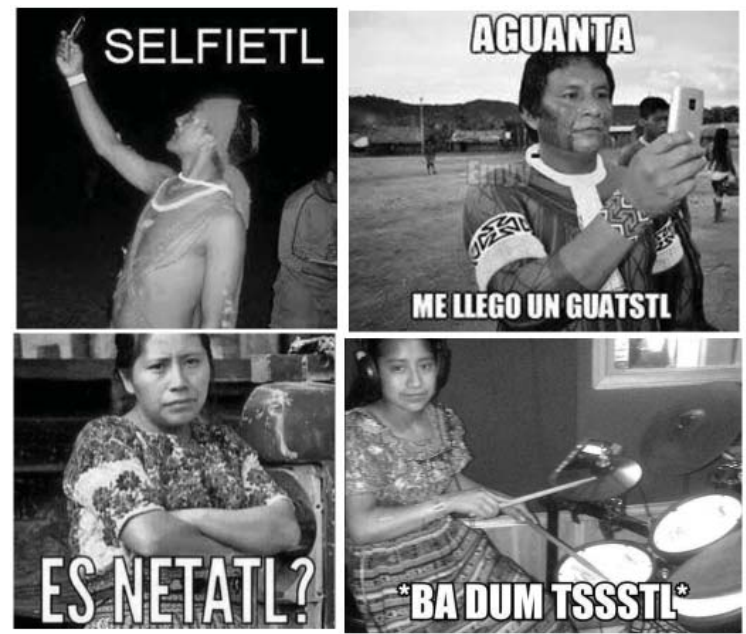

11 Con base en Durham (1991), un holomeme está dado por un sentido general, que puede adquirir distintas manifestaciones específicas. 
Fuente: Composición hecha a partir de capturas de pantalla en Twitter y Facebook.

Los memes que mostramos en la Figura 2, aluden a una representación social en la que, por el simple hecho de portar estos vestidos y ornamentos tradicionales, tales personas entonces deberían hablar en una especie de pseudo-náhuatl (como si fueran incapaces de expresarse de otra manera); rasgo donde proponemos que radica la discriminación cultural a la que hacen referencia los autores ya citados.

\subsection{Consumos culturales: banda y reggaetón}

La noción de que los consumos culturales de alguna manera se relacionan con el estatus de las personas, tiene una larga tradición. Como Gans (1974) propone, las distinciones entre la alta cultura (bighbrow) y baja cultura (lowbrow) se consolida alrededor de mediados del siglo XIX, a partir de la publicación de obras literarias populares en Europa Central, especialmente en Inglaterra. Con el establecimiento de la sociedad de masas como marco explicativo, y sobre todo a partir de la postura aristocrática que sustentó algunos de sus planteamientos desde la Escuela Crítica de Frankfurt, en obras de autores como Horkheimery Adorno (1998) ${ }^{12}$ y Benjamin (1989), ${ }^{13}$ se sugiere que en las industrias culturales prevalece un deterioro de la estética y que al pueblo se le ofrecen sólo manifestaciones artísticas prosaicas, especialmente en la literatura y la música. Si bien a partir de la Escuela de Birmingham (finales de la década de 1960) y la revaloración de lo popular, esta idea fue perdiendo vigencia en los entornos académicos; en algunos sectores sigue prevaleciendo la creencia de que algunos géneros musicales son preferibles a otros, simplemente por ajustarse a los cánones de la llamada alta cultura. En este sentido, Gans (1974) sugiere la existencia de una estructura cultural ${ }^{14}$ que dicta qué gustos son socialmente aceptados y cuáles no, a partir de factores que están atravesados por el ejercicio del poder. El consumo de formas culturales específicas, sugiere este autor, es considerado como un asunto relacionado fuertemente con el estatus, de manera que en ocasiones, los sujetos pueden dar lugar a sucesos performativos: se puede asistir a un concierto de ópera o a una presentación de ballet, con la intención de proyectar un nivel cultural de alguna manera considerado superior; y no necesariamente por un goce estético, lo que sugiere que dicho consumo

12 Se cita a partir de la edición consultada de Editorial Trotta, pero su elaboración ocurrió durante la segunda mitad de la década de 1940.

13 Se trata de un ensayo publicado originalmente en 1936.

14 El término que el autor emplea en el original es taste structure. 
está relacionado con un valor de uso que puede ser bastante complejo, en concordancia con lo planteado por García Canclini (1997).

Desde una perspectiva similar, Bourdieu (2010) señala que el gusto relacionado con los consumos culturales, es una construcción social que está mediada por instituciones como la educación. Se crean, de esta manera, jerarquías que privilegian algunas formas artísticas específicas, en función de las ideologías dominantes. Existe, según este autor, una nobleza cultural que manifiesta la distinción entre:
[...] dos grupos separados por su idea de cultura, de la relación legíti- ma con la cultura y con las obras de arte, y por lo tanto por las condi- ciones de adquisición de las cuales esas disposiciones son producto: la definición dominante del modo de apropiación legítimo de la cultura y de la obra de arte favorece, hasta en el terreno escolar, a quienes han tenido acceso a la cultura legítima desde un principio, en el seno de una familia cultivada (2010, p. 231).

Lo anterior sugiere que el consumo de determinadas manifestaciones artísticas, constituye un aparato ideológico que tiene como consecuencia la separación de distintos estratos sociales, que aunque pueden estar relacionados con diversas formas de capital (cultural, político, económico, etc.); al final se basa en la creencia de que la pertenencia a una élite, está también asociada con aquello que es consumido. Como hemos establecido en torno a la noción de identidad, sugerimos que se trata de una operación de distinción entre el alter y el ego, en la que éste último se asume como superior, dando como efecto el menosprecio a todo aquello ajeno a lo que ha sido socialmente identificado como culto. Como plantea Fernández: "Las músicas son entonces utilizadas para crear espacios culturales expresando formas colectivas de identidad" (2013, p. 167).

En los antecedentes, es posible encontrar numerosos trabajos que buscan establecer una relación entre los consumos culturales y la estratificación social, entre los que destacamos a Pakulski y Waters (1996), Wing y Goldthorpe (2010), así como Herrera-Usagre (2011). Aunque en términos generales estos autores coinciden en señalar que solía haber un traslape entre ambas variables (consumos relacionados con la alta cultura, estaban frecuentemente acompañados de relativamente altas posiciones jerárquicas); se reconoce que, como ya había sido sugerido por García Canclini (1997), las prácticas de consumo pueden están sujetas a una amplia diversidad de variables y factores específicos. Por ejemplo, para Pakulski y Waters (1996), en ocasiones se trata de un asunto aspiracional, es decir, se consumen formas culturales que son percibidas como propias de aquellos grupos a los que se desea pertenecer. Como apunta 
Herrera-Usagre (2011), esta es una muy intensa discusión en los ámbitos académicos, ya que algunos otros estudios ${ }^{15}$ señalan que no necesariamente hay tales estratificaciones y que integrantes de las clases más acomodadas, suelen acercarse a expresiones de la cultura popular. En todo caso, como veremos en los siguientes memes, parece prevalecer un sentido de que géneros musicales como la banda y el reggaetón están relacionados con estratos más bien bajos, desde enunciaciones claramente discriminatorias.

\section{Figura 3. Expresiones discriminatorias hacia consumidores de la música de banda}
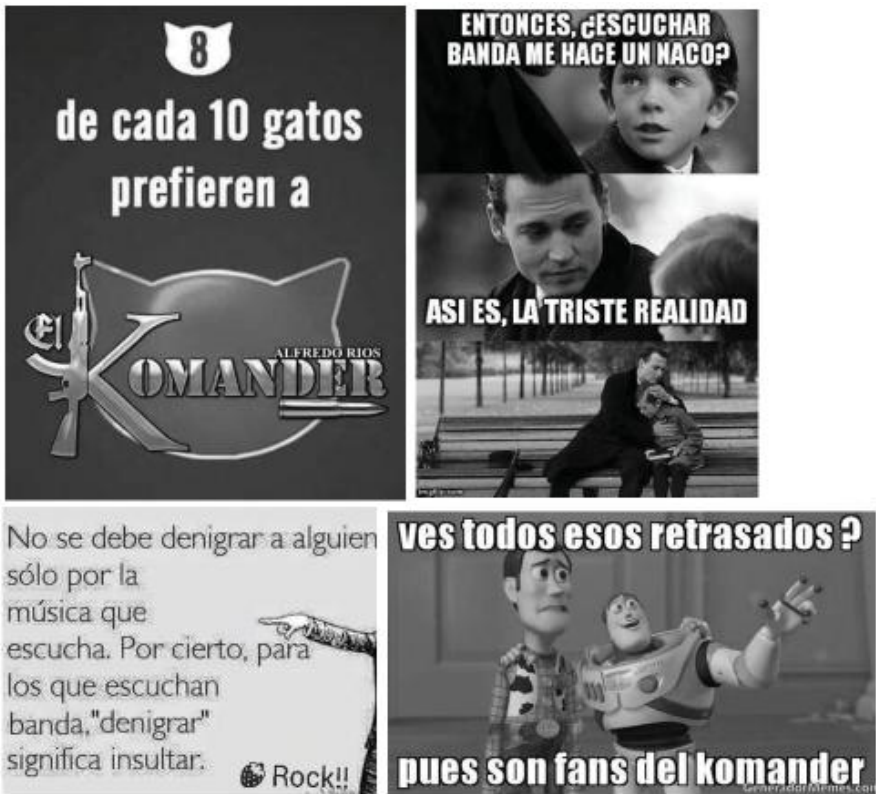

Fuente: Composición hecha a partir de capturas de pantalla en Twitter y Facebook.

Como es posible observar, las expresiones encontradas en estos ejemplos hacen una alusión a un supuesto bajo nivel intelectual, educativo y la condición social de quienes consumen este género, y en particular, de uno de

15 Se citan los trabajos de Peterson y Simkus (1992): «How musical tastes mark occupational status groups» en Lamont, M., y Fournier, M. (Eds.) Cultivating Differences: symbolic boundaries and the making of Inequality. Chicago: University of Chicago Press, pp. 152-186, y Peterson y Kern (1996): «Changing highbrow taste: from snob to omnivore», American Sociological Review, 61, pp. 901-907. 
sus intérpretes, Alfredo Ríos, El Komander. ${ }^{16} \mathrm{El}$ meme que presentamos en la parte superior izquierda, es una reinterpretación de una campaña publicitaria, que aprovecha la doble semántica del término gato, que en México es utilizado de manera más bien despectiva, para referirse a una persona con un empleo manual, como una empleada doméstica o un ayudante de escaso rango. La modificación sígnica es una frecuente característica de estas formas de expresión en línea, y se encuentra facilitada por su condición digital, como ya habíamos sugerido cuando nos referimos a los códigos programáticos. El término naco, empleado en la imagen superior derecha, es un despreciativo que denota el mal gusto de alguna persona, en cercanía al término anglosajón kitsch. En todos los casos, consideramos que hay una discriminación cultural muy evidente, dada la desigualdad y el etnocentrismo denotados.

Figura 4. Expresiones discriminatorias hacia el reggaetón

SI EL ROCK
FUE CREADO
POR EL DIABLO,
NO ME QUIERO
IMAGINAR
QUE CLASE DE
SER MALIGNO
FUE CAPAZ DE
CREAR EL

Si a tu novio le gusta el reggaeton, ¡déjalo ir!

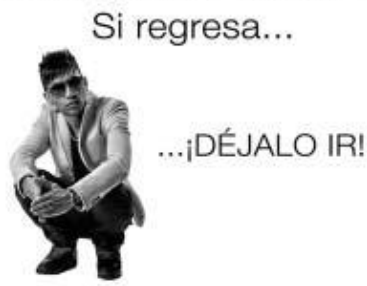

Piano para focar REGGAETON

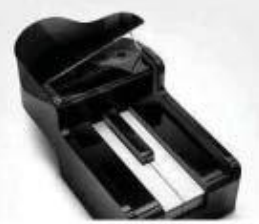

R.E.G.G.A.E.T.O.N. =

(R)uido

(E)xtremadamente

(G)rosero y

(G)rotesco

(A)Itamente

(E)stúpido y

(T)onto que

(O)bstruye las

(N)euronas

Fuente: Composición hecha a partir de capturas de pantalla en Twitter y Facebook.

16 Aunque omitimos presentar más ejemplos por limitaciones de espacio, son muy frecuentes los memes que tenemos registrados a partir de nuestra observación en las ya mencionadas redes sociales, que se refieren particularmente a este cantante. 
El sentido detrás de estas imágenes es similar al del caso anterior con los consumidores de música de banda, aunque en estos casos, el objeto al cual se dirigen las expresiones de denostación, son más al género en sí que a sus consumidores, salvo en el meme que mostramos en la parte inferior izquierda de la composición. En él, la yuxtaposición de la fotografía y el texto, se suman a su reinterpretación, que originalmente se aplica en la cultura popular, a la libertad que debe prevalecer en una relación sentimental, y que en esta enunciación, recurre al sarcasmo como premisa.

No obstante lo anterior, es evidente que en estos ejemplos prevalece un menosprecio hacia este género musical, que parte de un clasismo implícito en el proceso de distinción que se presenta a partir de su enunciación. En relación con ambas formas musicales, quien emplea imágenes de este tipo es probable que esté asumiendo un sentido de superioridad hacia la alteridad que consume tales géneros, desde la más aristocrática de las posturas.

\section{Discusión y consideraciones finales}

La noción de la cultura de masas prevaleció en muchos de los planteamientos sociológicos propuestos durante más de un siglo, en buena parte de la cultura occidental. La idea de que existe un conjunto de personas prácticamente indistinguibles entre sí, con muy escasa formación educativa, relativamente fáciles de manipular, y que llevan a cabo consumos culturales relacionados con formas artísticas de cuestionables ${ }^{17}$ valores estéticos; permeó en una gran parte de los planteamientos teóricos que trataban de explicar la manera en que ocurren algunos de los procesos socio-culturales propios de la modernidad, caracterizados por el empleo de diversas tecnologías de la comunicación que median el consumo del arte, y que son capaces de alcanzar a grandes cantidades de individuos. Como hemos planteado, particularmente a partir de algunos de los primeros trabajos de la Escuela Crítica de Frankfurt, se reproduce una visión aristocrática, en la que se propone la existencia de estratos sociales derivados no solo de su capital económico, sino también, cultural. Así, se reforzó una distinción entre lo culto y lo popular, que en la música se había empezado a construir prácticamente desde la Edad Media; de tal forma que entre finales del siglo XIX y el inicio del XX, era evidente la noción social de que la llamada alta cultura, era desde muchos puntos de vista, superior a la cultura popular.

17 Juicio hecho, por supuesto, desde las posiciones dominantes relativas a la apreciación artística. 
A pesar de los cambios que tuvieron lugar en los entornos académicos a partir de la década de 1960, cuando la Antropología contribuye al interior de los Estudios Culturales a revalorar lo popular; el sentido que hemos observado en los memes que hemos presentado, sugiere que, al menos en aquellos usuarios que los emplean, prevalece un menosprecio hacia géneros musicales que son consumidos por grandes sectores de la población. ${ }^{18}$ Las enunciaciones que encontramos en los entornos virtuales dados por Twitter y Facebook, reflejan una serie de operaciones identitarias en las que, como Bokser (2008) sugiere, hay una representación sesgada de la alteridad, así como una incapacidad para negociar la diversidad, incluso en el plano de lo cultural. En concordancia con lo sugerido por García Canclini (1997), consideramos que, en efecto, en los casos mostrados, están siendo aplicados criterios ideológicos que tienen implícitas relaciones desiguales de poder simbólico.

Algunas personas podrían sugerir que quizá esto esté ocurriendo de una manera distinta a como solía suceder antaño, cuando era posible identificar discursos mucho más explícitos en relación a la alta y la baja cultura. Sin embargo, a partir del fallecimiento del cantante y compositor popular conocido como Juan Gabriel, el asunto volvió a colocarse en la mesa de análisis, cuando el entonces director de TV-UNAM, ${ }^{19}$ emitió una serie de desafortunadas apreciaciones hacia la obra de dicho personaje, y que dieron lugar a una gran indignación que terminaron en la renuncia a su puesto.

Más allá de esta anécdota, consideramos que la tensión entre lo popular y otras formas artísticas valoradas por algunos sectores más bien minoritarios, siguen estando presentes en la actualidad, y resultan altamente visibles en los campos de interacción social dados por la virtualidad y las redes sociodigitales. El uso de memes, como recurso expresivo atravesado por complejos procesos de apropiación y reinterpretación, ciertamente puede ser un acercamiento a la construcción identitaria que realizan los usuarios de Internet, en el sentido de Giddens (1997) que mencionamos en la primera parte de este trabajo. Si se es lo que se dice, entonces, por

18 Vázquez (2016) señala que los géneros más populares que son consumidos a través de la plataforma Deezer por usuarios mexicanos, son: 1 . Regional o Banda, 2. Pop y 3. Electrónico.

19 En una nota editorial publicada en el periódico Milenio el 30 de agosto de 2016, Nicolás Alvarado expresó: "Mi rechazo al trabajo de Juan Gabriel es, pues, clasista: me irritan sus lentejuelas no por jotas sino por nacas, su histeria no por melodramática sino por elemental, su sintaxis no por poco literaria sino por iletrada", lo cual dio lugar a intensas críticas en redes sociales, que fueron reproducidas en otros medios, en espacios informativos y de análisis. 
lo menos quienes llevan a cabo este tipo de enunciaciones, pueden estar reflejando una parte de sus estructuras interpretativas que, de alguna manera, los representan ante los demás.

A partir de lo anterior, y profundizando nuestra reflexión en torno a estas modalidades emergentes de expresión, podemos sugerir que el meme se presenta como una unidad ensamblada, que posee una fuerte carga sígnica otorgada por la unión imagen-texto desde el código programático de la digitalidad, por lo que el significado también reconfigurado por el usuario, cobra nuevos sentidos e interpretaciones. Si para Cole (1996), el artefacto-signo es un aspecto del mundo material que se ha modificado durante la historia de su incorporación humana dirigida a metas, el meme como almalgama-sígnica está siendo empleado como una unidad reconfigurada y reconfigurante, cuyo uso se destina, al menos en los casos que hemos mostrado, a la burla, la denostación y la discriminación.

Por lo tanto, el meme como objeto derivado del artefacto tecnológico-cultural (entendiendo tecnología desde el mismo lenguaje hasta el dispositivo e interfaz), también está dirigido a metas concretas, como es el ejercicio del poder simbólico. Analizando estas características desde la postura de Ilyenkov (1977), el meme como artefacto/objeto/dispositivo, contiene una doble naturaleza que permite dotar de existencia al artefacto virtual (entiéndase que el meme carece de existencia sin el dispositivo que permite su elaboración/visualización/distribución), por lo que su materialidad visible posee la misma dualidad que el artefacto físico. Es, por un lado, ideal, en la medida que su forma material ha sido moldeada/adaptada por su participación activa en un sinnúmero de interacciones de las que son parte (como procesos sociales) y material en la medida en que su existencia sólo es posible por las potencialidades del código programático y por el artefacto que permite generarlo; y que no puede ser entendido fuera de las características de este entorno.

En este sentido, los memes son amalgamas imagen-texto que cobran un nuevo significado, en tanto el proceso de semantización se extiende por fuera de las pantallas para ser ubicado sobre otro proceso social distinto. De este modo, la readaptación de las interacciones de las que formaron parte como unidades independientes, en su unión poseen la capacidad de mediar en un presente caracterizado por múltiples tensiones, donde las variables que hemos abordado (alter-ego, culto-popular), son sólo parte de aquello que debemos seguir indagando en todos los entornos sociales, y de los que, por supuesto, también forman parte las redes sociodigitales. 
Ocho de cada diez gatos prefieren El Komander...

\section{Bibliografía}

Austin, J. (1962). How to do things with words. Oxford: Oxford University Press.

Balibar, E. y Wallerstein, I. (1988). Race, Nation, Class. Ambiguous Identities. Londres: Verso.

Beck, U. (2011). Multiculturalism or Cosmopolitanism: How Can We Describe and Understand the Diversity of the World? Social Sciences in China Press. XXXII (4), pp. 52-58.

Benjamin, W. (1989). La obra de arte en la época de su reproductibilidad técnica. Buenos Aires: Taurus.

Berger, P. L. y Luckmann, T. (2006). La construcción social de la realidad. Buenos Aires: Amorrortu.

Bokser, J. (2008). La Discriminación. Un fenómeno Difuso. Reflexiones a partir de la Primera Encuesta Nacional sobre Discriminación en México. Revista Mexicana de Ciencias Políticas y Sociales, 200, pp. 71-86.

Bourdieu, P. (2010). El sentido social del gusto. Elementos para una sociología de la cultura. México: Siglo Veintiuno Editores.

Castells, M. (1999). La sociedad red. El poder de la identidad. México: Siglo XXI.

Cole, M. (1996). Psicologia cultural. Madrid: Morata Ed.

Dawkins, R. (1976). The Selfish Gene. Nueva York: Oxford University Press.

DeL Cairo, C. L. (2004). La construcción eficaz en tiempos de la discriminación cultural. Universitas Humanistica, 57, pp. 27-37.

Del Río, P. (2006). Las tecnologías que nos cambian. Buenos Aires: Fundación Telefónica.

Durham, W.H. (1991). Coevolution: Genes, Culture and Human Diversity. Stanford, CA: Stanford University Press.

Ellison, N. B. (2007). Social network sites: Definition, history, and scholarship. Journal of Computer-Mediated Communication, 13 (1), pp. 210230.

Fernández, J. A. (2013). Una aproximación al estudio de las músicas como parte del consumo cultural. El Artista, 10, pp. 164-175.

Flores, R. y Telles, E. (2012). Social stratification in Mexico: disentangling color, ethnicity, and class. American Sociological Review, 77 (3): pp. 486-494. 
Gall, O. (2004). Identidad, exclusión y racismo: reflexiones teóricas y sobre México. Revista Mexicana de Sociología, 66 (2), pp. 221-259.

García Canclini, N. (1997). Culturas híbridas. Estrategias para entrar y salir de la modernidad. México: Grijalbo.

Gans, H. J. (1974). Popular culture E' high culture; an analysis and evaluation of taste. Nueva York: Basic Books Inc.

Gervasi, F. De la Peña, G. y Sánchez, M. (2016). El que ofrezca sacrificio a otros dioses, que no sean el Señor, será destruido por completo. Un modelo teórico para interpretar las formas de rechazo hacia la diversidad religiosa en México. En Gervasi, F. (Coord.). Diversidades. Perspectivas multidisciplinarias para el estudio de la interculturalidad y el desarrollo social, México: UAdeC / De Laurel, pp. 381-410.

Giddens, A. (1997). Modernidad e identidad del yo. Barcelona: Península.

Giddens, A. (2000). Sociología. Madrid: Alianza.

Giménez, G. (2000). Materiales para una teoría de las identidades sociales. En José Manuel Valenzuela Arce (coord.), Decadencia y auge de las identidades. México: El Colegio de la Frontera Norte / Plaza y Valdés, pp. 45-78.

Herrera-Usagre, M. (2011). El consumo cultural en España. Una aproximación al análisis de la estratificación social de los consumos culturales y sus dificultades metodológicas. EMPIRIA. Revista de Metodología de las Ciencias Sociales, 22, pp. 141-172.

Horkheimer, M. y Adorno, T. H. (1994). Dialéctica de la Ilustración. Madrid: Trotta.

Instituto Nacional de Estadística y Geografía -INEGI (2010). Censo de población y vivienda 2010. Lengua indígena. Recuperado de http:// cuentame.inegi.org.mx/hipertexto/todas_lenguas.htm

Kinder, D. R. y Sears, D. O. (1981). Prejudice and Politics: Symbolic Racism Versus Racial Threats to the Good Life. Journal of Personality and Social Psychology, 40 (3), pp. 414-431.

Mandoki, K. (2006). Prácticas estéticas e identidades sociales. México: CONACULTA.

Martínez, C. (2003). The 'Culture' of Exclusion: Representations of Indigenous Women Street Vendors in Tijuana, Mexico. Bulletin of Latin American Research, 22 (3), pp. 249-268.

Mead, G. H. (2009). Mind, self, and society: From the standpoint of a social behaviorist. Chicago: University of Chicago Press. 
Mijangos-Noh, J.C. (abril de 2009). Racism against the Mayan population in Yucatan, Mexico. Annual Meeting of the American Educational Research Association. San Diego, California.

O’Neill, C. (2003). Risk Avoidance, Cultural Discrimination, and Environmental Justice for Indigenous Peoples. Ecology Law Quarlerty, 30 (1), pp. 1-58.

Pakulski, J. y Waters, M. (1996). The death of class. Londres: Sage.

PÉrez Salazar, G. (2014). "El meme en redes sociales: Prácticas culturales de replicación en línea”. En Flores, S. (Coord.). Redes sociales digitales: nuevas prácticas para la construcción cultural. México: CONACULTA, pp. 113-132.

Pérez Salazar, G. y Gervasi, F. (2015). “Conflicto y religiosidad en línea. Enfrentamientos en usuarios de Facebook en torno al culto a la Santa Muerte”. En Winocour, R. y Sánchez,J.A. (Coords). Redes sociodigitales en México (pp. 136-163). México: CONACULTA / Fondo de Cultura Económica.

Sandoval, J. (2003). Ciudadanía y juventud: el dilema entre la integración social y la diversidad cultural. Última Década, 19, pp. 31-45.

Searle, J. (1994). Actos del habla. Ensayo de filosofía del lenguaje. Buenos Aires: Planeta.

VÁzquez, R. (2016). ¿Qué música escuchan los mexicanos? Forbes México. Recuperado de http://www.forbes.com.mx/que-musica-escuchan-los-mexicanos/

Weller, P., Feldman, A., Purdam, K., y Andrews, A. (2001). Religious discrimination in England and Wales. Londres: Home Office Research, Development and Statistics Directorate.

Wieviorka, M. (2007). La mutación del racismo. Revista Mexicana de Ciencias Políticas y Sociales, XLIX (200), pp. 13-23.

Wing, T. y Goldthorpe, J. (2010). Social status and cultural consumption. En Wing, T. (Ed.) Social Status and Cultural Consumption, Nueva York: Cambridge University Press, pp. 1-27. 


\title{
Movimientos conectivos y redes sociales: análisis de la Red Anonymous en Twitter
}

\author{
Rodrigo Perera Ramos
}

\section{Introducción}

Los movimientos conectivos pueden ser entendidos como aquellos que han surgido en la última década enmarcados dentro de la evolución de la web 1.0 a la 2.0. El término fue acuñado en 2004 por Tim Berners (inventor del hipertexto) y hace referencia a la web centrada en los usuarios, que les permite colaborar e interactuar entre sí, siendo éstos los productores del contenido, permitiendo la generación de comunidades virtuales, así como la evolución y expansión de las redes sociales virtuales.

Desde este punto de vista, los movimientos conectivos son aquellos que se han apropiado de este nuevo espacio social y que buena parte de su organización, comunicación y acción colectiva, transita por las redes y comunidades virtuales.

Asimismo, los movimientos conectivos tienen como antecedentes directos al Ejercito Zapatista de Liberación Nacional (1994), que fue pionero en la guerrilla comunicacional en Internet (Castells, 1996) y al Movimiento de Resistencia Global, que tiene sus inicios en la denominada "Batalla de Seattle", en 1999 el cual moldeó una nueva dinámica de movilización social de índole transnacional ${ }^{1}$ y con una visión ideológicamente incluyente y polifónica.

Estos movimientos además de enmarcarse dentro de la revolución informática, también comparten un contexto sociopolítico caracterizado por una creciente desigualdad social, una deslegitimación tanto del modelo democrático minimalista, ${ }^{2}$ como del sistema de partidos, por la desconfianza hacia las instituciones del Estado, así como, por una desacreditación

1 Se entiende al concepto de activista transnacional como es definido por Tarrow (2005) en cuanto a que son "individuos o grupos que movilizan tanto recursos como oportunidades domésticas e internacionales para apoyar reivindicaciones a favor de agentes externos, en contra de oponentes externos o a favor de metas que sostienen en común con aliados transnacionales" (p. 43).

2 La democracia minimalista es un tipo de democracia, inspirado en las ideas economicistas y en los teóricos de la elección racional, el cual reduce el papel del ciudadano al acto de votar y considera las elecciones competitivas como una condición necesaria y suficiente para definir la democracia. 
de los liderazgos en los movimientos sociales y un alejamiento de las élites, instituciones y organizaciones formales.

Al mismo tiempo, estos movimientos se encuadran dentro del fenómeno de la mediatización de la política, es decir, la legitimación de la élite política, sus procesos democráticos, la política y las políticas, mediante los medios masivos de comunicación, lo que ha generado que a partir de la última década del siglo XX el centro político, su eje gravitatorio, se mueva al espacio mediático, reforzado por un cerco mediático de los medios electrónicos masivos y la prensa, los cuales, al cerrar sus espacios a las demandas sociales mediante la monopolización de los medios masivos tradicionales y su estrecha relación con las élites económicas y políticas, han marginado las causas sociales (Sádaba, 2012).

Por otro lado, los movimientos conectivos surgen en un entorno socialmente fragmentado e individualizado, distintivo de las sociedades contemporáneas modernas que en paralelo a las Tecnologías de la Información y Comunicación (TIC), han cambiado la idea de los marcos generales de la acción colectiva, hacia movimientos conectivos que posibilitan organizaciones sociales no jerarquizadas, autogestivas formadas por una diversidad de identidades y marcos de acción conectivos (Lance Bennett y Alexandra Segerberg, 2012), basadas en objetivos y no en ideologías (Arquilla y Ronfeldt, 2001).

Así, los actores de este nuevo ciclo de protesta se han alejado de los paradigmas teóricos y conceptuales que dominaron el estudio de los movimientos sociales desde la década de los sesenta del siglo XX, lo que ha generado que los estudiosos de este tema reformulen teórica, conceptual y metodológicamente la forma de comprender y analizar la acción colectiva de los últimos años (p.ej. Castells, 2012; Tilly, 2005; Atton, 2003; Rheingold, 2002; Della Porta y Mosca, 2005; Natal y Perera, 2014; Sábada, 2012; Samuel, 2004; Van Laer y Van Aelst, 2009; Jacobs y Shapiro, 2011; Lance Bennett y Alexandra Segerberg, 2012).

En consecuencia, desde la mirada de las redes sociales, estudios recientes concuerdan en algunas características de los movimientos de resistencia social de los últimos años: 1) la horizontalidad estructural de estos grupos, con varios o nulos liderazgos (policéntrica); 2) la debilidad de los vínculos entre sus miembros; 3 ) grupos e individuos articulados en redes flexibles y versátiles, de tipo malla, a nivel transnacional; por lo que, 4) las redes son altamente densas y descentralizadas con una alta capacidad comunicativa, en cuanto a la rapidez y eficacia de la comunicación 
(p.ej. Bennett y Segerberg, 2012; Diani, 2003; Crossley e Ibrahim, 2011; Toret, 2013; Arquilla y Ronfeldt, 2001).

Desde estos supuestos teóricos, la indagación parte de una pregunta general: ¿En qué medida la red de Anonymous observa los atributos antes señalados?, es decir, ¿Qué tan horizontal o policéntrica es su red? ¿Qué fortaleza tienen los vínculos entre los diferentes grupos que componen la red? ¿Qué tanto se acercan al modelo de la red en malla? ¿Cuál es la densidad y centralidad que muestra la red? Y por lo tanto ¿Cuáles son las capacidades comunicativas de ésta?

En este sentido, el presente trabajo recurre al análisis de redes sociales como una de las estrategias teóricas y metodológicas, que ha tomado mayor fuerza en la literatura sobre movimientos sociales y la acción colectiva, principalmente en el último lustro. Así, desde este enfoque se analiza a un grupo de resistencia social, que ha sido uno de los actores protagonistas en las insurgencias, revueltas y movimientos sociales, más importantes de los últimos seis años y que desde su nacimiento en 2008, ha logrado expandirse rápidamente, organizándose en células a nivel transnacional, con una efectividad e impacto que pocos grupos han logrado hasta la fecha.

Para ello, en la primera parte del trabajo se expone la metodología empleada, seguida de un acercamiento de la perspectiva de redes aplicada a los movimientos sociales. Posteriormente, el documento se adentra a una conceptualización del grupo Anonymous, visto como un movimiento conectivo en red y finalmente se presenta un análisis de la red de Anonymous, con el objetivo de contrastar a este grupo de resistencia, ideal ${ }^{3}$ para el estudio de los movimientos conectivos, lo que la literatura de los últimos años, especializada en el tema, ha denominado como movimientos en red, movimientos conectivos, netwars y grupos enjambre.

\section{Metodología}

El estudio de la red de Anonymous se hizo a partir una muestra aleatoria, de las cuentas en Twitter de este grupo, así se obtuvieron 99 cuentas de los cinco continentes. ${ }^{4}$ Asimismo, se recolectaron los datos de los vínculos, interacción y geolocalización con el programa informático NodeXL.

3 Anonymous es un grupo ideal para el estudio de los movimientos de este siglo, debido no solamente a su impacto y desimanación, sino que además, su comunicación, estructura y organización está basada principalmente en las comunidades virtuales y a su vez, teóricamente representa un modelo ideal de lo que Arquilla y Ronfeldt (2001) denominan como netwars y estructura de enjambre.

4 Véase Apéndice 1 para mayor información. 
Si bien, ante la limitante de obtener una muestra estadística representativa de un grupo anónimo, flexible y en constante cambio, se optó por una selección aleatoria lo suficientemente amplia, que permite hacer una primera aproximación al sujeto de estudio (Anonymous), desde un análisis de redes sociales.

Cada cuenta Twitter Anonymous, en este estudio, representa una célula de la organización, por lo que el análisis de red se realizó a nivel meso, tomando como vínculo la relación como seguidor o seguido entre estas 99 células. Asimismo, la fortaleza de los vínculos se midió a partir de la interacción entre cada cuenta Twitter, es decir, las menciones y contestaciones (reply) a los twitts, entre las diferentes cuentas analizadas.

Por su parte, a partir del software Pajek (principalmente) y Gephi, se elaboraron los grafos de la red y midieron las diferentes características de ésta en su conjunto, como densidad, diámetro, grado medio y longitud media en el camino, con la finalidad de medirla de manera general y ver de esa forma, su centralidad, cohesión y efectividad para comunicarse en red.

Asimismo, con el programa Pajek se observaron las tres medidas de centralidad (grado, cercanía e intermediación) propuestas por Freeman (2000). Desde este punto de vista la centralidad por grado define la jerarquía de un nodo en cuanto a su potencialidad de ser una canal importante de comunicación, es decir, la centralidad de los flujos de comunicación. Por su parte, la centralidad por intermediación muestra la frecuencia con la que un nodo está entre otros pares de nodos en el camino más corto (geodésica) del que les conectan, por lo que analiza la centralidad del nodo a partir de su posición de influencia en la comunicación, teniendo la capacidad de ocultar o distorsionar la información, así como de coordinar y mantener la comunicación en la red, en síntesis, esta medida muestra la potencialidad de los nodos para controlar la información. Por último, la centralidad vista a partir de la cercanía, mide el grado de proximidad entre un nodo y los demás nodos de la red, por lo que analiza su centralidad, a partir de que no dependa de otros actores (nodos) como intermediarios o transmisores de los mensajes, ya que esta medida analiza la independencia y eficiencia de la comunicación (Freeman, 2000).

Por último, la red que aquí se analiza es una red de un sólo modo, es decir, el análisis de la red de Anonymous, que se presenta, está constituido por una sola categoría analítica (las cuentas Twitter de la organización). Asimismo, la red de Anonymous se elaboró con vínculos dirigidos, estando determinada la dirección desde el nodo seguidor, hacia la cuenta a la que sigue. Asimismo, la fuerza de cada vínculo se midió, a partir de la interac- 
ción entre los nodos (menciones, re-twitts). En caso de que ambos nodos se sigan, la relación es marcada como recíproca, por lo que el vínculo se muestra en ambas direcciones. A su vez, la red que aquí se presenta puede ser vista como una red completa del grupo Anonymous en Twitter.

\section{El estudio de redes en los movimientos sociales}

A partir del nuevo ciclo de protesta de este milenio y de la masificación y apropiación de las TIC por parte de los activistas y de los grupos de resistencia, para organizarse, comunicarse y realizar acciones colectivas en este nuevo espacio social, la metodología ha tenido que ir adaptándose para estudiar las insurgencias y grupos reivindicativos de estas nuevas formas de protesta y organización.

Por lo tanto, los estudiosos de este tema han encontrado en la etnografía virtual, el análisis de contenido en línea, la webmetría y el análisis de redes virtuales, entre otras, herramientas poderosas para describir y comprender a la acción colectiva de los últimos años.

Sin embargo, el estudio de redes en los movimientos sociales y grupos de resistencia social, no es novedoso: al menos desde finales de la década de los sesenta, diversos investigadores han aplicado esta perspectiva para analizar a los movimientos sociales. En este sentido, esta perspectiva teórica y metodológica conceptualiza a los movimientos sociales como redes de movilización, en donde los vínculos entre los diferentes actores (a nivel micro, meso o macro) es la unidad de análisis básica, mediante los cuales se desarrolla la interacción simbólica, se intercambian recursos (materiales y simbólicos), se llevan a cabo los procesos de comunicación y organización en donde se forman y constriñen identidades. Asimismo, la identidad no es entendida como un atributo de los individuos, sino que ellas "están incrustadas en redes, en estructuras de significado más complejas que los roles, las conciencias individuales y las expectativas mismas de los sujetos" (Jaramillo Marín, 2009, p. 81).

Por lo tanto, desde este paradigma, una red social puede ser entendida como "uno de muchos posibles conjuntos de relaciones sociales con un contenido específico - por ejemplo, comunicativo, de poder, afectivo o de intercambio- que vincula a los actores [identidades] dentro de una estructura social aún más grande" (Emirbayer y Goodwin, 1994, citado en: Jaramillo Marín, 2009, p. 77).

En este sentido, uno de los estudios pioneros más sobresalientes de esta perspectiva, es el de Granovetter (1973), quien estudió la capacidad 
para lograr objetivos en común, de dos organizaciones en Boston, las cuales luchaban contra la renovación urbana de la ciudad. Gronovetter (1973) analiza las redes a partir de examinar los vínculos que envuelven a la comunidad, para ver si los aspectos de su estructura pueden posibilitar o bloquear a una comunidad para organizarse como colectivo. Su estudio concluye que grupos cerrados, sin lazos débiles importantes, que puedan servir como puentes hacia otras redes son ineficientes para organizarse y conseguir resultados en común, del otro lado, demuestra que redes más abiertas, con un mayor número de vínculos débiles, son más efectivos para organizar la acción colectiva con éxito.

Posteriormente, Diani (2003) fortaleció el estudio de Granovetter (1973) al sustentar que los vínculos fuertes son una precondición necesaria para que se desarrollen movilizaciones sociales eficaces y estables en el tiempo, en donde la presencia de un número significativo de aliados fuera y dentro de la red aumentaría considerablemente el éxito de los movimientos sociales. En este sentido, el éxito de las movilizaciones sociales no sólo dependerá de los lazos débiles que sirvan como puentes hacia otras redes o grupos sociales, que les permitan generar mayores vínculos solidarios y movilizar un mayor número de recursos, sino que también, es necesario contar con una estructura primaria, que cuente con lazos fuertes, los cuales le puedan dar una mayor cohesión y estabilidad a la red. En este orden de ideas, para ambos autores el análisis de redes sociales tiene como objeto medir tanto la conectividad de los nodos, como la fuerza de los vínculos.

Asimismo, otros estudiosos de los movimientos sociales destacan la importancia de la densidad y multiplicidad de la red, ya que se argumenta que a una mayor densidad y multiplicidad (actores vinculados entre sí de múltiples formas), se genera mayor confianza, solidaridad e identidades definidas (Bott, 1957; Coleman, 1988, 1990; Gould, 1991, 1993; McAdam, 1982; Milroy, 1987; Crossley e Ibrahim, 2011).

Así, diferentes autores han dedicado sus esfuerzos a estudiar las insurgencias sociales de los últimos años desde el paradigma teórico y metodológico del análisis de las redes sociales, enfocándose en la conectividad de los actores (Bennett y Segerberg, 2012), la densidad y medidas de centralidad de activistas universitarios (Crossley e Ibrahim, 2011), la emergencia de identidades colectivas y la construcción de narrativas en red (Toret, 2013; Gutiérrez, 2015).

En general, se puede apreciar que en los últimos años y en especial desde la denominada Primavera Árabe, el análisis de las redes sociales se ha 
incorporado con bastante fuerza al estudio de las movilizaciones sociales y principalmente se han analizado desde las plataformas virtuales que ofrece Internet y de manera particular en Twitter.

Esta revalorización del análisis de redes sociales en la acción colectiva, se debe a tres factores preponderantes: la importancia de Internet y en particular de las redes virtuales en las movilizaciones sociales; un agotamiento de las herramientas teóricas y metodológicas con las que se habían estado estudiando a los movimientos sociales desde la segunda mitad del siglo XX, producto de los cambios sociales y contextuales de la era de la información, así como la rápida evolución de herramientas informáticas, que permiten medir y analizar estas redes desde el espacio virtual.

\section{Estudio de caso del grupo Anonymous}

Anonymous es un ejemplo de la complejidad de los grupos de resistencia actuales y de la debilidad de las teorías y metodologías clásicas para entenderlo, describirlo e incluso medirlo de forma precisa.

De manera general se puede decir que Anonymous es un grupo cyberhacktivista transnacional, ya que está influenciado tanto por la filosofía del cyberactivismo y del hacktivismo ${ }^{5}$ y a su vez sus miembros pertenecen a ambas formas de activismo. Por otro lado, la transnacionalidad de Anonymous es definida no sólo porque su red tiene presencia en todos los continentes, sino también porque ha realizado acciones colectivas con diferentes actores y ha apoyado una diversidad de reivindicaciones a nivel global.

Sin embargo, Anonymous tiene una historia particular, que lo hace aún más intrincado de describir. Este grupo no surgió en un principio, como una red activista, sino como una red lúdica que se empezó a conformar desde la página web 4Chan y dentro de ésta en el foro Random /b/. Esta página web y en especial este foro, era caracterizado por no filtrar ningún tipo de contenido, dejando al libre albedrío todo tipo de comunicación, el foro se distinguía por contener imágenes y publicaciones en general grotescas, sin sentido y graciosas. Asimismo, no exigía ninguna subscripción o identificación para interactuar dentro de los foros, por lo que muchos usuarios preferían no usar ningún tipo de nombre o seudónimo y el sistema automáticamente los nombraba como Anonymous.

Así, los usuarios Anonymous se distinguían por crear caos en el foro, ya sea molestando a otros usuarios o con contenidos controversiales, por lo

5 Para ahondar sobre el hacktivismo véase Natal y Perera, 2014. 
que el seudónimo Anonymous, con el tiempo, empezó a cobrar una cierta identidad dentro de este espacio. Al grado de que se llegó a pensar que todos los usuarios que publicaban con ese mote eran una misma persona. Dentro de esta dinámica de humor ácido, los Anonymous comenzaron a generar códigos compartidos a través de palabras y saludos clave, lo que a su vez generó que se empezaran a ver como una entidad.

Asimismo, los usuarios del foro Random /b/y en particular los Anonymous, además de tener un gusto en común por las bromas pesadas y reírse a expensas de los demás, muchos de ellos compartían el gusto y el conocimiento informático, por lo que dentro de sus bromas atacaban páginas web para evitar su funcionamiento.

En consecuencia, la autogeneración de una identidad colectiva a partir de un no-seudónimo (Anonymous) posiblemente los llevó a actuar colectivamente más allá del plano lúdico. Probablemente su primer objetivo, Chris Forcand, un pedófilo canadiense que actuaba en Internet, violentó a uno o más Anonymous, el hecho es que en 2007 "un grupo de individuos que se hacían llamar Anonymous envió información de Forcand y detalles de sus actividades a la Policía Real Montada de Canadá” (Cruz, 2011, p. 43). Forcand fue arrestado en diciembre de ese año.

Posiblemente el hecho de que el periodista Gus Kim los catalogara como "justicieros de Internet", a partir de la denuncia hacía el pedófilo, les haya detonado esa identidad o conciencia colectiva como vigilantes o justicieros de Internet. Sin embargo, su siguiente ataque, en 2007, ya como un colectivo más cohesionado, no fue por alguna causa relacionada con Internet. Su objetivo fue Hal Turner, un locutor de radio estadounidense caracterizado por sus posturas racistas y xenofóbicas, a quien le sabotearon su programa de radio a través de llamadas telefónicas y le bloquearon temporalmente su página web.

No obstante, el nacimiento de Anonymous como un grupo de resistencia social transnacional, se puede enmarcar a partir de la Operación Cienciología, en la cual se organizaron en torno a una de sus principales reivindicaciones (libertad de información y expresión, principalmente en Internet), que actualmente enarbolan. Además, fue la primera vez que pasaron del espacio online al offine, usando como símbolo la máscara de Guy Fawkes, ligada al protagonista anarquista de la película " $V$ of Vendetta" y cuando empezó la subcultura y narrativa distintiva del grupo: "Nosotros somos Anonymous, somos legión, nosotros no perdonamos, nosotros no olvidamos, espérennos”. 
Esta operación (como suelen llamarles a sus acciones colectivas), posiblemente no se hubiera realizado sin el éxito de las dos anteriores, las cuales le confirieron al grupo una capacidad subjetiva de agencia como actor social y al mismo tiempo lograron impactar en la prensa tradicional.

Así, las acciones colectivas que realizaron durante 2008, en contra de la Iglesia de la Cienciología, aglutinaron en las calles, en febrero de ese año, a miles de Anonymous en las ciudades más importantes de Estados Unidos, Australia, Inglaterra, Israel, Alemania y Holanda, principalmente, para protestar en contra de esa iglesia. Estas manifestaciones públicas de Anonymous giraron entorno a reivindicar a Internet como un espacio libre de censura, ya que la propia Iglesia de la Cienciología trató de prohibir la reproducción en Internet de un video producido por esta organización religiosa, a través de amenazas legales (derechos de autor) dirigidas a los sitios de Internet que tuvieran en línea este material videográfico, de tal forma que esta prohibición o intento de censura, fue el desencadenante de la movilización de Anonymous.

A partir de esa fecha, Anonymous se volvió un grupo protagónico de las movilizaciones sociales, reivindicando principalmente el derecho a la libertad de información y expresión, pero que también se ha solidarizado con grupos y causas diversas a nivel global y local.

En síntesis, la ausencia de una agenda reivindicativa, la apariencia de un grupo un tanto caótico e imprevisible, irónico, dramatúrgico, amenazante, petulante, anónimo, sin derecho de membresía, pero con una estética y semántica bien definida y con acciones de alto impacto en la prensa, le confiere a Anonymous características que dificultan su análisis a partir de las categorías clásicas de la acción colectiva y movimientos sociales (como identidad colectiva, reivindicaciones, liderazgos, estructura organizativa, antagonistas, etc.), particularidades, que a su vez lo vuelven un fenómeno por demás interesante para los estudiosos del tema.

\section{Hacia una tipología de la red de Anonymous}

Anonymous puede entenderse de manera general, como un grupo de resistencia social (cyberhacktivista), que encaja de manera amplia en lo que a aquí se describe como movimientos conectivos. Sin embargo, para tratar de profundizar en este grupo, es preciso retomar conceptos teóricos que puedan definirlo más claramente a partir de la teoría de redes, así como incorporar estrategias metodológicas que puedan describir al grupo desde un punto de vista empírico, desde el análisis de redes sociales. 
En este sentido, Anonymous puede entenderse como una actor protagónico ideal de lo que Arquilla y Ronfeldt (2001) denominan como netwars, el cual se refiere a un modo emergente de conflicto en diferentes niveles de la sociedad, visto como el resultado del nacimiento de formas de organización en red, que en parte se debe a la revolución informática, donde los protagonistas utilizan esta forma de organización, relacionadas a doctrinas, estrategias y tecnologías en sintonía con la era de la información.

A su vez, los protagonistas de las netwars se caracterizan por tener una organización dispersa, en pequeños grupos e individuos que se comunican, coordinan y conducen sus campañas en modo de inter-redes y a menudo sin un control de mando definido. Asimismo, sus identidades y lealtades pueden cambiar del Estado-nación al nivel transnacional, por lo que sus alcances pueden ser tanto a nivel subnacional como internacional (Arquilla y Ronfeldt, 2001).

Asimismo, a partir de las capacidades (Arquilla y Ronfeldt, 2001) y estructura de estas redes (Toret, 2013 y Gutiérrez, 2015), son definidas a partir de la metáfora del enjambre (swarming). En cuanto a sus capacidades ofensivas estas redes tienden a ser adaptables, flexibles y versátiles de acuerdo a las oportunidades y desafíos que se les presentan, en donde las dispersas unidades de la red convergen en un objetivo desde múltiples direcciones, "siendo capaces de juntarse rápida y sigilosamente en un objetivo, para después disolverse y dispersarse" (Arquilla y Ronfeldt, 2001, p. 12).

En cuanto a su estructura, se caracterizan por contar con lazos débiles ya que regularmente no comparten ideologías en común, sino objetivos en concreto. Son agrupaciones o movimientos que contienen diversas ideologías y reivindicaciones paquetizadas ${ }^{6}$ (Arquilla y Ronfeldt, 2001). Por lo tanto, su estructura es como señala Arquilla y Ronfeldt (2001, p. 10), citando a Gerlach (1987) y Hine (1970): "segmentada, policéntrica e ideológicamente integrada en red”. Esto significa que estas redes están compuestas por diferentes subredes, con muchos y diferentes líderes y centros de dirección, en una red segmentada, integrados los líderes en redes reticulares, a través de una variedad de estructuras, personas y lazos

6 Arquilla y Ronfeldt (2001) hacen referencia a que ese tipo de organizaciones contestatarias tienen una gran diversidad ideológica en sus filas para responder a un gran rango de temas que puedan surgir (derechos humanos, defensa del territorio, cuestiones ambientales, democracia, etc.), esta diversidad ideológica se encuentra enmarcada o paquetizada dentro de los marcos maestros o master frames, de los movimientos sociales. 
ideológicos. Por lo que la red es usualmente amorfa, contrayéndose y expandiéndose constantemente. Desde esta perspectiva, este tipo de organizaciones son vistas como entes vivos, flexibles, adaptables y fluidos.

Esta idea de las redes enjambre coincide con el concepto de movimientos rizomáticos empleado por Castells (2012) y Battocchio (2014):

En un rizoma, la organización de los elementos no sigue líneas jerárquicas sino que cualquier elemento puede afectar o incidir en cualquier otro sin importar su posición recíproca y, por lo tanto, carece de centro [...] Los rizomas crecen indefinidamente, con el curso de los años mueren las partes más viejas pero cada año producen nuevos brotes, pudiendo de ese modo cubrir grandes áreas de terreno (p. 32).

Figura 1. Modelo de red rizomática.

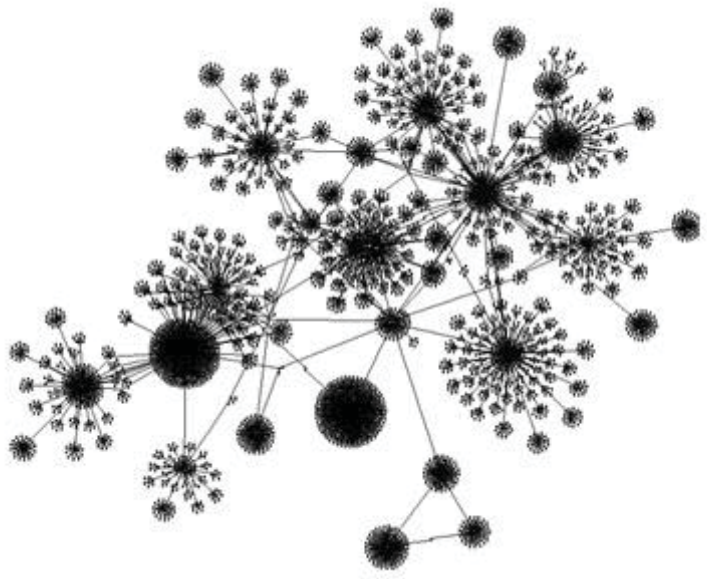

Fuente: Battocchio, 2014, p.32.

Por último, los modelos aquí expuestos, armonizan con la idea que algunos de los integrantes de Anonymous observan de su agrupación, así en entrevista un Anon (como suelen autonombrarse) comentó: "Lo llamamos una mente de panal...Es como una bandada: sabes que estás en una porque vuelas en la misma dirección que los demás pájaros. Eso es todo. No hay un líder y nadie decide quién entra y quién no" (Cruz 2011, p. 42). Otro Anon comenta: "Operamos por células, cada célula decide una actividad, se la comunica a otra célula y cualquiera es bienvenido a unirse. Nuestra falta de líder y de gratificación monetaria nos hace imposibles de corromper" (Battocchio, 2014, p. 33). En este mismo sentido Battocchio (2014) rescata de un video difundido por Anonymous la siguiente autodefinición: "Anonymous no es siempre el mismo grupo de gente, se dice en 
la constitución de los EEUU que es un documento vivo porque se puede editar, emendar y modificar conforme a la voluntad del pueblo para acomodarse a sus necesidades [...] No somos la misma conciencia cada hora, mes o año" (p. 34).

\section{Tipo de red ideal y la red Anonymous}

Como explican Arquilla y Ronfeldt (2001), en la literatura sobre teoría de redes, se pueden encontrar tres tipos ideales de red, que a partir de su estructura pueden operar con mayor o menor eficacia, dependiendo de los objetivos y contextos de cada organización. Estos modelos son: la red en cadena, la red en estrella y la red en malla (all-channel network) véase Figuras 2, 3 y 4.

Figura 2. Red en cadena

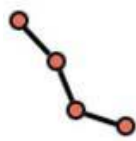

\section{Figura 3. Red en} estrella

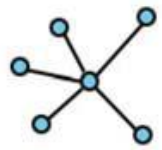

Figura 4. Red en malla

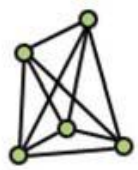

Fuente: elaboración propia

Por consiguiente, a partir del contexto que envuelve a los movimientos conectivos y en específico a los grupos protagonistas de las netwars que se articulan mediante el modelo de enjambre, el tipo de red ideal (de acuerdo a las descripciones señaladas en el apartado anterior) para este tipo de organizaciones, tendría que ser necesariamente el modelo en malla, ya que la principal característica de esta red es que todos los nodos están conectados entre sí, dando como resultado una densidad de red igual a uno.

A su vez, en las redes malla no existe un liderazgo medular o centro de dirección, es decir, es segmentada y policéntrica, no tiene un corazón o cabeza que pueda ser atacada, si la red pierde un nodo, ésta no se desarticula. La red en su totalidad (aunque no necesariamente cada nodo) tiene poca o ninguna jerarquía, esto quiere decir que es una red descentralizada.

Así, la estructura de esta red, permite descentralizar la toma de decisiones y las operaciones, lo que da como resultado un diseño en el cual podría no existir ninguna cabeza, o bien, múltiples cabezas. Asimismo, producto de esta descentralización, en donde no hay jerarquías bien establecidas, los miembros del grupo pueden actuar autónomamente sin recurrir a una guía o directriz, ya que todos "saben lo que deben hacer". Por otro lado, aunque no todos los nodos deben estar en comunicación constante, la estructura 
permite que cuando sea necesario, la información pueda ser rápida y eficazmente comunicada dentro y fuera de la red (Arquilla y Ronfeldt, 2001).

Sin embargo, lo que se ha visto hasta aquí, son tipologías ideales, modelos y supuestos teóricos que necesitan ser contrastados empíricamente. En este sentido, las redes de tipo malla, difícilmente (sino es que imposible) se pueden encontrar en grupos complejos, con un extenso número de actores como es el caso de Anonymous y en donde, la misma flexibilidad de la red, la cual se encuentra en constante cambio, imposibilita por un lado la conexión de todos los nodos, así como, hacer análisis precisos de ésta.

\section{Estructura general de la Red Anonymous}

Como Arquilla y Ronfeldt (2001) señalan, las redes de tipo malla son las más difíciles de organizar y sostener, ya que requieren una comunicación densa, la cual se ha facilitado con las TIC y por lo tanto esta revolución tecnológica está permitiendo que los grupos de resistencia se acerquen más a este tipo ideal de red.

Así, se observa que la red Anonymous se acerca más al tipo ideal de red malla, con una cohesión moderada, es decir, es una red moderadamente densa, ya que dentro de ésta existen el 17\% de los vínculos posibles y a su vez tiene un promedio de grado (average degree) de 15.06, o sea, que en promedio los nodos tienen 15 enlaces. Asimismo, el diámetro de la red es de cinco, por lo que la distancia máxima entre dos nodos es de cinco grados. Asimismo, la longitud media de camino entre los nodos es de 2.082, lo que indica que en promedio los nodos están separados por dos nodos.

\section{Figura 5. Red Anonymous.}

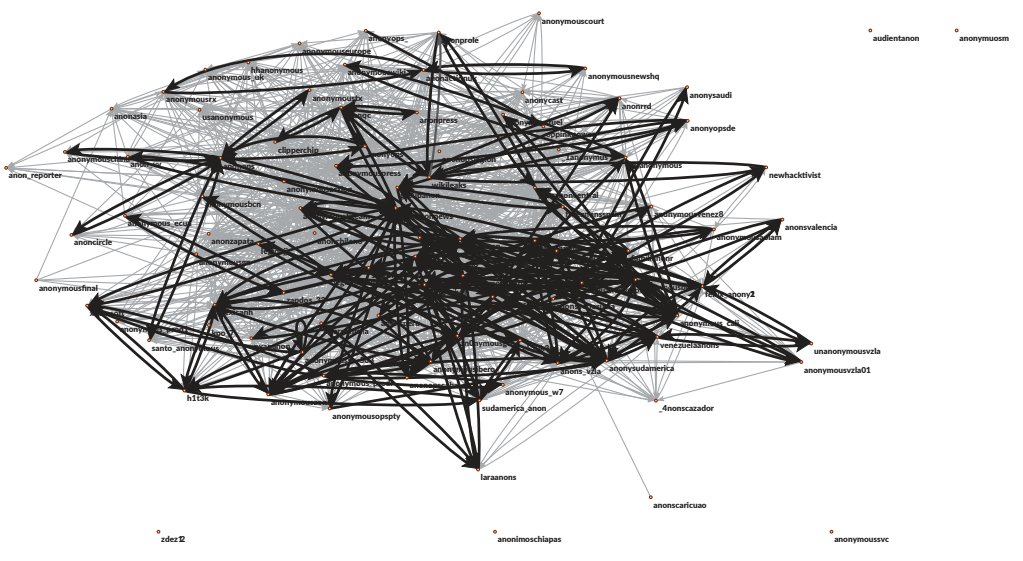

Fuente: elaboración propia. 
A su vez, aplicando el algoritmo Kamada-Kawai, separando sus componentes, se pueden observar cinco nodos desconectados de la red, así como un nodo (anoncaricuao) que sólo tiene un vínculo con otro de su mismo país (anonsvenezuela). Asimismo, en la figura se observan en el centro los nodos con mayor peso en la red (youranonnews, anonhispano, iberoanon, ibero_anon, anonophispano, anonymousperu, legionhonduras y anonymoustjteam). En este sentido, se puede observar una descentralización de la red, es decir no existe un único nodo que represente una posición jerárquica bien definida en donde se concentre el mayor peso (véase Figura 5).

Esto se comprueba también al aplicar el algoritmo $K$-Core, el cual divide a la figura en subredes a partir del grado nodal. Así, a través del $K$-Core, se percibe que $50 \%$ de los nodos comparten una misma centralidad, ya que su grado nodal es similar (véase Figura 6).

Figura 6. Red Anonymous subredes a partir del grado nodal en dirección Y, con K-Core.

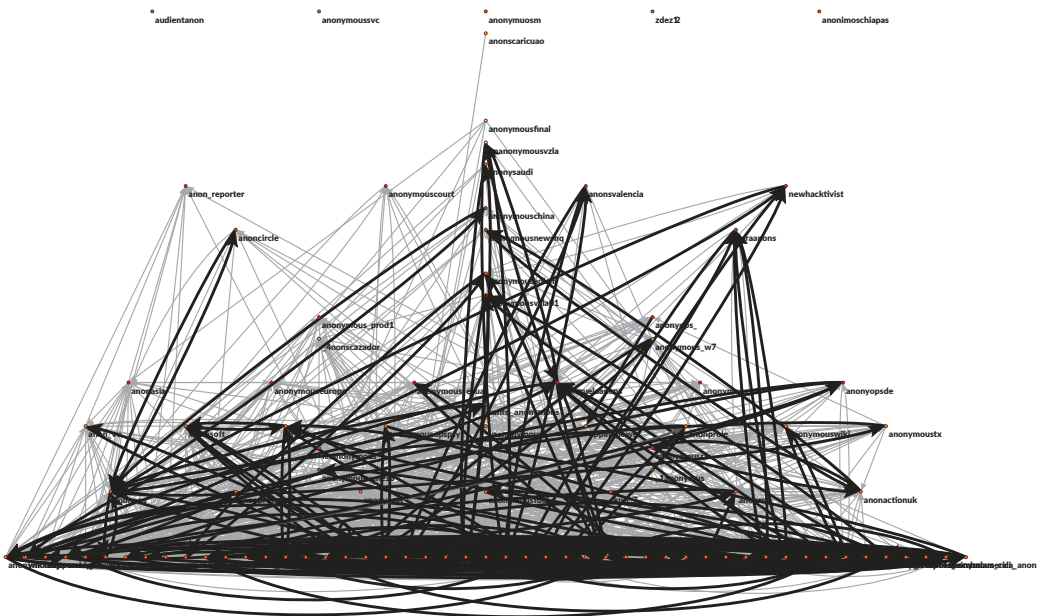

Fuente: elaboración propia.

En la Figura 6 se observan al menos cuatro subredes, en donde existen 49 nodos con un grado nodal alto, 30 con un grado nodal medio, 14 con grado nodal bajo y un subgrupo de cinco nodos desconectados, junto con un nodo con un solo vínculo?

7 En la subred con grado nodal alto se observa un rango de entre 95 y 41 vínculos, mientras que en la subred con un grado nodal bajo su rango varía de entre 17 y 5 . 


\section{Medidas de centralidad}

En cuanto al grado nodal por actor, se encuentra que tres de ellos son los que tienen mayor centralidad en la red (véase Figura 7) y los grados nodales varían de 95 vínculos (youranonnews) a uno (anonscaricuao). De esta forma, si se eliminan los cinco nodos desconectados, el grado nodal medio es de 35 , esto quiere decir que en promedio cada nodo tiene 35 vínculos en primer grado, obteniendo una desviación estándar de 21.92 (véase Figura 8).

Figura 7. Centralidad de la Red Anonymous a partir del grado nodal en Y.

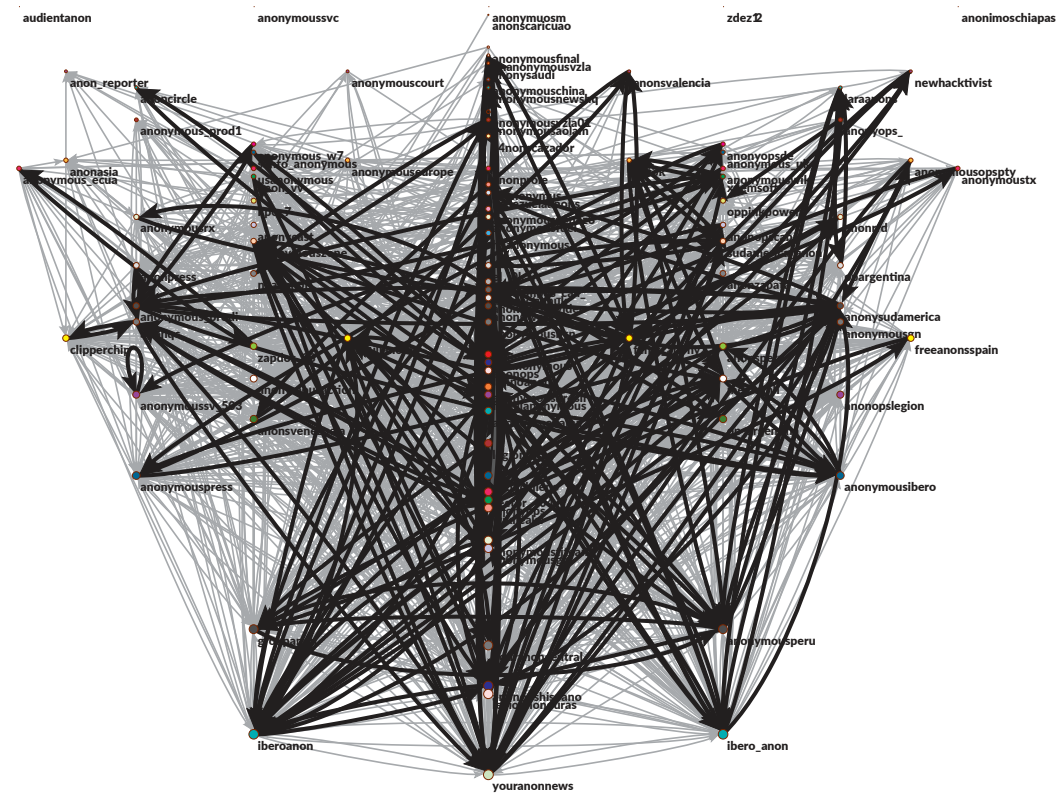

Fuente: elaboración propia. 
Figura 8. Centralidad de la Red Anonymous, a partir del grado nodal (el tamaño del nodo guarda una relación directa con su grado de centralidad).

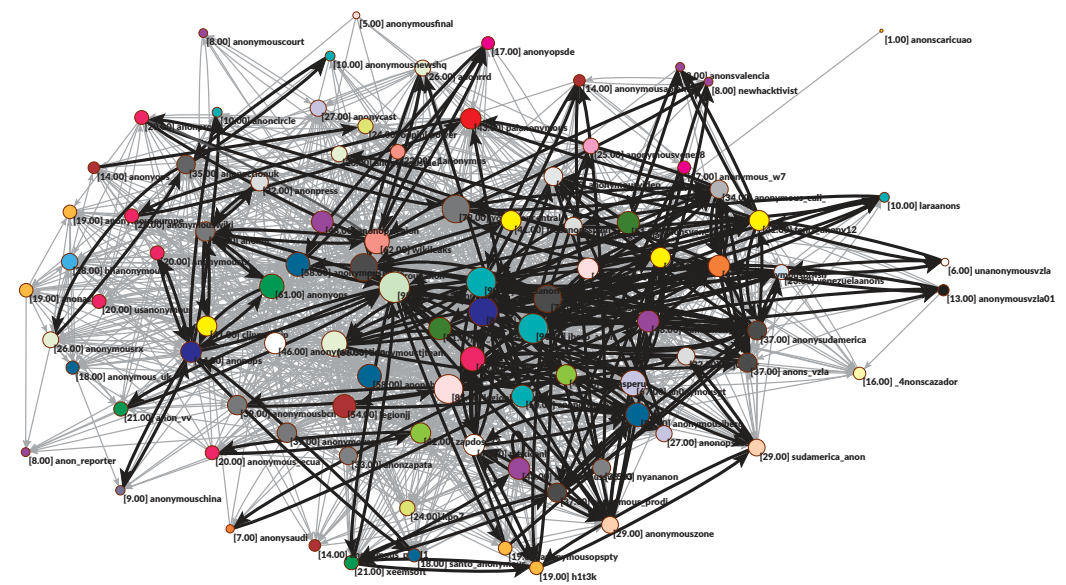

Fuente: elaboración propia.

Por otra parte, para medir la eficacia de la comunicación en la red en cuanto a la capacidad de los nodos para controlar y/o coordinar la información, es decir, la centralidad a partir de su posición como intermediario de la información, medida a través de la frecuencia con la que un nodo aparece en el camino más corto (geodésica) que conecta a otro nodo. Se encontró una red casi en su totalidad descentralizada. Así, aunque los mismos actores con mayor grado nodal observan también la mayor jerarquía en la intermediación, el nodo con un valor más alto apenas tiene un peso en la red de 0.09 y la gran mayoría de los nodos tiende a cero. Los nodos de la red alcanzan una media de 0.0096, excluyendo a los nodos desconectados, y una desviación estándar de 0.015 lo cual significa un nivel alto de descentralización entre los nodos (véase Figura 9). 
Figura 9. Centralidad de la Red Anonymous, a partir de su grado de intermediación (el tamaño del nodo guarda una relación directa con su grado de centralidad).

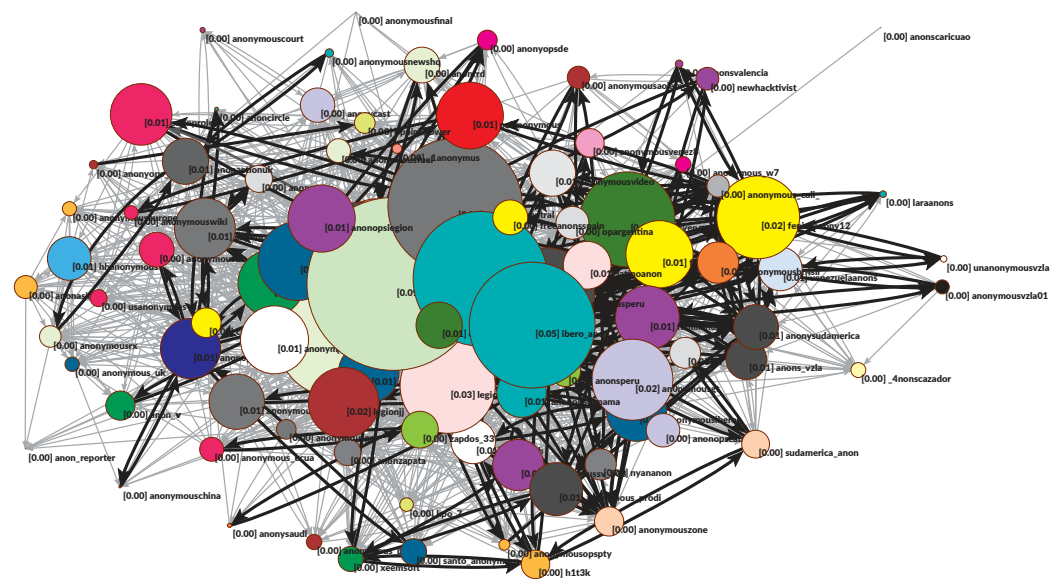

Fuente: elaboración propia.

A su vez, la centralidad (medida por la cercanía de los nodos) se comporta de forma muy similar a la de intermediación. En este caso, eliminando a los nodos desconectados, la centralidad varía muy poco, ya que va del nodo con mayor cercanía (con un valor de 0.61 , iberoanon) al nodo más alejado (anonscaricuau con 0.33). Lo que da una medida central de cercanía de 0.46 en promedio entre todos los nodos, con una desviación estándar de 0.084 . Por lo tanto, como se puede apreciar en la Figura 10, los nodos comparten una medida central de cercanía muy similar, por lo que los nodos en la red, son bastante independientes para transmitir y recibir información desde y hacia cualquier punto de ésta. 
Figura 10. Centralidad de la Red Anonymous, a partir de su centralidad de cercanía (el tamaño del nodo guarda una relación directa con su grado de centralidad).

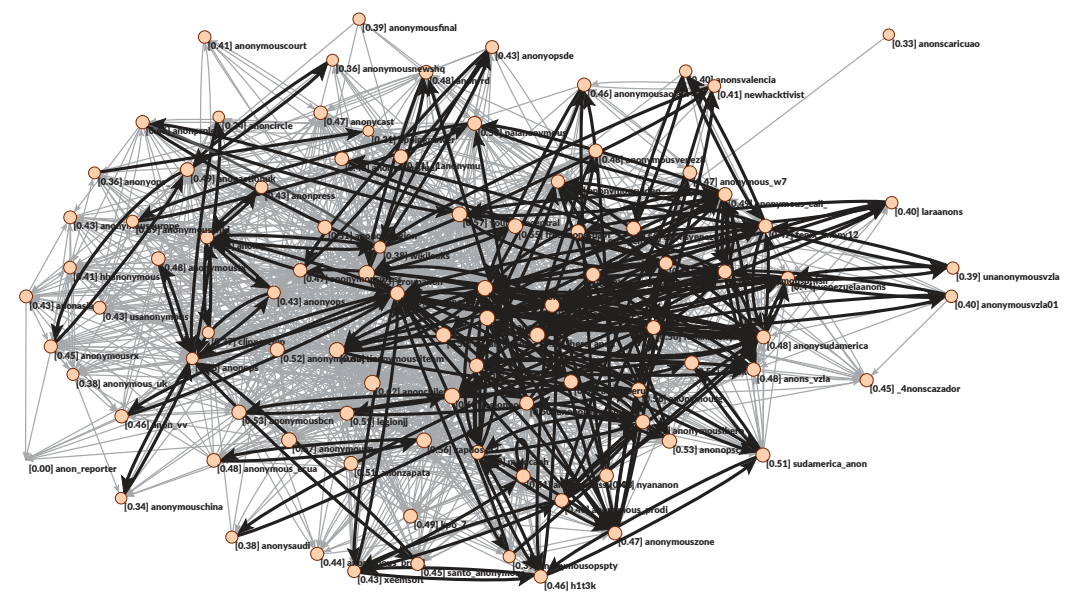

Fuente: elaboración propia.

\section{La fortaleza de los vínculos}

En lo que se refiere a la fortaleza de los lazos, ésta se midió a partir de las interacciones de los diferentes nodos, esto es, tomando como medida el número de menciones y re-twitts, de una cuenta hacia otra. Se encontró que en general existen sólo lazos débiles, ya que es poca la comunicación directa (menciones) entre los nodos y pocas veces un actor retwittea a otro. Esto, sin embargo, no excluye, que efectivamente los Anonymous, tengan otros canales de comunicación. Lo que aquí se midió fue la interacción pública a través de Twitter. En este sentido, sólo $12 \%$ de los vínculos, presentan una relación más allá de seguirse (follower). En la Figura 11, se muestran los vínculos en verde de aquellos nodos que tuvieron alguna interacción ya sea retwitteando algún mensaje de algún otro nodo o mencionándolo en algún twitt. 
Figura 11. Fuerza de los vínculos de la Red Anonymous, a partir de contar con al menos una interacción.

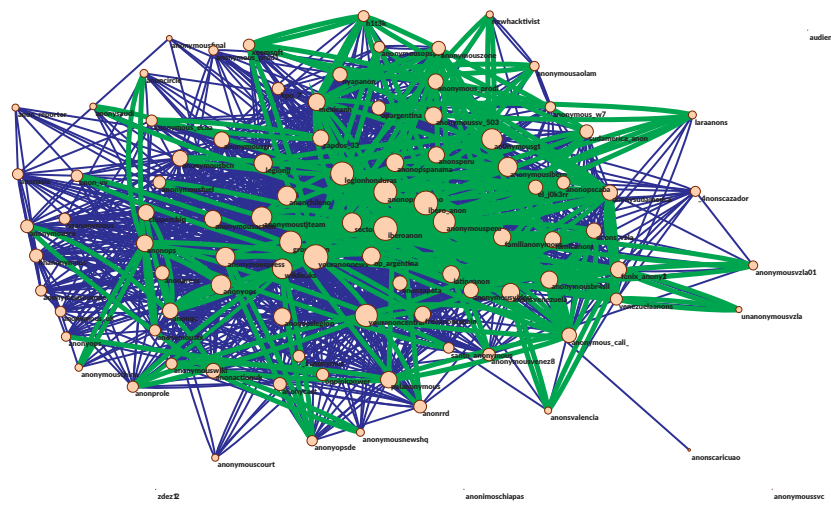

Fuente: elaboración propia.

Figura 12. La debilidad de los vínculos de la Red Anonymous (los vínculos guardan una anchura proporcional a la intensidad de éste).

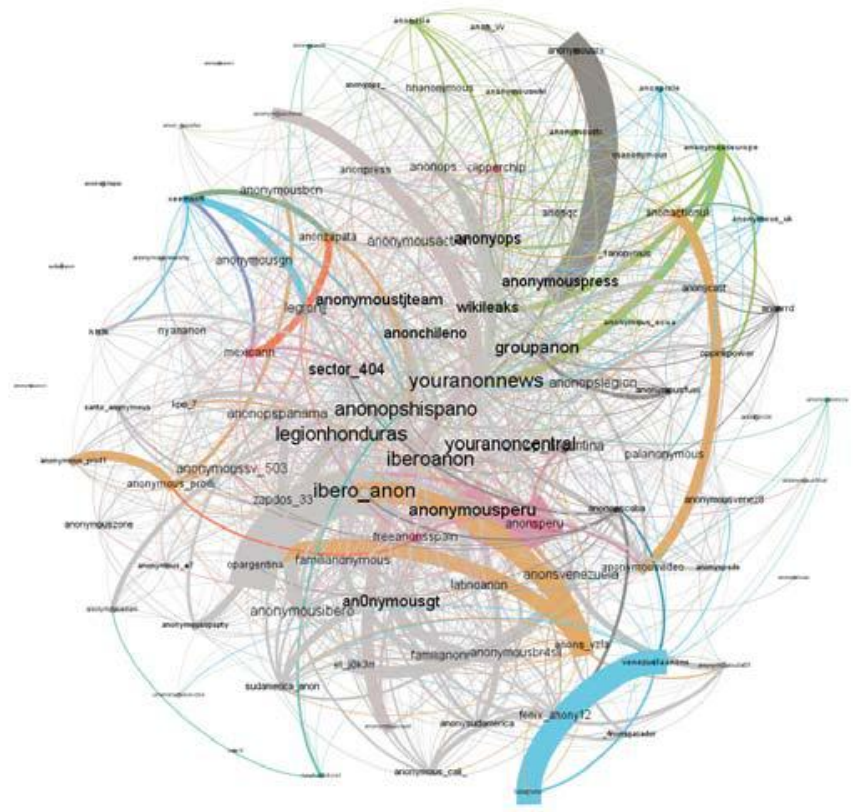

Fuente: elaboración propia. 
Por último, en la Figura 12 se observa, que tan sólo dos vínculos son realmente fuertes (opargentina-ibero_anon y anonsperu-anonymouspe$\mathrm{ru}$ ), ya que su interacción comunicativa es superior a los 15 retwitts o menciones, a su vez, se encuentran tres vínculos medianamente fuertes (anonymousrx-anonymouspress, iberoanon-anons_vzla y laraanons-venezuelaanons) quienes han interactuado con sus pares de entre cinco a 14 veces. $\mathrm{El}$ resto de los vínculos se encuentran entre débiles (de una a cinco interacciones) y muy débiles (sin interacción).

\section{Conclusiones}

El objetivo principal de la presente indagación fue contrastar empíricamente cinco características que la literatura actual sobre movimientos sociales y acción colectiva, con enfoque de redes, ha observado en las insurgencias sociales de los últimos años y los actores que las han protagonizado. En este sentido, se tomó al grupo Anonymous, como un actor protagónico ideal, para observar estos atributos y medirlos a través de la estrategia teórica y metodológica del análisis de redes sociales. De esta manera se puede concluir que:

1. En cuanto al grado de densidad que presenta la red de Anonymous, aunque no es una red de tipo malla pura, debido a que no todos los nodos están vinculados entre sí en primer grado, su estructura es cercana a este tipo ideal de red, ya que es moderadamente densa, con $17 \%$ de los vínculos posibles conectados en grado uno. Lo que sugiere de forma general una red efectiva en cuanto a sus capacidades para comunicarse rápidamente y sin distorsión dentro de la red. Este dato no corrobora el supuesto de Arquilla y Ronfeldt (2001), quienes argumentan que las redes de estos grupos son altamente densas, pero tampoco se aleja de manera sustancial de esta hipótesis.

2. En lo que se refiere al supuesto de falta de jerarquías, mandos policéntricos y horizontalidad de la red, esto se ratificó a partir de las medidas de centralidad, ya que, aunque existen ciertas jerarquías, principalmente en el grado nodal, éstas no son fuertes. En general se observa una red descentralizada y horizontal, lo que se confirmó con el algoritmo $K$-Core, con el cual se visualizó que 50\% de la red comparte una jerarquía similar en cuanto a su grado nodal. Asimismo, en las medidas de centralidad por cercanía e intermediación, no existe un nodo altamente central, existe policentricidad, muy cercana a la horizontalidad o nula centralidad de los nodos. 
3. En cuanto a la capacidad comunicativa de la red, se puede concluir que ésta es de alta a muy alta, ya que ningún nodo tiene el control y coordinación de la comunicación, por lo cual, difícilmente puede ser alterada u ocultada, aquí ningún nodo observa una centralidad importante que le permita tener control de la comunicación en la red.

4. Asimismo, la paradoja propuesta por Arquilla y Ronfeldt (2001) de redes muy densas con una alta dispersión, se sostiene a partir de medir el grado de cercanía. Aquí se encontró que aunque la red es moderadamente densa, existe un grado mínimo de cercanía entre los nodos, lo que sugiere que éstos están dispersos en la red, lo que la hace más flexible y adaptable, pero que a su vez, al existir una baja centralidad, a partir del grado de cercanía (que se encuentra repartido casi uniformemente), se puede inferir que para los objetivos y contexto de esta red, esta característica le puede ofrecer mayor eficacia en su organización, ya que no dependen los nodos entre sí para intermediar o transmitir los mensajes, por lo que los nodos son más independientes, lo que confirma el supuesto de Arquilla y Ronfeldt (2001), cuando afirma que este tipo de redes no necesitan de intermediarios para tomar decisiones, es decir, los miembros del grupo pueden actuar autónomamente sin recurrir a una guía o directriz, ya que todos "saben lo que deben hacer" (p.9).

5. Al analizar la fuerza de los lazos, este análisis sostiene los hallazgos de Granovetter (1973), en cuanto a la importancia de los lazos débiles en los grupos de acción colectiva. Asimismo, se confirma lo que diversos estudiosos de los movimientos sociales han sostenido, en cuanto a que los movimientos en red están principalmente vinculados por lazos débiles, esta característica podría representar para este tipo de redes una ventaja importante ya que les facilita tener más vínculos y comunicación al exterior de la red, lo que permite expandir la red más fácilmente. A su vez, este dato también da indicios para corroborar la heterogeneidad ideológica de estos nuevos grupos de resistencia social conectivos.

Por otro lado, el análisis que aquí se presenta puede sugerir que la eficacia que ha mostrado Anonymous, en su capacidad de expansión y en la consecución de la mayoría de los objetivos importantes, que se ha planteado, puede tener una razón explicativa importante en la estructura y características de la red mediante la cual opera.

Igualmente, es necesario enfatizar que la presente investigación es un estudio de caso, con una muestra no representativa. Sin embargo, ha arro- 
Movimientos conectivos y redes sociales: análisis de la Red Anonymous...

jado datos interesantes, que demuestran la utilidad del análisis de redes sociales, para analizar los grupos insurgentes en el contexto de la era de la información.

Por último, sería importante retomar, en posteriores indagaciones, la estrategia teórica y metodológica, así como al sujeto de estudio (Anonymous), con la finalidad de realizar pesquisas dinámicas y longitudinales, que pudieran observar cómo se transforma y actúa esta red con el tiempo (especialmente en momentos coyunturales) y que, con una muestra más amplia, pueda ofrecer explicaciones más precisas y generalizables. El presente trabajo tan sólo muestra un estudio transversal y, por lo tanto, la estructura de la red y sus componentes pueden sufrir cambios drásticos con el tiempo, más aún en estructuras flexibles y dinámicas, como la que se presenta en este estudio.

\section{Bibliografía}

Arquilla, J. y Ronfeldt D. (2001). Networks and Netwars: The Future of Terror. Crime, and Militancy. Estados Unidos: RAND Corporation.

Atтon, C. (2003). Reshaping Social Movement Media for a New Millennium. Social Movement Studies, 2(1), pp. 3-15.

Batтосchio, S.(2014). Transformaciones de la movilización social a través de la red. El caso Anonymous. Trabajo de fin de Master en Psicología Social. España: Universidad Complutense.

Bennett, L. y Segerberg, A. (2012). The logic of connective action. Information, Communication and Society, 15(5), pp. 739-768.

Bотт, E. (1957). Family and Social Network. Londres: Tavistock.

Castells, M. (1996). La era de la información. Economía, sociedad y cultura. Vol. 2 México: Siglo XXI.

Castells, M. (2012). Redes de indignación y esperanza. Los movimientos sociales en la era de Internet. España: Alianza Editorial.

Coleman, J. (1988). Free riders and zealots. Sociological Theory, 6(1), pp. 52-7.

Coleman, J. (1990). Foundations of Social Themy. Harvard, MA: Belknap

Crossley, N. y Ibrahim, J. (2011). Critical Mass, Social Networks and Collective Action: Exploring Student Political Worlds. Sociology, 44(4), pp. 596-612.

Cruz, M. (2011). Anonymous. De excéntricon bromistas a justicieros cibernéticos, Emmeequis, 1(1), pp. 42-44. 
Della Porta, D. y Mosca, L. (2005). Global-net for Global Movements? A Network of Networks for a Movement of Movement. Journal of Public Policy, 25(1), pp. 165-190.

Diani, M. (2003). Networks and Social Movements: A Research Programme. En M. Diani y D. Mc Adam (Eds). Social movement and networks. Relational approaches to collective action. New York: Oxford University Press, pp. 299-319.

Freeman, L. C. (2000). La centralidad en las redes sociales. Clarificación conceptual, Política y Sociedad, 33, pp. 131-148.

Galindo Cáceres, J. y González-Acosta, J. I. (2013). \#YoSoy132: La Primera Erupción Visible, México: Global Talent University Press.

Gould, R. (1991). Multiple networks and mobilisation in the Paris Commune 1871, American Sociological Review, 56, pp. 716-29.

Gould, R. (1993). Collective action and network structure, American Sociological Review 58(2), pp. 182-96.

Granovetter, M. S. (1973). La fuerza de los vínculos débiles, American Journal of Sociology, 78(6), pp. 1360-1380.

Gutiérrez, B. (2015). Nuevas dinámicas de comunicación, organización y acción social en América Latina. Reconfiguraciones tecnopolitica. Recuperado de http://issuu.com/bernardogutierrez1/docs/tecnopolotocalatamdefinitivo.

JAсов S, L. y Shapiro, R. (2011). Informational interdependence, en: Shapiro, Robert y Jacobs, Lawrence (edit). The Oxford Handbook of American Public Opinion and the Media, Oxford: Oxford Handbooks of American Politics.

Jaramillo Marín, J. (2009). La 'perspectiva relacional' y el 'enfoque de redes' en el análisis de los movimientos sociales. Aproximaciones preliminares a un estudio de caso, Prospectiva, 14, pp. 71-100.

JASPER, J. M. (2012). ¿De la estructura a la acción? La teoría de los movimientos sociales después de los grandes paradigmas, Revista Sociológica, (75), pp. 7-48.

McAdam, D. (1982). Political Process and the Development of Black Insurgency, Estados Unidos, IL: Chicago University Press.

Milroy, L. (1987). Language and Social Networks, Blackwell: Oxford.

Natal, A. y Perera, R. (2014). Hacktivismo y Participación Política. En: A. Natal, M. Benitez y G. Ortiz (coords). Ciudanía Digital, México: Universidad Autónoma Metropolitana-Juan Pablos. 
Movimientos conectivos y redes sociales: análisis de la Red Anonymous...

Rheingold, H. (2002). Smart mobs the next social revolution. Transforming cultures and communities in the age of instant access, Estados Unidos: Basic Books.

SÁdABA, I. (2012). Acción colectiva y movimientos sociales en las redes digitales. Aspectos históricos y metodológicos, ARBOR Ciencia, Pensamiento y Cultura, 188, pp. 755-794.

Scott, J. (2000). Los dominados y el arte de la resistencia. Discursos ocultos, México: Ediciones Era.

Tarrow, S. (2005). The new transnational activism, Estados Unidos: Cambridge University Press.

TARrow, S. (2009). O poder em movimiento: movimentos sociais e confronto politico, Brasil: Editora Vozes.

Tilly, C. (2005). Los movimientos sociales entran al siglo XXI, Política y Sociedad, 42(2), pp. 11-35.

Toret, J. (coord.) (2013). Tecnopolitica: la potencia de las multitudes conectadas. El sistema red 15M, un nuevo paradigma de la politica distribuida, España: Internet Interdisciplinary Institute-Universitat Oberta de $\mathrm{Ca}$ talunya.

VAn Laer, J. y Van Aelst, P. (2009). Cyber-Protest and Civil Society: the Internet and Action Repertoires in Social Movements. En Y. Jewkes y M. Yar. Handbook of internet crime. Gran Bretaña: Routledge, Taylor \& Francis Group. 


\section{Apéndice 1: Tabla de cuentas en Twitter de Anonymous analizadas}

\begin{tabular}{|c|c|c|}
\hline @anonymoustjteam & @_4nonscazador & @ kpo_7 \\
\hline @ anonasia & @ venezuelaanons & @ anons_vzla \\
\hline @anonops & @ anonsvenezuela & @ anonymous_w7 \\
\hline @wikileaks & @ familianonr & @ anonymousaolam \\
\hline @ clipperchip & @ anonymousibero & @ opargentina \\
\hline @anonqc & @ familianonymous & @ ibero_anon \\
\hline @anon_reporter & @ el_j0k3rr & @ anonymousvideo \\
\hline @ groupanon & @ fenix_anony12 & @ anonysudamerica \\
\hline @anonyops & @ anonymousperu & @ palanonymous \\
\hline @anonymouseurope & @ anOnymousgt & @_1anonymus \\
\hline @ hhanonymous & @anonymousvenez8 & @ anonrrd \\
\hline @ anonymousrx & @ anonymouscourt & @ anonymouschina \\
\hline @ anonymouspress & @ youranoncentral & @ anonymousgn \\
\hline @ anon_vv & @ anonopslegion & @ anonymous_uk \\
\hline @ anonpress & @ anonycast & @ anoncircle \\
\hline @ anonymous_ecua & @ iberoanon & @ anonactionuk \\
\hline @ anonymousfinal & @ anonysaudi & @ usanonymous \\
\hline @ anonymousbcn & @ audientanon & @ anonymousbr4sil \\
\hline @ anonymousaction & @ anonymoussvc & @ unanonymousvzla \\
\hline @ xeemsoft & @ anonymuosm & @ oppinkpower \\
\hline @ nyananon & @ anonscaricuao & @ anonprole \\
\hline @ anonopshispano & @ zapdos_33 & @ anonsvalencia \\
\hline @ anonchileno & @ op_argentina & @anonymousnewshq \\
\hline @ sector_404 & @ anonsperu & @ anonymouswiki \\
\hline @ legionjj & @ latinoanon & @ freeanonsspain \\
\hline @ mexicanh & @anonymousopspty & @ anonopscaba \\
\hline @ anonzapata & @anonymous_prod1 & @ newhacktivist \\
\hline @ legionhonduras & @santo_anonymous & @ anonymoustx \\
\hline @anonymoussv_503 & @ anonopspanama & @ anonyops_ \\
\hline @ h1t3k & @ anonymouszone & @ anonymous_cali_ \\
\hline @ anonymous_prodi & @ anonymousfuel & @ anonyopsde \\
\hline @ youranonnews & @ zdez12 & @ sudamerica_anon \\
\hline @ anonymousvzla01 & @ laraanons & @ anonimoschiapas \\
\hline
\end{tabular}





\title{
El imaginario tecnocomunicacional del tuitero. Usuarios activos de Twitter en la ciudad de Querétaro, México
}

\author{
Enrique Iturralde Chaparro
}

\section{Introducción}

Las sociedades occidentales posindustriales se caracterizan por un discurso dominante futurista que tiende a mitificar el papel de las tecnologías de la información y la comunicación. Un ejemplo de ello es la imagen construida alrededor de los usuarios activos de un sitio de redes sociales digitales como Twitter (los tuiteros), quienes son presentados por los medios de comunicación como agentes sociales que cuentan con determinadas habilidades tecnológicas y cognitivas, además de capacidad para convocar a la movilización civil.

Las presentes reflexiones parten de una investigación de Posgrado llevada a cabo para la Universidad Autónoma de Querétaro (UAQ) en 2015, con usuarios activos de Twitter en la capital queretana. En dicho estudio se plantearon las siguientes preguntas: ¿Cómo empatan con el imaginario global del tuitero los usuarios activos de un sitio de redes sociales como Twitter, dentro del contexto de la ciudad de Querétaro, en México? ¿Cómo interpretan y resignifican estas personas los imaginarios dominantes sobre las tecnologías? ¿Qué capitales informacionales invierten en sus prácticas comunicativas dentro de esta herramienta?

En búsqueda de respuestas a estas preguntas, se trazaron como objetivos:

- Investigar cómo, algunos usuarios activos de un sitio de redes sociales como Twitter, dentro del contexto de la Ciudad de Querétaro, pueden empatar con el imaginario global del tuitero.

- Averiguar de qué manera estos usuarios interpretan y resignifican los imaginarios dominantes sobre las tecnologías.

- Encontrar qué capitales informacionales invierten dentro de sus prácticas comunicativas en esta herramienta.

Para ello se llevó a cabo un estudio etnográfico digital, basado en el análisis simbólico de las representaciones sociales en torno a las tecnologías, en el que se aplicaron entrevistas cualitativas semiestructuradas a 14 usuarios 
activos de Twitter que viven en la Ciudad de Querétaro, México. Se indagó acerca de las formas en que estos agentes entretejen los imaginarios dominantes sobre las tecnologías con sus prácticas comunicativas en esta plataforma digital. El objetivo principal fue identificar qué tanto este grupo de personas se aproxima a la representación global que se ha construido sobre los tuiteros como agentes sociales con un capital cognitivo e informacional considerable, además de contar con capacidad de convocatoria para la movilización social.

Si bien se descubrió que la muestra se acerca en algunos rasgos a dicha representación en cuanto a los capitales socioeconómicos e informacionales que sus integrantes poseen, también se encontró que ellos reproducen los imaginarios dominantes sobre Internet, además de que no apuestan por subvertir las estructuras sociales tradicionalmente establecidas.

A través del presente texto se muestra, en primer lugar, una revisión sobre la teoría de los imaginarios sociales desarrollada por el académico griego Cornelius Castoriadis (1997). El concepto se retoma por autores como Cabrera (2004) para descifrar la matriz de significados que gira en torno a las tecnologías de la información y la comunicación (TIC) en las sociedades actuales. Continúa con un análisis sobre el imaginario construido acerca de los tuiteros a nivel global y en México. Posteriormente se expone el marco metodológico del estudio de campo, fundamentado en la etnografía digital. Por último, se exponen los resultados y las reflexiones finales sobre las analogías entre el imaginario global del tuitero y las personas entrevistadas.

\section{Los imaginarios como espejos que condensan la cosmovisión de una sociedad}

Entender la complejidad de una sociedad determinada y su red de significaciones, así como la manera que éstas conforman las prácticas cotidianas de sus habitantes, es un desafío que requiere abordarse desde un marco ontológico que contemple lo político y sociohistórico, pero también lo cultural, así como la construcción de la subjetividad de sus integrantes.

Castoriadis (1997) aborda esta problemática cuando desentraña los vínculos entre lo social y lo simbólico. Concibe el término imaginario social para referirse a las representaciones interpretadas por los individuos y sus instituciones dentro de una colectividad ubicada en un contexto específico: 
Los individuos socializados son fragmentos hablantes y caminantes de una sociedad dada; y son fragmentos totales; es decir que encarnan -en parte efectivamente, en parte potencialmente- el núcleo esencial de las instituciones y de las significaciones de su sociedad (p. 3).

En otras palabras: las creencias, los valores, las imágenes y cada manifestación del pensamiento se concatena a un momento histórico determinado que dota de sentido a las prácticas individuales y colectivas de los sujetos. Desde el lente del materialismo histórico, Castoriadis (1983) describe las cosmovisiones de una sociedad inserta en una época específica, siempre en relación a la reproducción de las condiciones materiales de producción. De modo que, no es lo mismo el sentido que otorga a la vida un aldeano que contempla bajo un árbol la campiña feudal, que la manera en que organiza su poco tiempo libre el obrero de alguna urbe humeante de la Revolución Industrial. Castoriadis (1983) considera que los imaginarios sociales son instituyentes al interiorizar las estructuras de la dominación en los individuos, pero al mismo tiempo les posibilita una participación efectiva autónoma que les permita liberar nuevos resultados. Lo anterior significa que las personas tienden a reproducir conductas amoldadas a lo institucionalmente establecido, aunque, en determinado momento y dadas las circunstancias, pueden modificarlas e incluso subvertirlas.

\section{Los imaginarios tecnocomunicacionales}

Una manera de estudiar la cosmovisión de las sociedades modernas posindustriales es revisar el tejido del discurso edificado en torno a Internet y las tecnologías de la información y la comunicación (TIC) como un imaginario dominante que, como lo indica Sáez (2008), se construye desde los intereses de las fuerzas económico-políticas que protagonizan el proceso de globalización capitalista.

Desde finales del siglo XX y principios del siglo XXI, la irrupción de artefactos electrónicos cada vez más sofisticados vino acompañada por un discurso dominante y futurista, orientado a la masificación de Internet y a los intereses de los países más desarrollados en occidente. Para Almirón y Jarque (2009), una de las características más comunes de los discursos mitificadores es una visión totalizadora que pretende dar explicación y solución a todos los ámbitos de la vida. Un ejemplo claro es el discurso hegemónico sobre las tecnologías digitales de la comunicación, en el que se toma el cambio tecnológico como "inequívoco e irreversible motor de cambio social y ofrece un futuro lleno de promesas de progreso global" (p.115). Ya Vicent Mosco (2004) había detectado que dichos discursos no 
son exclusivos de la era digital. Ocurren cada vez que ha surgido un nuevo dispositivo de comunicación -como el telégrafo, el teléfono o la radiodentro de las sociedades capitalistas.

Tal situación alimentó la mitificación de las TIC e Internet con términos como Web 2.0, ${ }^{1}$ y el "Ciberespacio", este último emanado de las novelas de ciencia ficción. ${ }^{2}$ Como lo señalan Scolari y Pardo (2006), alrededor de la palabra Web 2.0 giraron una serie de términos-satélite que forman parte del mismo subsistema semántico: software social, contenidos generados por el usuario, Rich Internet Applications, videocasting, podcasting y redes sociales. Sobre tal imaginario de avance tecnológico lineal, los autores advierten: "resulta cuanto menos arriesgado pensar que lo nuevo desplazará a lo viejo. Es mucho más probable que las tecnologías participativas se sumen a la ecología de los medios y, al interactuar con los medios tradicionales, transformen dicho ecosistema" (p. 6).

En otras palabras, no todos los sitios de Internet son interactivos ni todas las personas que acceden a la web son productores de contenidos. El ecosistema de las llamadas nuevas tecnologías se compone en realidad por hibridaciones entre viejas y nuevas prácticas comunicativas en las que los usuarios pueden usar de forma tradicional las plataformas digitales, consumiendo contenidos, o en forma proactiva, al producir los suyos propios. $^{3}$

Hasta este punto se establece que invenciones tecnológicas como Internet y las TIC, suelen acompañarse de un discurso mitificador que va

$1 \quad \mathrm{Al}$ editor y activista del Software libre, Tim O'Reilly, se suele atribuir la autoría del término "Web 2.0", en 2004, el cual se entiende principalmente desde dos vertientes: una tecnológica, que define la evolución de un modelo estático de la web a uno interactivo, conocido como "beta perpetua". Mientras que, desde un enfoque empresarial, la Web 2.0 es vista como un retorno del boom punto com. El regreso de los capitales de riesgo, inversionistas y empresarios al espacio virtual, tras el fracaso de la Web 1.0, en una nueva batalla por el estatus y el poder en la escena de la tecnología (Ellison y Boyd, 2013).

2 Fue el escritor de ciencia de ficción William Gibson (Citado por Toudert, 2013), quien, en la década de los ochenta acunó el término "ciberespacio", inicialmente en uno de sus cuentos Quemando cromo y después en la novela: Neuromante. El ciberespacio era el espacio virtual o sustitutivo del espacio real, al que se conectaban de forma sensorial los personajes.

3 De hecho, algunos autores plantean sustituir términos como Web 2.0 o Ciberespacio, por otros más complejos, planteados desde una perspectiva orgánica, como "sistema tecnosocial complejo" (Fuchs, 2010) o "ecosistema" (Scolari y Pardo, 2006), el cual abarca la relación entre sociedad, cultura y tecnología donde las nuevas tecnologías participativas no desplazan a las anteriores, sino que transforman el ecosistema al interactuar entre ellas y dar lugar a nuevas configuraciones. 
acorde con la idea de un progreso inapelable de las sociedades capitalistas occidentales. Después de hacer una revisión epistemológica sobre dicha narrativa dominante, Almirón y Jarque (2009) observan que la misma resulta de una iteración discursiva irradiada desde cuatro ámbitos principales:

1. El académico, compuesto por las élites científicas y culturales que ensalzan las virtudes de las "revoluciones tecnológicas", con investigadores como Nicholas Negroponte.

2. El círculo empresarial, encabezado por los grandes gurús de los emporios informáticos, como Steve Jobs, Bill Gates o Mark Zuckerberg.

3. La esfera política y todo su corpus de informes, así como planes sobre la sociedad de la información.

4. Los medios de comunicación que fungen como altavoces acríticos de mensajes prometéicos tecnodeterministas.

Cabrera (2004) define las cosmovisiones construidas alrededor de los dispositivos digitales como imaginarios tecnocomunicacionales:

El imaginario tecnocomunicacional es el magma de representaciones, afectos y deseos centrados en las "nuevas tecnologías de la información y la comunicación” [...] Este imaginario constituye el núcleo de la sociedad de la información y la matriz simbólica de las nuevas tecnologías (p. 40).

Las principales características del imaginario tecnocomunicacional son una sobredimensión social de la comunicación (panacomunicación) ${ }^{4}$, una centralidad que se otorga a las plataformas digitales en la sociedad actual (tecnoinformación) ${ }^{5}$ y una orientación al futuro como contingencia o riesgo, ante el desconcierto que engendró el fracaso de la promesa del progre-

4 Cabrera (2004) entiende a la panacomunicación como la idea de que todo es comunicación y todo se soluciona por la comunicación, "hay que comunicarse sin que importe todo lo que se comunica. El imperativo comunicacional es tienes que estar conectado, es decir, enchufado: a la red telefónica, mediática, pero también a la red financiera y estatal. Es la “video-ética de la conexión continua de la que habla Baudrillard". Los enchufes a la red son los verdaderos medios de comunicación: el ordenador, los receptores televisivo y radial, el teléfono fijo y móvil, los documentos de identidad, la tarjeta de crédito y, en general, todas las tarjetas magnéticas y/o con chips. Esto es la verdadera Internet: la red -social- de redes -institucionales- donde el individuo es una terminal conectada" (pp. 35-36).

5 Con esto el autor establece que el actual tecnologismo tiene una de sus formas privilegiadas en el informacionismo contemporáneo, ya que "el análisis desde las teorías de la información constituye una elucidación de la matriz simbólica desde la que se postula que la tecnología es comunicación, por lo tanto la tecnología debe 'ser buena'. Donde 'buena' quiere decir deseable y esperable” (Cabrera, 2004: 36) 
so burgués. Según el investigador argentino, el discurso dominante dotó de neutralidad a la tecnología atribuyendo al manejo de quien la use, el que conduzca o no al edén de un futuro mejor prometido por la modernidad. En esta dirección se orientan aquellas ideas sobre el progreso científico o tecnológico como arma de dos filos que puede ser nocivo o benéfico, según la ética de quienes lo manejen.

A su vez, Cabrera (2004) plantea que el imaginario tecnocomunicacional es, en un primer sentido, ideológico, porque justifica el orden social (a través de discursos-promesas adheridos a los aparatos tecnológicos); pero por el otro lado es utópico, debido a que participa de la esperanza de cambio de los actores sociales que tienen otra visión de la apropiación de los aparatos técnicos. Está utopía se manifiesta en los discursos sociales de otro mundo es posible: "conjunto magmático de representaciones, imágenes, afectos y deseos compartidos a modo de una creencia que motiva a la acción" (p. 41).

En las sociedades actuales, el imaginario tecnocomunicacional se construye en torno al discurso de la dominación. La ilusión de Internet, como elemento central e imprescindible que dota de sentido las vidas de los individuos, disfraza el alcance de las corporaciones mercantiles y las industrias del entretenimiento a sus prácticas más cotidianas. No obstante, de entre las formas en que los actores emplean las tecnologías, existe la posibilidad de que le den un uso utópico que participe de la esperanza colectiva de cambio o redistribución de recursos en una sociedad. Desde este segundo aspecto, para Flichy (2003), el imaginario en Internet está en el centro de la concepción y los usos de esta plataforma, y tiene dos funciones: construir la identidad de un grupo social o de una sociedad, además de suministrar los recursos para la preparación y ejecución de proyectos. En nuestros días el imaginario dominante se construye desde los intereses de las fuerzas económico-políticas que protagonizan el proceso de globalización capitalista, por lo que el espacio que debería ocupar un verdadero proyecto social, lo usurpa un determinismo mercantil que, en términos de Sáez (2008), instituye a la comunicación como heredera del progreso ilimitado.

Si la sociedad consiste en la institución de un mundo de imaginarios sociales, supone un juego entre las significaciones de los individuos y las instituciones. Los primeros pueden perseguir unos fines que les sean propios, sin considerar los del orden social global, retroalimentando de esta forma a los imaginarios centrales instituyentes que orientan la acción y la representación social (Cabrera, 2004). Pero para tal objetivo, los individuos deben movilizar una serie de recursos que incluyen tanto sus propias 
capacidades personales como una serie de capitales presentes a lo largo del tejido de las estructuras sociales.

Al hablar de capitales sociales, Pierre Bourdieu (1995) se refería a la suma de recursos, actuales o potenciales, correspondientes a un grupo o individuo, en virtud de que éstos poseen una red duradera de relaciones, conocimientos y reconocimientos mutuos más o menos institucionalizados. Esto es, la suma de los capitales y poderes que dicha red permite movilizar. ${ }^{6}$ Los agentes sociales son portadores de capital y según su trayectoria, suman la posición que ocupan en el campo en virtud de su dotación de capital, debido a lo cual propenden a orientarse activamente a la conservación o a la subversión de la distribución de capitales.

En el contexto de Internet, Hamelink (2000) concibe el término de capital informacional, que comprende tanto la capacidad financiera de los agentes para pagar servicios informáticos como la habilidad técnica que tengan para manejar las infraestructuras de tales redes, así como la capacidad intelectual que posean para filtrar y evaluar información, aplicándola luego a situaciones sociales. Con base en esta definición, Sáez (2008) distingue las tres formas en que los agentes sociales poseen y dotan de sentido las TIC:

1. La posesión de infraestructuras necesarias: energía eléctrica, líneas telefónicas, ordenadores, software, actuamente además son indispensables los dispositivos móviles como los smartphones y las tablets.

2. La formación necesaria (habilidades digitales) para manejar los equipos, programas informáticos y dispositivos tecnológicos.

3. El uso de las TIC relacionado con procesos de cambio social, descubriendo las posibilidades que ofrecen para el trabajo en red con modelos horizontales de circulación de información, para una construcción del conocimiento colectivo mediante las tecnologías digitales.

6 Para Bourdieu (1995), las estructuras del mundo social se configuran tanto por la distribución de medios materiales como por los sistemas simbólicos que impregnan las prácticas de los agentes (babitus). Dentro del ámbito de los capitales simbólicos desarrolló el término "capital cultural" como los conocimientos que poseen los agentes dentro de un determinado espacio social (campus) y que garantiza su posición dentro de este. El término capital cultural consiste entonces en conocimiento, competencia y disposiciones culturales que puede acumular un individuo. Engloba cualificaciones formales (escolares) junto con habilidades y saberes informales. Puede ser incorporado -disposiciones biológicas del individuo, como su memoria-; objetivado (encarnado en bienes como libros); o institucionalizado -reconocimiento social a una práctica o competencia, como un título universitario-. 
Con base en la teoría anteriormente revisada, se deduce que dentro del ecosistema digital los individuos invierten una serie de capitales informacionales para configurar sus rutinas comunicativas, en las que ponen en juego los sistemas de significados que poseen, varios de ellos relacionados con las tecnologías. Destaca el caso de los sitios de redes sociales, definidos por Ellison y Boyd (2013) como "sitios que permiten a los individuos articular listas públicas de conexiones - para presentar una red social y para ver las redes de los demás"(p. 8). En México también se encuentran presentes una serie de imaginarios acerca de plataformas tecnológicas como Twitter.

\section{Twitter y la representación global del tuitero}

Twitter es una plataforma de microblogging creada en San Francisco en 2006, por un grupo de arquitectos de software encabezado por Jack Dorsey, para comunicarse entre ellos con mensajes cortos (tuits) constituidos por un límite de 140 caracteres, para facilitar su envío por teléfonos móviles a través de SMS (servicio de mensajes cortos).

En noviembre de 2009 se lanzó la versión en español de Twitter debido a la cantidad de hablantes en lengua castellana que estaban usando el sitio. Marwik y Boyd (2010) consideran que la función principal de Twitter se transformó en el 2009, cuando los medios de comunicación pusieron atención en este sitio de redes sociales digitales que adquirió resonancia, tanto en medios tradicionales como digitales, por lo que sus contenidos trascendieron el efecto de difusión en la propia red social.

Características como los hashtags de Twitter permiten que las personas se dirijan hacia los temas con sólo darles clic para revelar todos los mensajes que hacen referencia a algún término en específico. Con este procedimiento se impulsa el papel informativo de la plataforma ${ }^{7}$.Los Trending Tópics (en español: temas tendencia), por su parte, nos indican los temas más relevantes del día, condensados en hashtags. Estos Trending Tópics son configurados por medio de un algoritmo que contempla dos variables: el número de usuarios que participan en cada tema y el intervalo de tiempo entre cada tuit que se publica al respecto (Valadés, 2011).

Parte del análisis sobre Twitter se inscribe en un discurso tecno-romántico que mitificó el papel de los sitios de redes sociales digitales en

7 Los hashtags son etiquetas compuestas por alguna frase, precedida por el signo numeral “\#”. Por ejemplo, el hashtag \#YoSoy132 sirvió para que los tuiteros se aglomeraran en torno a una serie de manifestaciones estudiantiles iniciada por alumnos de la Universidad Iberoamericana en 2012, en México. 
acontecimientos como las protestas civiles en Irán, en 2009, o las primaveras árabes en 2011. Se comenzaron a usar términos como el de Twitter-Revolutions, de Shirky, (2010). Otros autores cuestionaron su impacto real en los acontecimientos sociales (Olorunnisola y Martin 2013), en cambios políticos como los del Este de Europa (Morozov, 2011) o el Mediterráneo (Al-Kandari y Hasanen, 2012). Para Díez, Fernández y Anguita, (2011) la imagen que promovieron los medios masivos sobre los usuarios de Facebook y Twitter participantes en las primaveras árabes, como jóvenes predominantemente estudiantes y profesionales de las clases medias, fue sesgada e incompleta. La prensa habría ocultado la importante colaboración de la clase trabajadora en los eventos, para ponderar una imagen "occidentalizada" de los usuarios de las redes socio-digitales que luchaban contra los "déspotas tercermundistas y malvados" en turno, según los designios del "mundo libre" (p. 90).

En la academia nacional, en un extremo, el politólogo Cansino (2014) considera a Twitter como un "parteaguas evolutivo", que restaura la atrofia cognitiva de los individuos causada por el mensaje televisivo, en una especie de antídoto al Homo Videns de Sartori. Con una posición más moderada, otros autores consideran que sitios como el de Jack Dorsey propician la formación de "Ciudadanos 2.0" (Islas y Arribas, 2012) o "JoveNets" (Candón Mena, 2013). En 2011 se calculaba que sólo 13 por ciento del total de los usuarios en México tuiteaban más de un mensaje al día (Mente Digital, 2011). Sin embargo, Gerhenson y Robles (2011) aseguran que esta minoría se compone por early adopters: usuarios "políticamente sofisticados", con niveles altos de educación y bien informados sobre su entorno, que forman parte de una minoría con acceso a Internet, la educación, la información y a las herramientas tecnológicas, ya que suelen ser los primeros en experimentar con las mismas. Cabe destacar que, dentro de la literatura sobre el tema, científicos sociales como Casas (2013) niegan cualquier posibilidad consensual de esta plataforma, pues los tuiteros estarían atrapados en un narcisismo en el que se fetichiza el "Yo", en declive del hombre público. No obstante, se observa un punto de concordancia en la mayoría de los autores anteriormente citados pues sus argumentos van alrededor de una imagen sobre los tuiteros como jóvenes con ciertos capitales cognitivos y tecnológicos, además de una actitud crítica que convoca a la acción social. Ahora, además de una fracción del ámbito académico nacional con una posición entusiasta sobre las posibilidades de comunicación horizontal que ofrece un medio digital como Twitter, ¿De qué forma se concibe a este sitio de redes sociales digitales dentro del discurso de las esferas empresarial, gubernamental y mediática en nuestro país? 
En el caso de las empresas dedicadas al marketing, las encuestas y medición de audiencias digitales, presentan una imagen del tuitero mexicano que empata con la descripción de algunos académicos. Así, conforme a los resultados del estudio Perfil del usuario de redes sociales en Internet, de Consulta Mitofski (2011), Twitter tiene más penetración en jóvenes y personas con altos niveles de escolaridad en México que Facebook, pues el 60 por ciento de sus usuarios tienen entre 18 y 30 años de edad, y el 95 por ciento habitan en zonas urbanas.

Peer Reach (2013), por su parte, concluyó en 2013 que la edad promedio de los tuiteros en México es de 24 años de edad. Adicionalmente, la agencia Mente Digital (2011) auguraba a inicios de la presente década un crecimiento potencial del sitio de micro mensajes en nuestro país pues, según sus mediciones, pasó de los 32 mil usuarios en el 2009 (año en que lanzó su versión en español) hasta los 4.1 millones en el 2011 (48 por ciento hombres y 52 por ciento mujeres).

No obstante, con el paso de los años, la plataforma de Jack Dorsey presenta un estancamiento a nivel mundial y mientras Facebook está por alcanzar los dos mil millones de usuarios, Twitter apenas y rebasa los 300 mil. Con respecto al gobierno mexicano, no existen cifras oficiales sobre el uso de sitios de redes sociales digitales específicos. No obstante, el Instituto Nacional de Estadística y Geografía (INEGI) presenta datos cuantitativos sobre sociedad de la información y usuarios de Internet en nuestro país, en el sentido de cobertura como sinónimo de progreso. El INEGI (2016a) contabiliza actualmente que el 57 por ciento de los mexicanos tienen acceso a Internet aun cuando todavía existe un margen considerable de brecha digital. A su vez indica que 44.6 millones de mexicanos acceden a las llamadas redes sociales. En cuanto al perfil que el Instituto presenta sobre los usuarios de la web, es con una pertenencia predominante a sectores económicamente activos del entorno urbano y una edad promedio entre 12 y 34 años.

Por último, el papel de la prensa mexicana ha sido incluir como parte de su agenda mediática protestas emanadas desde sitios como Facebook, Youtube o Twitter, o algunas movilizaciones sociales que se han valido de estas herramientas para su difusión. Sin duda, es importante el papel que ha tenido Twitter en México como caja de resonancia en cuestiones como las denuncias del movimiento \#YoSoy132 sobre el acarreo en la presentación del entonces candidato presidencial Enrique Peña Nieto en la Universidad Iberoamericana; o sobre casos de violencia amparada por la inacción del Estado mexicano, como la desaparición de 43 normalistas por fuerzas policiacas de Iguala, Guerrero, en 2014, a través del hashtag \#Ya- 
MeCansé. No obstante, parte de la agenda mediática nacional también suele presentar notas más superficiales sobre los tuiteros como personajes que suelen tundir con críticas tanto a políticos como personajes públicos que llegan a cometer alguna falta ética o moral, según el criterio de quienes se erigen como jueces del acontecer público, emitiendo veredictos de 140 caracteres. Un caso representativo fueron las notas que se publicaron sobre las burlas que los tuiteros hicieron a la cuenta que tiene en esta red de microblogging la animadora de programas del consorcio Televisa, Andrea Legarreta, después de que trató de justificar al aire la devaluación del peso ante al dólar, en 2016.

Todo el discurso tejido alrededor de Twitter nos lleva a pensarlo como un sitio de redes sociales digitales en el que sus usuarios son poseedores de un conjunto de capitales cognitivos e informacionales considerables, además de una gran capacidad crítica y consciencia social pero, ¿̇realmente sus usuarios empatan con la imagen que se nos presenta sobre el tuitero? De los 44.6 millones de mexicanos que acceden a las llamadas redes sociales, 4 millones, 750 mil viven en la Ciudad de México, mientras que en el estado de Querétaro existen 717 mil (INEGI, 2016b). En el caso de un sitio como Twitter, GlobalWebIndex (2014) calculaba que en 2016 habría 9 millones de personas de nuestro país que ingresan a la plataforma de micro mensajes, mientras que ese mismo año Gilherme Ribenboim, vicepresidente en América Latina de la empresa dirigida por Jack Dorsey, aseguraba que existen 35.3 millones de usuarios mensuales activos que tuitean desde México (DINERO EN IMAGEN, 2016).

\section{Metodología}

La metodología utilizada en el trabajo que estamos refiriendo, es la que Hine (2004) define como etnografía virtual, está enfocada en los significados y usos que las personas construyen alrededor de Internet. En 2015 se realizaron entrevistas cualitativas semi estructuradas, cara a cara, a 14 habitantes de la ciudad de Querétaro, quienes tienen como único rasgo común ser usuarios activos de Twitter (tuiteros) que producen contenidos más de una vez a la semana. Para contactar a dichos participantes se recurrió a varias de las fases que Postill y Pink (2012) recomiendan para hacer etnografía digital: primero se hizo una inmersión profunda en Twitter para contactar, en efecto de bola de nieve, a los posibles informantes, a quienes posteriormente se entrevistó de forma presencial. El universo de estudio se integró con 14 personas $(\mathrm{n}=14)$ equilibradas por género y edades: siete hombres y siete mujeres entre los 17 y los 56 años de edad. Los 
cuestionarios se elaboraron conforme a la teoría anteriormente expuesta, principalmente los postulados de Cabrera (2004) sobre los rasgos principales de los imaginarios tecnocomunicacionales, así como los que Sáez (2008) estipula para los capitales informacionales.

Tabla 1: Descripción de los informantes de la muestra.

\begin{tabular}{|c|c|c|}
\hline Actuante & Descripción & Fecha de entrevista \\
\hline A1 & $\begin{array}{l}\text { Mujer de } 32 \text { años. Egresada de la Licenciatura en De- } \\
\text { recho de la UAQ. }\end{array}$ & 16 de diciembre 2014 \\
\hline $\mathrm{A} 2$ & $\begin{array}{l}\text { Hombre de } 36 \text { años, con Licenciatura en Derecho por } \\
\text { la UAQ. }\end{array}$ & 17 de diciembre 2014 \\
\hline A3 & $\begin{array}{l}\text { Hombre de } 17 \text { años. Estudia la Preparatoria en es- } \\
\text { cuela particular. }\end{array}$ & 15 de enero 2015 \\
\hline A4 & Mujer de 41 años. Con Maestría en Ciencias Sociales. & 16 de abril 2015 \\
\hline A5 & Mujer de 43 años. Con estudios técnicos. & 18 de abril 2015 \\
\hline A6 & Hombre de 36 años. Comunicólogo trunco. & 21 de abril 2015 \\
\hline A7 & Hombre de 47 años, con Maestría en Derecho. & 22 de abril 2015 \\
\hline A8 & $\begin{array}{l}\text { Mujer de } 22 \text { años. Estudiante de Psicología de la } \\
\text { UAQ. }\end{array}$ & 22 de abril 2015 \\
\hline A9 & $\begin{array}{l}\text { Mujer de } 27 \text { años. Estudiante de Psicología de la } \\
\text { UVM. }\end{array}$ & 21 de mayo 2015 \\
\hline A10 & $\begin{array}{l}\text { Hombre de } 23 \text { años. Estudiante de Derecho en uni- } \\
\text { versidad particular. }\end{array}$ & 19 de junio 2015 \\
\hline A11 & $\begin{array}{l}\text { Hombre de } 56 \text { años. Con estudios de Maestría en la } \\
\text { UAQ. }\end{array}$ & 26 de junio de 2015 \\
\hline A12 & $\begin{array}{l}\text { Hombre de } 40 \text { años. Ingeniero en Electrónica y Co- } \\
\text { municaciones. }\end{array}$ & 26 de junio de 2015 \\
\hline A13 & $\begin{array}{l}\text { Mujer de } 30 \text { años. Con Maestría en Gestión de Tec- } \\
\text { nologías de la Información. }\end{array}$ & 27 de junio de 2015 \\
\hline A14 & $\begin{array}{l}\text { Mujer de } 23 \text { años. Estudiante de Psicología de la } \\
\text { UAQ. }\end{array}$ & 30 de junio de 2015 \\
\hline
\end{tabular}

Fuente: elaboración propia

\section{Resultados:}

Una primera observación que se extrae de las entrevistas son los capitales informacionales que invierten los agentes de la muestra en sus prácticas comunicativas mediante una red socio-digital como Twitter. En general, son agentes que llevan en promedio cinco años experimentando procesos comunicativos en el sitio. La mayoría se conecta en promedio tres horas diarias a Twitter, de forma intermitente durante varios lapsos del día. Las 
mujeres son quienes permanecen más tiempo en la plataforma (tres horas diarias en promedio, con un mínimo de 11 tuits diarios). Los informantes de la muestra aseguraron pertenecer a un nivel socioeconómico medio-alto que les permite contar con la infraestructura tecnológica necesaria para posibilitar su conectividad a Internet en el momento que lo deseen. Nueve de ellos aseguraron contar con las habilidades suficientes para manejar las Tecnologías de la Información y la Comunicación, destacando quienes son más jóvenes y quienes tienen más niveles de estudio. Once informantes aseguraron poseer las capacidades ortográficas y de síntesis suficientes para expresar sin mayor problema sus ideas en 140 caracteres, principalmente los que tienen mayor nivel de estudio, quienes consecuentemente, aseveraron ser los más informados al leer periódicos, libros y revistas.

En cuanto a las percepciones que tienen sobre Twitter y las TIC, la totalidad del universo de estudio se asume como tuiteros. La mayoría (11 informantes) poseen un imaginario tecnocomunicacional con una característica principal de Tecnoinformación: centralidad que se otorga a las plataformas digitales en la que los agentes no conciben su vida sin Internet y las Tecnologías de la Información y la Comunicación, tal y como lo aseguró A13, mujer de 30 años:

He tenido la experiencia de estar en lugares donde no tengo nada de eso...y lo disfruto. Pero es una, dos...un fin de semana. Ya pensar de lleno que tengo una duda y no puedo buscarla en Internet, es como... de hecho publiqué hace poco un blog de, justo en la empresa en que trabajo, en la que hacía la analogía de cómo antes, por ejemplo, querías regalar un...música y entonces mil horas grabando tu casete y escribiendo el nombre de las canciones. Y ahora si haces un playlist y se lo compartes, ya está. No me imagino sin eso.

Otro imaginario común en los informantes (nueve agentes) es la contingencia: cuando se interioriza el discurso dominante que dota de neutralidad a la tecnología y deja a los usuarios la responsabilidad sobre las consecuencias éticas, como el caso de A1, mujer de 32 años:

Yo creo que sí. No creo que haya alguien que invente algo como para hacer que...siempre los que tienen esa capacidad de inventar, siempre son para mejorar ¿No? Y depende de nosotros si lo utilizamos para bien o para mal. Pero sí...claro que sí, ha sido para mejorar.

En lo relativo a temas públicos, cinco agentes de la muestra manifestaron expresar abiertamente su enojo e inconformidad hacia autoridades políticas locales y federales, vía Twitter. Sin embargo, sólo tres de los informantes (dos hombres [A11 y A12] y una mujer [A13]) dijeron participar o haber participado en su vida presencial en organizaciones colectivas como 
sindicatos, asociaciones civiles o partidos políticos. Y sólo dos informantes más, del sexo femenino (A8 y A14), estudiantes de la UAQ aseguraron haber participado en acciones de protesta ciudadana, como las marchas del \#YoSoy132 o por los estudiantes normalistas desaparecidos de Ayotzinapa, que se han realizado en Querétaro.

Tres personas del género masculino (A2, A6 y A11) admitieron, por su parte, asistir sólo a algunas manifestaciones públicas ya que aseguraron aplicar un criterio selectivo en torno a éstas. Dentro de esta misma temática, se detectó en cinco agentes (tres hombres [A3, A6, A10] y dos mujeres [A5 y A13]) expresiones que se podrían definir como legitimación de los discursos dominantes, pues denostan cualquier tendencia colectiva que apueste por una vía utópica de redistribución de los recursos simbólicos y materiales de las estructuras sociales:

Hace muchos años que no asisto... pero a las que de a tiro no, las marchas de cuestiones políticas. En verdad no iría porque yo...yo siento que así no cambias un país. Yo siento que así no vas a revivir a los muertos de Ayotzinapa. Pero... a mí sí me da coraje el hecho de: "No... sí y por un México mejor vamos a hacer la marcha”. Güey, ponte a estudiar, ponte a trabajar cabrón. Fórjate un futuro. Sé un buen ciudadano, güey, o sea...no lo vas a arreglar con una marcha, es por eso que no asisto (A6, hombre de 36 años).

Otro de los entrevistados expresó al respecto:

Yo pienso que también hay manipulación, no manipulación sino influencia masiva hacia ciertos sectores, que en eso también puede ser... por ejemplo en el movimiento de Ayotzinapa, se magnificó demasiado, mucho, se hizo demasiado grande. Digo, sí se murieron o los mataron, como haya sido, pero creo fue demasiado (A5, mujer de 43 años).

Los tuiteros de la ciudad de Querétaro forman pequeñas comunidades locales que extienden sus vínculos al ámbito presencial. Pero, a pesar de ello, no apuestan por un uso de las tecnologías que busque un cambio de fondo en las estructuras socio políticas y culturales de la región, como se puede observar en un artículo anterior (Iturralde, 2016) basado en el estudio aquí referido.

Es importante destacar que Twitter y otras plataformas digitales populares como Facebook, Whatsapp o Instagram pertenecen a corporaciones comerciales con una lógica mercantil, en las que los contenidos y datos personales de los usuarios son vulnerables a intereses empresariales o al espionaje gubernamental. Así, un bloguero puede llamar a la revolución contra el imperialismo desde su cuenta de Wordpress, mientras aparece a un lado un anuncio de Coca-Cola. 


\section{Conclusiones}

El perfil de los tuiteros queretanos del presente estudio, ciertamente empata en algunos rasgos con el imaginario global acerca de la figura del tuitero: son una minoría de early adopters que tienen en promedio cinco años realizando prácticas comunicativas con esta herramienta y cuentan con un capital socioeconómico medio-alto, así como determinadas capacidades cognitivas Se calcula que por su edad del tuitero queretano no es tan joven como la imagen que se proyecta a nivel nacional, sino que se encuentra en un promedio de 33.7 años.

Lejos del imaginario libertario que suele girar en torno a Twitter, en el presente estudio de caso se identificó que la función de esta herramienta en los informantes no parece ser el llamado a las Tweet-Revoluciones. Las protestas ciudadanas que ejercen en el sitio suelen quedarse atrapadas dentro del ecosistema del mismo. ${ }^{8}$ No obstante, sería limitado asignar una función puramente instrumental a Twitter. Esta plataforma tiene, ante todo, una multiplicidad de usos y apropiaciones por parte de los individuos, colectivos, empresas e instituciones que acceden a la misma y que son motivo de diferentes análisis.

Como lo señalan Treré, Jepessen y Matonni (2017) son necesarios estudios sobre los imaginarios mediáticos digitales que vayan más allá de concepciones binarias, como las tecno-románticas e instrumentales, para considerarlos dentro del cruce de ecosistemas tecnológicos con contextos socio políticos y culturales específicos. En el caso de los tuiteros del presente análisis, poseen un imaginario predominantemente tecnoinformacional, que concibe a Internet y las TIC como centrales en sus vidas, además de una visión de contingencia que dota de neutralidad a dichas herramientas. También es un imaginario hegemónico, pues refuerza los discursos alimentados por un conservadurismo que ha caracterizado tradicionalmente a varios sectores de la sociedad queretana, como bien lo observó Águilar (2012) en su investigación sobre jóvenes y Facebook en Querétaro.

Se destaca que se trató de un trabajo basado en actores sociales individuales que sólo tienen en común un uso activo de Twitter. Harían falta

8 Quienes ejercen la protesta ciudadana en Twitter, no suelen hacerlo regularmente en el ámbito físico. Paradójicamente, durante el proceso de selección de la muestra para esta investigación, se descubrió que quienes convocan a la movilización colectiva en las calles, no suelen coordinar sus actividades en este sitio. Activistas sociales y defensores de los derechos humanos en Querétaro muestran muy poca actividad en sus cuentas, mientras que otros no tienen perfil en esta plataforma. 
investigaciones sobre colectivos de la ciudad de Querétaro dedicados al activismo social y que sí poseen cuentas en el sitio. Averiguar las cosmovisiones que construyen en relación con estas plataformas y si también consideran el uso de medios digitales alternativos combinados con políticas comunicativas que convoquen a la acción social. Por tratarse de una investigación cualitativa en cuyo estudio de caso participaron 14 personas, los resultados no pueden generalizarse.

\section{Bibliografía}

Aguilar González, Carlo Daniel (2012). Uso de Facebook entre jóvenes universitarios de Querétaro como herramienta para fortalecer su cultura politica. Tesis de Maestría. UNAM/UAQ.

Al-Kandari, A., \& Hasanen, M. (2012). The impact of the Internet on political attitudes in Kuwait and Egypt. En Telematics and Informatics, 29(3), pp. 245-253.

Almiron, N., y Jarque, J. M. (2009). Mito, digitalismo y convergencia tecnológica: discursos hegemónicos y economía política. En Quaderns del CAC, pp. 115-121.

Bourdieu, P., y Wacquant, L. J. (1995). Respuestas: por una antropología reflexiva. México: Grijalbo.

Cabrera, H. (2004). La matriz imaginaria de las nuevas tecnologías. En Comunicación y Sociedad, 17 (1), pp. 9-45.

Candón Mena, José (2013). Movimientos por la democratización de la comunicación: los casos del 15-M y \#YoSoy132. En Razón y Palabra, 82, pp. 36-21.

Cansino, C. (2014). Ten thesis on Homo Twitter. En Revista de Occidente, 394, pp. 21-29.

Casas, María de la Luz (2013). Twitter, ¿̇herramienta para la expresión privada, la participación pública o la construcción de acuerdos? la participación en redes sociales desde la teoría de la acción social. En Investigar las redes sociales, México: Razón y Palabra, pp. 19-30.

Castoriadis, C. (1983). La institución imaginaria de la sociedad. Buenos Aires: Tusquest

Castoriadis, C. (1997). El imaginario social instituyente. En Zona erógena, (35), pp.1-9.

Consulta Mitofski (2011). Perfil del usuario de redes sociales en internet. Recuperado el 21 de marzo de 2014 de: http://www.slideshare.net/ rperalromea/redes-sociales-mitofskymultimedia 
Díez G., E., Fernández, E. y Anguita, R. (2011). Hacia una teoría política de la civilización cívica virtual. Revista Interuniversitaria de Formación de Profesorado 25(2) (pp. 73-100).

Dinero en imagen (2016). ¿Cuántos mexicanos usan Twitter al mes? Recuperado del 1 de junio de 2016, de: ww.dineroenimagen.com/201603-16/70257

Ellison, N., y Boyd, D. (2013). Sociality through social network sites. En The Oxford handbook of internet studies, pp. 151-172.

FLichy, P. (2003). Lo imaginario de Internet. Madrid, Tecnos.

Fuchs C (2010) Alternative media as critical media. European Journal of Social Theory 13(2), pp. 173-192.

Gershenson, D. y Robles Maloof, J. (2011). “Twitter como caja de resonancia: la guardería ABC y la masacre de Juárez". En Ciudadanos.mx. México: De Bolsillo, pp. 81-110.

GlobalWebIndex (2014). Quertely report on the latest trends in social networking (Q4 2014). Recuperado el 2 de abril de 2016, de: https:// app.globalwebindex.net/products/report/gwi-social-q4-201

Hamelink, Cees (2000). The Ethics of Cyberspace. London, Sage.

Hine, Christine (2004). Etnografía virtual. UOC, España

InEgi (2015a). Usuarios de internet por entidad federativa, 2015 (datos actualizados el 14 de marzo de 2016). Recuperado el 10 de abril de 2016 de: http://www3.inegi.org.mx/sistemas/sisept/default.aspx?t=tinf421\&s $=$ est $\& c=26487$

INEGI (2015b). Usuarios de Internet por ciudad seleccionada, 2015. Recuperado el 10 de abril de 2016 de: http://www3.inegi.org.mx/sistemas/ sisept/default.aspx?t=tinf821\&s=est\&c=35679

IturRAlde, E. (2016). "Ser o no ser": los referentes temáticos en la configuración de identidades de un grupo de tuiteros de la Ciudad de Querétaro. En Anuario de la investigación en comunicación, 23, México, Coneicc, pp. 227-246.

Islas, O., y Arribas, A. (2012). Enseñanza y ejemplo de la primavera mexicana. En Razón y Palabra, 80, pp.16-21.

Marwik, Alice y Boyd, D. (2010), I tweet honestly, I tweet passionately: Twitter users, context collapse, and the imagined audience. En New Media ESociety, 13 (1), pp. 114-133.

Mente Digital (2011). Twitter en México, marzo 2011. Recuperado el 5 de febrero de 2013 de: http://es.slideshare.net/gpbolde 
El imaginario tecnocomunicacional del tuitero...

Morozov, Evgeny (2011). El desengaño de Internet: Los mitos de libertad de la Red. Bercelona: Destino.

Mosco, V. (2004). The Digital Sublime: Myth, Power, and Cyberspace. Cambridge, MA \& London.

Olorunnisola, A., y Martin, B. (2013). Influences of media on social movements: Problematizing hyperbolic inferences about impacts. EnTelematics and Informatics, 30(3), pp. 275-288.

Postill, J. y S. Pink in press 2012. Social media ethnography: the digital researcher in a messy web. En Media International Australia, 145(1), pp. 123-134.

Peer Reach (2013). 4 ways how Twitter can keep geowing. Recuperado el 5 de febrero de 2015 de: http://blog.peerreach.com/2013/11/4-wayshow-twitter-can-keep-growing/

SÁEz, V. M. (2008). Capital informacional y apropiación social de las Tecnologías de la Información y de la Comunicación. Análisis de los usos ciudadanos de Internet en el espacio local de Jerez de la Frontera. Recuperado el 5 de febrero de 2013 de: http://www.aeic2010malaga.org/ upload/ok/97.pdf

Scolari y Pardo, H. (2006), Web 2.0 Casos conceptual y nuevos mitos en el discurso cibercultural. En IX Congreso IBERCOM, 6, pp. 15-30.

Shirky, C. (2010). The Twitter Revolution: more than just a slogan. Prospect Magazine (166). Recuperado el 1 de septiembre de 2013 de: http:// www.prospectmagazine.co.uk/magazine/the-twitter-revolution-more-than-just-a-slogan

Treré, E., Jeppesen, S., y Mattoni, A. (2017). Comparing Digital Protest Media Imaginaries: Anti-Austerity Movements in Greece, Italy \& Spain. tripleC: Communication, Capitalism E Critique. Open Access Journal for a Global Sustainable Information Society, 15(2), pp. 406-424.

Toudert, D. (2013). "El ciberespacio: entre la ambigüedad de la metáfora geográfica y la gloria del lirismo gibsoniano". En, El espacio en las ciencias sociales. Chávez Torres, Martha y Martín Checa (Eds.), México: Colegio de Michoacán, pp. 369-380.

VALAdÉs, Bertín (2011). Twitter ¿Plataforma para redefinir la acción colectiva? El caso \#InternetNecesario. México:Tesis de Maestría UNAM.

VegA, Ana Francisca y Merino, José (2011). Ciudadanos.Mx. México: De Bolsillo. 


\title{
Un abordaje a las redes sociales digitales, los videojuegos, y los medios sociales
}

\author{
David Cuenca Orozco
}

\section{Introducción}

Hoy en día una buena parte del planeta usa con bastante frecuencia las redes sociales digitales. Según datos del Statistic Brain Research Institute, la principal plataforma de redes sociales digitales, Facebook, cuenta con 1,900 millones de usuarios activos ${ }^{1}$. Dentro de ese mismo estudio ${ }^{2}$ se indica además que la segunda red social digital con mayor número de usuarios alrededor del mundo es YouTube, contando con más de 1,325 millones. Por su parte, Instagram, plataforma que si bien en sus inicios consistía en una aplicación para subir fotos y videos a la red es ahora la tercera red social digital más utilizada. Actualmente supera los 600 millones de consumidores activos a nivel mundial.

En el caso de México, la Asociación Mexicana de Internet.mx ${ }^{3}$, deta1la que si bien la red social más importante en términos de consumo también es Facebook, la segunda plataforma más utilizada por los mexicanos es WhatsApp. Lo anterior sugiere que el empleo de tecnologías digitales en el país sigue la tendencia mundial (Facebook) y al mismo tiempo puede ubicarse una preferencia entre sus usuarios por otros sistemas de comunicación (WhatsApp).

Ese fenómeno en parte es resultado de la capacidad que tienen las redes sociales digitales para diversificarse y adaptarse de forma vertiginosa a las distintas necesidades de sus consumidores (Nass, 2011). Por ejemplo, diversos sistemas de mensajería instantánea, como WhatsApp o Line ${ }^{4}$, han

1 Otros datos provenientes de ese instituto pueden ser consultados dentro de su sitio web oficial: http://www.statisticbrain.com/

2 Otras informaciones relevantes de ese estudio arrojan el número de horas que los usuarios permanecen conectados a las redes sociales digitales. En promedio una persona que posee su cuenta activa para dichos servicios digitales las usa cuando menos cinco horas diariamente.

3 Ver el documento de la Asociación de Internet.mx: "Estudio sobre los hábitos de los usuarios de internet en México", disponible en: https://www.asociaciondeinternet.mx/

4 Ambos servicios de comunicación instantánea están basados en mensajes P2P (peer to peer) que les permiten compartir archivos e informaciones cifradas. Esa cualidad les ha permitido adaptarse como plataformas que articulan servicios propios de las redes sociales digitales. 
evolucionado sus interfaces al punto de ofrecer servicios propios de las más populares redes sociales digitales (Facebook, Twitter, etc). Dichos servicios actualmente incluyen la generación de un perfil, la capacidad para conversar mediante grupos de intereses e incluso poder compartir distintos tipos de archivos entre contactos.

Las redes socio-digitales ${ }^{5}$, entre otras cuestiones, poseen una gradual capacidad para amalgamar al interior de sus interfaces electrónicas diversos mecanismos de comunicación. Los grupos de Facebook, por ejemplo, se reúnen según los intereses de la comunidad que le da pie, por lo tanto pueden abarcar rubros diversos. Tal fenómeno bien puede tomarse en cuenta como un síntoma propio de la cultura visual digital de nuestros días $^{6}$. Se trata de un mundo en donde se cruzan y adaptan tanto entornos como aplicaciones electrónicas en más de un sentido (Darley, 2002). Derivado de este fenómeno, las redes sociales digitales de hoy en día cuentan con aplicaciones que permiten expresar un número cada vez mayor de estados emocionales y cognitivos ${ }^{7}$.

Esas plataformas pueden emplearse, entre otras cuestiones, como un tipo de diario en el que se escriben y comparten anhelos, buenos y malos ratos, gustos y hasta estados de ánimo. Si bien se pueden colocar detalles sobre diversas actividades de la vida cotidiana que se desean mostrar a los demás, personas extrañas pueden entrar a espiar, sin ser invitados. Precisamente en la capacidad de esas herramientas tecnológicas para articular contenidos que pueden compartirse entre diversos usuarios, incide en el hecho mismo de que querer matizar y editar la información. Los filtros, encuadres y otras aplicaciones para montaje y edición digital, permiten

5 Se trata de otro nombre para definir las redes sociales digitales. Ambos pueden ser válidos para conceptualizar instrumentos útiles para la interlocución en torno a diferentes asuntos, entre los que bien puede caber la agenda política de un país o hasta temas basados en creencias populares (Trejo, 2015).

6 Para ampliar el tema revisar el texto Darley, A. (2002) Cultura visual digital: Espectáculo y nuevos géneros en los medios de comunicación. Barcelona. Paidós. Muestra las principales claves para comprender la cultura con las pantallas electrónicas y sus entornos virtuales. Se trata de una verdadera ecología mediática en la que aplicaciones e interfaces se van conglomerando al interior de distintos servicios de comunicación digital.

$7 \quad$ Facebook permite enviar a otros contactos diversos recursos de comunicación como los emoticons, rostros y personajes que muestran estados de ánimo. Además, los archivos de imágenes animadas llamados gif's, los videos, los memes y los video memes son también recursos populares para expresar distintos estados cognitivos. El fenómeno `me enflorece` es otro de esos recursos con el que es posible mostrar lo que se piensa y siente con respecto a la publicación que hace un contacto dentro de esa red social digital. 
retocar comentarios, imágenes, etcétera, dentro de las propias interfaces electrónicas de las redes socio-digitales. Esas y otras aplicaciones provienen originalmente de otros servicios informáticos, pero se han adaptado al interior de las redes sociales digitales junto con plataformas tales como las de videojuegos.

En realidad esa última posibilidad no es exclusiva de las redes sociales digitales. La capacidad de retoque de los objetos ${ }^{8}$ de los medios de comunicación se encuentra presente desde el surgimiento de los primeros referentes de los sistemas de expresión audiovisuales, tales como la fotografía o el cine ${ }^{9}$ (Benjamin, 2003; Manovich, 2006). Sin embargo, ese hecho cobra mayor auge en la era actual, precisamente cuando la identidad puede ser expuesta a otros dentro de una plataforma digital. También se ha vuelto posible gracias a la existencia de novedosas herramientas para la edición integradas dentro de una misma plataforma.

\section{Planteamiento del problema}

Las graduales transformaciones tecnológicas que han experimentado las redes socio-digitales les brindan hoy la capacidad para ofrecer a sus usuarios una cantidad mayor de servicios de comunicación. A través de sus herramientas digitales, pueden conocer detalles e informaciones respecto a la vida y actividades cotidianas de propios y extraños, al mismo pueden interactuar con ellos. No obstante, algunos autores advierten sobre una serie de riesgos presentes al interior de las redes sociales digitales. Depositar datos e informaciones privadas dentro de ese espacio puede ocasionar que otros puedan acceder a ellos. Además podrían generar adicción debido al uso prolongado y la necesidad de sus usuarios a estar conectados de forma constante (Murdochowicz, Marcon, Sylvestre \& Ballestrini, 2010).

Si bien las plataformas sociales electrónicas actuales se asumen como herramientas útiles para asuntos tales como la construcción de la opinión pública y la democracia (Ellison \& Boyd, 2013), al mismo tiempo pueden

8 Los objetos de los medios de comunicación van desde una imagen, un fotograma, una carta, etc. (medios tradicionales), hasta un archivo de audio, un clip de video o una animación (nuevos medios) (Manovich, 2006).

9 Los primeros esfuerzos de retoque de la imagen para el cine se desarrollaron al interior de los fotogramas mismos que daban pie a una película. Directores como Georges Méliès coloreaban incluso los cuadros de imagen para generar efectos audiovisuales. Los medios de comunicación digitales aplican esos mismos principios de edición ya no de forma manual sino más bien aprovechando las bondades de la tecnología actual (Manovich, 2006). 
ser tecnologías que permiten desarrollar intereses relativos a campos de la sociedad como es el entretenimiento ${ }^{10}$.

Recientemente, las redes sociales digitales permiten jugar videojuegos dentro de ellas. Existen plataformas, como Facebook, capaces de desplegar en su interior una serie de títulos de juegos de video. El servicio de mensajería instantánea (Messenger ${ }^{11}$ ), incluido dentro de Facebook, ofrece a sus consumidores un repertorio cada vez más sofisticado de herramientas para la expresión y, por supuesto, también permite invitar a otros usuarios a jugar videojuegos.

El presente trabajo tiene como por objetivo, precisamente, comprender el fenómeno de la oferta de videojuegos dentro de las redes sociales digitales, con la finalidad de analizar el panorama en que se piensan dichas plataformas hoy en día. Este trabajo se desarrolla a partir del supuesto de que las redes sociales digitales bien podrían entenderse más que como un elaborado conjunto de estructuras sociales, como una serie de plataformas electrónicas que reúnen dentro de sus interfaces diversos servicios de comunicación entre los que se encuentra, justamente, el desarrollo de redes sociales.

Se considera incluso la posibilidad de que las redes sociales digitales llegasen a definirse como parte esencial de una noción más amplia, denominada medios sociales. Los videojuegos en ese sentido podrían estimarse a partir de sus herramientas de comunicación como un tipo de medio social. Ello permitiría pensar a esas últimas tecnologías desde distintos referentes epistémicos. Por ejemplo, los videojuegos tipo multijugador en línea emplean distintos dispositivos electrónicos de comunicación para generar puentes de sentido entre los jugadores y al mismo tiempo las dinámicas del juego de video usan esas interfaces, de este modo, la información que se socializa entre jugadores vuelve más integral una partida de juego. Como podrá verse a lo largo de este texto, si bien dentro de los juegos de video se articulan redes sociales, éstas se vuelven necesarias para sostener partidas de juego de video.

10 El videojuego es una pieza importante dentro de la industria del entretenimiento digital. Sin embargo, también es tomado en cuenta como industria cultural y creativa (Garfias, 2013). Para mayores se sugiere consultar: Crovi, D. (Coordinadora). 2013. Industrias culturales en México. Reflexiones para actualizar el debate, México. Universidad Nacional Autónoma de México y Editorial Tintable.

11 Los servicios de mensajería instantánea también han incursionado en el rubro de los videojuegos. Messenger de Facebook recientemente permite a sus usuarios enviar invitaciones a sus contactos para retarlos a una partida de juego de video. Existen desde los títulos de cartas hasta tramas más elaboradas de videojuegos. 
Este trabajo, en primer lugar, desarrolla un panorama conceptual a partir de las definiciones de red social digital y de medio social, teniendo como eje la noción de videojuego. Más adelante se presenta un panorama actual sobre las distintas utilidades que pueden tener las redes sociales digitales, mostrando el uso de videojuegos en esas plataformas. Enseguida se ofrece un panorama sobre las distintas redes sociales basadas en el tema de los videojuegos; $y$ por último, se brindan detalles del fenómeno de gestación y desarrollo de redes colectivas de personas dentro de los sistemas de videojuego, para dejar en claro la correspondencia entre estos servicios tecnológicos.

\section{El marco conceptual para el presente estudio}

La primera definición contemplada en este estudio es red social digital, que se puede definir como una serie de herramientas o instrumentos útiles para la interlocución de diferentes asuntos por parte de sus usuarios (Trejo, 2015). En el mismo sentido que el párrafo anterior, las redes sociales digitales son "plataformas de Internet que agrupan a personas que se relacionan entre sí y comparten información e intereses comunes" (Murdochowicz, Marcon, Sylvestre \& Ballestrini, 2010: 3). Ambas definiciones describen a las redes sociales digitales como un conjunto de mecanismos electrónicos los cuales posibilitan tanto la interacción como la comunicación humana.

El principal objetivo de esas herramientas digitales consiste en entablar contactos entre personas, ya sea para reencontrarse con antiguos vínculos o para generar nuevos (Murdochowicz, Marcon, Sylvestre \& Ballestrini, 2010: 3). Consisten entonces en un conjunto de plataformas electrónicas que permiten el desarrollo de redes sociales. Es decir, brindan a sus usuarios la capacidad de articular un elaborado entramado entre personas.

Las redes sociales offline (también llamadas tradicionales) son aquellos entramados de individuos relacionados entre sí desarrollados sin la necesidad de mediaciones electrónicas, mientras que las redes sociales online son aquellas que se establecen a través de medios electrónicos ( $\mathrm{Campu}-$ zano, 2011). Pueden integarse, entre otras formas, a partir del uso de las distintas herramientas y servicios disponibles en las plataformas sociales (Campuzano, 2011). Esto indica que serán primero herramientas electrónicas para la comunicación en red (las tecnologías digitales), que redes de sociabilidad (Garibay, 2016).

En ese sentido, un problema conceptual a propósito de las redes sociales digitales deriva del hecho de que se las entienda como un sinónimo 
de red social. Sin embargo, es posible dejar en claro que la noción de red social es un asunto distinto al de red social digital, tal como lo especifica Campuzano (2011) al distinguir red social en línea y red social fuera de línea. Como ya se refirió, las redes sociales en línea consisten en las redes sociales que usan la tecnología para establecer puentes comunicativos, mientras que las redes sociales fuera de línea consisten en los entramados entre personas que se realizan sin necesidad de artefactos electrónicos (Campuzano, 2011).

En otras palabras, las redes sociales pueden ser tanto en línea (redes por medio de plataformas electrónicas) como fuera de línea (redes sociales tradicionales). Mientras que las redes sociales digitales serían, primero, las plataformas de comunicación capaces de permitir la articulación de redes sociales en línea y luego, redes sociales en línea.

Otra de las definiciones incluidas en este abordaje es medio social. Los también llamados Social Media, o medios de comunicación sociales, consisten en una serie de herramientas digitales para comunicarse, cuyos contenidos son generados precisamente por los mismos usuarios de dichos sistemas electrónicos (Kaplan \& Haenhlein, 2012) ${ }^{12}$. Es decir, los medios sociales representan un conjunto de aplicaciones basadas en Internet que permiten la creación e intercambio de una serie de contenidos autogenerados, los cuales van desde un comentario, una publicación, un meme ${ }^{13}$, un video, una fotografía, una imagen y hasta un guiño en forma de ícono.

La principal característica que define a un medio social es que, a diferencia de los medios tradicionales en donde el contenido se elabora generalmente por unos pocos emisores, dentro de los primeros la información se genera mediante un grupo de personas o una comunidad la cual se encarga de interactuar mediante retroalimentaciones (Kaplan \& Haenhlein, 2012).

Cabe aclarar que, los ahora llamados medios tradicionales, difieren de los nuevos medios de comunicación por al menos cinco principios. El primero consiste que en los digitales, su representación es numérica, es decir, su codificación se realiza a través de un lenguaje digital. El segundo

12 Las herramientas de los medios sociales incluyen servicios como son los programas que permiten, entre otras cuestiones, conocer la influencia que cobra un determinado contenido. Además existen aplicaciones de medición del uso de redes sociales digitales, de servicios de geolocalización, etc.

13 El contenido visual (y ahora también audiovisual) es capaz de representar a un conjunto de signos de carácter expresivo. Dicho contenido es compartido de forma frecuente dentro de plataformas como Facebook y llevado a otros entornos y aplicaciones dentro de Internet (Pérez, Aguilar, Archilla \& Ernestina, 2014) 
principio de los nuevos medios es su modularidad, su capacidad para presentar adhesiones y amalgamas entre sus objetos (imágenes, videos, audio, etc.) e interfaces. El tercer principio de un nuevo medio consiste en su automatización, ya tratan de eliminar la presencia del ser humano en alguna parte de sus mecanismos de operación. El cuarto principio que diferencia a los nuevos medios de los tradicionales tiene que ver con su variabilidad, la posibilidad de representar sus objetos dentro de diferentes versiones y actualizaciones. Finalmente, el quinto indica que los nuevos medios permiten su trans-codificación: el cambio entre formatos de sus distintos objetos (Manovich, 2006).

Así, aunque se puede pensar que un medio social y las redes sociales digitales son lo mismo, no lo son: ambos son sistemas electrónicos para la articulación de puentes comunicativos a manera de entramados (Campuzano, 2011). Sin embargo, definir a los medios sociales precisa incluir, además de las redes sociales digitales, a distintas plataformas tecnológicas diseñadas para el envío y elaboración de contenidos.

Si bien los medios sociales figuran en entornos electrónicos en donde pueden incluirse las redes sociales digitales, también son interfaces electrónicas que alojan en su interior a otras plataformas como los blogs, los foros, los servicios de sindicación remota, los mapas, los sistemas de localización satelital, etc. (Garibay, 2016). A partir de lo anterior puede decirse que una red social digital tendrá la capacidad para llegar a desarrollarse e incluso extender sus servicios, en parte gracias a la ayuda de las herramientas digitales con que cuentan los medios sociales.

E1 tercer elemento considerado en el presente abordaje es videojuego, definido como una tecnología audiovisual que permite el despliegue de una serie de datos e informaciones representadas al interior de una pantalla (Levis, 2003). También pueden definirse como tecnologías que sirven para el juego digital y al mismo tiempo, permiten establecer puentes comunicantes entre sus usuarios por medio de diversos servicios como son el Internet y los servidores de juego ${ }^{14}$ (Wolf, 2009, Garfias, 2011). En este contexto, los videojuegos hoy en día permiten la generación de un conjunto elaborado de redes sociales que se despliegan dentro de sus sistemas digitales (Garfias, 2011). Por ello, los videojuegos son dispositivos electrónicos que favorecen la generación de comunidades virtuales en las

14 Los servidores de videojuego consisten en equipos de cómputo que alojan una serie de repositorios digitales capaces de contener una partida de juego de tipo multijugador en línea. Los servidores de juego usualmente son propiedad de distintas empresas dedicadas al mundo del videojuego. Se trata de proveedores que ofrecen herramientas en línea para controlar, configurar y almacenar distintas partidas de juego. 
que coexisten miles de personas dentro de un mismo título de juego de video o un servidor (Cortés, García, Lacasa, 2012).

Los juegos de video también pueden ser entendidos como entornos virtuales cuya arquitectura se encuentra en constante transformación, debido a su potencial manipulación por parte de los jugadores (Estrella, 2011). Cabe considerar entonces la posibilidad de que los propios videojuegos sean entendidos como un tipo de medio social, ya que por un lado, dentro de ellos pueden generarse redes sociales en línea; y por otro, debido a que diversos contenidos que circulan en su interior pueden ser generados y retocados por sus mismos jugadores dentro de sus comunidades.

\section{Usos múltiples para las redes sociales digitales}

Como un elaborado conjunto de herramientas electrónicas para la comunicación humana, las redes sociales digitales pueden tener múltiples utilidades y servicios. Un ejemplo de lo anterior se encuentra en la plataforma Anikku, actualmente una de las más populares redes sociales digitales entre los usuarios de la cultura otaku $u^{15}$, es decir, los amantes de las industrias audiovisuales animadas e interactivas provenientes de Japón.

La plataforma Anikku también ha logrado posicionarse como una de las preferidas dentro de esa comunidad ${ }^{16}$, gracias a sus posibilidades de interactividad comunicativa y selectiva en torno al mundo animado y también gracias a su interfaz gráfica manipulable. Se trata de una plataforma digital que si bien guarda un parecido con otras redes como Twitter, en realidad su importancia radica en que es empleada principalmente para la difusión de novedades y lanzamientos de productos como anime ${ }^{17}$, videojuegos y

15 La palabra otaku es usada para definir a aquellas personas con gustos y aficiones provenientes del mundo de los videojuegos, la animación japonesa y las revistas gráficas conocidas como mangas. La aparición de este término se atribuye a Japón desde inicios de los años ochenta, a partir de una adaptación popular de la palabra `aficionado '. Sin embargo, con el paso del tiempo la palabra se ha importado en diversas partes del mundo (Steinberg, 2004).

16 Existen actualmente otras redes sociales digitales especializadas única y exclusivamente en el anime, el manga y los videojuegos además. Una de ellas es Wocial. A diferencia de $A n i k k u$, dicha plataforma contiene una menor cantidad de gráficos manipulables por sus usuarios.

17 Se trata de un sistema de expresión audiovisual animado cuyo principal referente es Japón. Si bien la palabra anime deriva de animation concretamente tiene que ver con un estilo para la elaboración de dibujos animados generado por los nipones (Cobos, 2010). Es un sistema audiovisual con cien años de antigüedad que se ha distribuido a diversas regiones del planeta. 
manga ${ }^{18}$. Incluso la publicidad electrónica dentro de esa interfaz ayuda a sus usuarios a conocer detalles sobre esos mismos asuntos.

Dentro de Anikku es posible articular diferentes sistemas de amigos y comunidades por medio de la creación de perfiles virtuales, modelados precisamente por ellos mismos dentro de esa plataforma. Su interfaz gráfica permite personalizar elementos como el fondo y crear un banner ${ }^{19}$. También es posible colocar videos de perfil y detalles sobre el sitio web particular de sus usuarios. Además Anikku permite vincularse con otras plataformas de comunicación como Facebook o Twitter. De esta manera, el usuario de esos entornos puede generar puentes con personas cuyos intereses y afinidades sobrepasan el ámbito exclusivo del videojuego y el anime.

Otra de las redes sociales digitales importantes en el mundo es $V k o n-$ takte. Podría estimarse que esa es la tercera red social más importante de Europa $^{20}$, por supuesto después de Facebook y Twitter.

Vkontakte es una plataforma diseñada para la articulación redes socio-digitales, disponible en más de setenta idiomas, la cual reúne intereses de distinto tipo. A pesar de lucir una interfaz gráfica semejante a la de Facebook, los intereses de Vkontakte pueden llegar hasta al ámbito empresarial y la difusión exclusiva para personalidades públicas, principalmente desde sus grupos y comunidades. Esto evidencia que esta red social digital se ha construido, probablemente, estimando los beneficios de otros espacios dentro de la red como MySpace y ha empalmado su arquitectura con las bondades de otras como Facebook, lo que sugiere que podría bien ser una especie de híbrido de servicios de comunicación.

18 Los mangas son publicaciones gráficas impresas provenientes originariamente de Japón. Su origen se remonta a los sistemas de grabado e impresión de tinta sobre papel conocidos como Xilograbados. El término manga deriva de man (informal) y ga (dibujo) y puede traducirse como 'garabatos`. Hoy en día se importan en diversos países alrededor del mundo (Berndt, 1996).

19 Un banner consiste en una banderola, una imagen rectangular hecha con imágenes (GPJ, GIF, PNG, BMP, etc.) o bien mediante animaciones generadas por medio de programas computacionales para tratamiento digital de la imagen (Photoshop, Flash, etc.). Tienen la finalidad de ser un mensaje capaz de impactar y llamar la atención, personal o como estrategia publicitaria.

20 Según el canal de televisión internacional por cable y satélite de la Federación Rusa, RT. Para mayor información respecto a este y otros datos puede consultarse: https://actualidad.rt.com/rtpedia/178079-vkontakte-vk-red-social-rusia 


\section{Videojuegos dentro de las redes sociales digitales}

Las redes sociales digitales reúnen un cúmulo de aplicaciones cuya presencia va en crecimiento. Si bien dichas plataformas permiten la interacción teledirigida entre usuarios así como gestionar informaciones, fotos, videos, etc., al mismo tiempo permiten otro tipo de servicios, como jugar videojuegos $^{21}$.

Hoy en día se pueden jugar videojuegos dentro de Facebook y otras plataformas sociales semejantes. A partir de ello diversas empresas, gradualmente, han implementado novedosos esquemas publicitarios basados en experiencias interactivas ${ }^{22}$.

Los advergames ${ }^{23}$, publicidad interactiva dentro de las redes sociales, son títulos de juego de video articulados a partir del conocimiento que reúnen las empresas comerciales sobre sus consumidores dentro de los medios sociales. Diversas empresas (por ejemplo las cadenas de servicios de comida rápida) utilizan Facebook y otras redes sociales digitales para anunciar sus productos por medio de una serie de títulos de juegos de video presentes interior de esos entornos electrónicos. Lo anterior indica que las redes sociales digitales se van amoldando a las necesidades de sus públicos, retomando elementos de los medios sociales a partir de las exigencias que ellos presentan (Moral \& Guzmán, 2016).

Relacionado ello, están las invitaciones dentro de Facebook a jugar FarmVille o Candy Crush. El primero de esos videojuegos (de tipo advergame) consiste en el desarrollo de una granja virtual en la que se puede

21 Con el paso del tiempo, los videojuegos en línea han sufrido transformaciones en su arquitectura interna. Eso les ha permitido construir plataforma para la interacción social entre internautas y con ello generaron redes sociales dentro de sus plataformas interactivas (Yousafzai, Hussain \& Griffiths, 2014).

22 Uno de los ejemplos más claros de ello es Panadería Bimbo. Se trata de un videojuego en donde la marca de los productos relacionados con el pan dulce está siempre presente. El jugador debe aprender a hacer pan bajo el sistema de producción de esa empresa. Al mismo tiempo tiene que ir revelando la variedad de productos que ofrece esa marca. El videojugador al mismo tiempo que juega se engancha con bienes simbólicos relacionados con la empresa.

23 Los advergames son un subgénero de los serious games. Estos últimos consisten en aplicaciones interactivas que pueden jugarse para revelar dentro de ellas una serie de utilidades reales benéficas para diferentes campos de la sociedad. Los serious games (traducidos del inglés como juegos serios) permiten alfabetizar a sus usuarios. También les brindan la capacidad de comprender sobre hechos noticiosos. Incluso son entornos efectivos para la publicidad. Los advergames, publicidad jugable, serán por tanto videojuegos serios que publicitan bienes y servicios de diferentes marcas comerciales. 
cosechar todo tipo de vegetales. Incluso es posible jugar a cuidar animales de granja. El hecho de poder agregar vecinos (otros videojugadores) y compartir en tiempo real con ellos (y también otros usuarios de Facebook) vuelve más atractiva a esta herramienta digital. Candy Crush es uno de los más populares juegos dentro y fuera de la red. Son videojuegos casuales que pueden experimentarse sin grandes conocimientos sobre esos temas y sin un gran dominio de las interfaces exclusivas con que cuentan los videojuegos de última generación.

Es importante resaltar el hecho de que estas plataformas de juego dentro de Facebook han sido adaptadas para los sistemas operativos portátiles Androidy $i O s$, por lo que la experiencia de juego puede extenderse fuera de dicha red social digital ${ }^{24}$. Cabe mencionar además, que el hecho de incorporar mecanismos tecnológicos para realidad virtual y aumentada dentro de las redes sociales digitales, podría extenderse a la experiencia del juego dentro de esos espacios ${ }^{25}$.

Facebook entró al mercado de los videojuegos por dos vías: por un lado, implementando juegos de video dentro de su interfaz electrónica; y por el otro, se ha trepado hacia ese sector elaborando el prototipo de una plataforma exclusiva para jugar videojuegos disponible en un futuro en su interior (Moral \& Guzmán, 2016).

Los videojuegos de esta manera permanecen dentro de las redes sociales digitales, ya sea como una posibilidad de interacción y encuentro entre personas (Moral \& Guzmán, 2016), o como herramientas con lógicas y mecánicas propias de otro tipo de sistemas de juego de video. Pero los videojuegos también se han posicionado dentro de las redes sociales digitales debido a sus capacidades para representar comunidades de forma virtual dentro de sus entornos interactivos, como bien hace Facebook con sus grupos y comunidades. Este hecho permite considerar a los videojuegos como herramientas útiles para la conformación de redes sociales, ya que se trata de plataformas que permiten la sociabilidad en línea y por tanto, podrían pensarse como un tipo de medio social.

24 Desde la primera década del presente siglo, cuando servicios de comunicación en línea, como MSN, desarrollaran plataformas de juegos de video en su interior, otras empresas han optado por llevar a cabo una práctica semejante.

25 Esa afirmación resulta posible debido a la compra de Occulus (empresa dedicada a la generación de aplicaciones y herramientas de realidad virtual) por parte de Mark Zuckerberg, dueño de Facebook. 


\section{Redes sociales dentro de los videojuegos}

En nuestros días resulta cada vez más frecuente encontrar videojuegos que permiten distintos grados de sociabilidad al interior de sus plataformas. Los niveles de participación dentro de esos entornos son varios y de diverso tipo. En algunos casos se extienden más allá de la pantalla (Cortés, García, Lacasa, 2012). Entre ellos destacan dos dispositivos de juego que permiten tal posibilidad: The Sims y Second Life, que bien pueden considerase herramientas para la construcción de puentes sociales, es decir, para el encuentro e interacción virtual de miles de personas alrededor del mundo (Cortés, García, Lacasa, 2012) ${ }^{26}$.

Dentro de esos videojuegos se puede jugar a construir una vida semejante a la que existe fuera de pantalla. Sus jugadores pueden usar esa plataforma como un simulador para probar suerte respecto a miles de actividades, y al mismo tiempo, pueden conocer, charlar e interactuar con personas tal como hacen en Facebook.

The Sims es un simulador de la vida articulado mediante entornos en tres dimensiones interactivos. Jugar este videojuego, por tanto, implica la generación de una experiencia cognitiva, cultural y emocional que busca ser lo más apegada a la realidad de sus jugadores, y al mismo tiempo, es un puente electrónico que permite el encuentro virtual de miles de personas alrededor del mundo.

Por su parte, Second Life se ha considerado como una vida 2.0 (Spingarn-koff,2010). Representa un espacio semejante a los chats del Messenger de Facebook, pero con la particularidad de contar con avatares que articulan elementos sobre la personalidad de aquellas personas con las que se conversa de forma virtual.

Este fenómeno ha detonado una serie de innovaciones e inventivas por parte de empresarios, sectores culturales y educativos, etc., llevando así a Second Life fuera del marco del entretenimiento, orientándolo a nuevas aplicaciones. Un ejemplo de ello se encuentra en el caso de la Universidad San Martín de Porres en Perú. Esta institución académica ha implementado una serie de cursos, charlas, conferencias, etc., dentro de Second

26 The Sims y Second Life son plataformas digitales interactivas de simulación de la realidad fuera de pantalla. Sus sistemas de juego permiten construir y modelar un mundo de acuerdo a las necesidades y gustos de sus usuarios. Actualmente las dos plataformas pueden desplegarse en sistemas operativos para PC y la primera de ellas tiene versiones para las consolas portátiles de última generación de juego digital (Play Station 4 y Xbox One). 
Life. Es decir, ha migrado una buena parte de sus sistemas a distancia al interior de ese videojuego (Arriola \& Amparo, 2012). De esta manera, los estudiantes con mayores problemas de sociabilidad y poco hábiles para el desarrollo de relaciones sociales que difícilmente entablarían interacción con diversas personas en su vida cotidiana, dentro de esta plataforma de juego pueden desenvolverse con mayor facilidad (Arriola \& Amparo, 2012). Esto resulta posible debido a que Second Life, al igual que The Sims, permiten la manipulación de sus entornos y la creación de avatares dentro del videojuego.

Uno de los fenómenos relacionados con la articulación de redes sociales dentro del juego de video es el racismo, que se llega a presentar al acceder a los servidores en línea de diversos videojuegos. Por ejemplo, cuando un jugador mexicano genera un Gamer Tag (una identidad de jugador mediante el uso de una rúbrica digital) y alinea su partida con la de jugadores de otras nacionalidades, como pueden ser Japón o Estados Unidos, no resulta raro que éstos últimos le envíen mensajes relacionados con los estereotipos de su sociedad. Dentro de Metal Slug Defense $e^{27}$, plataforma de videojuego en línea disponible para los sistemas operativos Android y $i O s$, ocurre incluso con frecuencia que los jugadores de otros países, al ver una bandera mexicana, salgan inmediatamente de los servidores de juego.

Por otro lado, League of Legends es otro de los casos emblemáticos en torno al fenómeno de la construcción de redes sociales dentro de los videojuegos. Se trata de un juego de tipo multijugador masivo en línea, en el que miles y hasta millones de usuarios permanecen conectados a diario entablando partidas de juego en modo cooperativo (Bertrán \& Chamarro, 2016). En este videojuego es posible comunicarse tanto de forma escrita como verbal. También se pueden generar comunidades de jugadores conocidas como hermandades de juego.

Se trata de entornos virtuales en los que se pueden dar cita personas de distintas partes del mundo para discutir y dialogar sobre diversos intereses. El juego de video se puede pensar así como una estructura social en la que sus participantes comparten e intercambian información, más allá de la idea de que se trata de una plataforma para el entretenimiento o

27 Metal Slug Defense es un videojuego propiedad de la empresa SNK, proveniente de Japón. Se trata de una de las franquicias más exitosas y populares de juego de video en los años noventa. Su versión Defense es una reciente adaptación que incluye partidas de juego en línea de modo cooperativo. Existe otra versión más actual llamada Metal Slug Attack. Para mayores informes sobre esa plataforma puede consultarse el sitio oficial de la empresa Shin Nihon Kikaku (SNK Corporration) dentro de enlace: https://www.snk-corp.co.jp/us/games/apps/metalslug_defense/ 
bien para la generación de experiencias sensibles o estéticas, como podría ser el caso del cine o la televisión. El videojuego se constituye así, en una instancia para la construcción de redes de comunicación y de relaciones sociales virtuales.

\section{Las redes sociales digitales de videojuegos}

Un fenómeno cada vez más presente dentro de Internet son las redes sociales digitales especializadas en el tema de los videojuegos. Se trata de verdaderas comunidades digitales donde millones de jugadores se dan cita diariamente para ahondar en detalle respecto al mundo del juego digital de video. Estos espacios, poblados por usuarios conectados desde diversas partes del planeta, se desarrollan a partir de una serie de intereses, centrados ya sea en algún videojuego en particular o bien en alguna parte de su industria (un personaje, una franquicia, etc.).

También es posible encontrar comunidades articuladas dentro de estas redes sociales digitales, mismas que se reúnen de forma virtual a partir del conocimiento que tienen sobre una saga de videojuegos específica o bien una consola en particular. Un ejemplo claro sobre lo anterior es el caso de una de las redes sociales digitales más populares para los videojugadores: Rolbook, una plataforma exclusiva para videojuegos de rol, es decir videojuegos que se experimentan mediante turnos. Es el Facebook para videojugadores. Este espacio digital reúne a grupos de jugadores de distintas partes del mundo. Todos ellos se dan cita para generar conocimiento y compartir estratagemas sobre juegos donde el turno y la táctica son esenciales.

Otra plataforma electrónica que permite reunir a los videojugadores es Twitch, propiedad de la empresa Amazon, que es tanto un sistema de transmisión en tiempo real de contenidos audiovisuales, como una plataforma de comunicación. Se trata del sistema de streaming (transmisión de video en tiempo real) exclusivo para videojuegos más importante del mundo. Este espacio reúne a millones de usuarios que suben sus partidas de juego mientras otros millones más los observan. Twitch tiene una función semejante a Facebook y Twitter, llamada Pulse. Consiste en una aplicación de streaming mediante la que los videojugadores pueden ver los mensajes de sus canales favoritos así como las noticias relacionadas tanto con la aplicación como con otros usuarios destacados.

Además de esa posibilidad, actualmente Twitch cuenta con capacidad para que sus usuarios (trasmisores de video y públicos observadores) publiquen mensajes, envíen fotos, videos, clips de sus partidas y archivos 
de diverso tipo. Twitch incluso cuenta con un servicio de chat privado y exclusivo llamado Whispers. Se trata de uno de los esfuerzos más importantes de esta plataforma de comunicación por volverse social. Por si todo lo anterior no fuera suficiente para considerarla ya una red social digital, cabe mencionar que Tritch cuenta también con todo un amplio servicio digital destinado al almacenamiento y la gestión de grupos de amigos y contactos, llamado Channel Feed - Friends System.

Como puede verse, el fenómeno de las redes sociales digitales orientadas hacia intereses particulares (en este caso el mundo de los videojuegos), muestra que la oferta de plataformas se ha diversificado al mismo tiempo en que las aplicaciones han ido convirtiéndose, de una u otra forma, en redes sociales digitales.

\section{Conclusiones}

El tema de las redes sociales digitales sin duda dará mucho de qué hablar en un futuro. Si bien es cierto que las formas de comunicarse hoy en día requieren de nuevos adelantos tecnológicos que sustenten su sociabilidad, también se hace necesario considerar que las mismas redes sociales son una actividad tan antigua como la sociedad misma. Pensar hoy en día a las redes sociales digitales debe considerar o al menos distinguir, entre las plataformas de comunicación (las plataformas sociales o social media) y su resultado, es decir, las redes sociales (entramados colectivos de personas).

En este contexto, cabe tomar en cuenta que el hecho de establecer puentes comunicantes dentro de los videojuegos, incluso podría estimarse como una forma de articulación de redes sociales digitales. Sin embargo, considerar que los videojuegos puedan ser tomados en cuenta como medios sociales, es decir plataformas sociales, requiere seguir reflexionando acerca de este tema.

Aunque los servicios de comunicación y de generación de comunidades por parte del videojuego van en aumento, sus principales servicios o utilidades no se basan exclusivamente en el desarrollo de esas posibilidades. En cambio, lo que se hace dentro de Facebook es participar en una red social digital, debido a que articula y despliega un conjunto de redes sociales y de tejidos de relaciones humanas con intereses particulares. Es una red social digital porque es una plataforma que hace posible ese encuentro entre personas.

El fenómeno de los videojuegos dentro de las redes sociales digitales permite visualizar las posibilidades de amalgama o cruce entre servicios y 
Un abordaje a las redes sociales digitales, los videojuegos..

herramientas dentro de sus interfaces, y a la vez muestra que la definición misma de red social digital puede ser cada vez más amplia.

Las personas hoy en día generan contactos y abren sus horizontes de interés dentro de servicios digitales como los videojuegos, tal como lo hacen con las redes sociales digitales. O bien pueden optar por jugar videojuegos e incluso hasta tejer redes sociales dentro de las mismas plataformas de redes sociales digitales. Plataformas como Twitch, si bien en sus inicios generaban contenidos específicos para su transmisión en tiempo real, hoy en día cuentan con servicios propios de las redes sociales digitales. Ello sugiere que esa puede ser una tendencia a futuro dentro de las plataformas sociales y otros servicios de comunicación.

\section{Bibliografía}

Arriola, C. \& M. Amparo (2012). Simulaciones educativas en Second Life en Revista EduTic Innova. Septiembre. Perú. Universidad de San Martín de Porres.

Benjamin, W. (2003). La obra de arte en la época de su reproductibilidad técnica. México. Ítaca.

Berndt, J. (1996). El fenómeno manga. Barcelona. Martinez Roca.

Bertrán, N. \& A. Chamarro (2016). Videojugadores de League of Legends. Revista Adicciones. Sociedad Científica Española de Estudios sobre el Alcohol, el Alcoholismo y otras toxicomanías. Vol. 28. No. 1.

Campusano, H. (2011). Las redes sociales digitales. Concepto, clases y problemática jurídica que plantean en los albores del siglo XXI. España. Universidad de Oviedo.

Coвos, T., (2010). Animación japonesa y globalización en Revista Razón y palabra. México. No. 72.

Cortés, S., García M. \& P. Lacasa (2012). Videojuegos y redes sociales. El proceso de identidad en Los Sims en Revista Educación a Distancia. No. 33. España. Universidad de Murcia.

Darley, A. (2002). Cultura visual digital. Espectáculo y nuevos géneros en los medios de comunicación. España. Paidós.

Domínguez, D. (2010). Las redes sociales. Tipología, uso y consumo de las redes sociales 2.0 en la sociedad digital actual. España. Universidad Complutense de Madrid. 
Ellison, A. \& D. Boyd (2013). Sociality through social network sites en Duthon W. (Ed.) The Oxford handbook of internet studies. Oxford. Oxford University Press.

Estrella, H. (2011). Antropología de los mundos virtuales. Avatares, comunidades y piratas digitales. Ecuador. Abya-Yala \& Flacso Ecuador.

Garibay, J. (2016). Diferencia entre social media y redes sociales, clave para tu estrategia. Revista Merca2.0. México. 30 de mayo de 2016. https:// www.merca20.com/diferencia-social-media-redes-sociales-clave-estrategia/ Disponible en línea. Consultado el 17 de junio de 2017.

Garfias, J. (2011). El ritual del videojuego para la reproducción de la industria del entretenimiento. Tesis de doctorado en Ciencias Políticas y Sociales. Universidad Nacional Autónoma de México.

Garfias, J. (2013). Teorías del videojuego. El estudio serio del entretenimiento en Crovi D. (Coord.) Industrias culturales en México. Reflexiones para actualizar el debate. México. Universidad Nacional Autónoma de México. Tintable.

Gubern, R. (1996). Del bisonte a la realidad virtual. La escena y el laberinto. Barcelona: Anagrama.

Kaplan, A. \& M. Haenhlein (2012). Social media: back to the roots and back to the future en Journal of systems and information technology. Vol. 4. No. 2. Emerald Group Publishing Limited.

Levis, D. (2003). Videojuegos, cambios y permanencias en Revista Comunicación y pedagogía. Barcelona.

Life 2.0 (2010). Documental dirigido por Jason Springarn-koff. Estados Unidos. PalmStar media \& Andrew Lauren productions.

Manovich, L. (2006). El lenguaje de los nuevos medios de comunicación. La imagen en la era digital. Buenos Aires: Paidós.

Manovich, L. (2013). Software takes command. Extending the lenguaje of new media. Londres: Bloomsbury Academic.

Moral, D \& E. Guzmán (2016). Jugar en red social. Adicción digital versus comunicación e interacción en CityVille. Chile. Pontifica Universidad Católica de Chile.

Murdochowicz, R., Marcon, A., Sylvestre, V. \& Ballestrini, F. (2010). Los adolescentes y las redes sociales. Escuela y Medios. Argentina. Ministerio de Educación de la Nación.

Pérez, G. Aguilar, A., Archilla G. y M. Ernestina (2014).El meme en internet. Usos sociales, reinterpretación y significados, a partir de Harlem 
Un abordaje a las redes sociales digitales, los videojuegos..

Shake en Revista Argumentos. Vol. 27. No. 5. Universidad Autónoma Metropolitana.

Portal del canal de televisión internacional por cable y satélite de la Federación Rusa RT (Tv Novosti) https://actualidad.rt.com/rtpedia/178079-vkontakte-vk-red-social-rusia (consultado el 15 de junio de 2017).

Portal de la Asociación de Internet.mx (World Trustmark Alliance, Estados Unidos de Norteamérica) https://www.asociaciondeinternet.mx/ (consultado el 15 de junio de 2017).

Portal oficial de la empresa de videojuegos Shin Nihon Kikaku (SNK corporation) https://www.snk-corp.co.jp/us/games/apps/metalslug defense/ (consultado el 15 de junio de 2017).

Requena, F. (1989). El concepto de red social en Revista española de investigaciones sociológicas. No. 48.

Sartori, G. (1998). Homo videns. La sociedad teledirigida. Madrid. Taurus.

Statistic Brain (Statistic Brain Research Institute, Estados Unidos de Norteamérica). http://www.statisticbrain.com (consultado el 15 de junio de 2017).

Steinberg, M. (2004). Otaku consuption, superflat art and the return to Edo. Japan Forum No. 16. Vol. 16. No. 3.

Trejo, R. (2015). Ser visibles para ser ciudadanos. Política y redes sociodigitales en América Latina en Revista Latinoamericana de Ciencias de la Comunicación. Asociación Latinoamericana de Investigadores de la Comunicación. Enero-Junio.

Wolf, M. (2009). An introduction to the video game theory en Wolf, M. $\&$ B. Perron (Eds.) The video game theory reader 2. New York. Routledge.

Yousafzai, S., Hussain, Z. \& M. Griffiths (2014). Social responsibility in online videogaming: What should the videogame industry do? en Adiction Research and theory. No. 22. 


\section{Interactividad desde la tecnología Web: de la conceptualización a la operacionalización}

\section{Rafael Leonardo Ochoa Urrego ${ }^{1}$}

Es evidente que la sociedad actual es una sociedad conectada, cada vez más en tiempo real y siempre en línea, dentro de la cual las personas perciben como necesario comunicarse en cualquier momento y desde cualquier lugar (Fan, Liu, Wang, \& Wang, 2016) Ante este panorama el estudio de los medios de comunicación digitales gana relevancia para una multiplicidad de disciplinas. Uno de los aspectos más estudiados dentro de la comunicación digital es la interactividad, ya que se lo considera como el centro de las actividades con nuevas tecnologías, además, su estudio en comunicaciones basadas en las redes tiene importantes implicaciones sociales (Bucy, 2004).

El concepto de interactividad existe desde la década de 1940 cuando la cibernética trajo a colación la retroalimentación y lo asoció con la interacción con el medio. Para este tiempo la interactividad era un elemento propio de la tecnología usada como canal de comunicación (Stromer-Galley, 2000). Posteriormente, en la década de 1970 y en el ámbito de las comunicaciones, se comenzó a utilizar vinculándolo a la aparición de los primeros medios y servicios de información. Este nuevo esquema retaba al modelo comunicativo planteado por los medios masivos y cuestionaba en especial el flujo predominantemente unidireccional sobre el cual se basan los medios tradicionales (Barredo-Ibáñez \& Díaz-Cerveró, 2017). A partir de este momento numerosos estudios de la comunicación se concentraron en la continua reformulación de la definición de la interactividad (Bucy, 2004), creando una amplia gama de opciones, dificultando el consenso. Al mismo tiempo, aumentó la necesidad de formular propuestas que lo operacionalicen y permitan su implementación, así como su posterior medición (Bucy, 2004; Downes \& McMillan, 2000; Kiousis, 2002).

En este contexto, el presenta trabajo pretende hacer una breve introducción a las distintas posturas propuestas por la literatura sobre la defi-

1 Doctor en Ingeniería - Industria y Organizaciones de la Universidad Nacional de Colombia. Académico invitado en la Universidad Nacional Autónoma de México, estancia financiada por el Programa de Becas para estancias posdoctorales de la DGAPA - UNAM. 
nición de interactividad, para concentrarse en el análisis de la visión de la interactividad como un elemento propio de la tecnología usada como canal de comunicación, desde donde se busca construir la base para la operacionalización y medición de la interactividad en ambientes web. No se pretende la construcción de una teoría, de una definición o de un modelo de medición, por el contrario, el objetivo principal es realizar una recopilación teórica de amplio espectro que haga énfasis en los elementos claves de la definición y operacionalización de la interactividad, y que permita abrir la discusión sobre la posible unificación de conceptos y parámetros, con el fin de fortalecer las acciones ejecutadas por organizaciones con modelos de comunicación basados en la WEB.

En los demás capítulos de esta obra se han analizado las prácticas comunicativas en entornos digitales desde la perspectiva del usuario. Es decir, se analizaron las características de las personas que interactúan mediante el uso de redes digitales de comunicación. Desde dicha visión es posible comprender, en palabras de Proulx (2002), el uso y la apropiación de las redes sociodigitales por parte de los grupos sociales. Sin embargo, y de manera adicional, se considera necesario construir una base conceptual y de operacionalización de la interactividad desde una visión tecnológica, ya que es esta base la que permite la construcción de plataformas de intercambio y comunicación entre los usuarios, plataformas que son el elemento indispensable para la construcción de prácticas comunicativas en entornos digitales.

Es así que el presente capítulo pretender abrir paso a la construcción de un escenario que, partiendo del entendimiento de la interactividad como un fenómeno social y comunicativo, aporte los elementos tecnológicos pertinentes para enriquecer la experiencia de interacción entre los usuarios de las redes sociodigitales. Esto en concordancia con la idea de que la plataforma tecnológica y su diseño condicionarán, positiva o negativamente, las posibilidades de comunicación entre los miembros de una red sociodigital. En otras palabras, la plataforma tecnológica sirve como facilitador para la construcción de una red sociodigital y determina las posibilidades de intercambio entre los miembros del sistema social.

Con esto en mente, se iniciará con un recorrido por distintas definiciones del concepto de interactividad, para luego sintetizarlas a través de un conjunto de dimensiones. Como sección final, se analizarán algunos modelos tendientes a su operacionalización y medición. Para terminar, se exponen algunas conclusiones relevantes y se plantean escenarios de trabajo futuros. 


\section{Conceptualizar interactividad. ¿Una misión imposible?}

La penetración de las tecnologías de la información y las comunicaciones (TIC) en las distintas esferas de la sociedad es cada vez más evidente. La tecnología más presente en muchas de las actividades diarias de las personas es Internet, específicamente la $W e b$. Se considera que una de las capacidades clave de Internet es su posibilidad técnica para soportar un mayor nivel de interactividad de los usuarios (Palmer, 2002). Esta capacidad se crea y potencia gracias a la creación de un escenario de comunicación muchos a muchos, donde todos los participantes tienen la potencialidad de actuar como origen y destino de múltiples intercambios comunicacionales que coexisten en el ciberespacio (Ha \& James, 1998).

En consecuencia, tanto la interactividad facilitada por los sistemas de información como la percibida por los usuarios, han ganado relevancia para la evaluación de desempeño y la medición del éxito de un sistema de comunicación mediado por la tecnología (Fan et al., 2016). En otras palabras, la interactividad ha dejado de ser un elemento puramente técnico y dependiente de la tecnología utilizada como canal para convertirse en una de las características de los medios digitales de comunicación (Barredo-Ibáñez \& Díaz-Cerveró, 2017).

Igualmente, la interactividad es una característica que distingue de manera radical a las comunicaciones mediadas frente a los medios masivos (Song \& Zinkhan, 2008) lo que ha obligado a la redefinición o reinvención de muchos de los conceptos tradicionales asociados a la comunicación interpersonal y masiva (Kiousis, 2002). Es por esto que se presenta un recorrido por distintas propuestas realizadas sobre el concepto de interactividad basada en ambientes WEB.

La literatura que analiza la interactividad está comprendida por una amplia gama de definiciones, todas con elementos valiosos y distintivos, pero en ocasiones contradictorios. Esto se debe, principalmente, al carácter social y variable que tienen tanto los procesos de comunicación mediados por tecnología, como la tecnología misma, la cual crea oportunidades de intercambio cada vez más variadas y con características realmente disímiles. Sin embargo, existe un asomo de consenso en lo relacionado con las variantes o escuelas que agrupan las distintas definiciones.

Kiousis (2002) y Bucy (2004) proponen que se pueden agrupar las definiciones en tres grandes grupos. Como primer grupo se encuentran 
las que identifican a la interactividad como una característica propia de la tecnología o el medio, idea que tiene sus raíces en la Cibernética (Newhagen, Cordes, \& Levy, 1995), siendo esta corriente en la que se concentrará el presente trabajo. El segundo grupo reúne a las definiciones que ven la interactividad como un elemento propio de un proceso comunicativo, el autor más representativo es Rafaeli (1988). Por último, en el tercer grupo de definiciones se encuentran aquellas que afirman que la interactividad tiene un alto componente psicológico y de percepción por parte de los participantes en el intercambio comunicativo. Uno de los principales trabajos que se concentran en este enfoque es el realizado por Newhagen y otros (1995) al analizar la comunicación por correo electrónico entre un programa de televisión y su audiencia. A continuación, se analizarán las propuestas más relevantes en la vertiente que ve la interactividad como una característica propia del medio tecnológico utilizado para la realización de la comunicación.

\section{Interactividad como característica de la tecnología}

Como se anunció previamente, el presente trabajo se concentrará en relacionar la interactividad con las capacidades o características del medio o de la tecnología utilizada para mediar la comunicación entre los participantes. Esta vertiente extrapola el concepto de realimentación acuñado por la cibernética y lo extiende a un ambiente de comunicaciones mediadas por la tecnología (Newhagen et al., 1995). Como primera aproximación, se entiende a la interactividad "como el potencial que tiene un sistema tecnológico para promover procesos de eficiencia comunicativa a partir de elementos que permitan trasladar el diálogo humano a la comunicación mediada" (Llano-Aristizábal, 2005, p. 9).

Las ciencias de la computación es una de las áreas del conocimiento que se ha concentrado en el estudio de la interactividad desde esta perspectiva, a través de sus teorías de interacción humano-máquina y en donde el objetivo primordial es la adaptación de interfaces de hardware y software amigables y usables para los humanos (Downes \& McMillan, 2000). Esta orientación entiende la interactividad como un constructo teórico asociado a la fascinación inherente que despiertan los grupos de comunicación mediados por computador (Rafaeli \& Sedweeks (1997) citado por Downes \& McMillan, 2000).

Para el caso específico de Internet, se considera que la interactividad es una característica propia de este medio, ya que permite que los usuarios no sólo reciban información, sino que la modifiquen y diseminen (Deuze, 
2003; Navarro Zamora, 2009). Esto implica que el sistema les otorga a los usuarios herramientas de navegación que le permiten seleccionar la información que desea consumir y el orden en el cual serán consumidos. Asimismo, el medio permite la interacción con otros miembros del sistema social y la posibilidad de generar contenidos (Díaz Noci, 2004).

Por otra parte, es necesario distinguir la comunicación mediada de la interacción social, la comunicación personal o la comunicación cara a cara. Esta diferenciación puede verse como una respuesta aportada por esta vertiente para incorporar intercambios donde sólo existe un participante humano y aun así se configura una comunicación; tal como cuando se usan sistemas de información basados en sistemas expertos, o en la descarga de audio o video, los videojuegos o el comercio electrónico (Bucy, 2004). Adicionalmente, esta separación responde a la necesidad de incluir dentro de los intercambios interactivos los procesos de comunicación asíncrona, donde los participantes pueden elegir el tiempo y la duración de la comunicación, alejándose así del referente de la comunicación cara a cara como el estándar de comunicación interactiva (Ha \& James, 1998).

Este distanciamiento de la comunicación cara a cara lleva a entender la interactividad como la habilidad que tiene un sistema tecnológico de generar una experiencia de interacción sin importar la contraparte, abriendo así la posibilidad a la comunicación humano-máquina, donde la contrapartida sería un sistema tecnológico capaz de simular el intercambio comunicativo (Kiousis, 2002). De esta forma aparecen dos dimensiones de la interactividad en ambientes mediados por la tecnología: la interactividad de máquina, manifestada en la interacción del usuario con los contenidos de la interfaz del sistema; y la interactividad de personas, la cual ocurre cuando hay comunicación de dos o más personas a través de un medio en línea (Fan et al., 2016).

Sumadas a los elementos anteriores aparecen las dimensiones de la dirección de la comunicación, la flexibilidad de la temporalidad, la capacidad de respuesta ${ }^{2}$ y el propósito percibido de la comunicación. El primer concepto hace referencia a la posibilidad de tener comunicación de doble vía en configuraciones uno a uno, uno a muchos y muchos a muchos. Por otra parte, la flexibilidad temporal de la comunicación se refiere a la capacidad tecnológica de realizar comunicaciones síncronas o asíncronas. Asimismo, la capacidad de respuesta del sistema es entendida como la habilidad de los sistemas tecnológicos para dar respuesta oportuna y pertinente a las

2 Para efectos del presente texto se ha traducido el concepto de responsiveness como capacidad de repuesta. 
solicitudes de los usuarios. Por último, el propósito percibido de la comunicación es la habilidad de realizar intercambios con dependencia de tercer grado (Downes \& McMillan, 2000; Kiousis, 2002; McMillan \& Hwang, 2002), entendiendo dicha dependencia como la relación que se crea entre los mensajes que integran un mismo intercambio comunicativo cuando estos hacen referencia unos a otros.

A manera de resumen, esta perspectiva entiende la interactividad como una combinación entre el número y complejidad de opciones de elección disponibles para el usuario, con la capacidad de repuesta del sistema, el nivel de facilitación de una comunicación interpersonal y la capacidad tecnológica otorgada al usuario para adicionar información al sistema (Deuze, 2003; Heeter (1989) citado por Kiousis, 2002; Massey \& Levy, 1999).

Una de las aportaciones significativas de esta vertiente consiste en el reconocimiento de la importancia de la interfaz y sus capacidades en el proceso de comunicación interactiva, haciendo así visibles los posibles comportamientos que tendría el usuario (Bucy, 2004). Sin embargo, éste es visto como un elemento pasivo dentro de la construcción del sistema de comunicación, elemento que se concentra en activar o desactivar las capacidades de interacción que le son suministradas por el medio tecnológico. Además, asume que los resultados de la interacción serán uniformes sin tener en cuenta las características individuales de los usuarios.

Como cierre de la discusión se construyó la Tabla 1 donde se resumen los elementos claves de la interactividad como característica de la tecnología.

\section{Tabla 1. Elementos clave de las definiciones de interactividad según vertiente.}

\begin{tabular}{|l|l|}
\hline \multicolumn{2}{|c|}{ Interactividad como característica aportada de la tecnología } \\
\hline Mapeo & Steuer; Kiousis \\
\hline Riqueza Sensorial & Durlak; Kiousis \\
\hline $\begin{array}{l}\text { Habilidad del sistema para facilitar la influencia del } \\
\text { usuario }\end{array}$ & Jensen \\
\hline Complejidad de la elección & Heeter; Massey y Levy \\
\hline Elección & Ha y James \\
\hline Flexibilidad Temporal & Downes y McMillian \\
\hline Funcionalidad del Sistema & Schneiderman \\
\hline Envío de Mensajes & Hutheesing \\
\hline Capacidades Multimedia & Sims; Ahren, Stromer-Galley y Neuman \\
\hline Capacidades de comunicación en doble vía & Ahren, Stromer-Galley y Neuman; McMillan \\
\hline
\end{tabular}




\begin{tabular}{|l|l|}
\hline \multicolumn{2}{|c|}{ Interactividad como característica aportada de la tecnología } \\
\hline $\begin{array}{l}\text { Canales para comunicación humano-humano y hu- } \\
\text { mano-máquina }\end{array}$ & Carey \\
\hline Cinco características de la interactividad & Ha y James \\
\hline Capacidades para facilitar el control del usuario & Jensen; Lombard, Snyder-Dutch \\
\hline Tiempo requerido para la interacción & Straubhaar y LaRose \\
\hline Opciones de realimentación & Song y Zinkhan \\
\hline Recolección de información & Song y Zinkhan \\
\hline Velocidad de navegación & Song y Zinkhan; Stromer-Galley; Kiousis \\
\hline Técnicas dialógicas & McMillan y Hwang \\
\hline $\begin{array}{l}\text { Percepción de la capacidad de respuesta del siste- } \\
\text { ma }\end{array}$ & Wiaz Noci; Palacios y Diaz Noci \\
\hline Sensación de eficacia del usuario & Fan et al. \\
\hline Sensación del usuario de la eficacia del sistema & Fan et al.; Wu; Song y Zinkhan \\
\hline
\end{tabular}

Fuente: Elaboración propia basada en Kiousis (2002), Massey \& Levy (1999) y otros.

Como complemento al análisis de la definición, se procederá a la identificación de las dimensiones que se suelen asociar a la interactividad; reconociéndola como un fenómeno multidimensional. Esto con el fin de iniciar la identificación de elementos que ayuden a su operacionalización.

\section{Interactividad: un fenómeno multidimensional}

De manera recurrente se entiende a la interactividad como un conjunto de dimensiones o componentes que se relacionan para crear una experiencia interactiva. En este apartado se realizará un recorrido por algunas de las propuestas encontradas en la literatura sobre dichas dimensiones.

Una de las primeras propuestas en este sentido es la realizada por Durlak en 1987 (Kiousis, 2002) quien busca hacer un símil de la comunicación mediada por tecnologías con los componentes físicos de un sistema interactivo. Como resultado se proponen tres dimensiones. La primera, denominada riqueza sensorial, se asocia a la posibilidad de estimular los sentidos del usuario (Song \& Zinkhan, 2008). La segunda, llamada gestión espacial, se manifiesta como la posibilidad de estimular la telepresencia del usuario. Por último, este autor propone la capacidad de respuesta, entendida como la capacidad del sistema para responder de manera pertinente al usuario (Massey \& Levy, 1999). Es clara la orientación que tiene este tipo de dimensiones hacia la configuración de capacidades del sistema tecnológico, dejando a un lado las características del usuario. 
Posteriormente, Ha y James (1998) proponen que la interactividad está compuesta por cinco dimensiones relacionada directamente con las características de la tecnología utilizada como medio de comunicación; las cuales abren posibilidades interactivas a los usuarios. Las cinco dimensiones propuestas se muestran en la Tabla 2.

\section{Tabla 2. Dimensiones de la interactividad según Ha \& James (1988).}

\begin{tabular}{|l|l|}
\hline \multicolumn{1}{|c|}{ Dimensión } & \multicolumn{1}{c|}{ Descripción } \\
\hline Capacidad de juego* & $\begin{array}{l}\text { Se basa en el concepto de que el juego es una conversación consigo mis- } \\
\text { mo que satisface al usuario. } \\
\text { Es la capacidad del sistema para satisfacer de manera electrónica las nece- } \\
\text { sidades de autocomunicación de las audiencias }\end{array}$ \\
\hline Elección & $\begin{array}{l}\text { Disponibilidad de opciones para elegir que crean una navegación irres- } \\
\text { tricta en la web. Esto implica la disminución del esfuerzo del usuario para } \\
\text { realizar una tarea específica }\end{array}$ \\
\hline $\begin{array}{l}\text { Conectividad basada } \\
\text { en Hipertextos }\end{array}$ & $\begin{array}{l}\text { Utilización de hipertextos para construir una sensación de conexión con el } \\
\text { mundo, permitiendo que el usuario salte de un lado a otro del ciberespacio } \\
\text { con el mínimo esfuerzo }\end{array}$ \\
\hline $\begin{array}{l}\text { Recolección de infor- } \\
\text { mación }\end{array}$ & $\begin{array}{l}\text { Posibilidad que tiene el sistema de recolectar información del usuario. } \\
\text { Esta información puede ser recolectada de manera activa (p.ej. formula- } \\
\text { rios de registro) o de manera pasiva (p.ej. cookies files) (Downes \& Mc- } \\
\text { Millan, 2000) }\end{array}$ \\
\hline $\begin{array}{l}\text { Comunicación } \\
\text { recíproca }\end{array}$ & $\begin{array}{l}\text { Capacidad del sistema de establecer una comunicación de dos vías, en la } \\
\text { que la comunicación puede ser iniciada por cualquiera de las dos partes. }\end{array}$ \\
\hline
\end{tabular}

* Para este trabajo se tradujo el concepto de playfulness como capacidad de juego.

Fuente: elaboración propia basada en Ha \& James (1998).

Los autores dividen las dimensiones en dos niveles de interactividad: alto y bajo. El nivel más alto está compuesto por las dimensiones de comunicación recíproca y de recolección de información. En este nivel los mayores beneficios los obtiene la fuente de los contenidos, ya que recopila tanta información como sea posible y así puede ofrecer contenidos, soluciones y comunicaciones cada vez más pertinentes para los usuarios (Ha \& James, 1998). Sin embargo, el uso excesivo de elementos técnicos asociados a estas dimensiones puede atentar contra la privacidad de la audiencia (Downes \& McMillan, 2000). El segundo nivel, o nivel bajo, está compuesto por las tres categorías restantes (capacidad de juego, elección, y conectividad basada en hipertextos) que reúnen las características técnicas ofrecidas por el sitio y por medio de las cuales los usuarios satisfacen sus necesidades. Dichos elementos sirven como mecanismos para impulsar a los usuarios a iniciar procesos de interacción de alto nivel (Ha \& James, 1998).

Los enfoques expuestos hasta este punto ven la interactividad exclusivamente como un elemento propio de la tecnología utilizada como base 
para el proceso de comunicación limitando así las posibilidades de entendimiento del fenómeno. Como respuesta a esta condición, y al considerar la interactividad como un concepto complejo y pluridimensional, aparecen planteamientos que buscan enriquecer la visión basada en la tecnología con otros elementos, ampliando el espectro de componentes del sistema de comunicación tomados en cuenta en el análisis.

Uno de los planteamientos ampliamente referenciados en la literatura y que se orienta bajo esta mirada unificadora, es el que considera que la interactividad está compuesta por dos dimensiones: la interactividad de máquina y la interactividad de personas. La primera hace referencia a las capacidades de interacción entre los humanos y los contenidos desplegados por la interfaz. Adicionalmente, esta dimensión incluye la capacidad de los usuarios para modificar en tiempo real el contenido y su forma (Bucy, 2004; Downes \& McMillan, 2000; Fan et al., 2016; Teo, Oh, Liu, \& Wei, 2003).

Bajo esta propuesta, la interactividad de máquina se subdivide a su vez en dos: interactividad usuario-contenidos e interactividad usuario-sistema. En la primera subdivisión el usuario no puede modificar el contenido presentado, sólo se le es permitido consultarlo. Mientras tanto, en la interactividad usuario-sistema se le brinda al usuario la posibilidad de alterar la información al modificar algunas de sus características (Fan et al., 2016; McMillan \& Hwang, 2002). Todos estos componentes llevan de manera directa al estudio de la interacción humano-máquina (Stromer-Galley, 2004). Esta dimensión también es denominada interactividad como producto (Bucy, 2004) e interacción en el medio (Stromer-Galley, 2000), entre otros.

Por su parte, la interactividad de personas encierra la comunicación entre dos o más personas a través de un medio en línea; comunicación que puede darse de manera directa o por a través de un medio tecnológico (Fan et al., 2016). En otras palabras, es la interactividad con otro a través de una máquina (Teo et al., 2003). También es conocida como interactividad como proceso (Bucy, 2004), interactividad interpersonal (Massey \& Levy, 1999), interacción usuario-usuario (McMillan \& Hwang, 2002) e interacción humana (Stromer-Galley, 2000).

En trabajos posteriores, se añade una tercera dimensión denominada dirección de la comunicación, que hace referencia a la facilidad percibida por los usuarios para la realización de una comunicación de dos vías (Fan et al., 2016; McMillan \& Hwang, 2002) y que puede desplegarse entre usuarios o entre usuarios y una organización (Liu \& Shrum, 2002). Una manifestación de esta dimensión puede también verse al momento 
de realizar una transacción de comercio electrónico sin tener que acudir a otro medio de comunicación distinto a la Internet (Liu \& Shrum, 2002). Las dimensiones anteriormente descritas se representan en la Figura 1.

\section{Figura 1. Dimensiones de la interactividad desde una mirada unificadora}

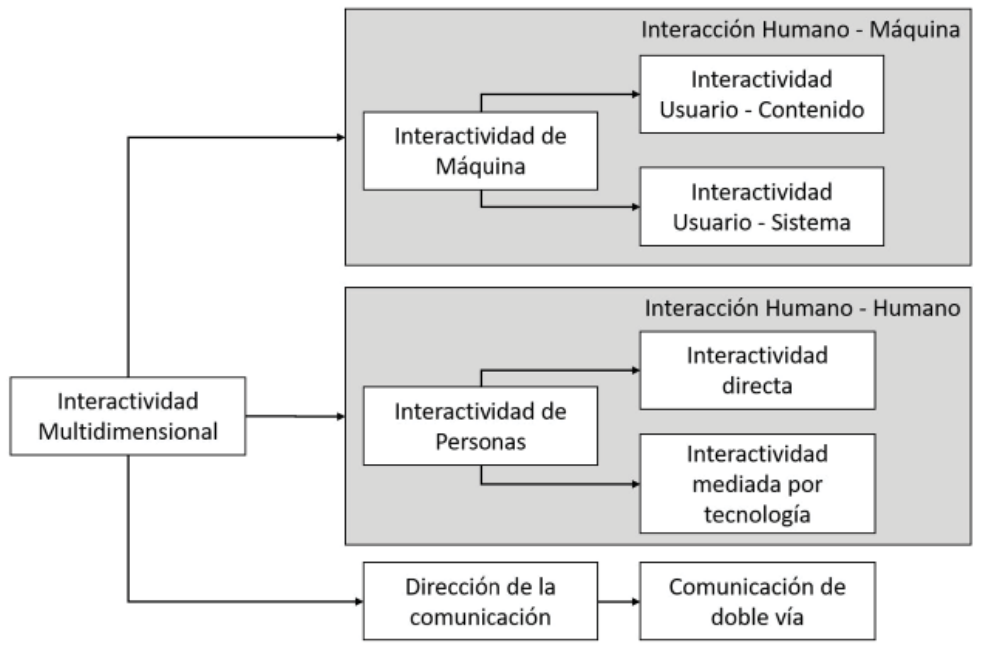

Fuente: elaboración propia.

Una propuesta concreta que utiliza algunas de estas tres dimensiones es la realizada por McMillan \& Hwang (2002), autores que consideran tres dimensiones sobrepuestas: elección (interactividad de máquina), comunicación en dos vías (dirección de la comunicación) y tiempo de carga o de búsqueda. La intersección de estas tres dimensiones genera comportamientos específicos entre los usuarios y en el sistema mismo. Por ejemplo, al momento de tener un sistema que ofrezca una amplia gama de elecciones y, además, permita una comunicación en dos vías, crea en el usuario una participación más activa. Por su parte la combinación entre un tiempo de respuesta y la sensación de comunicación en dos vías genera comunicaciones síncronas o asíncronas. Por último, la combinación entre el tiempo de carga y una amplia gama de opciones para elegir, crea experiencias comunicativas complejas y atractivas.

Recogiendo la propuesta anterior, Fan y otros (2016) proponen tres dimensiones que permiten entender el comportamiento de utilización de una tecnología específica a partir de la interactividad. Los autores retoman la elección y la comunicación de dos vías, agregándoles la capacidad de respuesta, la cual integra la percepción del usuario sobre la pertinencia de la 
información proporcionada por la tecnología. Adicionalmente, los autores consideran las dimensiones como variables independientes que alimentan un sistema de predicción del uso y aceptación de una tecnología.

Como parte del análisis de la interactividad en el contexto iberoamericano, Diaz Noci y otros (Díaz Noci, 2004; Palacios \& Díaz Noci, 2009) proponen que la interactividad puede ser entendida a través de seis dimensiones: el tipo de interactividad, las estructuras resultantes, el grado de dialogismo, la temporalidad, las técnicas dialógicas y de personalización, y la intervención de la fuente. Estas seis dimensiones y sus posibles configuraciones se resumen en la siguiente tabla.

Tabla 3. Dimensiones asociadas a la interactividad

\begin{tabular}{|l|l|l|}
\hline \multicolumn{1}{|c|}{ Dimensión } & \multicolumn{2}{|c|}{ Categoría } \\
\hline Tipo de Interactividad & Inclusiva & Propietario \\
\hline Grado de Dialogismo & $\begin{array}{l}\text { Simétrico } \\
\text { Uno a uno }\end{array}$ & $\begin{array}{l}\text { Asimétrico } \\
\text { Uno a muchos }\end{array}$ \\
& $-\quad$ Muchos a muchos & Muchos a muchos \\
\hline Temporalidad & Sincrónico & Asincrónico \\
\hline Técnica & $\begin{array}{l}\text { Dialógica } \\
-\quad \text { Correo electrónico }\end{array}$ & $\begin{array}{l}\text { Personalización } \\
\text { Búsqueda en Base de datos }\end{array}$ \\
& $-\quad$ Foro & Configuración de interface \\
\hline $\begin{array}{l}\text { Intervención de un } \\
\text { intermediario }\end{array}$ & Moderado & Ausencia de moderación \\
\hline
\end{tabular}

Fuente: (Díaz Noci, 2004, p. 20; Palacios \& Díaz Noci, 2009, p. 35)

Este conjunto de propuestas inicia el camino hacia la formulación de esquemas que ayuden a los diseñadores de sistemas tecnológicos a crear experiencias interactivas significantes para los usuarios. En otras palabras, entender las dimensiones establece una línea base para la operacionalización del concepto, al mismo tiempo que allana el camino para el planteamiento de esquemas de medición de la interactividad, medición que puede ser realizada por su grado o nivel de realización o por la efectividad de los mecanismos tecnológicos y dialógicos implementados, tópicos que se atacarán en el siguiente apartado. 


\section{Iniciando el camino hacia la operacionalización de la medición de la interactividad.}

Antes de iniciar el recorrido sobre las propuestas de operacionalización y medición es importante analizar la relación que tiene la interactividad como concepto frente a otros conceptos relacionados con el desarrollo de sistemas y plataformas de comunicación e intercambio vía web. Con este fin se construyó un análisis de redes utilizando como variable principal el nivel de coocurrencia de las palabras clave de la literatura disponible en las principales bases de datos electrónicas ${ }^{3}$. El cálculo de la red se realizó utilizando como herramienta de cómputo y graficación el software VosViewer ${ }^{4}$.

Este tipo de análisis permite la identificación de agrupaciones o clústers de palabras claves. Dichas agrupaciones están constituidas por aquellas palabras que presenten mayores niveles de coocurrencia. Como comportamiento general, las agrupaciones tienden a tener algunos conceptos que concentran el mayor número de coocurrencias dentro del grupo por lo que son identificados como los tópicos centrales de la agrupación. Como consecuencia, el análisis de redes permite identificar corrientes o escuelas de estudio sobre una temática específica. Para el caso de este capítulo se realizó este análisis con el fin de visibilizar la interactividad como un elemento abordado desde distintas perspectivas, disciplinas y áreas del conocimiento. Igualmente, permite poner de manifiesto el carácter sistémico del fenómeno comunicacional siendo necesario conocer las distintas aproximaciones al estudio de la interactividad y así poder iniciar la construcción de una mirada unificadora de dicho elemento primordial en la construcción de escenarios que favorezcan la realización de prácticas comunicativas en entornos digitales.

En la Figura 2 pueden observarse claramente cuatro agrupaciones de palabras clave, cada uno con un concepto que sirve como eje articulador. La primera agrupación es la asociada al concepto de interactividad, ubicada en la esquina inferior derecha del gráfico, el cual tiene altos niveles de coocurrencia con términos como world wide web (www), tecnología, sistemas de información, recuperación de información, nuevos medios, entre otros. De manera general se podría afirmar que esta agrupación identifica

3 Como referencia para el presente ejercicio de análisis de redes se tomaron los resultados de las bases de datos SCOPUS, ISI web of knowledge, Proquest y Scielo.

4 La herramienta VosViewer es una herramienta de para la construcción y visualización de redes bibliométricas diseñada por el Centre for Science and Technology Studies de la Universidad de Leiden, Holanda. 
la vertiente que estudia la interactividad como una característica propia de la tecnología.

\section{Figura 2. Red de niveles de coocurrencia de palabras clave por coocurrencia}

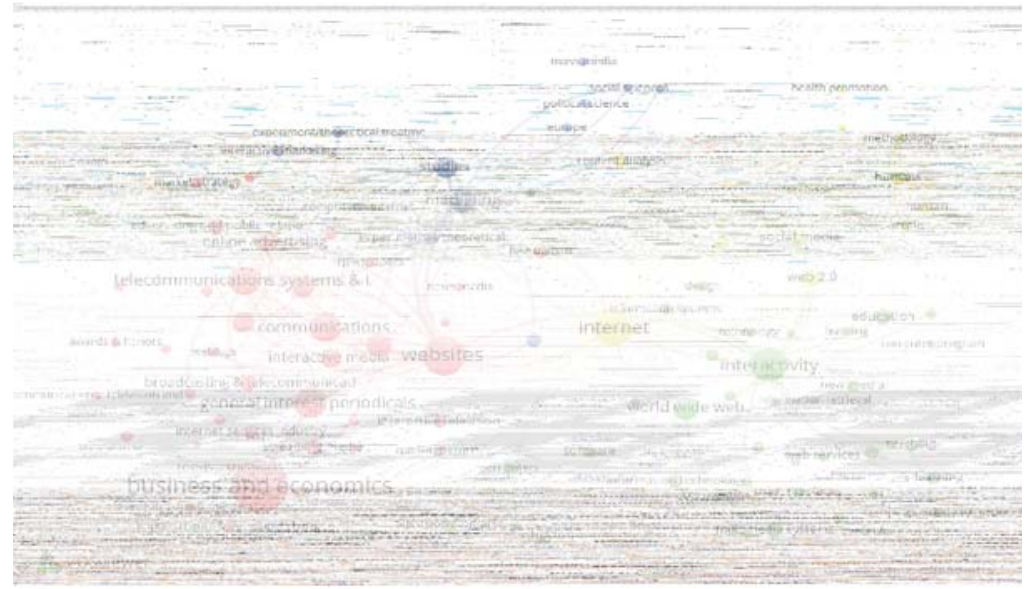

Fuente: elaboración propia.

Como segunda agrupación, y ubicada en la esquina superior derecha, están las palabras clave que circulan alrededor del concepto de Internet y se concentran en el análisis de la comunicación humana, así como en las relaciones creadas a través de las redes sociales digitales.

Como tercera agrupación, y ubicada en la esquina superior izquierda, se encuentra la que tiene como conceptos pivote los estudios de marketing y se puede asociar a la vertiente que entiende a la interactividad como una variable psicológica o de percepción del usuario. Esta agrupación de palabras busca al entendimiento de la percepción del usuario con el fin de orientar $\mathrm{y}$ fortalecer los esfuerzos de mercadeo de las organizaciones.

La cuarta agrupación, ubicada en la esquina inferior izquierda, aporta elementos reveladores sobre áreas de estudio distintas a la comunicación y a la tecnología donde el concepto de interactividad tiene un alto interés. En esta agrupación los conceptos centrales son sitios web, negocios y economía. Al primer concepto se articulan elementos tecnológicos de la implementación de plataformas de servicios web, sin embargo, y como se puede inferir de la gráfica, estos elementos tecnológicos no son el fin principal, sino que son considerados herramientas puestas al servicio de servicios web cuyo objetivo es la explotación comercial de las potencialidades 
de las tecnologías en línea. Esto se evidencia con la aparición de conceptos asociados a modelos de negocio propios del entorno digital como publicidad en línea, televisión interactiva, periódicos digitales, servicios de streaming, entre otros.

Como resultado de este análisis de redes, se identifica la importancia de operacionalizar el concepto de interactividad y así poder ponerlo al servicio de los modelos de negocio digitales con el fin de convertir los esfuerzos de conceptualización y entendimiento del fenómeno, en aplicaciones que transformen la experiencia interactiva del usuario o lector.

Sin embargo, desde los inicios del estudio de la interactividad los investigadores han fijado su interés en la definición, descripción y clasificación, más que en el establecimiento de mecanismos de operacionalización y mucho menos en la prueba empírica de las propuestas teóricas o el planteamiento de esquemas que lleven a su correcta medición (Bucy, 2004). Este escenario, conformado por una amplia gama de presunciones y definiciones, y por la falta de herramientas de operacionalización, se repite igualmente en los ambientes mediados por computador, con el agravante que tiene la complejidad propia del escenario de tecnologías web (Downes \& McMillan, 2000).

Bajo estas premisas, se hace necesario hacer un barrido sobre las propuestas existentes tendientes a la operacionalización y medición de los esfuerzos interactivos en un ambiente mediado por computador, y más específicamente en ambientes web.

Para estos esquemas, al igual que pasa con las definiciones y las dimensiones, es posible encontrar propuestas e indicadores de medición que encajan en alguna de las tres vertientes o enfoques para comprender la interactividad. Sin embargo, sólo se analizarán aquellas propuestas que se concentran en analizar la interactividad como una característica propia de la tecnología.

De manera general, la operacionalización y medición desde el punto de vista tecnológico propone que el número de características proporcionadas por el medio y que pueden ser empleadas por el usuario, es el mejor indicador de la implementación del concepto de interactividad (Song \& Zinkhan, 2008). Bajo esta perspectiva, para operacionalizar el concepto de interactividad es necesario implementar una amplia gama de opciones tecnológicas que permitan al usuario tener una comunicación de doble vía, con flexibilidad temporal, altas posibilidades de elección sobre los contenidos y respuestas oportunas y pertinentes, entre otros elementos (Downes \& McMillan, 2000; Kiousis, 2002; McMillan \& Hwang, 2002). 
En esta misma línea, la medición puede plantearse como el puntaje de interactividad tecnológica constituido por el número de acciones permitidas por un medio (Kiousis, 2002), manifestadas en elementos como el número de hipertextos (Díaz Noci, 2004; Fondevila, 2014; Fondevila \& Segura, 2012; Kiousis, 2002; Ochoa, 2016) y la existencia de opciones de realimentación como los chat, blogs de usuario, correo electrónico, comentarios, teléfonos, preguntas y respuestas, BBS, FAQ(Albornoz, 2006; Díaz Noci, 2004; Ochoa, 2016; Rodríguez-Martínez, Codina, \& Pedraza-Jiménez, 2010, 2012; Said-Hung \& Arcila-Calderón, 2011; Said-Hung, Arcila-Calderón, \& Méndez-Barraza, 2011; Song \& Zinkhan, 2008). Adicionalmente, se plantean cálculos de carácter más técnico y tendientes a la medición de la capacidad de repuesta del sistema a las solicitudes del usuario. Dentro de este grupo de indicadores se encuentran la velocidad o tiempo de descarga (Song \& Zinkhan, 2008), velocidad para la realización de una tarea (McMillan \& Hwang, 2002; Stromer-Galley, 2004) y puntaje $\mathrm{SEO}^{5}$ (García-Carretero, Codina, Díaz-Noci, \& Iglesias-García, 2016) son opciones que aparecen en la literatura.

Adicionalmente, y como respuesta a la necesidad de implementar elementos tecnológicos que permitan el acceso de personas con capacidades variadas, se propone la utilización de distintas herramientas que midan el cumplimiento de las pautas de accesibilidad al contenido web (WCAG por sus siglas en inglés) en la versión 1.0 y 2.0. Estas recomendaciones hacen parte de las pautas de movilidad y accesibilidad realizadas por el World Wide Web Consortium (W3C), a través de su grupo de trabajo Web Accessibility Initiative (WAI) (Ochoa, 2016; Rodríguez-Martínez et al., 2010; Said-Hung et al., 2011). Las herramientas más conocidas para realizar este tipo de auditorías son el test de accesibilidad web o pruebas TAW por sus siglas en inglés y las pruebas HERA.

De manera general, las pautas WCAG 1.0 buscan establecer un estándar abierto para la creación de contenidos web accesibles para personas con discapacidad. Estas pautas están dirigidas a desarrolladores de plataformas web y de herramientas de creación web y definen 14 elementos de comprobación para el diseño de contenidos accesibles para todos los usuarios sin importar el dispositivo de acceso (World Wide Web Consortium, 1999).

$5 \quad$ El puntaje SEO - Search Engine Optimization por sus siglas en inglés - mide la efectividad del proceso técnico mediante el cual se realizan cambios en la estructura e información de una página web, con el objetivo de mejorar la visibilidad de un sitio web en los resultados orgánicos de los diferentes buscadores. 
Por su parte, las pautas WCAG 2.0 buscan diseñar contenidos más accesibles involucrando un rango mayor de discapacidades, incluyendo las visuales, auditivas, motoras, de habla, cognitivas, de aprendizaje y neuronales. Asimismo, esta nueva involucra el diseño de contenidos para personas que tienen cambios en sus capacidades como resultado del envejecimiento (World Wide Web Consortium, 2008).

Con este fin, las WCAG 2.0 definen siete componentes básicos para el desarrollo e interacción web los cuales deben trabajar de manera coordinada con el fin de crear una web accesible para todas las personas. La Figura 3 muestra estos siete componentes, dentro de los cuales existen dos agentes humanos: los desarrolladores y los usuarios, los cuales utilizan distintos tipos de herramientas para interactuar con el contenido. Los desarrolladores utilizan herramientas de creación para diseñar contenidos para los sitios web y herramientas de evaluación para verificar que dichos contenidos y su diseño cumplan con las condiciones de accesibilidad. Por su parte, los usuarios acceden a los contenidos mediante distintas plataformas de acceso tales como navegadores web o reproductores de contenidos. Debido a que las pautas están diseñadas para personas con algún tipo de discapacidad, se contempla la integración de tecnologías de asistencia diseñadas de manera específica para la discapacidad del usuario (World Wide Web Consortium, 2016).

Como complemento, las WCAG 2.0 definen tres principios básicos para el diseño de contenidos. El primero denominado principio de percepción que determina que la información y los componentes de la interfaz se presenten de acuerdo a las capacidades de percepción del usuario. El segundo principio o principio de operación determina que los componentes de la interfaz de usuario deben ser diseñados para que operen en distintas plataformas y dispositivos de acceso. Como tercer elemento se encuentra el principio de comprensión el cual dispone que la información y la operación de la interfaz de usuario debe ser entendible sin importar las modificaciones que le imponga la tecnología de asistencia. Por último, el principio de robustez el cual determina que el contenido debe ser suficientemente robusto como para poder ser interpretado de manera confiable por una amplia gama de agentes incluyendo las tecnologías de asistencia (World Wide Web Consortium, 2017). Utilizando como base estos tres principios, las herramientas de análisis de accesibilidad TAW contabiliza el número de errores que presenta un sitio web en cada uno de ellos para así verificar el nivel de cumplimiento de las WCAG 2.0. 
Figura 3. Componentes esenciales de la accesibilidad web

Fuente: (World Wide Web Consortium, 2016)

En la Tabla 4, y como complemento, se relacionan los indicadores encontrados de manera recurrente y que buscan medir la implementación de elementos tecnológicos que coadyuven a la consolidación de una plataforma tecnológica interactiva.

Tabla 4 Indicadores de medición de la interactividad como característica propia de la tecnología y como característica del proceso.

\begin{tabular}{|c|c|c|c|c|c|c|c|c|c|c|c|c|c|c|c|}
\hline & & & & & & & Pub & lica & ión & & & & & & \\
\hline Indicador & 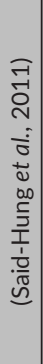 & 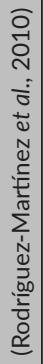 & 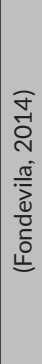 & 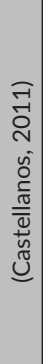 & 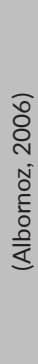 & 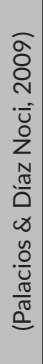 & 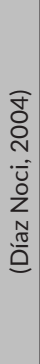 & 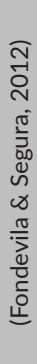 & 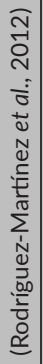 & 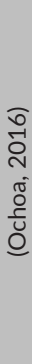 & 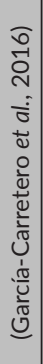 & 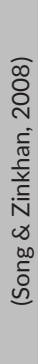 & 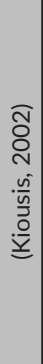 & 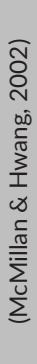 & 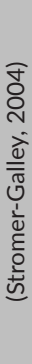 \\
\hline $\begin{array}{l}\text { ¿Ofrece a sus usuarios la posibili- } \\
\text { dad de crear un blog? }\end{array}$ & $x$ & $x$ & & & $x$ & & $\mathrm{x}$ & & $\mathrm{x}$ & $\mathrm{x}$ & & & & & \\
\hline $\begin{array}{l}\text { ¿Permite a los usuarios calificar las } \\
\text { noticias publicadas? }\end{array}$ & $\mathrm{x}$ & & & & & & & & $x$ & $\mathrm{x}$ & & & & & \\
\hline $\begin{array}{l}\text { ¿Se pueden hacer comentarios a } \\
\text { las noticias publicadas? }\end{array}$ & $x$ & $x$ & & & & & & & $\mathrm{x}$ & $\mathrm{x}$ & & $\mathrm{x}$ & & & \\
\hline
\end{tabular}


Interactividad desde la tecnología Web...

\begin{tabular}{|c|c|c|c|c|c|c|c|c|c|c|c|c|c|c|c|}
\hline & & & & & & & Publ & licac & ción & & & & & & \\
\hline Indicador & 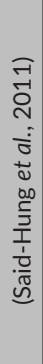 & 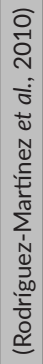 & 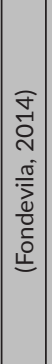 & 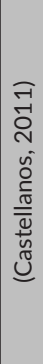 & 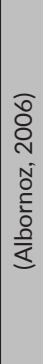 & 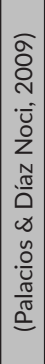 & 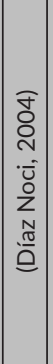 & 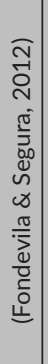 & 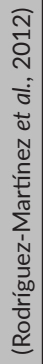 & 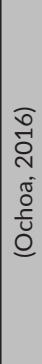 & 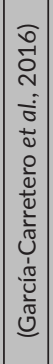 & 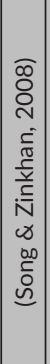 & 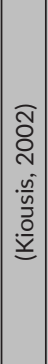 & 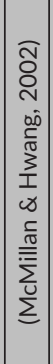 & 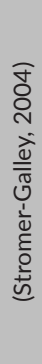 \\
\hline ¿Cuenta con sección FAQ? & & & & & & & & & & & & $\mathrm{x}$ & & & \\
\hline ¿Cuenta con sistema BBS? & & & & & & & & & & & & $x$ & & & \\
\hline ¿Cuenta con encuestas? & & & $x$ & & $x$ & & & & & $x$ & & $x$ & & & \\
\hline $\begin{array}{l}\text { ¿Permite a los lectores contactar } \\
\text { por correo electrónico al autor de } \\
\text { la noticia? }\end{array}$ & $x$ & $\mathrm{x}$ & & & & $x$ & & & $\mathrm{x}$ & $\mathrm{x}$ & & & & & \\
\hline $\begin{array}{l}\text { ¿Acepta contribuciones de los } \\
\text { lectores? }\end{array}$ & $x$ & & & & & & $\mathrm{x}$ & & $x$ & $\mathrm{x}$ & & & & & \\
\hline ¿Tiene chats para sus usuarios? & $x$ & $x$ & & & & & $x$ & & & $x$ & & $x$ & & & \\
\hline $\begin{array}{l}\text { ¿Posee sección con las noticias } \\
\text { más leídas? }\end{array}$ & & $\mathrm{x}$ & & & & & & & $\mathrm{x}$ & $\mathrm{x}$ & & & & & \\
\hline ¿Posee servicio de alertas? & $x$ & $\mathrm{x}$ & & & & & & & $\mathrm{x}$ & $\mathrm{x}$ & & & & & \\
\hline $\begin{array}{l}\text { ¿Dispone de canales de contenido } \\
\text { sindicado? }\end{array}$ & $x$ & $\mathrm{x}$ & & & $x$ & $x$ & & & $x$ & $x$ & & & & & \\
\hline $\begin{array}{l}\text { ¿Es posible el envío de noticias vía } \\
\text { correo electrónico? }\end{array}$ & $\mathrm{x}$ & $\mathrm{x}$ & & & $\mathrm{x}$ & & & & & $\mathrm{x}$ & & $\mathrm{x}$ & & & \\
\hline $\begin{array}{l}\text { ¿Facilita el envío de noticias a } \\
\text { teléfonos móviles? }\end{array}$ & $\mathrm{x}$ & $\mathrm{x}$ & & & $\mathrm{x}$ & & & & & $\mathrm{x}$ & & & & & \\
\hline $\begin{array}{l}\text { ¿Ofrece a sus usuarios la opción de } \\
\text { registrarse? }\end{array}$ & $x$ & $\mathrm{x}$ & & & & & & & & $\mathrm{x}$ & & & & & \\
\hline $\begin{array}{l}\text { ¿Cuenta con aplicaciones que per- } \\
\text { mitan a los usuarios personalizar } \\
\text { contenidos? }\end{array}$ & $\mathrm{x}$ & $\mathrm{x}$ & & & & $x$ & & & $\mathrm{x}$ & $x$ & & & & & \\
\hline $\begin{array}{l}\text { ¿Hacen uso de herramientas pro- } \\
\text { pias de la web } 2.0 \text { para compartir } \\
\text { información? }\end{array}$ & $x$ & $x$ & & $\mathrm{x}$ & & & & & $x$ & $x$ & & & & & \\
\hline $\begin{array}{l}\text { ¿Hay enlaces a artículos de la } \\
\text { hemeroteca digital? }\end{array}$ & $x$ & $\mathrm{x}$ & & & & & & & & $\mathrm{x}$ & & & & & \\
\hline $\begin{array}{l}\text { ¿Es posible acceder a artículos de } \\
\text { un autor específico? }\end{array}$ & & $\mathrm{x}$ & & & & & & & & $\mathrm{x}$ & & & & & \\
\hline ¿Se identifica el autor de la noticia? & & $\mathrm{x}$ & & & & & & & & $\mathrm{x}$ & & & & & \\
\hline
\end{tabular}




\begin{tabular}{|c|c|c|c|c|c|c|c|c|c|c|c|c|c|c|c|}
\hline & & & & & & & Pub & lica & ión & & & & & & \\
\hline Indicador & 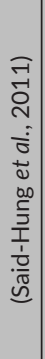 & 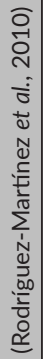 & 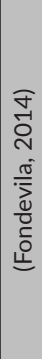 & 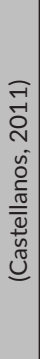 & 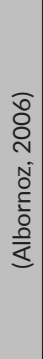 & 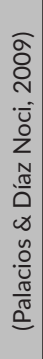 & 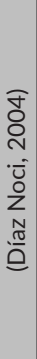 & 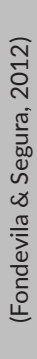 & 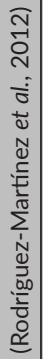 & 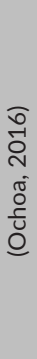 & 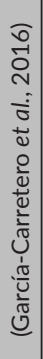 & 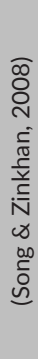 & 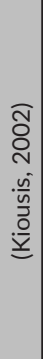 & 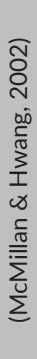 & 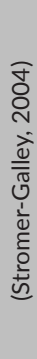 \\
\hline $\begin{array}{l}\text { ¿Aparece la hora de la última } \\
\text { actualización? }\end{array}$ & $\mathrm{x}$ & & $\mathrm{x}$ & & & & & $\mathrm{x}$ & & $\mathrm{x}$ & & & & & \\
\hline $\begin{array}{l}\text { ¿Cuenta con buscador simple / } \\
\text { avanzado? }\end{array}$ & & & & & & & & & $\mathrm{x}$ & $\mathrm{x}$ & & $\mathrm{x}$ & & & \\
\hline ¿Cuenta con hemeroteca? & & & & & & & & & & $\mathrm{x}$ & & & & & \\
\hline ¿Cuenta con Mapa de Sitio? & $\mathrm{x}$ & $\mathrm{x}$ & & & $\mathrm{x}$ & & & & $\mathrm{x}$ & $\mathrm{x}$ & & $\mathrm{x}$ & & & \\
\hline Puntaje SEO & & & & & & & & & & $\mathrm{x}$ & $\mathrm{x}$ & & & & \\
\hline Tiempo de carga & & & & & & & & & & & & & $x$ & $\mathrm{x}$ & $x$ \\
\hline Complejidad sensorial & & & & & & & & & & & & $\mathrm{x}$ & $\mathrm{x}$ & & \\
\hline Errores de Percepción & $\mathrm{x}$ & $x$ & & & & & & & & $\mathrm{x}$ & & & & & \\
\hline Errores de Operación & $\mathrm{x}$ & $\mathrm{x}$ & & & & & & & & $\mathrm{x}$ & & & & & \\
\hline Errores de Comprensión & $\mathrm{x}$ & $\mathrm{x}$ & & & & & & & & $\mathrm{x}$ & & & & & \\
\hline Errores de Robustez & $\mathrm{x}$ & $\mathrm{x}$ & & & & & & & & $\mathrm{x}$ & & & & & \\
\hline
\end{tabular}

Fuente: elaboración propia

\section{Reflexiones finales.}

En el panorama ofrecido se encuentran algunas fortalezas y debilidades de la visión de la interactividad como un elemento propio de la tecnología. En primer lugar, es evidente que la mayoría de los indicadores construidos son independientes del observador. Esto garantiza la objetividad e imparcialidad de posibles mediciones que se realicen y tiendan a crear escenarios de comparación entre distintos sitios web.

Por otro lado, los indicadores son de fácil recolección y análisis. Esto debido a que el diseño e implementación de sitios web se basa en estándares de carácter abierto. Como complemento, la utilización de estándares de este estilo hace posible analizar mediante herramientas de análisis 
automático, tanto los contenidos como su diseño, agilizando la labor de recolección y ampliando el espectro de sitios web que pueden analizarse.

Sin embargo, y como principal debilidad, este tipo de indicadores no permite visualizar los resultados obtenidos por el comunicador luego de poner a disposición las opciones tecnológicas, por lo que sólo dan cuenta de la preparación que tiene el medio para generar o incitar la interactividad por parte de sus usuarios. En otras palabras, estos indicadores darían cuenta de los posibles puntos iniciales de la comunicación, pero sería invisible la interacción en sí misma.

Es por esto que se hace necesario enfilar esfuerzos hacia la construcción de propuestas de medición que mezclen las distintas posiciones y permitan construir una mirada tan completa como sea posible del fenómeno en estudio. Asimismo, estas propuestas de medición deberán propender a la construcción de escenarios donde sea posible la comparación entre distintos medios analizados; evitando quedarse en el planteamiento de escenarios descriptivos o conformados por largas listas de chequeo, en las cuales no se puedan evidenciar verdaderamente las distintas dimensiones que encierra la interactividad.

\section{Bibliografía}

Albornoz, L. A. (2006). Periodismo digital. Los grandes diarios en la Red. La Crujía.

Barredo-Ibáñez, D., \& Díaz-Cerveró, E. (2017). La interactividad en el periodismo digital latinoamericano. Un análisis de los principales cibermedios de Colombia, México y Ecuador (2016). 2Revista Latina de Comunicación Social, 72, 271-294. Retrieved from 10.4185/RLCS 65-2010-887-114-125\%5Cnhttp://search.ebscohost.com/login.aspx?direct=true\&db=ufh\&AN=60167039\&lang=es\&site=ehost-live

Bucy, E. P. (2004). Interactivity in Society: Locating an Elusive Concept. The Information Society: An International Journal, 20 (5), 373-383. Retrieved from http:/www.tandfonline.com/doi/abs/10.1080/01972240490508063

Deuze, M. (2003). The Web and its Journalisms: Considering the Consequences of Different Types of Newsmedia Online. New Media E Society, 5(2), 203-230. Retrieved from http://journals.sagepub.com/ doi/10.1177/1461444803005002004

Díaz Noci, J. (2004). Los géneros Ciberperiodísticos: Un aproximación teórica a los cibertextos, sus elementos y tipologia. II Congreso Iberoamericano de Periodismo Digital, p. 33. 
Downes, E. J., \& McMillan, S. J. (2000). Defining Interactivity: A Quialitative Identification of Key Dimensions. New Media EO Society, 2(2), 157-179. Retrieved from http://journals.sagepub.com/ doi/10.1177/14614440022225751

FAN, L., Liu, X., Wang, B., \& Wang, L. (2016). Interactivity, engagement, and technology dependence: understanding users' technology utilisation behaviour. Behaviour E Information Technology, 36(2), 113-124. Taylor \& Francis. Retrieved from https://www.tandfonline.com/doi/ full/10.1080/0144929X.2016.1199051

Fondevila, J. (2014). El uso del hipertexto, multimedia e interactividad en periodismo digital: propuesta metodológica de ranking de calidad. Zer: Revista de estudios de comunicación, 19(36), pp. 1-5.

Fondevila, J., \& Segura, H. (2012). Uso del hipertexto en el ciberperiodismo: el caso de Colombia. Revista Latinoamericana de Comunicación. Chasqui, 117, pp. 80-84.

García-Carretero, L., Codina, L., Díaz-Noci, J., \& Iglesias-García, M. (2016). Herramientas e indicadores SEO: características y aplicación al análisis de cibermedios $=\mathrm{SEO}$ tools and indicators $:$ characteristics and application to online media analysis. El Profesional de la Información, 25(3), 497-504. Retrieved from http://www.elprofesionaldelainformacion.com/contenidos/2016/may/19.pdf

HA, L., \& James, E. L. (1998). Interactivity reexamined: A baseline analysis of early business web sites. Journal of Broadcasting E Electronic Media, 42(4), 457-474. Retrieved from http://www.tandfonline.com/doi/ abs $/ 10.1080 / 08838159809364462$

KIousis, S. (2002). Interactivity: a concept explication. New Media $\mathcal{E}^{\circ}$ Society, 4(3), 355-383. Retrieved from http://journals.sagepub.com/ doi/10.1177/146144480200400303

Liu, Y., \& Shrum, L. J. (2002). What is Interactivity and is it Always Such a Good Thing? Implications of Definition, Person, and Situation for the Influence of Interactivity on Advertising Effectiveness. Journal of Advertising, 31(4), 53-64. Retrieved from http://www.tandfonline. com/doi/abs/10.1080/00913367.2002.10673685

Llano-Aristizábal, S. (2005). Hipermedia e interactividad en el periodismo digital colombiano. Palabra Clave, 12(0).

Massey, B. L., \& Levy, M. R. (1999). Interactivity, Online Journalism, and English-Language Web Newspapers in Asia. Journalism Eo Mass Communication Quarterly, 76(1), 138-151. Retrieved from http://journals.sagepub.com/doi/10.1177/107769909907600110 
McMillan, S. J., \& Hwang, J.-S. (2002). Measures of Perceived Interactivity: An Exploration of the Role of Direction of Communication, User Control, and Time in Shaping Perceptions of Interactivity. Journal of Advertising, 31(3), 29-42. Retrieved from http://www.tandfonline.com/doi/abs/10.1080/00913367.2002.10673674

Navarro Zamora, L. (2009). Tres lustros del periodismo digital: Interactividad e hipertextualidad. Comunicar, 17(33), pp. 35-43.

Newhagen, J. E., Cordes, J. W., \& Levy, M. R. (1995). Nightly@nbc. com: Audience Scope and the Perception of Interactivity in Viewer Mail on the Internet. Journal of Communication, 45(3), pp. 164-175.

Оснол, R. L. (2016). Modelo para la medición de la difusión de innovaciones en procesos al interior de organizaciones proveedoras de contenidos en línea. Universidad Nacional de Colombia.

Palacios, M., \& Díaz Noci, J. (2009). Online journalism : research methods. Bilbao: Servicio Editorial de la Universidad del País Vasco.

Palmer, J. W. (2002). Web site usability, design, and performance metrics. Information Systems Research, 13(2), pp. 151-167.

Rafaeli, S. (1988). Interactivity: From new media to communication. Sage Annual Review of Communication Research: Advancing Communication Science (Vol. 16, pp. 111-134). Retrieved from http://scholar. google.com/scholar?hl=en\&btnG=Search\&q=intitle:Interactivity:+From+New+Media+to+Communication\#0\%5Cnfile:///Users/Home/ Dropbox/Masters Thesis/Articles/Interactivity/Rafeili_?.Interactivity. pdf

Rodríguez-Martínez, R., Codina, L., \& Pedraza-Jiménez, R. (2010). Cibermedios y web 2.0: modelo de análisis y resultados de aplicación. El Profesional de la Informacion, 19(1), 35-44. Retrieved June 3, 2014, from http://elprofesionaldelainformacion.metapress.com/openurl.asp?genre $=$ article\&id $=$ doi:10.3145/epi.2010.ene. 05

Rodríguez-Martínez, R., Codina, L., \& Pedraza-Jiménez, R. (2012). Indicadores para la evaluación de la calidad en cibermedios: análisis de la interacción y de la adopción de la Web 2.0. Revista española de Documentación Cientifica, 35(1), pp. 61-93.

SAID-Hung, E., \& Arcila-Calderón, C. (2011). Los cibermedios en America Latina y la web 2.0. Comunicar: Revista cientifica de Comunicación y Educación, 19(37), pp. 125-131.

Said-Hung, E., Arcila-Calderón, C., \& Méndez-Barraza, J. (2011). Desarrollo de Los Cibermedios en Colombia. El Profesional de la Infor- 
formacion, 20(1), 47-53. Retrieved November 26, 2013, from http:// elprofesionaldelainformacion. metapress.com/openurl.asp?genre $=$ article\&id=doi:10.3145/epi.2011.ene.06

Song, J. H., \& Zinkhan, G. M. (2008). Determinants of Perceived Web Site Interactivity. Journal of Marketing, 72(2), 99-113. Retrieved from http://journals.ama.org/doi/abs/10.1509/jmkg.72.2.99

Stromer-Galley, J. (2000). On-line interaction and why candidates avoid it. Journal of Communication, 50(4), 111-132. Retrieved from http://dx.doi.org/10.1111/j.1460-2466.2000.tb02865.x

Stromer-Galley, J. (2004). Interactivity-as-Product and Interactivity-as-Process. The Information Society: An International Journal, 20(5), 391-394. Retrieved from http://www.tandfonline.com/doi/ abs/10.1080/01972240490508081

Teo, H. H., Oh, L. Bin, Liu, C., \& Wei, K. K. (2003). An empirical study of the effects of interactivity on web user attitude. International Journal of Human Computer Studies, 58(3), 281-305.

World Wide Web Consortium. (1999). Web Content Accessibility Guidelines 1.0. W3C Recommendation. Retrieved June 1, 2017, from https://www.w3.org/TR/WAI-WEBCONTENT/

World Wide Web Consortium. (2008). Web Content Accessibility Guidelines (WCAG) 2.0. Web Accessibility intiative. Retrieved June 1, 2017, from https://www.w3.org/TR/WCAG20/

World Wide Web Consortium. (2016). Essential Components of Web Accessibility. Web Accessibility intiative. Retrieved June 1, 2017, from https:/www.w3.org/WAI/intro/components.php

World Wide Web Consortium. (2017). How to Meet WCAG 2.0. Web Accessibility intiative. Retrieved July 1, 2017, from https://www.w3.org/ WAI/WCAG20/quickref/ 



\title{
Anexo 1. Cuestionario del proyecto SEP-CONACYT 2012/178329
}

\author{
JOVENES Y CULTURA DIGITAL. NUEVOS ESCENARIOS DE \\ INTERACCIÓN SOCIAL \\ CUESTIONARIO ELABORADO POR EL PROYECTO \\ SEP-CONACYT 2012/178329
}

Este cuestionario está dirigido a estudiantes universitarios de diversas instituciones del país, con la finalidad de identificar el uso que le das a las diversas tecnologías en tu vida cotidiana. Este cuestionario es anónimo y las respuestas completamente confidenciales. Agradecemos tu colaboración y te invitamos a responderlo de forma clara y honesta.

A. IDENTIFÍCATE: Marca o completa la información solicitada

\begin{tabular}{|c|c|c|c|c|}
\hline \multicolumn{2}{|c|}{ Género } & Edad & 3. ¿Act & abajas? \\
\hline 1) Hombre & 2) Mujer & años & Sí & No \\
\hline
\end{tabular}

4. Pensando en tu actitud cuando navegas por Internet y estás en las redes sociales ¿con cuál descripción te identificas más? (Marca con una X en el recuadro y elige sólo 1 opción. Lee detenidamente las descripciones)

\begin{tabular}{|c|c|c|c|c|}
\hline 1. Discreto & 2. Selectivo & 3. Puente & 4. Sociable & 5. Ninguno \\
\hline $\begin{array}{c}\text { Formo parte de } \\
\text { una red pero no } \\
\text { tengo interacción } \\
\begin{array}{c}\text { con ninguna otra } \\
\text { persona }\end{array}\end{array}$ & $\begin{array}{c}\text { Tengo interacción } \\
\text { con pocas personas, } \\
\text { no tengo muchas } \\
\text { razones para comu- } \\
\text { nicarme o no me } \\
\text { gusta hacerlo }\end{array}$ & $\begin{array}{c}\text { Tengo interacción } \\
\text { con algunas } \\
\text { personas, me } \\
\text { agrada hacerlo pero } \\
\text { me comunico sólo } \\
\text { cuando hay razones } \\
\text { importantes }\end{array}$ & $\begin{array}{c}\text { Tengo interacción } \\
\text { con muchas y diver- } \\
\text { sas personas, me } \\
\text { gusta comunicarme } \\
\text { yestar en contacto } \\
\text { con todos constan- } \\
\text { temente }\end{array}$ & $\begin{array}{c}\text { Ninguna opción me } \\
\text { describe. Más bien } \\
\text { yo soy: }\end{array}$ \\
\hline
\end{tabular}

B. ¿QUÉ OPINAS?: Marca en la siguiente escala qué tan de acuerdo o en desacuerdo estás con las siguientes afirmaciones

\begin{tabular}{|c|c|c|c|c|c|}
\hline & $\begin{array}{c}5 \\
\text { Completamente } \\
\text { de acuerdo }\end{array}$ & 4 & 3 & 2 & $\begin{array}{c}1 \\
\text { Completamente } \\
\text { en desacuerdo }\end{array}$ \\
\hline $\begin{array}{l}\text { 5. Soy un usuario activo de Internet des- } \\
\text { de corta edad (infancia o adolescencia) }\end{array}$ & & & & & \\
\hline
\end{tabular}




\begin{tabular}{|l|l|l|l|l|l|}
\hline & \multicolumn{1}{|c|}{5} & & & \\
\hline $\begin{array}{l}\text { Completamente } \\
\text { de acuerdo }\end{array}$ & 4 & 3 & 2 & $\begin{array}{c}1 \\
\text { Completamente } \\
\text { en desacuerdo }\end{array}$ \\
\hline $\begin{array}{l}\text { 6. No puedo imaginar mi vida sin las } \\
\text { plataformas digitales y las redes sociales } \\
\text { (Facebook, Twitter, Instagram, YouTube, } \\
\text { WhatsApp) }\end{array}$ & & & & & \\
\hline $\begin{array}{l}\text { 7. Soy capaz de hacer muchas cosas al } \\
\text { mismo tiempo mientras uso Internet o } \\
\text { alguna otra tecnología }\end{array}$ & & & & & \\
\hline $\begin{array}{l}\text { 8. Tengo acceso a Internet desde dife- } \\
\text { rentes dispositivos (computadora, telé- } \\
\text { fono celular, tablets, etc.) }\end{array}$ & & & & & \\
\hline $\begin{array}{l}\text { 9. Cuando navego por Internet lo hago } \\
\text { individualmente y desde mi dispositivo } \\
\text { personal (laptop, pc, Tablet, celular, etc.) }\end{array}$ & & & & & \\
\hline $\begin{array}{l}\text { 10. Si olvido o pierdo el teléfono celular } \\
\text { me siento aislado y ansioso }\end{array}$ & & & & & \\
\hline $\begin{array}{l}\text { 11. Tengo las habilidades para navegar } \\
\text { en Internet y resolver cualquier proble- } \\
\text { ma técnico de la conexión }\end{array}$ & & & & & \\
\hline $\begin{array}{l}\text { 12. Creo que Internet es un nuevo es- } \\
\text { pacio para expresarme, defender alguna } \\
\text { causa o luchar en contra de injusticias. }\end{array}$ & & & & & \\
\hline
\end{tabular}

\section{C. ¿QUÉ ES LO QUETE GUSTA? Cuéntanos si existe algún tema que te interese señalándolo y contestando las columnas siguientes.}

\begin{tabular}{|c|c|c|c|c|c|c|c|}
\hline \multirow{2}{*}{$\begin{array}{l}\text { Marca aquellos temas con los que } \\
\text { tengas algún tipo de participación } \\
\text { Si contestas "Nada" en la pregunta } \\
14 \text { deja en blanco la pregunta } 15\end{array}$} & \multicolumn{4}{|c|}{$\begin{array}{l}\text { 13. ¿Qué nivel de compromiso tienes } \\
\text { con este(os) tema (s)? }\end{array}$} & \multicolumn{3}{|c|}{$\begin{array}{l}\text { 14. En dado caso ¿Dónde llevas } \\
\text { a cabo la defensa de estos } \\
\text { temas? }\end{array}$} \\
\hline & $\begin{array}{l}\text { 안 } \\
\text { i }\end{array}$ & $\begin{array}{l}\frac{0}{\overline{0}} \\
\sum_{i}^{\frac{0}{N}}\end{array}$ & $\begin{array}{l}\stackrel{\circ}{\pi} \\
\stackrel{\infty}{\infty} \\
\dot{m}\end{array}$ & 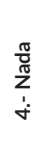 & 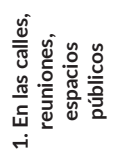 & 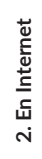 & 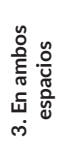 \\
\hline \multicolumn{8}{|l|}{$\begin{array}{l}\text { a. Medio ambiente, ecología y } \\
\text { protección de animales }\end{array}$} \\
\hline \multicolumn{8}{|l|}{ b. Temas educativos/académicos } \\
\hline \multicolumn{8}{|l|}{ c. De trabajo y empleo } \\
\hline \multicolumn{8}{|l|}{ d. Temas artísticos/ culturales } \\
\hline \multicolumn{8}{|l|}{$\begin{array}{l}\text { e. De ocio, diversión y entrete- } \\
\text { nimiento }\end{array}$} \\
\hline \multicolumn{8}{|l|}{ f. Problemas sociales y ciudadanos } \\
\hline \multicolumn{8}{|l|}{ g. Defensa de derechos humanos } \\
\hline \multicolumn{8}{|l|}{ h. Temas políticos } \\
\hline i. Temas religiosos & & & & & & & \\
\hline
\end{tabular}


15. ¡OJO! Si utilizas Internet como espacio para participar o defender de los temas anteriores ¿A través de qué Plataformas has realizado alguna actividad a favor de esa causa? Puedes elegir más de una opción.

\begin{tabular}{|l|c|c|c|c|c|}
\hline 1. Facebook & 2. YouTube & 3. Twitter & 4. Instagram & 5. Whatsapp & 6. Blog \\
\hline 7. Página web & $\begin{array}{c}\text { Youl } \\
\text { 8. Correo }\end{array}$ & $\begin{array}{c}\text { 9. Mensaje } \\
\text { de texto }\end{array}$ & 10. Llamadas & $\begin{array}{c}\text { 11. Otro } \\
\text { (especifica } \\
\text { cuál) }\end{array}$ & \\
\hline
\end{tabular}

16. Derivado de tu participación ¿Has visto alguno de estos resultados...? Puedes elegir más de una opción

\begin{tabular}{|c|c|c|c|c|}
\hline $\begin{array}{c}\text { 1. Todo se ha } \\
\text { quedado en } \\
\text { expresiones y } \\
\text { acciones dentro } \\
\text { de Internet }\end{array}$ & $\begin{array}{c}\text { 2. El movimiento } \\
\text { ha provocado } \\
\text { que algún grupo } \\
\text { tome conscien- } \\
\text { cia sobre el tema }\end{array}$ & $\begin{array}{c}\text { 3. Ha originado } \\
\text { documentos de } \\
\text { inconformidad, } \\
\text { marchas u otro } \\
\text { tipo de manifes- } \\
\text { taciones }\end{array}$ & $\begin{array}{c}\text { 4. Se ha creado } \\
\text { o modificado } \\
\text { alguna ley }\end{array}$ & $\begin{array}{c}\text { 5. Otro tipo de } \\
\text { resultados } \\
\text { (iCuéntanos } \\
\text { cuál!) }\end{array}$ \\
\hline
\end{tabular}

17. ¿Tú participación en el movimiento o causa forma parte de una organización o institución que promueve esas acciones?

\begin{tabular}{|c|c|}
\hline 1. & 2. \\
\hline No, sólo somos ciudadanos & $\begin{array}{c}\text { Sí, formo parte de una organización/institución } \\
\text { que dirige u organiza }\end{array}$ \\
\hline
\end{tabular}


D. ¿CÓMO NAVEGAS EN INTERNET? Cuéntanos qué haces cuando estás en la red señalando las actividades que realizas. Por favor marca las columnas siguientes cuando aplique.

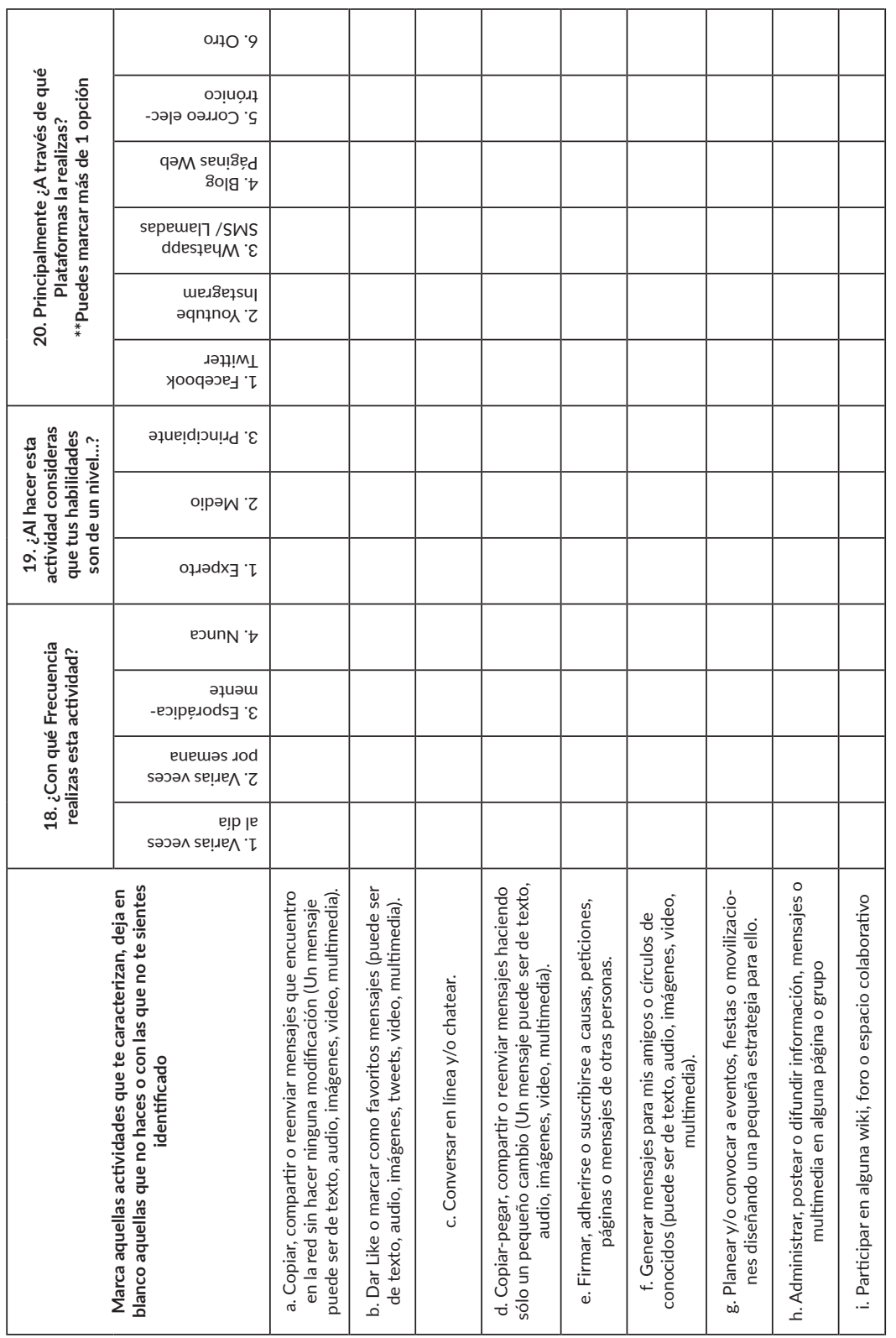




\section{CÓMO NAVEGAS EN INTERNET. Esta es una continuación de} la pregunta anterior

\begin{tabular}{|c|c|c|c|c|c|c|c|c|c|c|c|}
\hline \multirow[b]{2}{*}{$\begin{array}{c}\text { ¡OJO! } \\
\text { Aunque es una continuación de la } \\
\text { pregunta anterior, ahora nos enfocamos } \\
\text { a los temas que te interesan }\end{array}$} & \multicolumn{11}{|c|}{$\begin{array}{l}\text { 21. Realizar esta actividad ¿está asociado con algún tema? } \\
\text { (Puedes elegir más de una opción) }\end{array}$} \\
\hline & 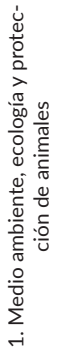 & 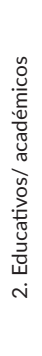 & 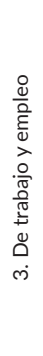 & 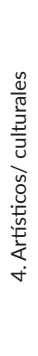 & 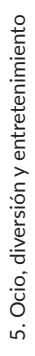 & 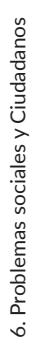 & 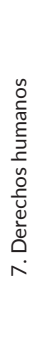 & 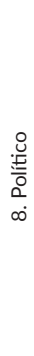 & 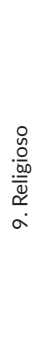 & 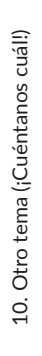 & 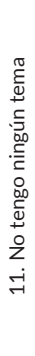 \\
\hline \multicolumn{12}{|l|}{$\begin{array}{l}\text { a. Copiar, compartir o reenviar mensajes } \\
\text { que encuentro en la red sin hacer nin- } \\
\text { guna modificación (Un mensaje puede } \\
\text { ser de texto, audio, imágenes, video, } \\
\text { multimedia). }\end{array}$} \\
\hline \multicolumn{12}{|l|}{$\begin{array}{l}\text { b. Dar Like o marcar como favoritos } \\
\text { mensajes (puede ser de texto, audio, } \\
\text { imágenes, tweets, video, multimedia). }\end{array}$} \\
\hline \multicolumn{12}{|l|}{ c. Conversar en línea y/o chatear. } \\
\hline \multicolumn{12}{|l|}{$\begin{array}{l}\text { d. Copiar-pegar, compartir o reenviar } \\
\text { mensajes haciendo sólo un pequeño } \\
\text { cambio (Un mensaje puede ser de texto, } \\
\text { audio, imágenes, video, multimedia). }\end{array}$} \\
\hline \multicolumn{12}{|l|}{$\begin{array}{l}\text { e. Firmar, adherirse o suscribirse a } \\
\text { causas, peticiones, páginas o mensajes } \\
\text { de otras personas. }\end{array}$} \\
\hline \multicolumn{12}{|l|}{$\begin{array}{l}\text { f. Generar mensajes para mis amigos o } \\
\text { círculos de conocidos (puede ser de tex- } \\
\text { to, audio, imágenes, video, multimedia). }\end{array}$} \\
\hline \multicolumn{12}{|l|}{$\begin{array}{l}\text { g. Planear y/o convocar a eventos, fiestas } \\
\text { o movilizaciones diseñando una pequeña } \\
\text { estrategia para ello. }\end{array}$} \\
\hline \multicolumn{12}{|l|}{$\begin{array}{l}\text { h. Administrar, postear o difundir } \\
\text { información, mensajes o multimedia en } \\
\text { alguna página o grupo }\end{array}$} \\
\hline $\begin{array}{l}\text { i. Participar en alguna wiki, foro o espa- } \\
\text { cio colaborativo }\end{array}$ & & & & & & & & & & & \\
\hline
\end{tabular}


E. OTROS DATOS MÁS. ¡Ya casi terminamos! Para concluir, te pedimos nos señales la siguiente información. Marca sólo una opción sobre el recuadro.

A.- ¿Cuál es el total de cuartos, piezas o habitaciones con los que cuenta tu hogar? No incluyas baños, medios baños, pasillos, patios y zotehuelas.

\begin{tabular}{|c|c|c|c|c|c|c|}
\hline 1 & 2 & 3 & 4 & 5 & 6 & 7 \\
\hline Uno & Dos & Tres & Cuatro & Cinco & Seis & Siete \\
\hline
\end{tabular}

B.- Contando todos los focos que utilizas para iluminar tu hogar, incluyendo los de techos, paredes y lámparas de buró o piso, dime ¿cuántos focos tiene tu vivienda?

\begin{tabular}{|c|c|c|c|c|}
\hline 1 & 2 & 3 & 4 & 5 \\
\hline De 0 a 5 & De 6 a 10 & De 11 a 15 & De 16 a 20 & $\begin{array}{c}21 \text { o más } \\
\text { focos }\end{array}$ \\
\hline
\end{tabular}

¿Tu casa cuenta con...?

\begin{tabular}{|c|c|c|}
\hline & 1. Sí tiene & 2. No tiene \\
\hline C. Piso diferente de tierra o cemento & & \\
\hline D. Regadera & & \\
\hline E. Estufa & & \\
\hline
\end{tabular}

¿Cuántos de los siguientes aparatos, espacios u objetos tienes en tu casa?

\begin{tabular}{|c|c|c|c|c|c|}
\hline & 0 & 1 & 2 & 3 & $4+$ \\
\cline { 2 - 6 } & $\begin{array}{c}\text { Cero/ No } \\
\text { tengo }\end{array}$ & Uno & Dos & Tres & $\begin{array}{c}\text { Cuatro o } \\
\text { más }\end{array}$ \\
\hline F. TV a color & & & & & \\
\hline G. Automóvil & & & & & \\
\hline H. Baños & & & & & \\
\hline I. Computadora & & & & & \\
\hline
\end{tabular}

J.- Pensando en la persona que aporta la mayor parte del ingreso en tu hogar, ¿cuál fue el último año de estudios que completó?

\begin{tabular}{|c|c|c|c|c|}
\hline 1 & 2 & 3 & 4 & 5 \\
\hline Sin instrucción & $\begin{array}{c}\text { Primaria o } \\
\text { secundaria } \\
\text { completa o } \\
\text { incompleta }\end{array}$ & $\begin{array}{c}\text { Carrera técnica, } \\
\text { preparatoria } \\
\text { completa o } \\
\text { incompleta }\end{array}$ & $\begin{array}{c}\text { Licenciatura } \\
\text { completa o } \\
\text { incompleta }\end{array}$ & Posgrado \\
\hline
\end{tabular}




\section{Aexo 2. Cuestionario diagnóstico de habilidades comunicativas digitales}

Maestría en Desarrollo Educativo | Universidad Pedagógica Nacional Tesis: Jóvenes, redes sociales digitales y educación superior: entre la vida cotidiana y la vida escolar

Presenta: Blanca M. Flores Ramírez Asesora: Dra. Luz María Garay Cruz

El presente cuestionario forma parte de un estudio sobre las habilidades digitales de los estudiantes universitarios y nos gustaría conocer tu opinión sobre lo hábil que te sientes respecto a una serie de cuestiones relacionadas con la tecnología digital. El cuestionario es anónimo. No hay preguntas correctas ni incorrectas. Los resultados que obtengamos serán útiles si lo contestas con sinceridad.

Antes de responder lee con tranquilidad la pregunta, no hay tiempo límite; recuerda que no debes preocuparte si no te sientes muy habilitado en alguna cuestión.

\section{Datos personales}

Instrucciones: marca con una $\mathrm{X}$ o escribe, según sea el caso

Género: Masculino Femenino

Edad:

Universidad:

Carrera:

Semestre:

Asignatura:

Datos sobre consumo de tecnología

Instrucciones: Marca con una $\mathrm{X}$ según sea el caso:

1. ¿Cuentas con los siguientes dispositivos? Puedes marcar más de una opción

Computadora (de escritorio) 
ANEXO 2. Cuestionario diagnóstico de habilidades comunicativas digitales

Lap top o mini lap top

Tablet

Smartphone

2. ¿Cómo aprendiste a usar tus dispositivos?

Puedes marcar más de una opción

En la Universidad

De forma autónoma

En cursos de formación privados

Con ayuda de mis padres, amigos, hermanos

Otro

3. ¿Has recibido formación sobre el uso, características y posibilidades de la web 2.0 y el internet?

Sí No

4. En caso de haber respondido en forma afirmativa a la pregunta anterior, por favor señala dónde: (Puedes marcar más de una opción)

En la Universidad

De forma autónoma

En cursos de formación privados

Con ayuda de mis padres, amigos, hermanos

Otro

5. ¿Utilizas alguna paquetería o programa específico para procesar texto, audio, video o páginas web? (Office, Photoshop, Audacity, iMove, Wix, etc)

Sí No

6. En caso de haber respondido en forma afirmativa a la pregunta anterior, por favor señala dónde aprendiste a utilizarlo. Puedes marcar más de una opción:

En la Universidad

De forma autónoma

En cursos de formación privados 
Con ayuda de mis padres, amigos, hermanos

Otro

\section{7. ¿Dónde te conectas habitualmente a Internet? Puedes marcar más de} una opción

En casa

En casa de amistades

En la Universidad

En el trabajo

En un cibercafé

En cualquier sitio porque dispongo de Internet en mi smartphone

Otra

\section{8. ¿Cuánto tiempo dedicas a navegar por Internet?}

Entre 1 y 3 horas al día

Entre 4 y 8 horas al día

Más de 8 horas al día

Otra

9. ¿Cuánto tiempo utilizas internet para las siguientes acciones?

Utiliza la siguiente escala: Nada (no lo utilizas nunca); Poco (menos de 5 horas semanales); Mucho (5 o más horas semanales)

a. Ver programas de televisión por internet
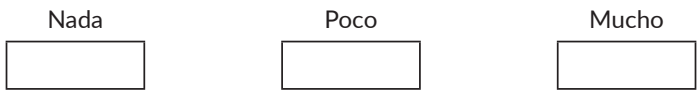

b. Escuchar música
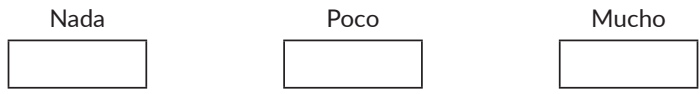

c. Informarme de temas que me interesan a nivel académico/profesional
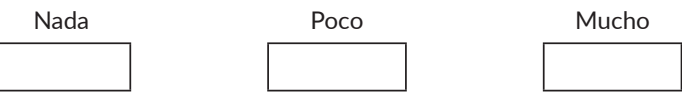
ANEXO 2. Cuestionario diagnóstico de habilidades comunicativas digitales

d. Jugar on line
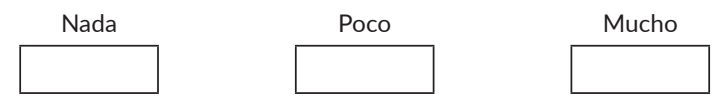

e. Buscar información para realizar las tareas universitarias

Nada

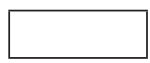

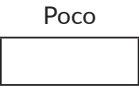

f. Publicar fotografías o videos

Nada
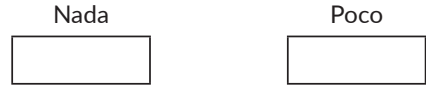

g. Bajar música, películas, juegos, etc.
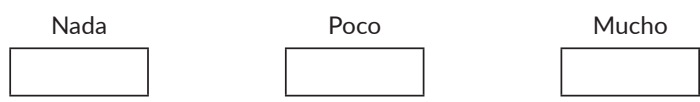

h. Hablar con amigos a través de redes sociales, chat, etc.
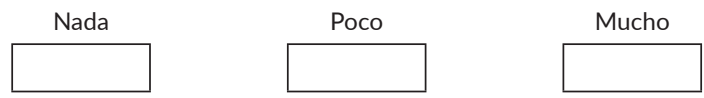

i. Buscar amigos/as nuevos mediante el uso de redes sociales

Nada

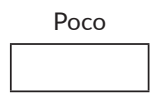

Mucho

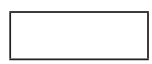

j. Trabajar en grupo con compañeros/as de clase para tareas académicas

Nada

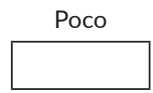

Mucho

10. ¿Qué redes sociales utilizas? Puedes marcar más de una opción

Facebook

Twitter

Whatsapp (grupos)

Instagram

YouTube 
11. ¿Cuánto tiempo dedicas a la revisión de tus redes sociales?

Entre 1 y 3 horas al día

Entre 4 y 8 horas al día

Más de 8 horas al día

Otra

12. Generalmente ¿̨para qué usas Facebook? Puedes marcar más de una opción

Ver videos

Leer periódicos

Compartir fotografías

Conversar con amigos

Organizar tareas escolares

Expresar estados de ánimo

13. ¿Cuál de las siguientes redes sociales usas más? Marca sólo una opción Facebook

Twitter

Whatsapp (grupos)

Instagram

YouTube

14. ¿Qué temas te interesan ver y/o buscar en la red social que usas más? 


\section{Habilidades comunicativas en entornos digitales}

Instrucciones: En esta sección del cuestionario debes responder en función de lo hábil que te sientas respecto al enunciado presentado en cada uno de los ítems. La escala va del 1 al 4; cada número significa la habilidad que consideras tener, donde: 1) ineficaz 2) eficaz 3) bábil 4) dominio. Además, puedes utilizar la opción NS/NC (no sé/no lo conozco) por si desconoces lo que te estamos preguntando.

\section{BLOQUE I}

\subsection{Gestión de la información en internet}

\section{a. Búsqueda y selección de información}

- Puedo navegar en Internet con diferentes navegadores (Mozilla, Chrome, Opera, Explorer, Safari, etc.)

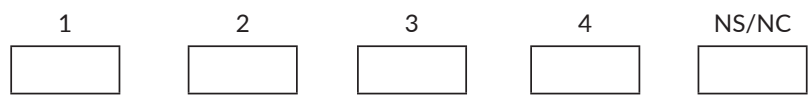

- Soy capaz de usar distintos buscadores (Google, Ixquick, Mashpedia, Bing, etc.)

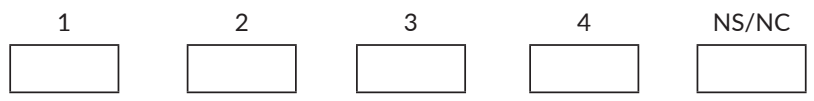

- Me siento hábil para trabajar con algún programa de cartografía digital para buscar lugares (Google maps, Google earth, Vpike, Tagzania, Bing maps, etc.)

1

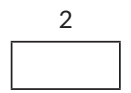

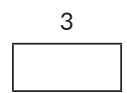

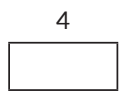

NS/NC

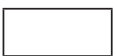

- Puedo utilizar diversas herramientas de la web para descubrir nuevas páginas que se relacionan con mis intereses (Google alerts, Hashtags, Stumbleupon, etc)

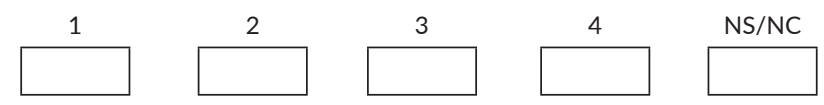

- Utilizo la biblioteca virtual de mi Universidad
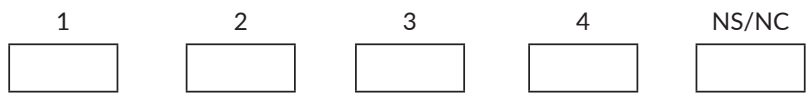


\section{b. Organización de información}

- Sé usar aplicaciones para planificar mi tiempo de estudio (Google calendar, Wunderlist, Nozbe, etc.)

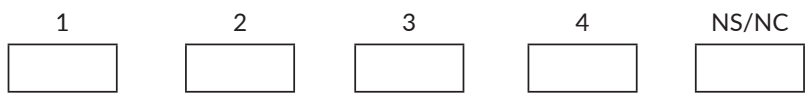

- Conozco el funcionamiento de diversos servicios de almacenamiento online (GoogleDrive, OneDrive, Dropbox, iCloud, etc.)

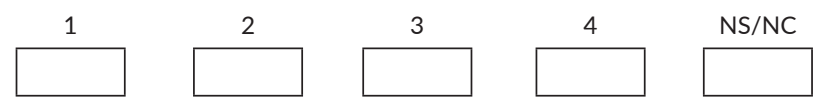

- Soy capaz de organizar y sintetizar información mediante mapas conceptuales utilizando alguna herramienta de software social (Cmaptool, Mindomo, Text2mindmap, Bubbl, etc.)

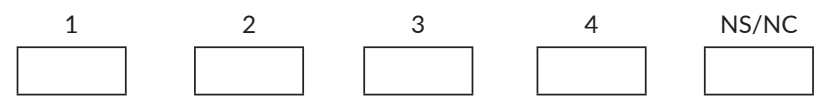

- Soy capaz de vincular y asociar la información que encuentro dentro de la red en mis diversos dispositivos (celular, computadora, tablet, etc)

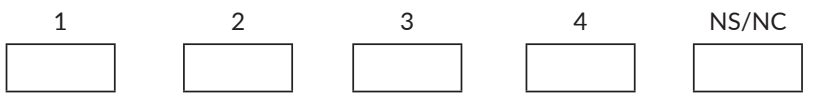

- Sé cómo usar diversas herramientas de internet para organizar enlaces de páginas web, imágenes, videos o textos (Pocket, Pinterest, Delicious, Evernote, etc)

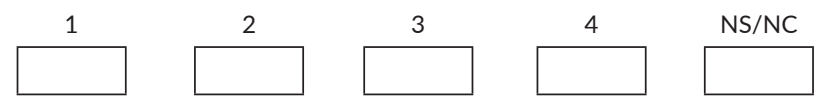

- Soy capaz de dar continuidad a un tema de interés dentro de la web pues puedo ordenar y mantener al día la información que requiero
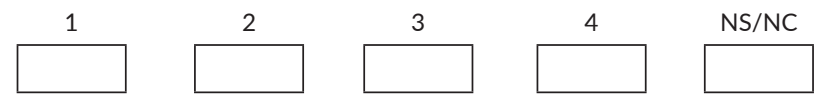

\section{c. Distribución de información}

- Me siento capaz de utilizar plataformas para el podcasting y el videocasts (Flicks, Odeo, Youtube, etc.)
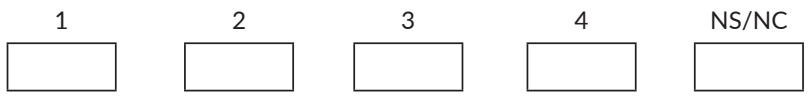
- Puedo utilizar programas para difundir presentaciones interactivas en red (Prezi, Slideshare, Scribd, etc.)

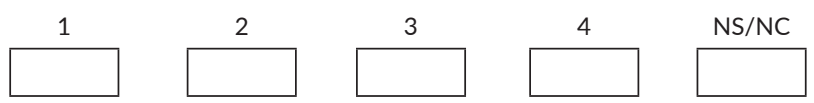

- Sé como utilizar los códigos QR para difundir información.

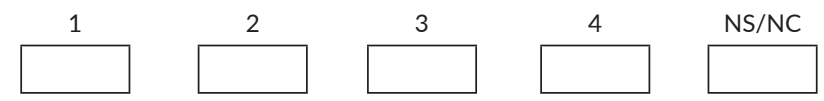

- Soy capaz de compartir información dependiendo del grupo a quien va dirigida, ya sean redes personales, académicas, amistades, de intereses, etc.

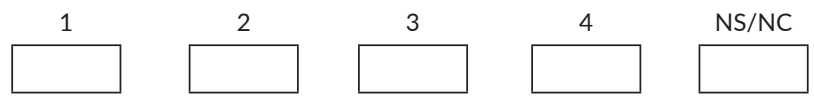

- Sé cómo utilizar los formatos RSS (Really Simple Syndication) para marcar y compartir contenido en la web

1

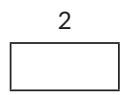

3

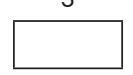

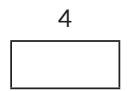

NS/NC

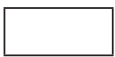

- Soy capaz de mantener al día un blog, página web, wiki, etc.
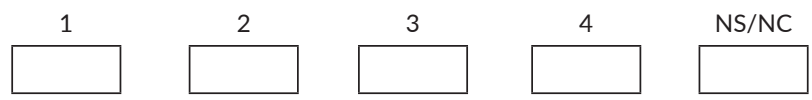

\subsection{Gestión de la información en Facebook}

\section{a. Búsqueda y selección de información}

- Puedo encontrar fácilmente páginas, grupos o amigos en Facebook
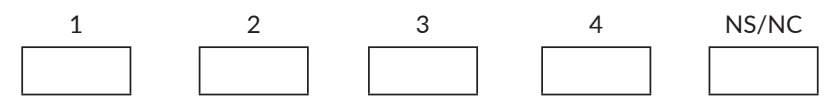

- Sé cómo seleccionar los contenidos que aparecen en mi página inicial de Facebook
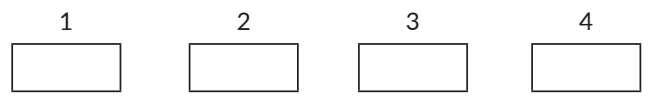

NS/NC 
- Puedo encontrar información relacionada con la escuela dentro de Facebook
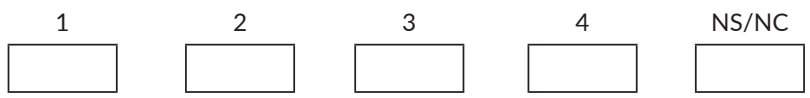

\section{b. Organización de información}

- Soy capaz de organizar la información de Facebook que me interesa
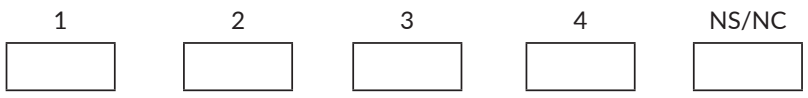

- Cuando un contenido me gusta en Facebook, sé cómo guardarlo
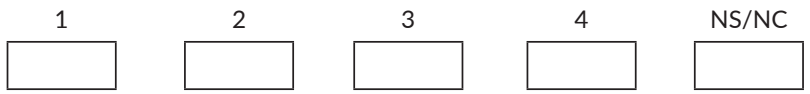

- Sé en qué situaciones crear un grupo, un chat, un evento u otra herramienta para organizarme con mis amigos en Facebook

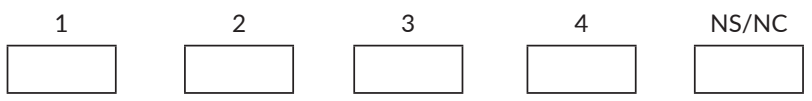

\section{c. Distribución de información}

- Sé cómo compartir archivos de manera directa, pública o para un grupo en particular, dentro de Facebook

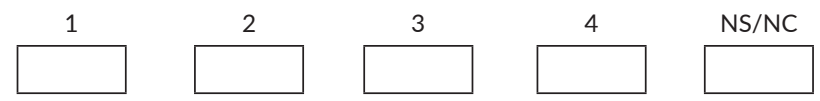

- Sé cómo insertar información (textos, imágenes, audio y video) de otras plataformas para compartir con los demás en Facebook

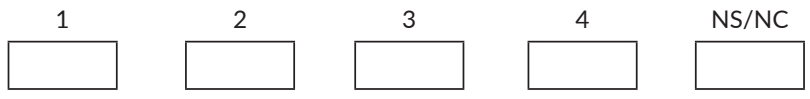

- Puedo seguir un tema de mi interés a través de los hashtags en Facebook
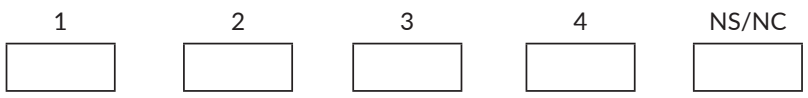
ANEXO 2. Cuestionario diagnóstico de habilidades comunicativas digitales

\section{BLOQUE II: Comunicación interpersonal}

Instrucciones: En este apartado la escala también va del 1 al 4 pero tiene otro significado. Numera en orden de importancia donde 1 es lo primero que harías y 4 lo último que harías.

\section{A. Intención comunicativa: resolución de problemas}

\section{Cuando tengo una duda sobre la utilización de algún servicio o} aplicación en red ¿̨ómo intento solucionarla?

Consulto a mis profesores para ver si pueden orientarme

Busco información por internet y lo soluciono por mi cuenta

Expongo mi duda en algún foro de dudas y preguntas

Contacto con algún compañero/a o con mi profesor/a a través de redes sociales o mensajería instantánea

\section{B. Intención comunicativa: distribuir información}

\section{Cuando tengo la necesidad de compartir contenidos que me gustan}

Pregunto a mis profesores sobre los mejores medios de difusión

Busco páginas en internet para compartir los contenidos

Encuentro espacios dentro de mis redes sociales

Le pido a algún amigo/a o profesor/a que me ayude a distribuir la información a través de los medios digitales

\section{Intención comunicativa: generar opiniones}

\section{Cuando participo en una discusión o debate en linea, generalmente:}

Analizo los argumentos a favor y en contra para emitir mi opinión

Me cuesta trabajo tomar en cuenta opiniones que no son similares a las mías

Considero que puedo influir en los puntos de vista de los demás

Generalmente no participo en ningún tipo de discusión en la red 


\section{BLOQUE III: Creación y organización de grupos}

Instrucciones: En este apartado la escala vuelve a ser del 1 a 4; cada número significa la habilidad que consideras tener, donde: 1) ineficaz 2) eficaz 3) hábil 4) dominio. Además, puedes utilizar la opción NS/NC (no sé/no lo conozco) por si desconoces lo que te estamos preguntando.

\section{Integración}

- Puedo crear grupos en Facebook para diferentes situaciones (reuniones, tareas, marchas, etc.)

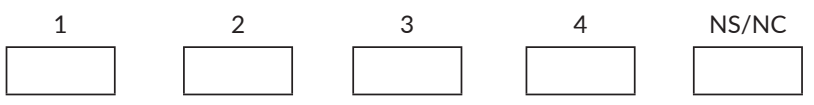

- Sé cómo conformar redes académicas, personales y profesionales para temas que me interesan

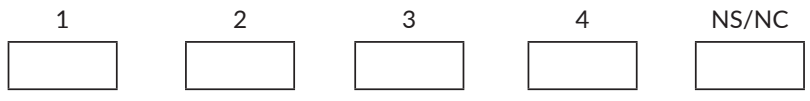

\section{Colaboración}

- Me siento capaz de colaborar en asociaciones u organizaciones a través de la red

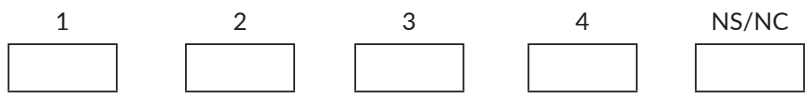

- Puedo establecer compromisos con ciertas páginas de ayuda o grupos en particular

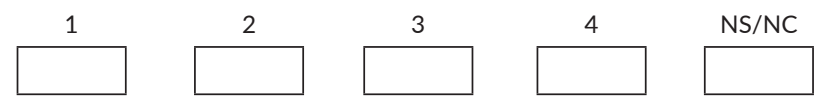

- Soy capaz de participar políticamente en colectivos o grupos de la universidad a través de la red

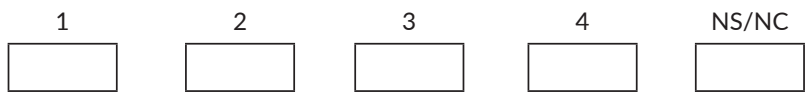

- Me siento capaz de mantenerme activo en diversos grupos dentro de las redes sociales de acuerdo con mis intereses

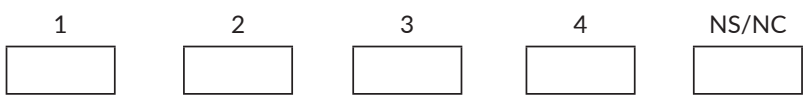


ANEXO 2. Cuestionario diagnóstico de habilidades comunicativas digitales

\section{Negociación}

- Soy capaz de argumentar y debatir opiniones a través de las redes sociales con diferentes personas

1
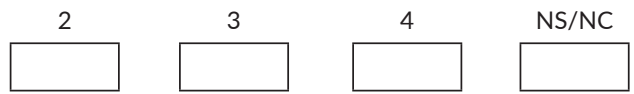

- Me siento capaz de ser propietario de un grupo en Facebook o WhatsApp y sé cómo administrarlo y mantenerlo con actividad
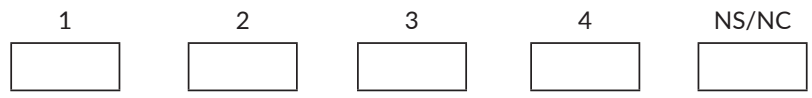

¡MUCHAS GRACIAS POR TU PARTICIPACIÓN! 


\section{Prácticas comunicativas en entornos digitales}

Facultad de Ciencias Políticas y Sociales Universidad Nacional Autónoma de México

Se terminó de editar el 5 de julio de 2018, en la ciudad de México y esta disponible en:

http://www.labiblioteca.com.mx/

Diseño y formación:

Fernando Bouzas Suárez

Cuidado editorial:

Departamento de Publicaciones, FCPyS, UNAM

En la formación se utilizó la fuente Adobe Caslon Pro en 10.5 puntos para el cuerpo del texto y Brandon Grotesque en 16 y 12 puntos para los titulares. 